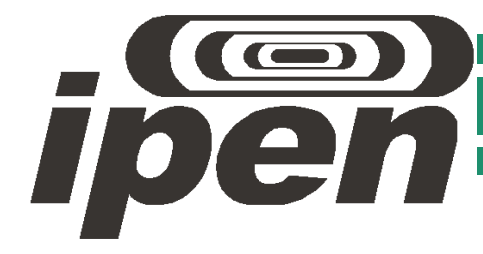

AUTARQUIA ASSOCIADA À UNIVERSIDADE DE SÃO PAULO

CALIBRAÇÃO DA POTÊNCIA DO REATOR IPEN/MB-01 NA CONFIGURAÇÃO CILÍNDRICA DE MENOR EXCESSO DE REATIVIDADE OBTIDA A PARTIR DA MEDIDA ABSOLUTA DO FLUXO MÉDIO DE NEUTRONS

ALEXANDRE FONSECA PÓVOA DA SILVA

Dissertação apresentada como parte dos requisitos para obtenção do Grau de Mestre em Ciências na Área de Tecnologia Nuclear - Reatores.

Orientador:

Prof. Dr. Ulysses d'Utra Bitelli 
INSTITUTO DE PESQUISAS ENERGÉTICAS E NUCLEARES - IPEN

Autarquia associada à Universidade de São Paulo

\title{
CALIBRAÇÃO DA POTÊNCIA DO REATOR IPEN/MB-01 NA CONFIGURAÇÃO CILÍNDRICA DE MENOR EXCESSO DE REATIVIDADE OBTIDA A PARTIR DA MEDIDA ABSOLUTA DO FLUXO MÉDIO DE NEUTRONS
}

ALEXANDRE FONSECA PÓVOA DA SILVA

\author{
Dissertação apresentada como \\ parte dos requisitos para \\ obtenção do título de Mestre em \\ Ciências na Área de Tecnologia \\ Nuclear - Reatores \\ Orientador: \\ Dr. Ulysses d’Utra Bitelli
}




\section{AGRADECIMENTOS}

Ao Dr. Ulysses d'Utra Bitelli, pela forma inteligente e amiga com que passou os valiosos conhecimentos e ensinamentos, pela força, tempo dedicado e atenção para a realização deste trabalho.

Às preciosas orientações e correções do Dr. Odair Lelis Gonçalez do Instituto de Estudos Avançados .

Ao Dr. Adimir do Santos pela liberação do código computacional MCNP-5 para a realização deste trabalho acadêmico, por ser na área de física de reatores nucleares.

À Dra. Ana Cecília de Souza Lima, pela forma muito receptiva e amiga de lidar, além da especial contribuição para a finalização e correção deste trabalho.

Ao amigo Luiz Ernesto Credídio Mura pelo apoio técnico e discussões nos diversos assuntos relacionados neste trabalho.

Ao IPEN/CNEN-SP pela disponibilização dos materiais e do reator IPEN/MB-01.

À Marinha do Brasil, pelos ensinamentos de vida e pela possibilidade de realizar este trabalho com o apoio necessário para sua finalização.

Aos operadores, engenheiros e técnicos do reator IPEN/MB-01, que se esforçaram de sobremaneira para passar os ensinamentos da física de reatores nucleares e realização das pesquisas necessárias neste trabalho.

À minha mãe Isis Póvoa Castello Branco de Paiva, pela força, crença, admiração, amor e vida a mim oferecidos da forma mais completa e amável que um ser humano pode ter.

À minha irmã Claudia Fonseca Póvoa da Silva, pelo amor e eterna amizade neste caminho de vida.

Ao meu sobrinho Lucas Póvoa Silva Scurti, por me lembrar sempre que existe a necessidade em aprender, mas também ensinar com amor.

Ao meu amado pai Roberto Pereira da Silva, pela força e vida a mim oferecidos.

Ao meu amado padrasto João Alberto Castello Branco de Paiva, por ser meu melhor exemplo de esforço, justiça, caráter e determinação na vida.

Aos meus familiares por existirem em minha vida e pelo amor do dia-a-dia. convivência.

A minha companheira Gesiane Fernandes Tavares pelo carinho e amável

Aos meus amigos de aprendizado Vitor Aredes, Rafael Purgato e Diogo dos Santos. 
Ao amigo Thiago Garcia pelos ensinamentos e discussões para melhorar meu aprendizado.

A todos os professores do IPEN pelo seu trabalho e esforço para passar os conhecimentos com o fim de engrandecer o universo das pesquisas na área de reatores nucleares. 


\title{
CALIBRAÇÃO DA POTÊNCIA DO REATOR IPEN/MB-01 NA CONFIGURAÇÃO CILÍNDRICA DE MENOR EXCESSO DE REATIVIDADE OBTIDA A PARTIR DA MEDIDA ABSOLUTA DO FLUXO MÉDIO DE NEUTRONS
}

\section{ALEXANDRE FONSECA PÓVOA DA SILVA}

\begin{abstract}
RESUMO
A ativação de folhas de ouro é uma das técnicas mais usadas para obter dados experimentais e assim comparar os resultados obtidos com aqueles calculados usando metodologias específicas e seus respectivos dados nucleares. Através da irradiação de folhas de ativação e posterior medida da atividade nelas induzida é possível determinar o fluxo de nêutrons no local da irradiação. O nível da potência de operação do reator é um parâmetro diretamente proporcional ao fluxo médio de nêutrons no núcleo do reator. O objetivo deste trabalho é obter, pela irradiação de folhas de ouro posicionadas simetricamente dentro do núcleo, utilizando a configuração cilíndrica que apresenta o menor excesso de reatividade, a potência gerada pela distribuição espacial do fluxo de nêutrons térmicos e epitérmicos no núcleo do reator IPEN/MB-01 e assim, calibrar seus canais nucleares. As folhas foram colocadas em uma placa de Lucite e irradiadas com e sem cobertura de cádmio, para se obter o valor absoluto de nêutrons térmicos $\mathrm{e}$ epitérmicos. A correlação entre a potência média do fluxo de nêutrons, como resultado da irradiação das folhas de ouro e, a potência média obtida a partir da aquisição de valores digitais dos canais nucleares, permite calibrar os canais nucleares do reator. Em 2008 foi feita a correlação para a configuração de núcleo retangular que resultou em uma calibração específica do nível de potência de operação para esta configuração geométrica de núcleo. Assim, esta calibração não pode ser utilizada como referência para a configuração em questão, ou seja, a cilíndrica, pois os parâmetros nucleares de distribuição de fluxo não são os mesmos, pois a distribuição difere para cada tipo de distribuição geométrica de núcleo. Além disto, o conhecimento preciso da potência de operação do reator nos permite obter os valores absolutos de fluxos de nêutrons e assim validar a metodologia de cálculo utilizada para este propósito.
\end{abstract}




\title{
POWER CALIBRATION OF THE IPEN/MB-01 REACTOR FOR THE CYLINDRICAL CONFIGURATION OF MINOR REACTIVITY EXCESS OBTAINED FROM THE MEASUREMENTS OF THE ABSOLUT AVERAGE NEUTRON FLUX
}

\section{ALEXANDRE FONSECA PÓVOA DA SILVA}

\begin{abstract}
The activation foils is one of the most used techniques to obtain nuclear parameters and thus compare the results with the calculated ones using specific methodologies and its nuclear data. Through the irradiation in the activation foils and ulterior measurement on its induced activity, it is possible to determine the neutron flux in the position where they were irradiated. The power level operation of the reactor is a parameter directly proportional to the average neutron flux in the core. The objective of this work is to obtain, by irradiating gold foils positioned symmetrically into the core for a cylindrical configuration, that presents the minor reactivity excess, the power generated through the spatial thermal and epitermal neutron flux distribution in the core of the IPEN/MB-01 Reactor, and thus calibrate its nuclear channels. The foils were put in a Lucite plate and irradiated with and without cadmium covered small plates, to obtain the absolute thermal and epithermal neutron flux. The correlation between the average power neutron flux, as a result of the gold foil's irradiation and, the average power obtained by the digital values of the nuclear channels, allows the calibration of the nuclear channels of the reactor. This same correlation was done in 2008 with the reactor in a rectangular configuration, which resulted in a specific calibration of the power level operation for this geometric configuration of the core. Thus this calibration cannot be used as a reference for the actual configuration, the cylindrical one, because the nuclear parameters of the neutrons distribution are not the same, it changes for every geometric configuration of the core. Furthermore, the precise knowledge of the power neutron flux allows us to obtain absolute value of the neutron flux and thus validate the methodology used for this purpose.
\end{abstract}




\section{SUMÁRIO}

\section{Páginas}

1 INTRODUÇÃO

1.1 A Instrumentação Nuclear do Reator IPEN/MB-01 ....................................... 4

1.2 A importância da Calibração.............................................. 8

1.3 Objetivos................................................................. 10

1.4 Roteiro da Dissertação................................................................................ $\quad 10$

2 A TÉCNICA DE ANÁLISE POR ATIVAÇÃO............................................ 12

2.1 Os Pré-requisitos do Detector de Ativação Au-197........................................... 12

2.2 A Taxa de Radiação................................................................................. 15

3 FLUXO DE NEUTRONS TÉRMICOS E INTERMEDIÁRIOS................. 22

3.1 Técnica da Razão de Cádmio......................................... 22

3.2 Fluxo de Nêutrons Térmicos....................................... 25

3.3 Fluxo de Nêutrons Intermediários.................................... 26

3.4 Fatores de Correção do Fluxo de Nêutrons Perturbado..................................... 29

4 POTÊNCIA DO REATOR ............................................................... 32

4.1 Densidade de Potência................................................ 32

4.2 Potência Obtida pela Taxa de Reação............................................................ $\quad 35$

5 CÓDIGO COMPUTACIONAL MCNP................................................ 36

5.1 Grandezas Obtidas com o MCPN-5................................ 37

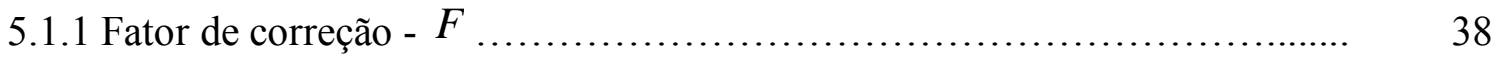

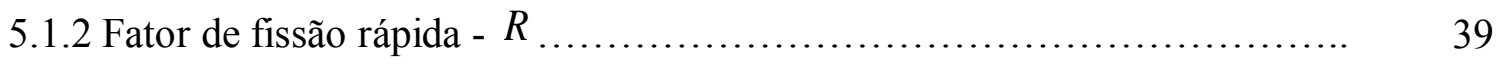

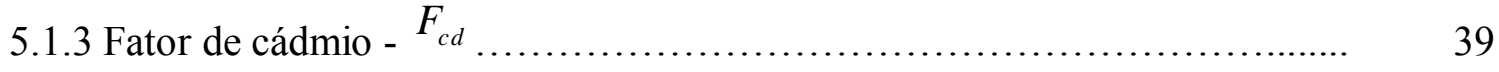

6 MATERIAIS E MÉTODOS................................................................. 42

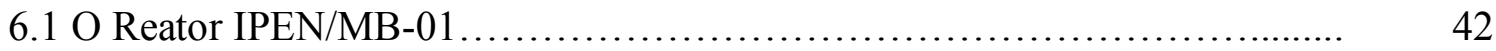

6.2 Características das Folhas de Ativação................................. $\quad 42$

6.3 Descrição do Procedimento Experimental....................................................... 45

6.4 Condições para a Irradiação........................................... 48

6.5 Fatores Experimentais de Correção.................................... 49

6.5.1 Fator de normalização.................................................. 49

6.6 Fator de Rampa......................................................... $\quad 50$

6.7 Fator de Autoabsorção...................................................... 52 
7 ANÁLISE DOS DADOS ............................................... 54

7.1 Eficiência Global do Sistema de Detecção HPGe. ............................ 57

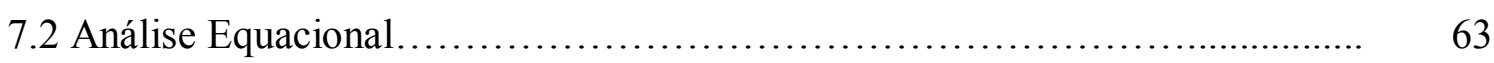

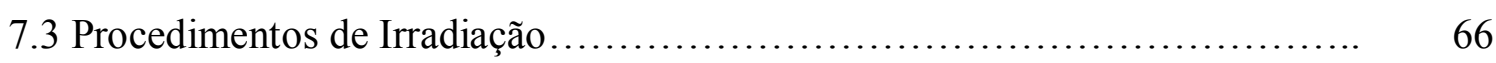

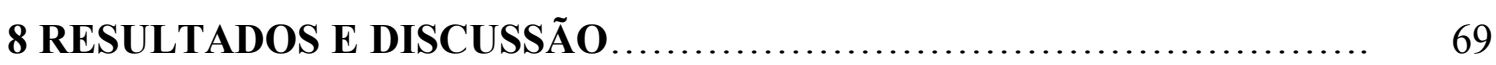

8.1 Metodologia para Obtenção do Valor Médio de Fluxo de Nêutrons e Variância 69

8.2 Medidas do Canal Nuclear de Pulsos $n^{\circ} 10\left({ }^{10} \mathrm{~B}\right)$.............................................. 71

8.3 Potência no Núcleo Cilíndrico......................................... 71

8.4 Calibração dos Canais Nucleares....................................... $\quad 72$

8.5 Considerações Sobre as Medidas das Contagens do Canal 10 .......................... 75

8.6. Fator de Correção do Canal de Pulsos 10...................................................... 76

8.6.1 Fator de correção para a configuração cilíndrica de 28 x 28 varetas............ 77

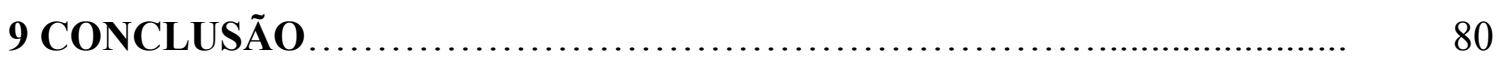

APÊNDICE A - Modelagem do reator IPEN/MB-01 pelo código MCNP 5... 83

APÊNDICE B - Atividades de saturação.................................... 109

APÊNDICE C - Razão de cádmio...................................... 113

APÊNDICE D - Fluxo de nêutrons térmicos................................... 117

APÊNDICE E - Fluxo de nêutrons epitérmicos............................................... 120

APÊNDICE F - Fatores de perturbação das folhas de ouro hiperpuras........ 123

APÊNDICE G - Fatores de autoabsorção das folhas de ouro hiperpuras...... 125

APÊNDICE H - Relação de potência versus contagens do canal 10 na configuração cilíndrica de núcleo do reator IPEN/MB-01........................... 126

APÊNDICE I - Núcleos cilind rizados.......................................................... 129

ANEXO A - Reator nuclear IPEN/MB-01 ............................................. 132

ANEXO B - Estimativa das incertezas associadas....................................... 143

ANEXO C - Simulação pelo código CITATION da distribuição do fluxo de nêutrons no núcleo do reator IPEN/MB-01 operando a 100 watts na configuração cilíndrica de $\mathbf{2 8 x 2 8}$ varetas combustíveis................................ 147

REFERÊNCIAS BIBLIOGRÁFICAS ..................................................... 160 


\section{SUMÁRIO DE FIGURAS}

Páginas

Figura 1.1- Posicionamento dos canais nucleares................................................. 5

Figura 2.1- Curva da atividade induzida no detector para o tempo de irradiação t.... 18

Figura 3.1- Perturbação sofrida pelo fluxo de nêutrons num detector do tipo folha

de ativação

Figura 4.1 - Distribuição do fluxo de nêutrons em um reator de configuração

geométrica cilíndrica finita.

Figura 5.1 - Vista superior do núcleo do reator no código MCNP-5

Figura 5.2 - Vista lateral do núcleo do reator no código MCNP-5

Figura 6.1 - Seção de choque do Au-197............................................. 43

Figura 6.2 - Região $1 / \mathrm{v}(2200 \mathrm{~m} / \mathrm{s})$ da seção de choque............................................ 44

Figura 6.3 - Região epitérmica da seção de choque do Au-197................................ 44

Figura 6.4 - Representação da placa inserida no núcleo do reator IPEN/MB-01.... 45

Figura 6.5 - Placa de lucite e posições das folhas de ouro........................................ 46

Figura 6.6 - Núcleo do reator IPEN/MB-01 na configuração cilíndrica.................... 47

Figura 6.7 - Arquivo de irradiação do canal nuclear 14-15.................................... 51

Figura 6.8 - Análise gráfica do tempo de rampa................................................ 52

Figura 7.1 - Diagrama de blocos do sistema de detecção de germânio hiperpuro. $\quad 54$

Figura 7.2 - Detector transdutor de germânio......................................................... 54

Figura 7.3 - Reservatório com nitrogênio, detector de germânio e castelo de chumbo.

Figura 7.4 - Blindagem de chumbo com as gavetas e base em acrílico para posicionamento da folha de ativação.

Figura 7.5 - Amplificador, placa multicanal e fonte de alta tensão.

Figura 7.6 - Tela do MAESTRO com apresentação de pico do Eu-152 (utilizado para calibração do sistema) e demais informações de análise das partículas contadas.

Figura 7.7 - Reta de eficiência da $5^{\circ}$ gaveta.

Figura 7.8 - Reta de eficiência da $6^{\circ}$ gaveta.......

Figura 7.9 - Reta de eficiência da $7^{\circ}$ gaveta.

Figura 8.1 - Contagens do canal nuclear de pulsos 10 na configuração padrão retangular (linha superior) 28x26 e cilíndrica 28×28 (Linha inferior). 
Figura 8.2 - Reta de calibração do canal nuclear de pulsos 10 na configuração retangular.

Figura 8.3 - Reta de calibração do canal 10 na configuração cilíndrica............... 73

Figura 8.4 - Reta de calibração para o canal nuclear 5 na configuração cilíndrica.... $\quad 74$

Figura 8.5 - Reta de calibração para o canal nuclear 6 na configuração cilíndrica... $\quad 75$

Figura 8.6 - Fator de Correção para a configuração cilíndrica de 28 x 28 varetas combustíveis

Figura I.1 - Configuração cilindrizada 30 x 30 com flux trap no centro do núcleo..

Figura A.1 - Vista do núcleo: Arranjo retangular de 30x30 varetas combustíveis..

Figura A.2 - Vista do núcleo: Arranjo cilíndrico de 28x28 varetas combustíveis.....

Figura A.3 - Diagrama esquemático das varetas de combustível e de controle........ 135

Figura A.4 - Faixa de operação dos canais nucleares.............................................. 140

Figura C.1 - Configuração Cilíndrica do Núcleo do Reator IPEN/MB-01.......... 148

Figura C.2 - Corte axial do núcleo do Reator IPEN/MB-01 com as posições de medidas. 


\section{SUMÁRIO DE TABELAS}

Páginas

Tabela 1.1 - Detectores da física de reatores nucleares e as partículas de interação.......... 3

Tabela 1.2 - Tipos , funções e posições dos canais nucleares do reator IPEN/MB-01...... 6

Tabela 1.3 - Faixa de monitoração dos detectores nucleares em nêutrons ......................... 7

Tabela 2.1 - Dados nucleares comparativos do Au-197 e Al-27...................................... 14

Tabela 3.1 - Dados nucleares comparativos do Au-197 e Cd-112 ................................... 24

Tabela 3.2 - Alguns detectores de ativação utilizados na região intermediária.................. 29

Tabela 7.1 - Dados nucleares da fonte de ${ }^{152} \mathrm{Eu}$............................................................ 59

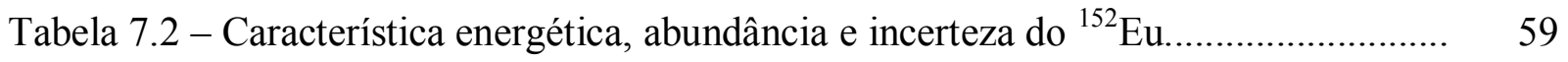

Tabela 7.3 - Dados das contagens da $5^{\circ}$ gaveta........................................................... 60

Tabela 7.4 - Dados das contagens da $6^{\circ}$ gaveta............................................................. 61

Tabela 7.5 - Dados das contagens da $7^{\circ}$ gaveta............................................................. 62

Tabela 7.6 - Metodologia das irradiações nos canais nucleares........................................... 67

Tabela 8.1 - Contagens do canal 10 corrigidas e não corrigidas e o fator de correção

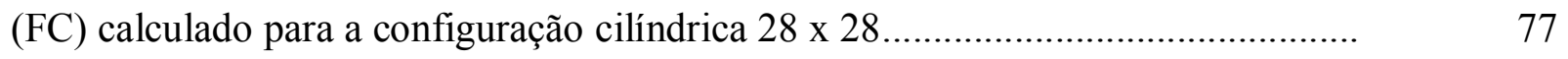

Tabela A.1 - Alguns tallies utilizados pelo MCNP......................................................... 85

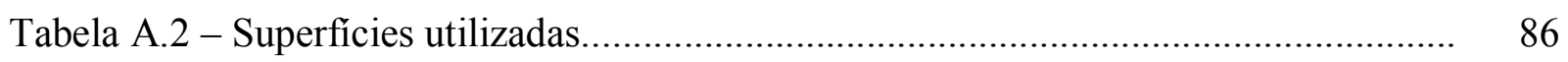

Tabela B.1 - Atividade de saturação das folhas de ouro hiperpuras no canal de

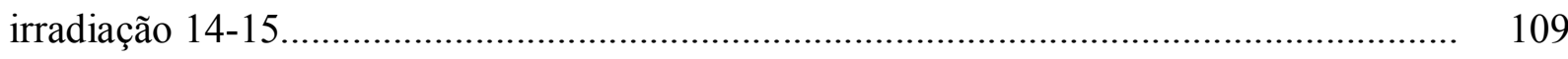

Tabela B.2 - Atividade de saturação das folhas de ouro infinitamente diluídas no canal de irradiação 14-15..

Tabela B.3 - Atividade de saturação das folhas de ouro infinitamente diluídas no canal de irradiação 10-11

Tabela B.4 - Atividade de saturação das folhas de ouro infinitamente diluídas no canal de irradiação 6-7.

Tabela B.5 - Atividade de saturação das folhas de ouro infinitamente diluídas no canal de irradiação 2-3.

Tabela C.1 - Razão de cádmio das folhas de ouro hiperpuras no canal de irradiação 1415.

Tabela C.2 - Razão de cádmio das folhas de ouro infinitamente diluídas no canal de irradiação 14-15.

Tabela C.3 - Razão de cádmio das folhas de ouro infinitamente diluídas no canal 115 
de irradiação 10-11

Tabela C.4 - Atividade de saturação das folhas de ouro infinitamente diluídas no canal de irradiação 6-7.

Tabela C.5 - Atividade de saturação das folhas de ouro infinitamente diluídas no canal de irradiação 2-3.

Tabela D.1 - Fluxo de nêutrons térmicos no canal de irradiação 14-15.

Tabela D.2 - Fluxo de nêutrons térmicos no canal de irradiação 10-11

Tabela D.3 - Fluxo de nêutrons térmicos no canal de irradiação 6-7.

Tabela D.4 - Fluxo de nêutrons térmicos no canal de irradiação 2-3.

Tabela E.1 - Fluxo de nêutrons epitérmicos no canal de irradiação 14-15.

Tabela E.2 - Fluxo de nêutrons epitérmicos no canal de irradiação 10-11

Tabela E.3 - Fluxo de nêutrons epitérmicos no canal de irradiação 6-7.

Tabela E.4 - Fluxo de nêutrons epitérmicos no canal de irradiação 2-3.

Tabela F.1 - Valores dos fatores de autoblindagem térmico e epitérmico para o canal de irradiação 14-15

Tabela G.1 - Valores dos fatores de autoabsorção para as folhas hiperpuras e infinitamente diluídas.

Tabela H.1 - Nível de potência de 20 a 100 mwatts e contagens do canal 10 na configuração cilíndrica.

Tabela H.2 - Nível de potência de 200 a 1000 mwatts e contagens do canal 10 na configuração cilíndrica.

Tabela H.3 - Nível de potência de 2 a 10 watts e contagens do canal 10 na configuração cilíndrica.

Tabela H.4 - Nível de potência de 12 a 44 watts e contagens do canal 10 na configuração cilíndrica.

Tabela H.5 - Nível de potência de 46 a 78 watts e contagens do canal 10 na configuração cilíndrica...

Tabela H.6 - Nível de potência de 80 a 120 watts e contagens do canal 10 na configuração cilíndrica.

Tabela I.1 - Valores de FC para a configuração cilindrizada 30 x 30 com flux trap de água pesada $\left(\mathrm{D}_{2} \mathrm{O}\right)$.

Tabela I.2 - Valores de FC para a configuração cilindrizada 30 x 30 com flux trap de água leve $\left(\mathrm{H}_{2} \mathrm{O}\right)$ 
Tabela A.1 - Dados geométricos da vareta de controle do reator IPEN/MB-01 ............... 136

Tabela A.2 - Dados geométricos da vareta de combustível do reator IPEN/MB-01 ......... 136

Tabela A.3 - Composição isotópica da vareta de combustível do reator IPEN/MB-01...... 137

Tabela A.4 - Composição isotópica da vareta de controle do reator IPEN/MB-01 ........... 137

Tabela A.5 - Sinais e escalas de medidas dos detectores.............................................. 139

Tabela C.1 - Coordenadas dos sete canais de irradiação para determinação da distribuição de fluxo de nêutrons......................................................................................

Tabela C.2 - Fluxo de nêutrons para as posições do canal de irradiação 1.......................... 151

Tabela C.3 - Fluxo de nêutrons para as posições do canal de irradiação 2 .......................... 152

Tabela C.4 - Fluxo de nêutrons para as posições do canal de irradiação 3........................ 153

Tabela C.5 - Fluxo de nêutrons para as posições do canal de irradiação 4........................ 154

Tabela C.6 - Fluxo de nêutrons para as posições do canal de irradiação 5........................ 155

Tabela C.7 - Fluxo de nêutrons para as posições do canal de irradiação 6......................... 156

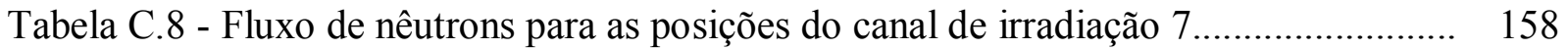




\section{INTRODUÇÃO}

O conhecimento da potência de operação de um reator nuclear com exatidão e precisão é fundamental num reator nuclear de pesquisa, pois do seu conhecimento podemos correlacionar os respectivos valores absolutos da distribuição espacial e energética de nêutrons no núcleo de um reator nuclear de pesquisa e com isso testar e validar a metodologia de cálculo dos valores estimados através de várias metodologias de cálculo e de suas bibliotecas de dados nucleares associadas.

Sabemos ser de suma importância o conhecimento da distribuição espacial de nêutrons e da sua energia associada, pois a todo o momento nêutrons de todas as energias estão distribuídos no interior do núcleo de um reator. Esta distribuição neutrônica, em uma visão macro, depende da geometria do núcleo e da composição interna dos materiais constituintes, ou seja, da configuração geométrica da forma do núcleo do reator (cilíndrica, retangular, esférica, etc), e dos materiais das estruturas suportes, elementos absorvedores, moderadores e refletores.

O conhecimento do perfil do fluxo de nêutrons térmicos no núcleo de um reator nuclear permite avaliar a potência gerada no mesmo e assim, calibrar seus canais nucleares correlacionando os dados obtidos experimentalmente com os valores da mesa de monitoração e controle dos canais digitais de potência. Tal calibração fornece a potência para uma respectiva configuração de núcleo do reator quando este atinge a sua criticalidade.

Atualmente, para se conhecer o fluxo de nêutrons de um reator, pode-se utilizar de vários métodos e técnicas experimentais. Sabe-se que pelo fato do nêutron ser uma partícula sem carga, deve provocar uma reação nuclear no meio ao qual interage cujo resultado gere partículas ionizantes para assim ser detectado de forma indireta. Para medir essa ionização podem-se usar detectores cuja indicação seja direta ou indireta. Como detectores de indicação direta têm-se: 
a) Cintiladores;

b) Semicondutores;

c) Detectores a gás;

d) Auto energizados; e

e) Câmaras de fissão.

Estes detectores ficam inseridos no campo neutrônico dentro do núcleo do reator, e juntamente com sua eletrônica associada, fornecem informações em tempo real do fluxo de nêutrons. Tal informação é de suma importância para o controle do reator. Entretanto para se obter a correlação entre a leitura do detector e o fluxo de nêutrons é necessário a sua calibração prévia em um campo neutrônico conhecido.

Como detectores de indicação indireta têm-se:

a) Sólido a traço; e

b) Ativação (ex. Au, Co, Ag, In, Mn e outros)

Estes detectores são inseridos dentro do núcleo. No caso daqueles que se tornam radioativos a radiação gama de decaimento é então medida em um sistema de contagem de espectrometria gama para fornecer, após o tratamento adequado dos dados da espectrometria gama, o valor absoluto do fluxo de nêutrons. Uma vez de posse do valor do fluxo de nêutrons, calcula-se a potência de operação do reator e correlaciona-se a mesma com as contagens dos diferentes canais nucleares de controle do reator nuclear, os quais por sua vez, são munidos de detectores de indicação direta no que concerne aos canais 5 e 6. Estes canais foram anteriormente calibrados em potência por Bitelli e Lucas [1].

$\mathrm{Na}$ TAB 1.1 apresentam-se os tipos de detectores utilizados e suas partículas características [2]. 
Tabela 1.1 - Detectores da física de reatores nucleares e as partículas de interação.

\begin{tabular}{|l|l|l|}
\hline \multicolumn{1}{|c|}{ Interação } & \multicolumn{1}{c|}{ Detector } & \multicolumn{1}{c|}{ Partículas } \\
\hline \multirow{4}{*}{ Ionização em gases } & $\begin{array}{l}\text { Câmara de ionização } \\
\text { proporcional }\end{array}$ & $\alpha, \mathrm{n}(\mathrm{F}), \mathrm{n}(\alpha), \gamma, \mathrm{X}$ \\
\cline { 2 - 3 } & $\begin{array}{l}\text { Contador } \\
\text { pontador Geiger } \\
\text { Müller }\end{array}$ & $\beta, \gamma, \mathrm{p}), \beta, \gamma, \mathrm{X}$ \\
\hline Ionização em sólidos & Semicondutor & Íons, $\mathrm{n}(\alpha), \mathrm{n}(\mathrm{F}), \gamma$ \\
\hline Fluorescência & Cintilador & $\beta, \gamma$, íons, $\mathrm{n}(\mathrm{p})$ \\
\hline Ativação & Folhas e fios & $\mathrm{n}(\beta), \mathrm{n}(\gamma)$ \\
\hline
\end{tabular}

A literatura descreve algumas técnicas experimentais para a obtenção direta da potência do reator, a saber:

a) Técnica da Calorimetria, que monitora a diferença de temperatura do refrigerante na entrada e na saída do núcleo do reator nuclear, e por meio de equacionamentos matemáticos obtém a potência final;

b) Técnica do Nitrogênio-16 (N16), que monitora a quantidade de N-16 constante no circuito primário (em alguns casos no secundário), o qual é proporcional à intensidade de fluxo de nêutrons no núcleo, e que igualmente por equacionamentos específicos chega ao valor da potência no núcleo do reator nuclear;

c) Técnica da medida da potência pela radiação Cherenkov, que utiliza o monitoramento dos fótons emitidos na radiação Cherenkov para obter o valor da potência. Esta técnica é utilizada no reator de pesquisa de 5MWt no Iran (Reator de pesquisa Tehran) como um método redundante que tem-se mostrado confiável e linear a partir de $100 \mathrm{KW}$ [3]; e

d) Técnica remota de medida de fluxo dos neutrinos, o qual é proporcional à potência do reator. Este método considera que com a queima de combustível a razão da proporcionalidade de fluxo com a potência deva ser ajustada em 5 a $7 \%$. Ainda se considera que a medição do fluxo de neutrinos forneça um espectro da produção de plutônio no núcleo [4]. 
No processo de calibração, faz-se necessário se conhecer alguns parâmetros, o que pode ser feito pela espectrometria gama de alguns elementos químicos irradiados no núcleo de um reator de pesquisa [4]. Este é o caso dos detectores de ativação como as folhas de ouro (Au-197) que, através da medida de sua radioatividade induzida, possibilita determinar o valor absoluto do fluxo de nêutrons no local em que as mesmas foram irradiadas, a partir de sua espectrometria gama em um sistema de germânio hiperpuro (HPGe). Este sistema fornece dados tais como, a contagem, a energia dos fótons gama de decaimento e o tempo de contagem. O elemento químico ouro é tido como um padrão de ativação por ter a abundância isotópica de 100\% (Au-197), peso atômico (196,9665 amu [5]) alta densidade $\left(19,30 \mathrm{~g} / \mathrm{cm}^{3}\right)$ e por ter muito bem determinado a energia do Au-198 após ativação $(411,80 \mathrm{keV})$, a probabilidade de emissão do fóton gama de 411,80 keV (95,56\%), bem como parâmetros nucleares importantes tais como a alta seção de choque de ativação neutrônica para nêutrons térmicos a $0,0253 \mathrm{eV}$ (98,8 barns).

Com os dados obtidos do sistema detector de germânio hiperpuro calcula-se a atividade de saturação das folhas de ativação que nada mais é do que o valor numérico da taxa de reação nuclear. A partir do conhecimento da taxa de reação nuclear, conhecida a seção de choque média de ativação podemos obter valores absolutos do fluxo de nêutrons.

\subsection{A Instrumentação Nuclear do Reator IPEN/MB-01.}

A instrumentação nuclear do reator IPEN/MB-01 é constituída por 10 canais nucleares acondicionados no interior de tubos de alumínios no entorno da placa matriz do núcleo do reator, conforme FIG 1.1. 


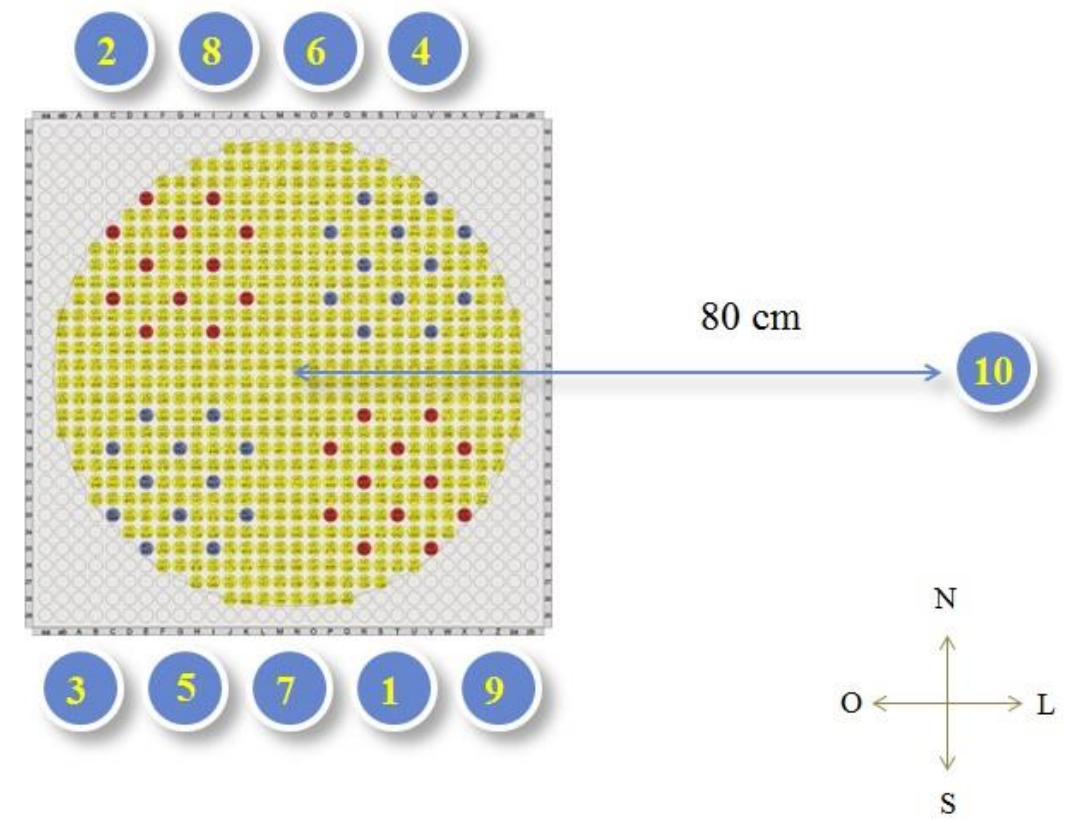

Figura 1.1- Posicionamento dos canais nucleares

Os canais nucleares representam um conjunto de detectores, mídia de dados, eletrônica associada e, programa computacionais analisadores. Esse conjunto fornece parâmetros a outros sistemas e seus respectivos controladores e atuadores, de modo a auxiliar a manutenção do processo em operação segura.

Cada canal nuclear monitora uma determinada faixa de operação, sendo estas faixas de partida, de potência, linear, e de segurança 1 (faixa de partida) e 2 (faixa de potência).

Os canais de partida ( 1 e 2) são canais de pulso que utilizam detectores do tipo proporcional $\left(\mathrm{BF}_{3}-\right.$ Trifluoreto de Boro), monitoram a potência na faixa inicial de operação e, possuem alta sensibilidade aos nêutrons $(5,5 \mathrm{cps} / \mathrm{nv})$, ou seja, são usados para uma contagem muito baixa da população de nêutrons.

Os canais de potência ( 3 e 4) são canais de corrente que utilizam detectores do tipo Câmara de Ionização Compensada (CIC), cuja faixa de operação se inicia desde a região superior dos canais de partida, até a primeira década acima da potência máxima de operação. 
Os canais lineares (5 e 6) são do tipo Câmara de Ionização Não Compensada (CINC) e são utilizados para medir o fluxo de nêutrons e assim a potência de operação do reator. Por cobrirem a faixa de $10^{-2}$ watts a $10^{2}$ watts, eles são usados para a calibração de potência do reator.

Os canais de segurança do tipo 1 (7 e 8) são canais de corrente do tipo Câmara de Ionização Não Compensada (CINC), operam na faixa superior de potência e cujo sinal de saída é proporcional ao fluxo neutrônico.

Um dos canais de segurança do tipo 2 (9) do tipo pulso, opera na faixa inferior de potência, igual ao canal de partida e, utiliza detector do tipo $\mathrm{BF}_{3}$. O outro canal de segurança do tipo 2 (10) opera na faixa superior de potência e utiliza detector tipo pulso (Boro-10).

Na TAB 1.2 apresenta-se um resumo dos tipos de detectores, funções e posições dos canais nucleares.

Tabela 1.2 - Tipos, funções e posições dos canais nucleares do reator IPEN/MB-01.

\begin{tabular}{|c|c|c|c|c|c|}
\hline \multicolumn{5}{|c|}{ Canal } & \multicolumn{3}{c|}{ Posição } \\
\hline Número & $\begin{array}{c}\text { Tipo do } \\
\text { Detector }\end{array}$ & Função & $\begin{array}{c}\text { X } \\
(\mathbf{m m}-\text { radial } \\
\text { Leste-Oeste) }\end{array}$ & $\begin{array}{c}\text { Y } \\
(\mathbf{m m}-\text { radial } \\
\text { Norte-Sul })\end{array}$ & $\begin{array}{c}\text { Z } \\
(\mathbf{m m} \text { - Axial) }\end{array}$ \\
\hline 1 & $\mathrm{BF}_{3}$ & Partida & +200 & -360 & +861 \\
\hline 2 & $\mathrm{BF}_{3}$ & Partida & -200 & +360 & +831 \\
\hline 3 & $\mathrm{CIC}$ & Potência & -360 & -200 & +208 \\
\hline 4 & $\mathrm{CIC}$ & Potência & +360 & +200 & +208 \\
\hline 5 & $\mathrm{CINC}$ & Linear & -140 & -360 & +637 \\
\hline 6 & $\mathrm{CINC}$ & Linear & +65 & +360 & +667 \\
\hline 7 & $\mathrm{CINC}$ & Segurança 1 & 0 & -360 & +712 \\
\hline 8 & $\mathrm{CINC}$ & Segurança 1 & -65 & +360 & +707 \\
\hline 9 & $\mathrm{BF}$ & Segurança 2 & +200 & +360 & +821 \\
\hline 10 & ${ }^{10} \mathrm{~B}$ & Segurança 2 & +800 & 0 & +841 \\
\hline
\end{tabular}


Em termos operacionais dividem-se estes canais em 3 grupos:

a) $1^{\circ}$ Grupo: Canais 1,2 e 9

- Faixa de Partida (zero à 100 miliwatts).

b) $2^{\circ}$ Grupo: Canais 3, 4, 7, 8 e 10 .

- Faixa de Potência (100 miliwatts à 100 watts)

c) $3^{\circ}$ Grupo: Canais: 5 e 6 .

- Controle de Potência

Na TAB 1.3 apresenta-se a faixa de monitoração dos detectores nucleares em nêutrons.

Tabela 1.3 - Faixa de monitoração dos detectores nucleares em nêutrons.

\begin{tabular}{|c|c|}
\hline $\begin{array}{c}\text { Canal } \\
\text { Nuclear }\end{array}$ & $\begin{array}{c}\text { Faixa de Monitoração do fluxo de } \\
\text { nêutrons }\end{array}$ \\
\hline 1 & $10^{-3}$ a $10^{4}$ nêutrons $/ \mathrm{cm}^{2} \mathrm{~s}$ \\
\hline 2 & $10^{-3}$ a $10^{4}$ nêutrons $/ \mathrm{cm}^{2} \mathrm{~s}$ \\
\hline 3 & $10^{2}$ a $10^{11}$ nêutrons $/ \mathrm{cm}^{2} \mathrm{~s}$ \\
\hline 4 & $10^{2}$ a $10^{11}$ nêutrons $/ \mathrm{cm}^{2} \mathrm{~s}$ \\
\hline 5 & $10^{3}$ a $10^{9}$ nêutrons $/ \mathrm{cm}^{2} \mathrm{~s}$ \\
\hline 6 & $10^{3}$ a $10^{9}$ nêutrons $/ \mathrm{cm}^{2} \mathrm{~s}$ \\
\hline 7 & $10^{3}$ a $10^{9}$ nêutrons $/ \mathrm{cm}^{2} \mathrm{~s}$ \\
\hline 8 & $10^{3}$ a $10^{9}$ nêutrons $/ \mathrm{cm}^{2} \mathrm{~s}$ \\
\hline 9 & $10^{-3}$ a $10^{4}$ nêutrons $/ \mathrm{cm}^{2} \mathrm{~s}$ \\
\hline 10 & $10^{-3}$ a $10^{4}$ nêutrons $/ \mathrm{cm}^{2} \mathrm{~s}$ \\
\hline
\end{tabular}




\subsection{A Importância da Calibração}

O primeiro a obter experimentalmente a potência de operação do Reator IPEN/MB01 foi Bitelli em 1988 [7] através da calibração dos canais nucleares do reator IPEN/MB01 em sua configuração de núcleo padrão retangular composto de 680 varetas combustíveis arranjadas numa configuração de $28 \times 26$ varetas, por meio da irradiação de folhas de ouro hiperpuras (Au-197). Na época se desprezou a correção advinda da perturbação do fluxo de nêutrons pela folha de ouro hiperpuro, neste caso o fator da perturbação por autoblindagem, acarretando com isso um erro sistemático de $6 \%$ estimado mais tarde por Gonçalves [1]. A potência medida foi de 2,76 watts $\pm 6 \%$, no entanto bem mais próxima da realidade física que o valor de 4 watts anteriormente estimado pelo código CITATION [7]. Na época o canal nuclear calibrado foi o de potência 5 que serviu de referência durante anos como o canal nuclear calibrado que definia a potência de operação do Reator IPEN/MB-01.

Vinte anos após a calibração realizada por Bitelli, já no ano de 2008, foi realizada outra calibração por Gonçalves [1] novamente com a configuração padrão retangular de $28 \times 26$ varetas combustíveis. Diferentemente, o experimento para a calibração do reator IPEN/MB-01 desta vez utilizou folhas de ouro infinitamente diluídas (1\% Au - 99\% Al). Estas folhas tornam desnecessário o cálculo de perturbação de fluxo advinda do fator de autoblindagem das folhas utilizadas, dada sua baixa concentração de ouro nas folhas de ativação de apenas $1 \%$ de massa. A potência obtida por Gonçalves foi de 106 watts, $6 \%$ superior aos 100 watts estimados por Bitelli em 1988 para o canal nuclear de potência 5 à corrente elétrica de $0,695 \times 10^{-5} \mathrm{~A}$.

A configuração cilíndrica sempre despertou um grande interesse em sua utilização pelo fato de que neste tipo de configuração temos uma menor fuga de nêutrons que a configuração retangular, ou seja, podemos obter a criticalidade com uma quantidade menor de combustível. No entanto a configuração cilíndrica utilizando-se a mesma quantidade de varetas combustível da configuração padrão retangular e por ter um excesso de reatividade bem maior (arranjo de 30x30 nas direções N-S) obriga o operador do reator a inserir 73\% das barras de controle acarretando com isso uma grande distorção do fluxo de nêutrons no interior do núcleo. Para evitar tal efeito começou-se a se investigar as propriedades 
neutrônicas de tal configuração de núcleo num arranjo menor de varetas combustíveis, ou seja, de apenas 28x28 nas direções do núcleo N-S e L-O [8,9] Por apresentar um excesso de reatividade bem menor, ou seja, 273 pcm contra 3245,18 pcm [10] da configuração 30x30. Assim o operador do reator para obter a criticalidade introduz apenas aproximadamente $13 \%$ das barras de controle e por consequência, a extensão da região assintótica do fluxo de nêutrons, livre das perturbações das barras de controle se torna bem maior, garantindo uma distribuição de fluxo de nêutrons axial que segue uma função cosseno e na direção radial uma função de Bessel, que são as funções características de uma configuração de núcleo de reator na forma cilíndrica.

Assim em 2013, realizou-se o experimento na configuração cilíndrica, com as varetas combustíveis dispostas $28 \times 28$ nas direções N-S e L-O. Este experimento foi realizado utilizando-se folhas hiperpuras, incluindo neste caso o fator de autoblindagem das folhas hiperpuras, e infinitamente diluídas, para a calibração dos canais nucleares de potência 5 e 6, que são câmaras de ionização não compensadas (CINC). Realizou-se também a calibração para o canal de contagem de pulsos, canal 10, por ser este o canal mais afastado do núcleo. Para a calibração deste canal tipo pulsos (detector proporcional de $\left.{ }^{10} \mathrm{~B}\right)$, obteve-se a reta de calibração na configuração cilíndrica de núcleo e comparou-se com a reta da configuração padrão retangular. A razão para a calibração do canal 10, se dá pelo fato dos canais de potência 5 e 6 estarem muito próximos ao núcleo do reator, e por conseguinte da influência (sombreamento) das barras de controle. Com a proximidade entre os canais nucleares 5 e 6 e as barras de controle a distribuição espacial do fluxo de nêutrons ao longo do comprimento ativo dos detectores citados é uma distribuição de fluxo de nêutrons perturbada e que depende muito da movimentação das barras de controle. $\mathrm{O}$ canal 10 pela sua posição mais afastada do núcleo (80 cm do centro do núcleo), obtém teoricamente os dados de maneira mais homogênea, isto é, sem distorções, informando a potência independente da posição das barras de controle e consequentemente da configuração em que o núcleo se encontre. A calibração de potência do canal 10 realizada apenas neste trabalho trará mais um método para se acompanhar a potência de operação do reator, método este que o tornará menos dependente do posicionamento das barras de controle no núcleo, bem como da configuração de núcleo do reator adotada na operação e experimentos realizados no reator IPEN/MB-01. 


\subsection{Objetivos}

Neste trabalho objetivamos calibrar os canais nucleares de potência do reator IPEN/MB-01 para a configuração cilíndrica 28×28 do núcleo do Reator IPEN/MB-01, a partir da distribuição espacial do fluxo de nêutrons no núcleo do reator, e correlacionar à informação dos canais nucleares com a potência gerada no núcleo a partir da medida do fluxo médio de nêutrons em seu interior.

Para a calibração foi utilizada a técnica experimental com detectores (folhas) de ativação. Esta técnica consiste na irradiação de folhas de Au-197 hiperpuras (100\% de Au) e infinitamente diluídas (1\% de Au dispersas numa matriz de $99 \%$ de Al). A utilização das folhas de ambas as concentrações de ouro possibilitou fornecer resultados convergentes para a obtenção do fluxo médio de nêutrons térmicos do núcleo cilíndrico $28 \times 28$.

A calibração do canal de potência 6 para a configuração cilíndrica de núcleo, serve de comparação para a configuração padrão retangular realizada por Gonçalves em 2008 [1], que utilizou somente folhas de Au-197 infinitamente diluídas.

A calibração do canal 10 de pulsos destacada neste trabalho será mais um importante parâmetro para auxiliar na operação do reator IPEN/MB-01, fornecendo valores mais próximos da realidade de uma forma mais independente da geometria de núcleo adotada nos experimentos.

\subsection{Roteiro da Dissertação}

No Capítulo 2 abordaremos as propriedades físicas e nucleares do Au-197 como folha de ativação e como obter o fluxo de nêutrons proveniente da atividade total induzida na folha. No Capítulo 3 trataremos da técnica de análise por ativação e de como obter o fluxo de nêutrons térmicos e epitérmicos em cada folha de ativação. No Capítulo 4 mostraremos como obter a potência média gerada no interior do reator nuclear IPEM/MB01, dado seu fluxo médio de nêutrons térmicos no núcleo. No Capítulo 5 apresentaremos suscintamente o código MCNP-5 e as grandezas obtidas para este trabalho por meio de 
suas simulações. No Capítulo 6 trataremos do tipo de reação radioativa que ocorre na folha de Au-197 quando absorve um nêutron térmico, a metodologia experimental aplicada neste trabalho e os fatores experimentais de correção de fluxo de nêutrons. No Capítulo 7 abordaremos como obter a eficiência da contagem do sistema de detecção de germânio hiperpuro, o qual foi utilizado para medir as contagens das folhas de ativação. Por fim, no Capítulo 8 apresentaremos os resultados obtidos neste trabalho e no Capítulo 9 as conclusões. 


\section{A TÉCNICA DE ANÁLISE POR ATIVAÇÃo}

A técnica de análise por ativação, leva em consideração alguns aspectos gerais positivos e negativos na sua utilização como método de obtenção de parâmetros nucleares de interesse à Física de Reatores [11].

Os Aspectos Positivos são:

a) Possui pouca susceptibilidade a interferências do campo gama do núcleo do reator;

b) Apresenta excelente sensibilidade neutrônica para inúmeros elementos, sendo este um dos motivos de sua grande aplicabilidade;

c) Pequena quantidade de átomos presentes na folha de ativação é suficiente. Alguns miligramas são suficientes, apresentando grande vantagem no caso de amostras de difícil obtenção;

d) Altos valores de seções de choque para a faixa térmica, intermediária ou rápida;

e) Independência de conexões elétricas e mecanismos de varredura no núcleo do reator;

Os Aspectos Negativos são:

a) O método não apresenta resultados imediatos, podendo necessitar de prazos longos para o decaimento dos radioisótopos a fim de se fazer a espectrometria gama das folhas de ativação irradiadas com valores aceitáveis de tempo morto $(<5 \%)$, uma vez que se faz necessário aguardar o decaimento para as leituras das contagens.

b) Além disso, todo o processo de leitura e tratamento dos dados deve ser realizado de maneira cuidadosa, envolvendo uma grande quantidade de cálculos.

2.1 A Utilização do Detector de Ativação Au-197

A escolha do Au-197 como detector (folha) de ativação utilizado neste trabalho considerou as seguintes propriedades físicas e nucleares [12]: 
a) O perfil da seção de choque - o material responde preferencialmente às energias de

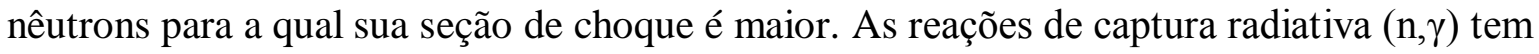
geralmente um dos maiores valores de seção de choque na região térmica. O ouro é um dos elementos que apresentam maior seção de choque nesta região. Existem ainda outras reações tais como $(n, p),(n, \alpha)$ e $(n, 2 n)$ que frequentemente requerem um limiar de energia mais alto para ocorrerem, ou seja, são insensíveis ao campo neutrônico de nêutrons térmicos.

b) A magnitude da seção de choque - a atividade de saturação é proporcional à seção de choque de ativação, ao fluxo de nêutrons e ao volume do detector, de tal forma que quanto maior a sensibilidade da seção de choque maior será a atividade induzida na irradiação da folha de ativação de ouro, porém, se a seção de choque for muito elevada, esta poderá absorver nêutrons em excesso, causando assim uma região de depressão no campo neutrônico e perturbar o fluxo de nêutrons que se deseja medir.

c) A constante de decaimento da atividade induzida - considera-se que a meia-vida do isótopo criado não deva ser nem muito grande, nem muito pequena. Se for muito grande, será necessário longo tempo de irradiação para alcançar a saturação. A atividade se torna menor quanto maior for a meia-vida. Se for muito pequena poderá prejudicar o experimento pela dificuldade e impossibilidade de acompanhar o decaimento das contagens em tempo de registro. A atividade se torna maior com uma meia-vida curta, podendo conflitar com o tempo morto do sistema de detecção, perdendo com isso as contagens geradas por superposição. A meia-vida do Au-197 é de 2,6949 dias, ajustandose bem à rotina da medição, atividade de saturação e demais características do sistema de detecção.

d) Pureza do material - a elevada pureza do material é de extrema importância, pois diferentes materiais (impurezas induzidas) podem ter diferentes meias-vidas, interferindo nas contagens do decaimento. A folha de Au-197 hiperpura possui a vantagem de ter também uma abundância isotópica de $100 \%$ do núcleo alvo Au-197, porém cria a necessidade de se corrigir as contagens induzidas, pelos fatores de perturbação de fluxo, como autoblindagem $(\mathrm{G})$ e depressão de fluxo $(\mathrm{H})$. No entanto, dada a alta magnitude da seção de choque é possível a utilização da folha de Au-197 infinitamente diluída, ou seja, composta apenas de $1 \%$ de ouro $(\mathrm{Au})$ e $99 \%$ de alumínio $(\mathrm{Al})$, tornando desnecessário a correção dos fatores de perturbação do fluxo de nêutrons. O elemento Al para a intensidade 
de fluxo, tempo de irradiação e sua seção de choque de ativação para a faixa térmica, não é ativado substancialmente de forma que cause interferência (superposição) devido a sua pequena magnitude de seção de choque para nêutrons térmicos, que pode ser observado na TAB 2.1 sendo praticamente considerado "transparente" aos nêutrons térmicos [13].

Tabela 2.1 - Dados nucleares comparativos do Au-197 e Al-27.

\begin{tabular}{|c|c|c|}
\hline Elemento & Au-197 & Al-27 \\
\hline $\begin{array}{c}\text { Densidade nominal }\left(\mathrm{g} / \mathrm{cm}^{3}\right) \\
\text { microscópica de absorção } \\
\text { (barns - 0,0253 eV) }\end{array}$ & 19,32 & 2,699 \\
\hline $\begin{array}{c}\text { Seção de choque } \\
\text { microscópica de ativação } \\
\text { (barns - 0,0253 eV) }\end{array}$ & $98,8 \pm 0,8 \pm 0,3$ & $-235 \pm 0,005$ \\
\hline $\begin{array}{c}\text { Seção de choque } \\
\text { microscópica de } \\
\text { espalhamento (barns) }\end{array}$ & ---- & $1,4 \pm 1$ \\
\hline $\begin{array}{c}\text { Integral de ressonância } \\
\text { (barns) }\end{array}$ & $1533 \pm 40$ & 0,18 \\
\hline
\end{tabular}

e) A natureza da atividade induzida - O decaimento do isótopo criado pela irradiação, geralmente ocorre por partículas beta ou gama. O gama pela sua característica de penetração é melhor para se trabalhar dada a baixa autoabsorção na folha de ativação. Assim, sistemas de espectrometria gama são mais usuais na obtenção de dados de ativação. O prédio do reator IPEN/MB-01 tem em suas instalações um sistema composto de detector de estado sólido sensível à radiação gama conhecido como HPGe (Hyper Pure Germaniun) que foi utilizado para obter as contagens do fotopico gama de $411,80 \mathrm{KeV}$.

f) Possuir diminutas dimensões - essa é uma excelente característica das folhas de Au, pois assim pode ser posicionada em locais de difícil acesso dentro do núcleo do reator, fornecendo valores absolutos do fluxo de nêutrons térmicos e epitérmicos - as pequenas dimensões também são responsáveis por inserir pouca interferência local dada à pouca absorção de nêutrons. 
g) Não sofrer indução pelo campo gama - o núcleo do reator está repleto de partículas gama. Caso o detector sofra indução por esta radiação, haverá partículas secundárias, alterando as contagens e o resultado do cálculo do fluxo de nêutrons térmicos.

\subsection{A Taxa de Radiação}

Quando um reator nuclear está crítico e existam detectores de ativação dispostos em seu núcleo, estes serão bombardeados por nêutrons e se tornarão radionuclídeos. A equação que descreve a taxa de produção destes radionuclídeos é [14],

$$
\frac{d n}{d t}=N \sigma_{a t i v} \phi-n \sigma_{a} \phi-n \lambda
$$

sendo,

$\sigma_{\text {ativ }}$ - seção de choque microscópica de ativação média.

$\sigma_{a}$ - seção de choque microscópica de absorção média.

$\lambda$ - constante de decaimento do radionuclídeo formado.

$n$ - número de átomos do radionuclídeo formado.

$N$ - número de átomos alvo do detector de ativação.

Considerando que a variação do número de átomos alvo em relação ao tempo é a taxa de consumo destes átomos no meio considerado, temos,

$$
\frac{d N}{d t}=-N \sigma_{t} \phi
$$

Sendo $\sigma_{t}=$ seção de choque microscópica média total, que considera todas as possíveis reações que ocorram consumindo o átomo.

A equação (2.2) é aqui considerada como uma equação diferencial linear homogênea de coeficiente constante, e assim sua solução é dada por [15], 


$$
N=N_{0} e^{-\sigma_{t} \phi t}
$$

sendo $N_{0}=$ número inicial de átomos alvo do detector de ativação. Ao substituirmos a equação (2.3) em (2.1) chegaremos ao seguinte resultado,

$$
\frac{d n}{d t}+n\left(\sigma_{a} \phi+\lambda\right)=N_{0} \sigma_{a t i v} \phi e^{-\sigma_{t} \phi t}
$$

essa equação assemelha-se a equação diferencial,

$$
\frac{d y}{d t}+p(t) y=q(t)
$$

cuja a solução matemática, implica na técnica da multiplicação da equação pelo fator integrante $\mu(t)$ definido como,

$$
\mu(t)=e^{\int p(t) d t}=e^{\left(\sigma_{a} \phi+\lambda\right) t}
$$

resultando em uma derivada de um produto,

$$
\frac{d\left(n e^{\left(\sigma_{a} \phi+\lambda\right) t}\right)}{d t}=N_{0} \sigma_{a t i} \phi e^{\left(\sigma_{a} \phi+\lambda-\sigma_{t} \phi\right) t}
$$

O fluxo de nêutrons do reator IPEM/MB-01 está na ordem de $10^{9} \mathrm{n} / \mathrm{cm}^{2} . \mathrm{s}$, as seções de choque $\sigma_{a}$ e $\sigma_{t}$ são da ordem de $10^{-20} \mathrm{~cm}^{2}$ e, $\lambda$ da ordem de $10^{-6} \mathrm{~s}^{-1}$, assim, pode-se considerar que a condição $\sigma_{a} \phi<<\lambda \mathrm{e}_{t} \sigma_{t} \phi<\lambda$ é válida [16]. Posto isto e integrando-se a equação (2.7) tem-se, 


$$
n(t)=\frac{N_{0} \sigma_{a t i v} \phi+K e^{-\lambda t}}{\lambda} .
$$

O $K$ representa a constante de integração. Aplicando as condições iniciais em que $\mathrm{t}=0, \mathrm{o}$ número de radionuclídeos é igual a zero para $(n(0)=0)$ e $K=-N_{0} \sigma_{a t i} \phi$, assim tem-se,

$$
n(t)=\frac{N_{0} \sigma_{a t i} \phi-N_{0} \sigma_{a t i} \phi e^{-\lambda t}}{\lambda}
$$

e por fim,

$$
n(t)=\frac{N_{0} \sigma_{\text {ativ }} \phi\left(1-e^{-\lambda t}\right)}{\lambda}
$$

Multiplicando-se por $\lambda$ ambos os lados tem-se a atividade induzida,

$$
A_{0}=n \lambda=N_{0} \sigma_{a t i} \phi\left(1-e^{-\lambda t}\right)
$$

Substituindo-se $N_{0}=N V$, onde $N_{0}$ é o número inicial de átomos alvo presentes na folha de ativação e $V$ o volume do detector. Obtém-se então a atividade da folha ao término da irradiação $\left(A_{0}\right)$, dada a seguir por

$$
A_{0}=N V \sigma_{\text {ativ }} \phi\left(1-e^{-\lambda t}\right)
$$

Sabendo-se que $\Sigma_{\text {ativ }}=N \sigma_{\text {ativ }}$, é a seção de choque macroscópica média de ativação resulta em, 


$$
A_{0}=\Sigma_{\text {ativ }} V \phi\left(1-e^{-\lambda t}\right) .
$$

A equação (2.13) fornece a atividade induzida para um tempo $t$ de irradiação. A representação gráfica da atividade pode ser vista na FIG 2.1 [12].

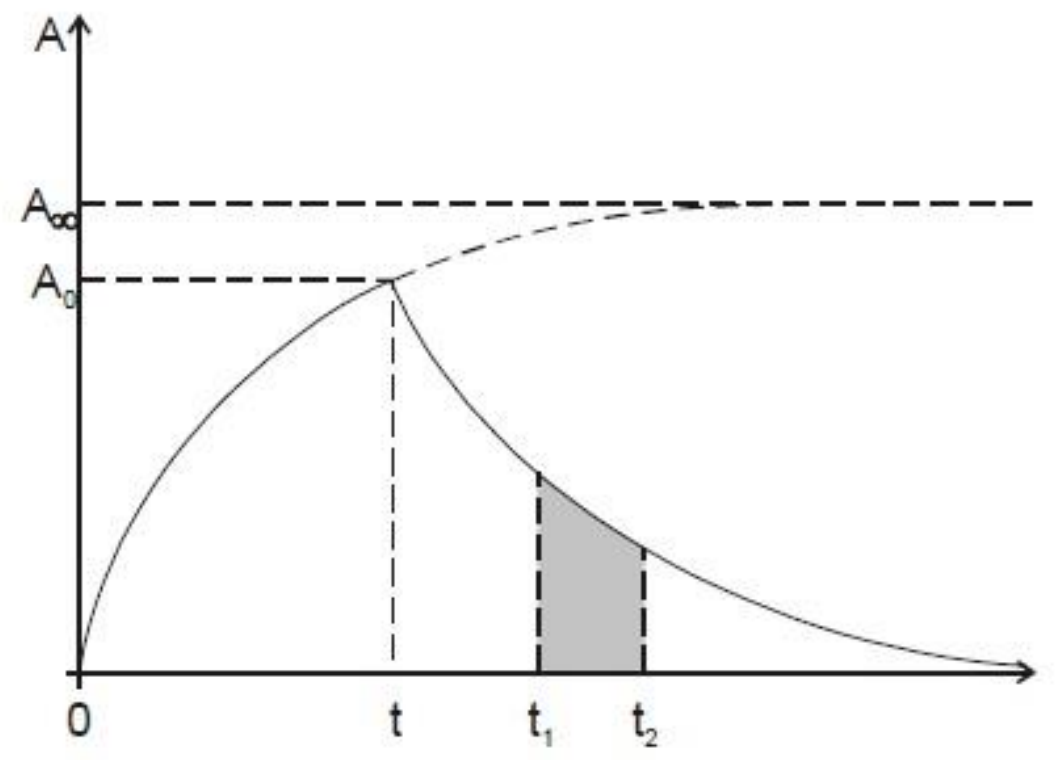

Figura 2.1- Curva da atividade induzida no detector para o tempo de irradiação t.

No eixo das abcissas, o tempo $t$ representa o tempo de irradiação $\left(t_{i}\right), t_{1}$ e $t_{2}$ o tempo de contagem $\left(t_{c}\right)$ no sistema detector e $t_{1^{-}} t$ o tempo de espera $\left(t_{e}\right)$. $O$ tempo de espera considera o tempo do final da irradiação até o início da contagem da amostra no sistema detector.

Ao atingir a saturação $\left(A^{\infty}\right)$, quando o tempo de irradiação for muito grande, ou seja, tender ao infinito a equação torna-se,

$$
A^{\infty}=\Sigma_{\text {ativ }} V \phi
$$

e portanto pode-se escrever, 


$$
A_{0}=A^{\infty}\left(1-e^{-\lambda t}\right)
$$

Usualmente não se irradia detectores de ativação até a sua saturação, mas sim até que se possa medir seu decaimento com razoável precisão.

Pode-se reescrever a atividade de saturação da equação (2.14), considerando que $N=\frac{\rho N_{a}}{P}$, onde $\rho$ é a densidade do detector, $N_{a}$ o número de Avogadro e $P$ o peso atômico do núcleo alvo. Sendo $\rho=\frac{m}{V}$, e $m$ a massa do detector. Define-se então a equação da atividade de saturação como,

$$
A^{\infty}=\frac{N_{a} m \phi \sigma_{\text {ativ }}}{P}
$$

sendo que o fluxo de nêutrons é dado por,

$$
\phi=\frac{A^{\infty} P}{N_{a} m \sigma_{a t i v}}
$$

A equação (2.17) permite obter o valor do fluxo de nêutrons em função da atividade de saturação, do peso atômico, do número de Avogadro, da massa do detector e da seção de choque microscópica média de ativação. Todos os valores podem ser encontrados em bibliotecas de dados à exceção da atividade de saturação que é determinada experimentalmente. Este parâmetro é obtido a partir das contagens líquidas (descontadas da radiação de fundo-BG) integradas no fotopico gama de maior abundância ( $\mathrm{I}=0,9556$ $[5,17])$ gama do ouro-198 $(411,80 \mathrm{keV}[5,17])$ no detector de espectrometria gama HPGe. A equação (2.18) apresenta a relação da contagem bruta integrada no citado fotopico gama no sistema de espectrometria gama, 


$$
C=\varepsilon I \int_{t_{1}}^{t_{2}} A_{0} e^{-\lambda t} d t+B G
$$

Sendo,

$\varepsilon$ - eficiência global da contagem.

I - abundância do fotopico gama contado (g/100 desintegrações).

$B G$ - a radiação de fundo entre os tempos $\mathrm{t}_{1}$ e $\mathrm{t}_{2}$.

Resolvendo a equação (2.17) temos,

$$
C=\frac{\varepsilon A_{0} I}{\lambda} e^{-\lambda t_{1}}\left(1-e^{-\lambda t_{c}}\right)+B G
$$

Observando a FIG 2.1 conclui-se que $t_{e}=t_{1}-t$, é o tempo de espera do término da irradiação até o início da contagem e, que quando ajustado na equação (2.19) obtém-se,

$$
C=\frac{\varepsilon A_{0} I}{\lambda}\left(e^{-\lambda t} e^{-\lambda t_{e}}\right)\left(1-e^{-\lambda t_{c}}\right)+B G
$$

Sendo que $e^{-\lambda t}=1$, pois em $t=t_{0}$ a probabilidade do átomo não se desintegrar é de $100 \%$, então,

$$
C=\frac{\varepsilon A_{0} I}{\lambda} e^{-\lambda t_{e}}\left(1-e^{-\lambda t_{c}}\right)+B G
$$

Isolando o $A_{0}$ da equação (2.21) e substituindo na (2.15), obtém-se de forma experimental a equação que representa a atividade de saturação, ou seja a taxa de reação nuclear induzida num detector de ativação ao ser irradiado num campo neutrônico, 


$$
A^{\infty}=\frac{\lambda e^{\lambda t_{e}}(C-B G)}{\varepsilon I\left(1-e^{-\lambda t_{c}}\right)\left(1-e^{-\lambda t_{i}}\right)},
$$

Sendo $t=t_{i}$, o tempo de irradiação do detector no núcleo do reator. Por fim se substituirmos a equação (2.22) na (2.17) obtém-se o fluxo de nêutrons, proveniente da contagem líquida (C-BG) integrada no fotopico gama de interesse,

$$
\phi=\frac{\lambda e^{\lambda t_{e}}(C-B G) P}{\varepsilon I\left(1-e^{-\lambda t_{c}}\right)\left(1-e^{-\lambda t_{i}}\right) m N_{a} \sigma_{\text {ativ }}}
$$

Pela equação (2.23) tem-se o fluxo de nêutrons obtido experimentalmente através da contagem (pela espectrometria gama) dos detectores de ativação. Caso se utilize as contagens líquidas da folha nua, ou seja, folhas irradiadas sem cobertura de cádmio, a equação (2.23) nos fornecerá o fluxo de nêutrons térmicos e epitérmicos medidos pela folha de ouro nua (neste caso a seção de choque utilizada deverá ser o valor médio em todo o espectro de energia dos nêutrons). Assim este valor não corrigido pela perturbação causada no fluxo de nêutrons pela presença das próprias folhas de ativação, fornece apenas uma primeira estimativa do valor absoluto do fluxo de nêutrons "enxergado" pela folha de ouro em todo o espectro de energia, sendo utilizado apenas para esta finalidade, não discriminando a parcela térmica da epitérmica, o que somente será possível com a utilização da técnica da razão de cádmio descrita a seguir. 


\section{FLUXO DE NÊUTRONS TÉRMICOS E INTERMEDIÁRIOS}

\subsection{Técnica da Razão de Cádmio}

Se houvesse um detector de ativação cujo material absorvesse apenas nêutrons térmicos então, poder-se-ia considerar que, a atividade de saturação $A^{\infty}$ obtida seria unicamente devido aos nêutrons da faixa de energia térmica, porém, parte da ativação induzida no detector é em função dos nêutrons epitérmicos. Assim, no caso dos detectores de ativação de ouro irradiados no núcleo cilíndrico do Reator IPEN/MB-01, aproximadamente $1 / 3$ da ativação induzida ocorre devido aos nêutrons epitérmicos.

Uma vez que a atividade de saturação induzida no detector nu é devida a toda faixa de energia dos nêutrons, ou seja, nêutrons térmicos e epitérmicos, pode-se escrever que [7],

$$
A_{\text {nua }}^{\infty}=A_{\text {ter }}^{\infty}+A_{\text {epit }}^{\infty}
$$

A atividade de saturação do detector de ativação sem cobertura de cádmio ( $\left.A_{\text {nua }}^{\infty}\right)$ é a soma da atividade induzida no detector pelos nêutrons térmicos $\left(A_{t e r}^{\infty}\right)$ mais a atividade induzida no detector pelos nêutrons epitérmicos $\left(A_{\text {epit }}^{\infty}\right)$.

Para se obter as atividades de saturação respectivas para cada faixa de energia dos nêutrons do núcleo do reator usa-se a técnica da razão de cádmio. Para aplicar esta técnica, faz-se necessário que se irradie detectores de características dimensionais semelhantes no mesmo local dentro do núcleo do reator. Deve ser realizada uma operação com detectores nus e outra com detectores cobertos com cádmio. Devem-se usar somente detectores de mesma composição, ou seja, hiperpuros (100\% de átomos alvo do Au-197) ou infinitamente diluídos (1\% Au-197 e 99\% Al). Deve-se manter a mesma metodologia experimental em que se deram as irradiações, ou seja, temperatura do moderador igual ou muito próxima nas demais operações de irradiação, mesmas posições das barras de controle e segurança, mesmo tempo de irradiação e mesma potência de operação. 
A razão de cádmio para dois detectores infinitamente diluídos (1\% Au e 99\% Al) de massas diferentes é dada por,

$$
R_{c d}=\frac{A_{\text {nиа }}^{\infty} / m_{\text {nиа }}}{A_{c d}^{\infty} / m_{c d}}
$$

sendo $R_{c d}$ a razão de cádmio, $m_{\text {пиа }}$ a massa do detector nu, $m_{c d}$ a massa do detector coberto com cádmio e $A_{c d}^{\infty}$ a atividade de saturação induzida pelos nêutrons epitérmicos. Nesta equação não se faz necessária à inserção do fator de perturbação (FP), pois esta se refere à folha de ouro infinitamente diluído que apresenta um fator de perturbação no meio, de valor desprezível quando comparado ao valor da folha de ouro hiperpura.

Para detectores de ativação de ouro hiperpuro $(100 \% \mathrm{Au})$ a razão de cádmio é dada por [18],

$$
R_{c d}=\left[\frac{A_{\text {nиа }}^{\infty}}{A_{c d}^{\infty}} \frac{F P_{\text {epit }}}{F P_{\text {ter }}}+F_{c d}\left(1-\frac{F P_{\text {epit }}}{F P_{\text {ter }}}\right)\right] \frac{m_{c d}}{m_{\text {пиа }}}
$$

sendo $F P_{e p i t}$ o fator de perturbação para a região epitérmica, $F P_{t e r}$ o fator de perturbação para a região térmica.

O fator de perturbação para a região epitérmica é dado pela equação,

$$
F P_{\text {epit }}=\frac{\left(A_{\text {epit }}^{\infty} / N\right)^{h i p}}{\left(A_{\text {epit }}^{\infty} / N\right)^{\mathrm{inf}}}
$$

sendo $N$ o número de átomos presentes nas folhas de Au hiperpura e infinitamente diluída, dado pela equação $N=m \frac{N_{a}}{P}$, cujos parâmetros $m, N_{a}$ e $P$ foram citados no item 2.2. 
O fator de perturbação para a região térmica é dado pela equação,

$$
F P_{t e r}=\frac{\left(A_{t e r}^{\infty} / N\right)^{h i p}}{\left(A_{t e r}^{\infty} / N\right)^{\text {inf }}}
$$

O cádmio tem a função de filtro para nêutrons térmicos devido a sua elevada seção de choque de absorção térmica, visto na TAB 3.1 [19], de tal forma que a atividade induzida em um detector de ativação coberto com cádmio, é dada por nêutrons epitérmicos. Porém, o cádmio não é um filtro ideal e uma pequena fração de nêutrons epitérmicos é capturada pela cobertura de cádmio.

Tabela 3.1 - Dados nucleares comparativos do Au-197 e Cd-112.

\begin{tabular}{|c|c|c|}
\hline Elemento & Au-197 & Cd-112 \\
\hline Densidade nominal $\left(\mathrm{g} / \mathrm{cm}^{3}\right)$ & 19,32 & 8,65 \\
\hline $\begin{array}{c}\text { Seção de choque } \\
\text { microscópica de absorção } \\
\text { (barns - 0,0253 eV) }\end{array}$ & $98,8 \pm 0,3$ & $2450 \pm 30$ \\
\hline $\begin{array}{c}\text { Seção de choque } \\
\text { microscópica de ativação } \\
\text { (barns - 0,0253 eV) }\end{array}$ & $98,8 \pm 0,3$ & --- \\
\hline $\begin{array}{c}\text { Seção de choque } \\
\text { microscópica de } \\
\text { espalhamento (barns) }\end{array}$ & --- & 7 \\
\hline $\begin{array}{c}\text { Integral de ressonância } \\
\text { (barns) }\end{array}$ & $1533 \pm 40$ & 102 \\
\hline
\end{tabular}

Desta forma, a atividade de saturação epitérmica com o detector coberto com cádmio não será dada apenas por $A_{c d}^{\infty}$, mas pela equação,

$$
A_{e p i t}^{\infty}=F_{c d} A_{c d}^{\infty}
$$


A aplicação do fator de cádmio $\left(F_{c d}\right)$ restaura a contribuição de nêutrons epitérmicos que foram absorvidos pela cobertura de cádmio. Ao trabalharmos com as equações (3.1), (3.2), e (3.6) obtemos a equação (3.7) que representa a atividade de saturação da folha de ouro devido a contribuição dos nêutrons térmicos. Assim,

$$
A_{\text {ter }}^{\infty}=A_{\text {пиа }}^{\infty}\left(1-\frac{F_{c d}}{R_{c d}}\right),
$$

e para a atividade de saturação epitérmica,

$$
A_{e p i t}^{\infty}=A_{\text {nua }}^{\infty} \frac{F_{c d}}{R_{c d}}
$$

\subsection{Fluxo de Nêutrons Térmicos}

Considerando-se a equação (3.7) da atividade de saturação térmica, e se a substituirmos na equação (2.17), obteremos o fluxo de nêutrons térmicos,

$$
\phi_{t e r}=\frac{A_{\text {nua }}^{\infty}\left(1-\frac{F_{c d}}{R_{c d}}\right) P}{N_{a} m \sigma_{a t i v} F P_{t e r}} .
$$

Introduzimos na equação (3.9) o fator $F P_{t e r}$ que leva em conta o fator de perturbação térmico. Este fator é necessário para restaurar o fluxo de nêutrons ao seu valor não perturbado. Em se tratando de detectores infinitamente diluídos $F P_{t e r}=1$, mas quando se usam detectores de ativação hiperpuros, este fator assume um valor que depende das características geométricas da folha. Caso as folhas hiperpuras de ativação de um determinado material estejam cobertas com cádmio $(\mathrm{Cd}), F P_{t e r}$ dependerá principalmente da espessura e diâmetro do cádmio. 


\subsection{Fluxo de Nêutrons Epitérmicos}

Por definição o fluxo de nêutrons intermediários é dado pela equação

$$
\phi_{\text {int }}=\int_{E_{c d}}^{E_{2}} \phi(E) d E
$$

sendo a energia de corte do cádmio dada por $E_{c d}$ [4] e o limite superior $E_{2}$ a energia de limiar entre a região intermediária e a rápida. O fluxo na região intermediária cumpre uma proporcionalidade de $\frac{1}{E}$, que representa uma variação na proporção inversa à energia do nêutron. Como a região intermediária cobre uma ampla faixa de energia de algumas décadas, torna-se conveniente introduzir a variável de letargia $\mu$ no lugar de $E_{2}$,

$$
\mu=\ln \frac{E_{0}}{E}
$$

Sendo $E_{0}$ o limite da energia dos nêutrons em um reator, cujo valor usual utilizado é igual a 10 Mev. A cada ocorrência de espalhamento os nêutrons são moderados e perdem energia, e assim a letargia aumenta. Então o fluxo de nêutrons intermediários pode ser dado por intervalos de letargia,

$$
\phi(\mu) d \mu=-\phi(E) d E
$$

sendo

$$
\phi(\mu)=E \phi(E)
$$


Se isolarmos $\phi(E)$ e substituir na equação (3.10) tem-se,

$$
\phi_{\mathrm{int}}=\int_{E_{c d}}^{E_{2}} \frac{\phi(\mu) d E}{E}
$$

cuja solução fica,

$$
\phi_{\mathrm{int}}=\phi(\mu) \ln \frac{E_{2}}{E_{c d}}
$$

Uma folha de ativação coberta com cádmio, irradiada no núcleo de um reator nuclear, apresenta após um tempo infinito de irradiação (na prática um tempo bem maior que a meia-vida do radionuclídeo formado), a seguinte atividade de saturação,

$$
A_{c d}^{\infty}=N_{t} \int_{E_{c d}}^{\infty} \sigma(E) \phi(E) d E
$$

Sendo $N_{t}$ o número de átomos alvo. Considerando a equação (3.13) tem-se

$$
A_{c d}^{\infty}=N_{t} \phi(\mu) \int_{E_{c d}}^{\infty} \sigma(E) \frac{d E}{E}
$$

Isolando o fluxo tem-se,

$$
\phi(\mu)=\frac{A_{c d}^{\infty}}{N_{t} \int_{E_{c d}}^{\infty} \sigma(E) \frac{d E}{E}} .
$$


E por fim tem-se a definição do fluxo em função da letargia,

$$
\phi(\mu)=\frac{A_{c d}^{\infty}}{N_{t} I_{R}^{\infty}}
$$

sendo $I_{R}^{\infty}$ a integral de ressonância para a energia de corte $E_{c d}$ de $0,55 \mathrm{eV}$ para uma cobertura de cádmio de $0,5 \mathrm{~mm}$ de espessura para fluxo de nêutrons intermediários [4]. O limite superior $E_{2}$ é 1,05 Mev [20].

Se substituir a equação (3.19) em (3.15) tem-se o fluxo para a região intermediária do espectro de energia neutrônico,

$$
\phi_{\mathrm{int}}(E)=\frac{A_{c d}^{\infty}}{N_{t} I_{R}^{\infty}} \ln \frac{E_{2}}{E_{c d}}
$$

A equação (3.20) que fornece o fluxo de nêutrons na região intermediária é utilizada para casos em que o fator de perturbação é desprezível, a exemplo da folha infinitamente diluída. Para os detectores hiperpuros deve-se introduzir o fator de correção $F P_{e p i t}$ para a perturbação no fluxo pelos nêutrons epitérmicos. Assim, utilizando-se a equação (3.2) tem-se

$$
\phi_{\text {epit }}(E)=\frac{A_{\text {nua }}^{\infty}}{N_{t} I_{R}^{\infty} F P_{\text {epit }} R_{c d}} \ln \frac{E_{2}}{E_{c d}}
$$


Tabela 3.2 - Alguns detectores de ativação utilizados na região intermediária.

\begin{tabular}{|c|c|c|c|c|c|}
\hline Elemento & Isótopo & Meia-vida & $\begin{array}{c}\text { Energia de } \\
\text { ressonância }\end{array}$ & $I_{R}^{\infty}$ (barns) & $\frac{A_{\mathrm{Re} s}^{\infty}}{A_{1 / v}^{\infty}}$ \\
\hline $\mathrm{Au}$ & 197 & 2,695 dias & $4,905 \mathrm{eV}$ & 1563,00 & $\approx 0,95$ \\
\hline $\mathrm{In}$ & 115 & 54,12 min & $1,457 \mathrm{eV}$ & 3268,00 & $\approx 0,96$ \\
\hline $\mathrm{La}$ & 139 & 40,12 horas & $73,500 \mathrm{eV}$ & 11,00 & $\approx 0,97$ \\
\hline $\mathrm{W}$ & 186 & 24 horas & $18,800 \mathrm{eV}$ & 114,40 & $\approx 0,98$ \\
\hline $\mathrm{Mn}$ & 55 & 2,58 horas & $337,000 \mathrm{eV}$ & 11,44 & $\approx 0,88$ \\
\hline
\end{tabular}

$A_{\mathrm{Res}}^{\infty}$ - Atividade de saturação intermediária na região de ressonância principal.

$A_{1 / v}^{\infty}$ - Atividade de saturação na região de comportamento 1/v.

\subsection{Fatores de Correção do Fluxo de Nêutrons Perturbado.}

A medida do fluxo neutrônico pelos detectores de ativação requer que nêutrons sejam absorvidos no núcleo do reator, reduzindo o número de nêutrons do núcleo. Esta perturbação no fluxo de nêutrons precisa ser restaurada para a condição de não perturbado e assim, faz-se uso de fatores de correção para esse processo. Esses fatores dependem da seção de choque, da geometria e da espessura do detector de ativação. A perturbação causada por um detector (folha) de ativação pode ser desprezada quando temos que [21],

$$
\left[\sum_{a}(E)+\sum_{s}(E)\right] d<<1
$$

Sendo $\sum_{a}(E)$ a seção de choque macroscópica de absorção, $\sum_{s}(E)$ a seção de choque macroscópica de espalhamento e $d$ a espessura do detector de ativação.

Quando o nuclídeo alvo está significativamente diluído em uma matriz de $\mathrm{Al}$ ou quando se usam detectores de limiar onde as seções de choque são de pequena magnitude, 
podem-se desprezar igualmente os fatores de perturbação $(F P)$. Os fatores de perturbação térmico e epitérmico são,

$$
F P_{t e r}=G_{t e r} H_{t e r}
$$

$\mathrm{e}$

$$
F P_{\text {epit }}=G_{\text {epit }} H_{\text {epit }} \text {. }
$$

Sendo $G_{t e r}$ o fator de autoblindagem térmico, $G_{e p i t}$ o fator de autoblindagem epitérmico, e $H$ o fator de depressão de fluxo térmico e epitérmico respectivamente. O fator de autoblindagem indica a probabilidade média de um nêutron escapar do detector sem ser absorvido. O fator de depressão de fluxo representa o fato de o detector ocupar um lugar antes ocupado pelo moderador, por possuir alta seção de choque de absorção e de não permitir que se mantenha a mesma taxa de espalhamento, causando com isso uma depressão no fluxo de nêutrons.

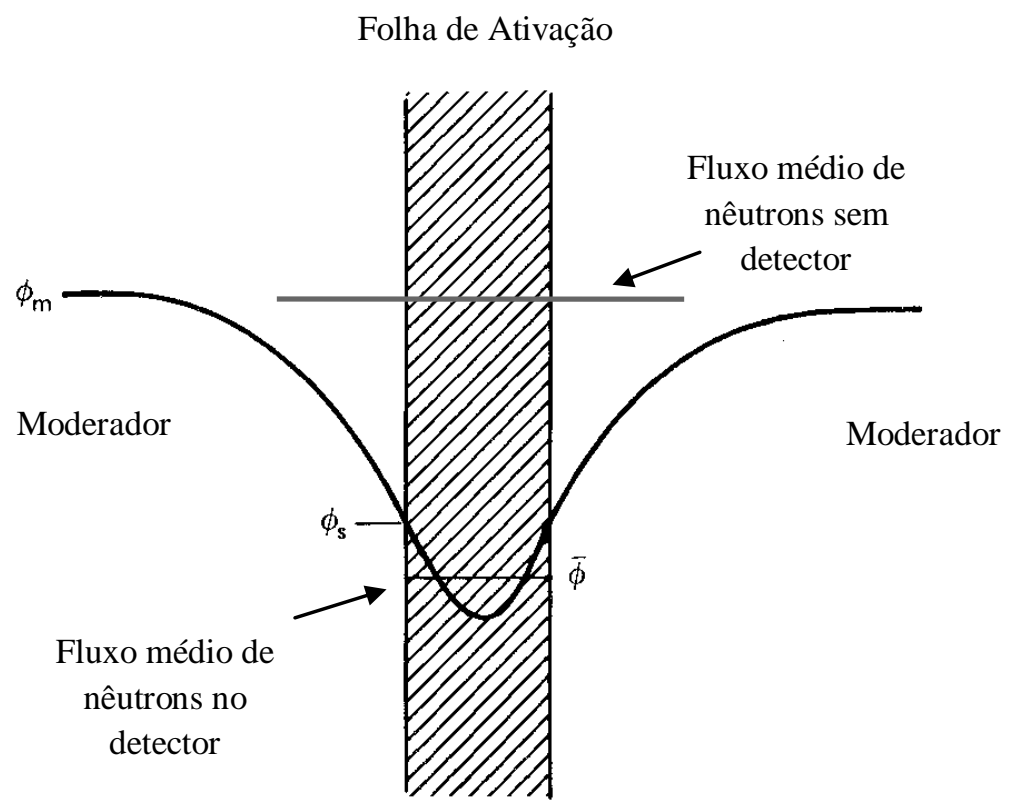

Figura 3.1- Perturbação sofrida pelo fluxo de nêutrons num detector do tipo folha de ativação. 
O fator de autoblindagem é definido como a razão entre o fluxo médio de nêutrons no volume do detector e o fluxo de nêutrons na superfície do detector $[4,7]$.

$$
G=\frac{\bar{\phi}}{\phi_{S}}
$$

O fator de depressão de fluxo é definido como a razão entre o fluxo de nêutrons na superfície e o fluxo não perturbado no moderador $[4,7]$.

$$
H=\frac{\phi_{S}}{\phi_{M}}
$$




\section{POTÊNCIA DO REATOR NUCLEAR}

\subsection{Densidade de Potência}

Conhecer a potência de operação de um reator nuclear é de extrema importância para a análise de fatores como a segurança e a queima de combustível. Para os fatores relacionados à segurança, sabe-se que a potência em um reator térmico é proporcional ao fluxo de nêutrons térmicos, os quais foram anteriormente moderados de forma que sua energia cinética foi convertida em ionização do meio, reações secundárias, calor para o moderador, combustível e estruturas do núcleo por meio de reações e colisões elásticas e inelásticas [22]. As reações de fissão quando não controladas, liberam grande quantidade de energia em forma de calor (energia esta depositada pelos fragmentos de fissão) e podem assim elevar a temperatura do núcleo a altíssimos níveis, podendo resultar em danos internos ao reator. Por sua vez, a queima de combustível está diretamente relacionada à potência de operação e a distribuição da queima à geometria do núcleo. Sendo assim, cada geometria tem um tempo de vida de operação relacionada a uma determinada potência de trabalho. Numa configuração cilíndrica temos um perfil do fluxo de nêutrons cossenoidal no sentido axial e uma curva de Bessel de primeiro tipo no sentido radial. Assim, caso se operasse o reator a um nível de potência tal que fosse significativa a queima de combustível, o consumo de átomos físseis se concentraria mais na região axial inferior no centro do núcleo. Nesta região mais afastada do refletor ocorre menos fuga de nêutrons, e assim, uma maior concentração de nêutrons induzindo novas fissões [23]. 


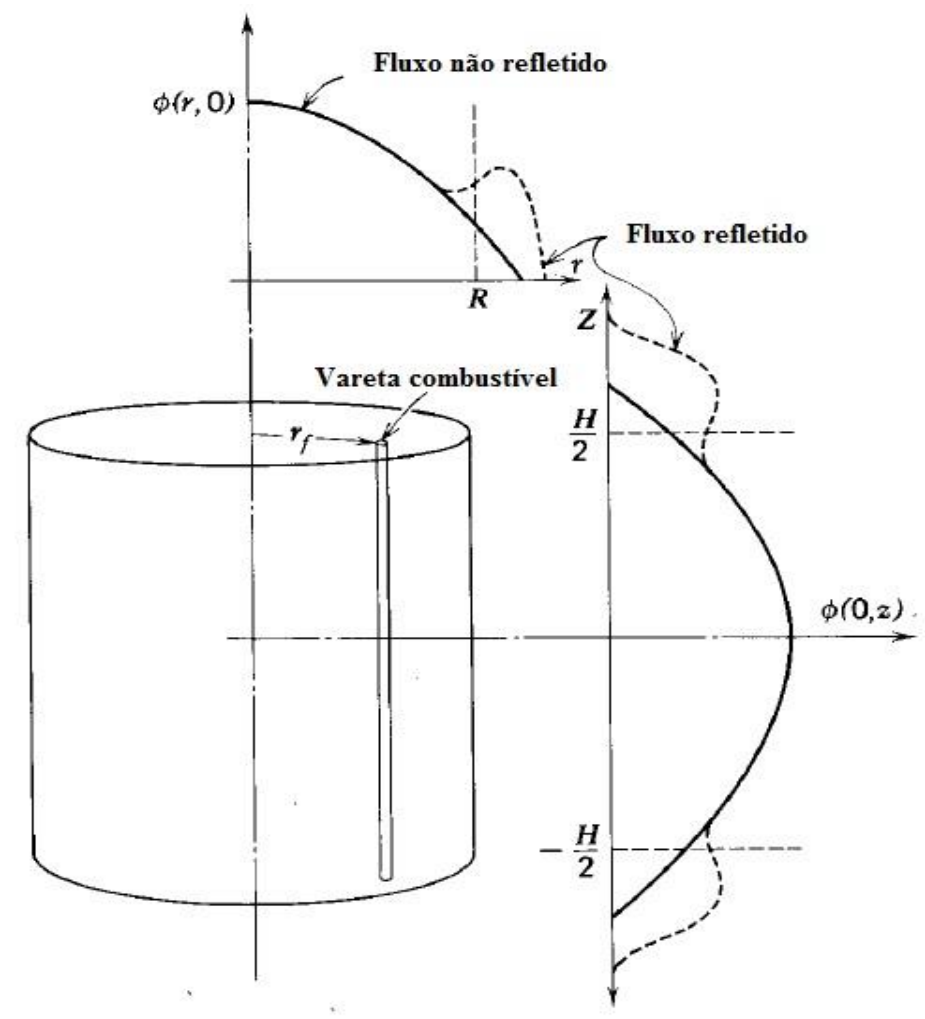

Figura 4.1 - Distribuição do fluxo de nêutrons em um reator de configuração geométrica cilíndrica finita.

A densidade de potência considerada em um determinado volume $\mathrm{V}$ do núcleo de um reator é dada por [18],

$$
P=G \int_{V} N_{f}(\bar{r}) \int_{E} \sigma_{f}(E) \phi(\bar{r}, E) d E d V
$$

Sendo que $G$ é a energia recuperável por fissão $\left(200 \mathrm{MeV}=3.2 \times 10^{-11}\right.$ joules $), N_{f}$ é o número de átomos físseis no volume $\mathrm{V}, \sigma_{f}$ a seção de choque microscópica de físsão e $\phi$ o fluxo de nêutrons em todo o espectro de energia em cada posição no interior do reator.

No reator IPEN/MB-01 devido à baixa magnitude de fluxo de nêutrons a queima é desprezível e assim $N_{f}$ pode ser retirado da integral. Considerando-se valores médios para 
os parâmetros $\sigma_{f}$ e $\phi$ integrados em todo o volume do espectro de energia de nêutrons, obtém-se como resultado a equação (4.2),

$$
P=G \cdot N_{f} \cdot \overline{\sigma_{f}} \cdot \bar{\phi} \cdot V
$$

sendo,

$$
\bar{\phi}(E)=\frac{\int_{V} \phi(\bar{r}, E) \cdot d V}{V}
$$

$\mathrm{e}$

$$
\bar{\sigma}_{f}=\frac{\int_{0}^{\infty} \bar{\phi}(E) \cdot \sigma(E) \cdot d E}{\int \bar{\phi}(E) \cdot d E} .
$$

Este trabalho entretanto, foi planejado para medir o fluxo médio de nêutrons térmicos, e não o fluxo médio de nêutrons em todo o espectro de energia, pois sabemos que num reator térmico $85 \%$ das fissões nucleares no ${ }^{235} \mathrm{U}$ e consequentemente da potência de operação do reator são devidas aos nêutrons térmicos. As reações de fissão ocorrem no combustível e não no moderador onde se mede o fluxo de nêutrons. Desta forma acrescentam-se dois fatores de correção na equação (4.2) para se chegar à equação da potência gerada no núcleo do reator em um determinado volume $\mathrm{V}$, considerando também nêutrons epitérmicos (intermediários e rápidos) e as reações de fissão que ocorrem dentro da região combustível. Tem-se então,

$$
P=G \cdot \overline{\sum_{f}} \cdot \overline{\phi_{t e r}} \cdot V \cdot F \cdot R
$$

Sendo $F$ a razão entre o fluxo de nêutrons no combustível e no moderador e, $R$ o fator de fissão rápida que considera a porção de fissões que ocorrem com nêutrons rápidos. Como todos os parâmetros são constantes na equação, a potência torna-se diretamente proporcional ao fluxo de nêutrons térmicos. 
A potência gerada por um determinado grupo de nêutrons é dada por Glasstone [1] A taxa de reação de nêutrons por unidade de volume é expressa por $\sum \phi\left(\mathrm{n} / \mathrm{cm}^{3} \mathrm{~s}\right)$, sendo respectivamente, a seção de choque macroscópica para a reação de interesse e o fluxo de nêutrons responsáveis pelas fissões nucleares no combustível (átomos físseis). A reação de interesse é a de fissão e o fluxo de nêutrons é o fluxo médio de nêutrons térmicos no volume $V$ de material físsil, onde ocorrerão $\sum . \phi . V$ fissões por segundo. Sendo necessária uma taxa de $3,1 \times 10^{10}$ fissões por segundo para se produzir 1 watt de energia. Então a potência gerada em watts é dada por

$$
P=\frac{\overline{\sum_{f}} \cdot \overline{\phi_{t e r}} \cdot V}{3,1 \times 10^{10}} \text { (watts) }
$$

Introduzindo as correções da razão entre o fluxo de nêutrons no combustível e no moderador e, do fator de fissão rápida, tem-se

$$
P=\frac{\overline{\sum_{f}} \overline{\phi_{t e r}} V F R}{3,1 \times 10^{10}}
$$

Ao inverter a constante $3,1 \times 10^{10}$, resulta em $3.2 \times 10^{-11}$ joules cujo valor representa a energia de fissão de $200 \mathrm{MeV}$, chegando-se então na equação (4.3) considerando que este valor é o G, ou seja a energia recuperada por fissão. 


\section{CÓDIGO COMPUTACIONAL MCNP}

O código MCNP-5 (MONTE CARLO N PARTICLES) que utiliza o método de Monte Carlo, é baseado em simulações estatísticas com funções densidade de probabilidade (pdf), as quais simulam matematicamente um determinado processo físico de interesse. Por meio de uma sequência de números aleatórios esta pdf é amostrada e seus resultados representarão possíveis eventos do processo físico. O resultado desejado é obtido através da estimativa do valor médio das grandezas observadas durante um determinado número de simulações. Assim sendo os resultados das amostragens aleatórias são acumulados de forma a se obter o resultado desejado.

O método de Monte Carlo é muito utilizado para solução de problemas envolvendo, transporte de radiação, blindagens nucleares, projetos de reatores nucleares, instrumentação nuclear e na dosimetria em física médica [24].

O código apresenta a facilidade de modelagem de diversas geometrias, esférica, quadrada, retangular, helicoidal e outras. Tal característica possibilitou a simulação do reator IPEN/MB-01 na configuração geométrica cilíndrica de núcleo como visto na FIG 5.1 e 5.2 .

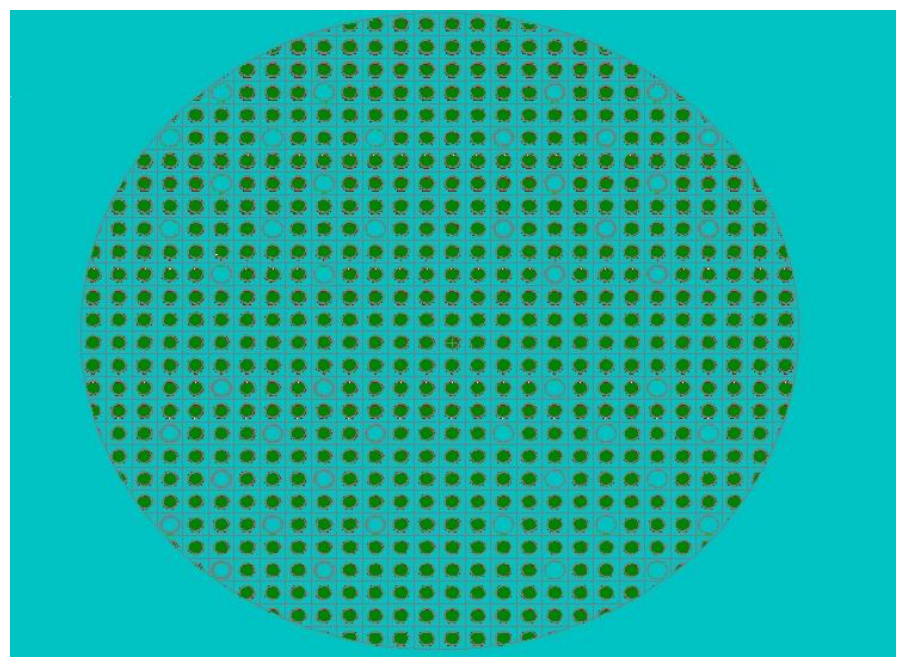

Figura 5.1 - Vista superior do núcleo do reator no código MCNP-5. 


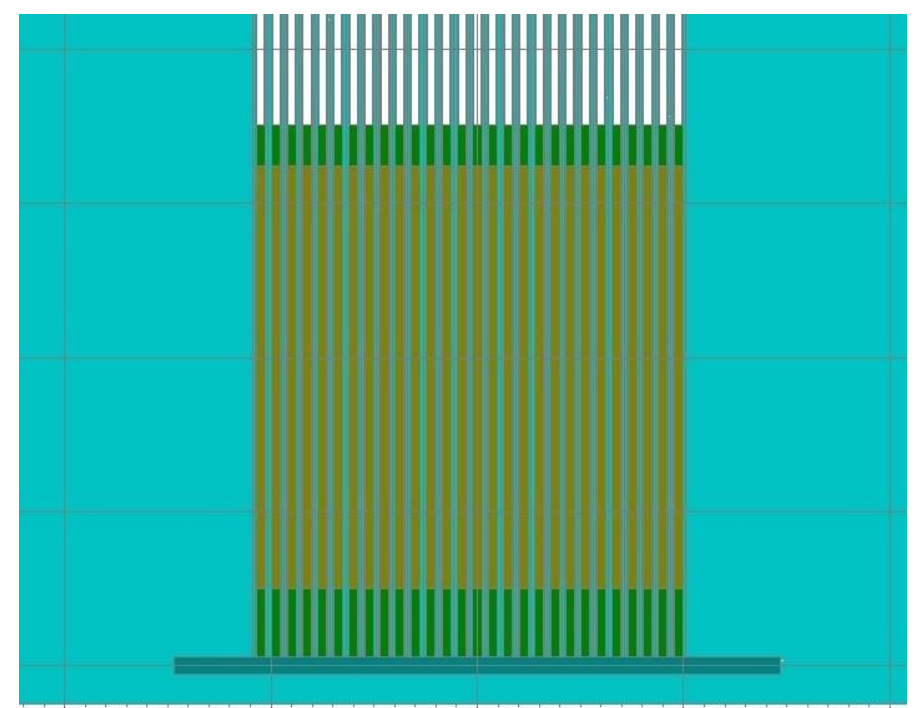

Figura 5.2 - Vista lateral do núcleo do reator no código MCNP-5.

O resultado da simulação forneceu dados das grandezas de interesse da física de reatores que possibilitaram obter valores de fluxos de nêutrons. A composição dos materiais de suas estruturas internas de suporte, todos os materiais componentes como, moderador, barras de controle, de segurança, folhas de ouro hiperpuras e infinitamente diluídas, o combustível utilizado e seu enriquecimento, foram devidamente especificados nos blocos dos cartões de entrada do programa computacional. As informações dos materiais, tais como seções de choque de fissão, absorção e ativação, são fornecidas pela biblioteca de dados nucleares (ENDF-B/VI). Para a simulação do experimento o posicionamento das barras de controle (Barras de Controle \#1 e Barras de Controle \#2) foi de $11,08 \%$ inseridas no comprimento ativo de $54,84 \mathrm{~cm}$ das varetas de combustível. As barras de segurança foram totalmente retiradas.

O detalhamento do código utilizado para a obtenção das grandezas nucleares, está no APÊNDICE A deste trabalho.

\subsection{Grandezas Obtidas com o MCPN-5}

A equação para a potência (4.5) define o valor da potência no núcleo do reator IPEN/MB-01 numa relação de proporcionalidade ao fluxo de nêutrons térmicos. Nesta equação foram ainda considerados dois fatores de correção para a potência, um para a 
razão do fluxo de nêutrons no combustível e no moderador, e outro para a taxa de fissões que ocorrem em função de nêutrons rápidos. Além destes o fator de cádmio para as operações com folhas de $\mathrm{Au}$ infinitamente diluídas e hiperpuras foi obtido por meio de simulações do código MCNP fazendo uso da biblioteca de dados nucleares (Evaluated Nuclear Data) ENDF-B/VI.

\subsubsection{Fator de correção - $F$}

As medidas de fluxo de nêutrons realizadas no experimento consideram o fluxo no moderador, pois as folhas estão posicionadas no moderador e não no combustível. Uma vez que o processo de geração de potência se dá no combustível, se faz necessária à correção por um fator de correção $F$ que é dado por [19],

$$
F=\frac{\phi_{C}}{\phi_{M}}
$$

sendo $\phi_{C}$ o fluxo no combustível e o $\phi_{M}$ o fluxo no moderador.

O problema físico reside no fato de que no combustível o fluxo de nêutrons é menor que no moderador, pois ao atravessarem o combustível os nêutrons são absorvidos pelo mesmo, diminuindo a população de nêutrons na região. Esse fenômeno também ocorre quando inserimos detectores de nêutrons, tais como folhas de Au no núcleo do reator, causando a depressão de fluxo e o fenômeno da autoblindagem. A diferença se dá que no combustível aqui considerado $\left({ }^{238} \mathrm{U}\right.$ enriquecido com ${ }^{235} \mathrm{U}$ a $\left.4,3 \%\right)$, parte dos nêutrons absorvidos darão início às reações de fissão, que liberam calor e assim energia. Energia esta que é quantificada em watts.

A complexidade na obtenção dos fluxos do combustível e do moderador resultou na utilização do código MCNP. O valor de $F$ considerado foi [7],

$$
F=0,78735 \pm 0,05 \%
$$




\subsubsection{Fator de fissão rápida - $R$}

Parte das fissões que ocorrem no combustível, particularmente ${ }^{238} \mathrm{U}$ enriquecido com ${ }^{235} \mathrm{U}$ a 4,3\% utilizado no reator IPEN/MB-01, são causadas por nêutrons rápidos cuja energia está torno de alguns $\mathrm{MeV}$. No isótopo fissionável ${ }^{238} \mathrm{U}$ somente ocorre fissão quando são atingidos por nêutrons rápidos [23], de tal forma que haverá nêutrons como produto de fissão proveniente dos nêutrons rápidos e, que poderão por sua vez ocasionar novas fissões.

Considerou-se o fator de fissão rápida obtido acima da energia de 0,55 eV em [7], através do código MCNP obtido por meio da equação,

$$
R=\frac{f_{\text {Rap }}}{f_{\text {Total }}}
$$

Sendo $f_{\text {Rap }}$ a taxa de fissão rápida e $f_{\text {Total }}$ a taxa de fissão em todo o espectro de energia.

O valor obtido pelo MCNP para o fator de fissão rápida foi

$$
R=1,1559 \pm 0,36 \%
$$

\subsubsection{Fator de cádmio - $F_{c d}$}

Para a obtenção dos fatores de cádmio neste trabalho, foram realizadas simulações no código MCNP-5 para as folhas hiperpuras e infinitamente diluídas. O reator IPEN/MB01 foi modelado de forma a conter todo o detalhamento construtivo, tais como estruturas suporte, moderador, folhas de ativação hiperpuras e infinitamente diluídas com cobertura de cádmio e sem cobertura, combustível, barras de controle, de segurança, assim como a composição dos materiais que os compunham. Dado o pequeno tamanho dos detectores de ativação, teve-se de declarar o volume calculado de $0.00883125 \mathrm{~cm}^{3}$, para obter-se um boa estatística. Foram simuladas quatro situações, duas para se obter a taxa de reação epitérmica da folha da Au nua, hiperpura e infinitamente diluída, e duas para se obter a 
taxa de reação da folha de Au coberta com cádmio, hiperpura e infinitamente diluída. Os resultados foram aplicados na equação

$$
F_{c d}=\frac{R_{e p i t}}{R_{c d}}
$$

Sendo $R_{e p i t}$ a taxa de reação acima da energia de junção térmica e intermediária para um detector nu, e $R_{c d}$ a taxa de reação acima da energia de corte do cádmio para um detector coberto com cádmio.

A taxa de reação epitérmica foi obtida pela equação,

$$
R_{\text {epit }}=\sum_{\text {ativ }} \phi_{\text {epit }} V
$$

Sendo $\sum_{\text {ativ }}$ a seção de choque macroscópica de ativação, $\phi_{\text {epit }}$ o fluxo epitérmico na folha de ativação e $V$ o volume da folha.

A taxa de reação do cádmio foi obtida pela equação,

$$
R_{c d}=\sum_{a t i v} \phi_{c d} V
$$

Sendo $\phi_{c d}$ o fluxo de nêutrons na folha de ativação acima da energia de corte do cádmio.

O valor de $R_{c d}$ pode ser também obtido por simulação do código MCNP-5, mas pelo fato de ter-se irradiado folhas de Au nuas (sem cobertura de cádmio) e, com cobertura de cádmio nas mesmas posições no interior do núcleo sob as mesmas condições experimentais, $R_{c d}$ foi determinado experimentalmente. Os valores obtidos de $R_{c d}$ estão no APÊNDICE C. 
O resultado para a simulação realizada no MCNP-5 para a folha hiperpura foi de

$$
F^{H}{ }_{c d}=1,10 \pm 6 \%
$$

e para a folha infinitamente diluída foi de

$$
F_{c d}^{I}=1,06 \pm 2 \%
$$

As simulações consideraram 420 milhões de histórias em 70 ciclos para a folha hiperpura e infinitamente diluída.

Nas simulações foram consideradas as dimensões da folha de ouro hiperpura com raio de $1,5 \mathrm{~cm}$, e espessura de $0,0013 \mathrm{~cm}$. Para a folha de ouro infinitamente diluído, raio de $1,5 \mathrm{~cm}$ e espessura de $0,02 \mathrm{~cm}$. O raio real da folha utilizada no experimento é de 0,375 $\mathrm{cm}$, porém para reduzir o erro estatístico houve a necessidade de aumentar o raio para 1,5 cm. A cobertura de cádmio para ambas as simulações possuía espessura de 0,0508 cm e raio de $0,2 \mathrm{~cm}$. 


\section{MATERIAIS E MÉTODOS}

\subsection{O Reator IPEN/MB-01}

Para a realização do experimento foi utilizado o reator IPEN/MB-01 na geometria cilíndrica de núcleo em um de arranjo radial de 28x28 varetas e altura ativa de 54,84 cm. Este arranjo foi constituído por 568 varetas combustíveis de $\mathrm{UO}_{2}$ enriquecido a 4,3\%, sendo que cada vareta contém $300 \mathrm{~g}$ de combustível, distribuídos em 52 pastilhas. Este combustível está acondicionado em tubos de aço inoxidável de tipo AISI 304. Todo este conjunto encontra-se alojado dentro de um tanque cilíndrico o qual, quando em operação, fica submerso em água leve $\left(\mathrm{H}_{2} \mathrm{O}\right)$. A função da água leve é a de moderar os nêutrons de fissão, blindar o núcleo e resfriar o combustível.

O núcleo contém ainda dois grupos de controle e segurança fixados em quatro estruturas denominadas de aranha. Nas aranhas estão fixados os dois grupos de 12 varetas de controle e dois grupos de 12 varetas de segurança. As barras de controle são constituídas por uma liga de $\mathrm{Al}-\mathrm{In}-\mathrm{Cd}$ e as de segurança de $\mathrm{B}_{4} \mathrm{C}$ (Carbeto de Boro). A função destas barras é a de inserir reatividade positiva e negativa, assim controlando as reações de fissão induzidas no núcleo. Na extração das barras insere-se reatividade positiva, aumentando a população de nêutrons térmicos disponíveis às reações de fissão. $\mathrm{Na}$ inserção das barras insere-se reatividade negativa, absorvendo os nêutrons que iriam induzir novas fissões, reduzindo a liberação de energia e por fim a potência no núcleo.

No Anexo A apresentam-se informações mais detalhadas do reator IPEN/MB-01.

\subsection{Características das Folhas de Ativação}

As folhas de Au-197 hiperpuras utilizadas nos experimentos foram fabricadas na Inglaterra pela empresa GoodFellow [25], com pureza de 99,95\% com espessura de 0,0013 $\mathrm{cm}$ e raio de $0,4 \mathrm{~cm}$. 
As folhas de Au-197 infinitamente diluídas utilizadas foram fabricadas no Institute of Material and Measurements [26] (Joint Research Centre), cuja constituição é de 1\% de Au diluído numa matriz de $99 \% \mathrm{Al}$, com espessura de $0,02 \mathrm{~cm}$ e raio de $0,375 \mathrm{~cm}$.

O ouro foi escolhido, além das características já apresentadas, pelo fato de ocorrer predominantemente a reação de captura radiativa $(\mathrm{n}, \gamma)$ quando um nêutron é absorvido pelo material. Ao absorver um nêutron o Au-197 torna-se Au-198 e emite um fóton gama com energia de 411,80 keV, com probabilidade de emissão de 95,56 \% [17]. Escrevendo a equação de forma resumida tem-se,

$$
{ }^{197} A u+n \rightarrow{ }^{198} A u+\gamma .
$$

Apresenta-se abaixo na FIG 6.1 a seção de choque do Au-197 da reação.

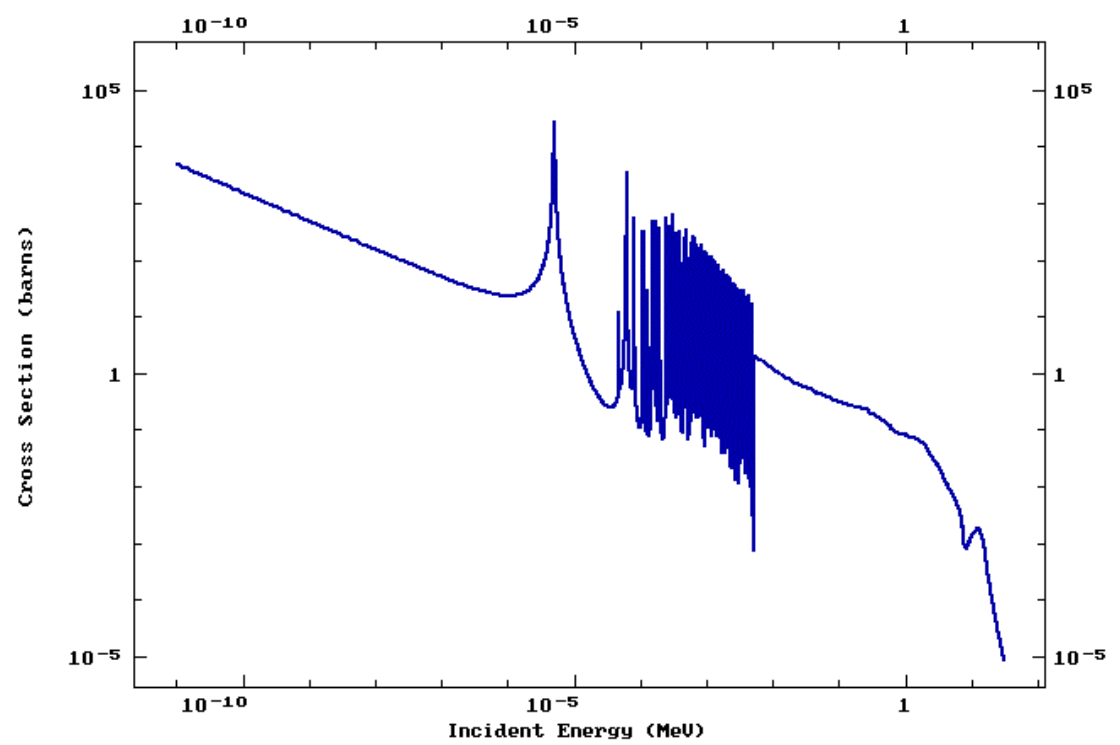

Figura 6.1 - Seção de choque do Au-197 [27].

Um fator de grande importância é o conhecimento da seção de choque na região de térmica que obedece a razão 1/v. Esta região pode ser bem visualizada na FIG 6.2. 


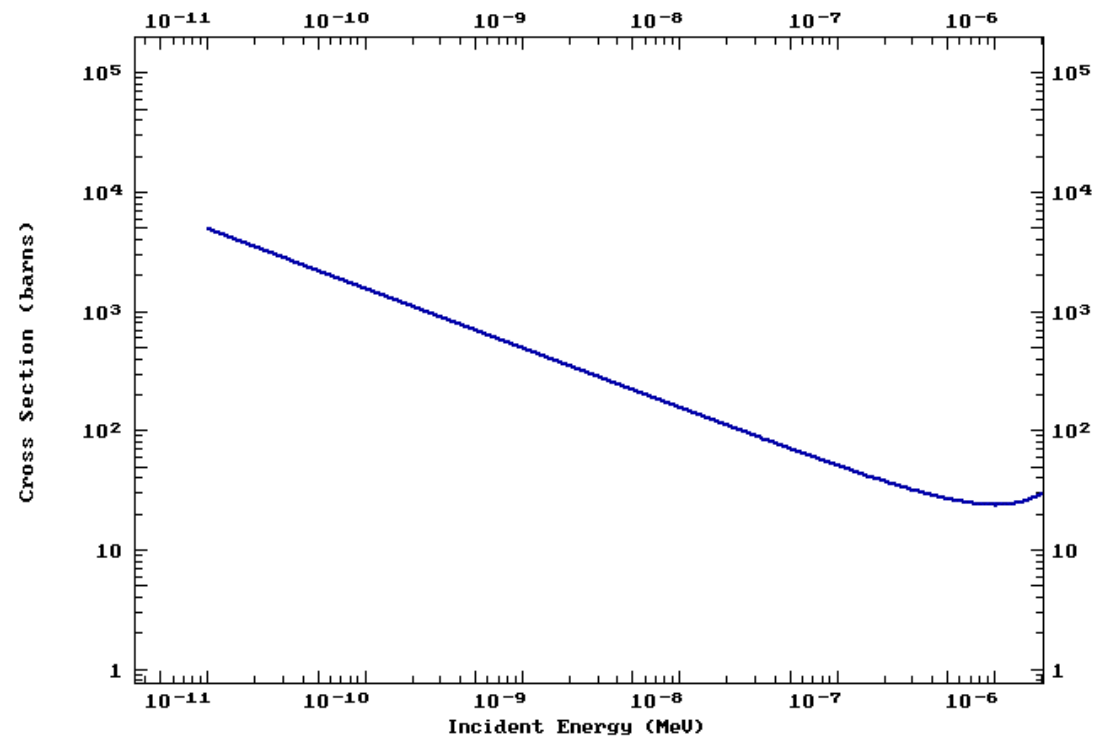

Figura 6.2 - Região 1/v (2200m/s) da seção de choque [27].

Outro fator importante é o conhecimento das ressonâncias presentes na região epitérmica cuja energia de ressonância principal está centrada em 4,90 eV. A região epitérmica está representada na FIG 6.3.

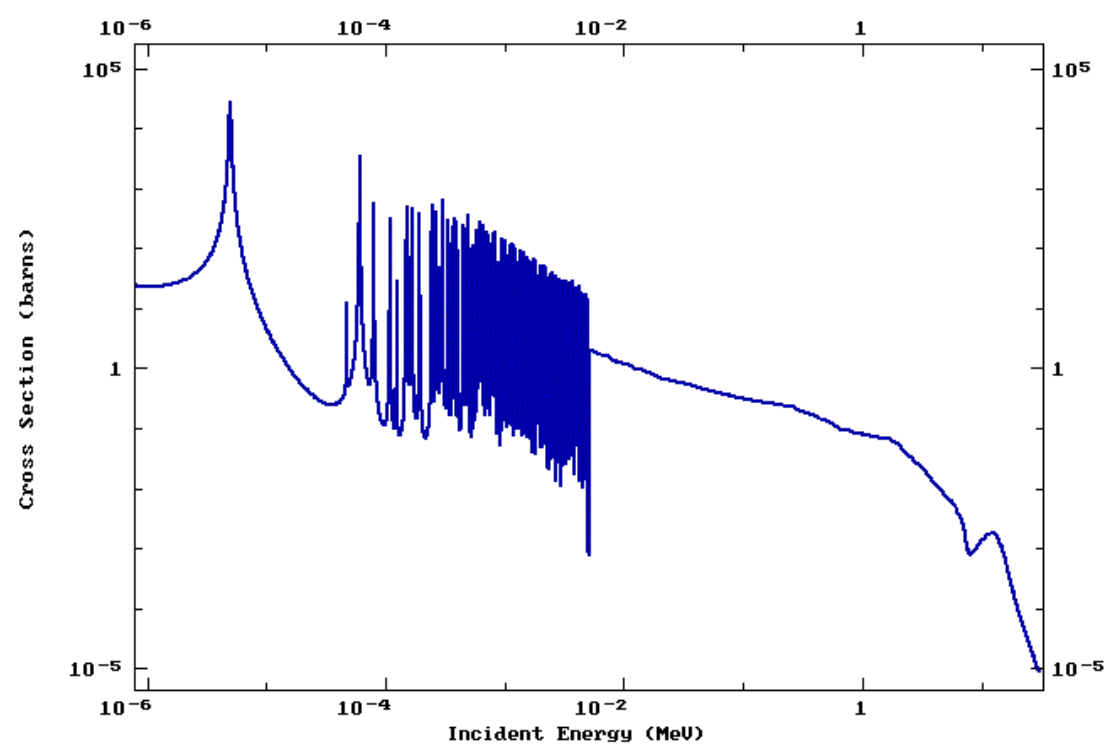

Figura 6.3 - Região epitérmica da seção de choque do Au-197 [27]. 


\subsection{Descrição do Procedimento Experimental}

Para a obtenção do fluxo de nêutrons, as folhas de ouro foram distribuídas simetricamente no núcleo do reator IPEN/MB-01 por meio de uma placa de lucite com espessura de 0,4 cm, a qual possui nas suas propriedades de moderação de nêutrons, semelhanças com a moderação dos nêutrons pela água. O propósito desta escolha é o de não interferir no comportamento do fluxo de nêutrons no núcleo do reator.

Para as irradiações, as folhas foram distribuídas em sete cotas axiais, sendo 637, 546, 455, 364, 273, 182 e 91 mm, ao longo da altura ativa no núcleo do reator. Na FIG 6.4 apresentam-se as cotas axiais na placa de lucite em relação ao núcleo do reator IPEN/MB01.

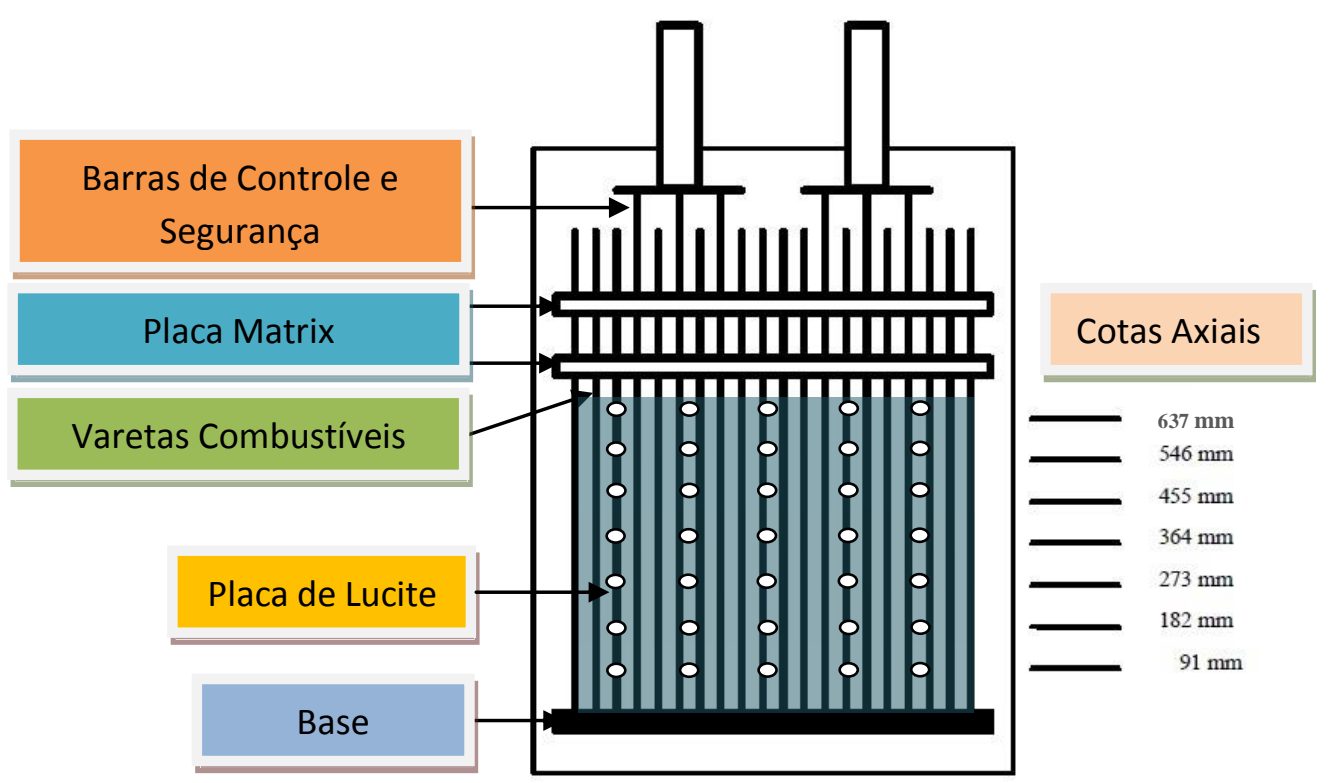

Figura 6.4 - Representação da placa inserida no núcleo do reator IPEN/MB-01.

Cada posição axial se repete em cinco posições radiais, que são 15,0, 112,5, 210,0, 307,5, e 405,0 mm, denominadas aqui de posições 1, 2, 3, 4 e 5 respectivamente. Desta forma na placa de lucite há 35 posições para folhas de ouro que está representado na FIG 6.5 . 


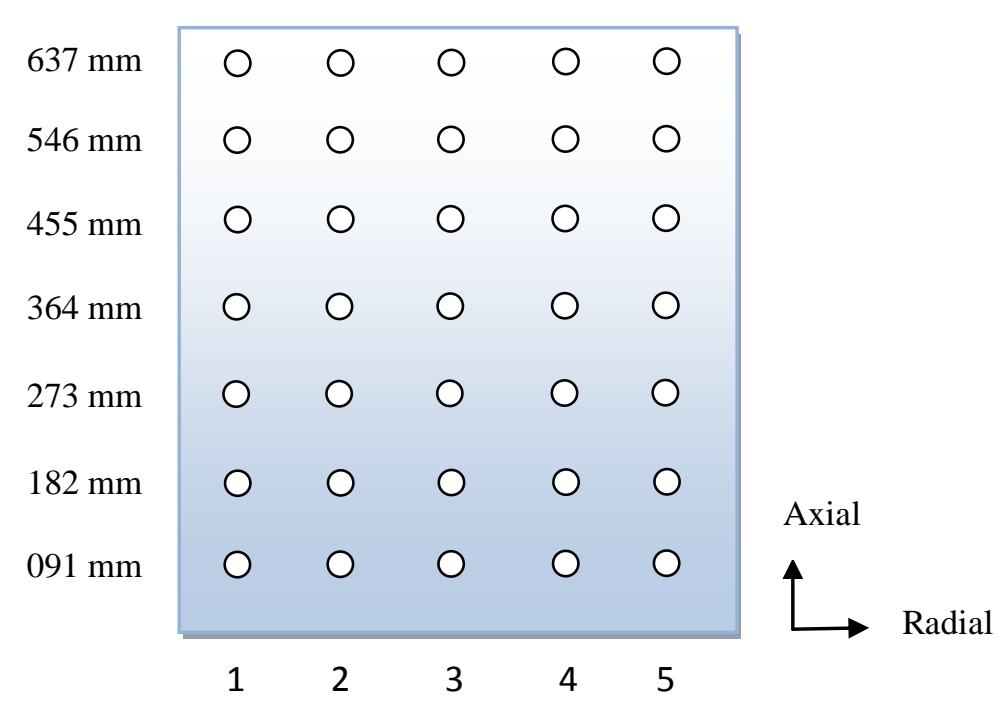

Figura 6.5 - Placa de lucite e posições das folhas de ouro.

Foram realizadas 10 irradiações no núcleo do reator, utilizando-se folhas hiperpuras e infinitamente diluídas em 4 diferentes canais de irradiação. Duas irradiações para as folhas hiperpuras e oito para as infinitamente diluídas. A quantidade total de detectores de ativação irradiados foi de 266 folhas de ouro, sendo 70 hiperpuras e 196 infinitamente diluídas.

Para posicionar a placa de lucite nos canais nucleares, seguiram-se as coordenadas identificadas na placa matriz no núcleo do reator nuclear IPEN/MB-01, desta forma os canais nucleares utilizados foram 14-15, 10-11, 6-7 e 2-3.

No canal 14-15 foram realizadas duas irradiações para as folhas hiperpuras, com cobertura de cádmio e sem cádmio e, duas irradiações para as folhas infinitamente diluídas, com cobertura de cádmio e sem cádmio. Neste canal foram colocadas 35 folhas para cada irradiação.

Para os canais 10-11, 6-7 e 2-3, foram realizadas duas irradiações utilizando-se folhas infinitamente diluídas, com cobertura de cádmio e sem cádmio. No canal 10-11 
foram irradiadas 35 folhas por irradiação, no canal 6-7, 21 folhas e no canal 2-3, 7 folhas.

Essa distribuição seguiu o volume ativo do núcleo.

Na FIG 6.6 apresenta-se o núcleo do reator na configuração cilíndrica em corte transversal, as coordenadas da placa matriz e os canais de irradiação.

\section{Direção Radial Leste - Oeste}

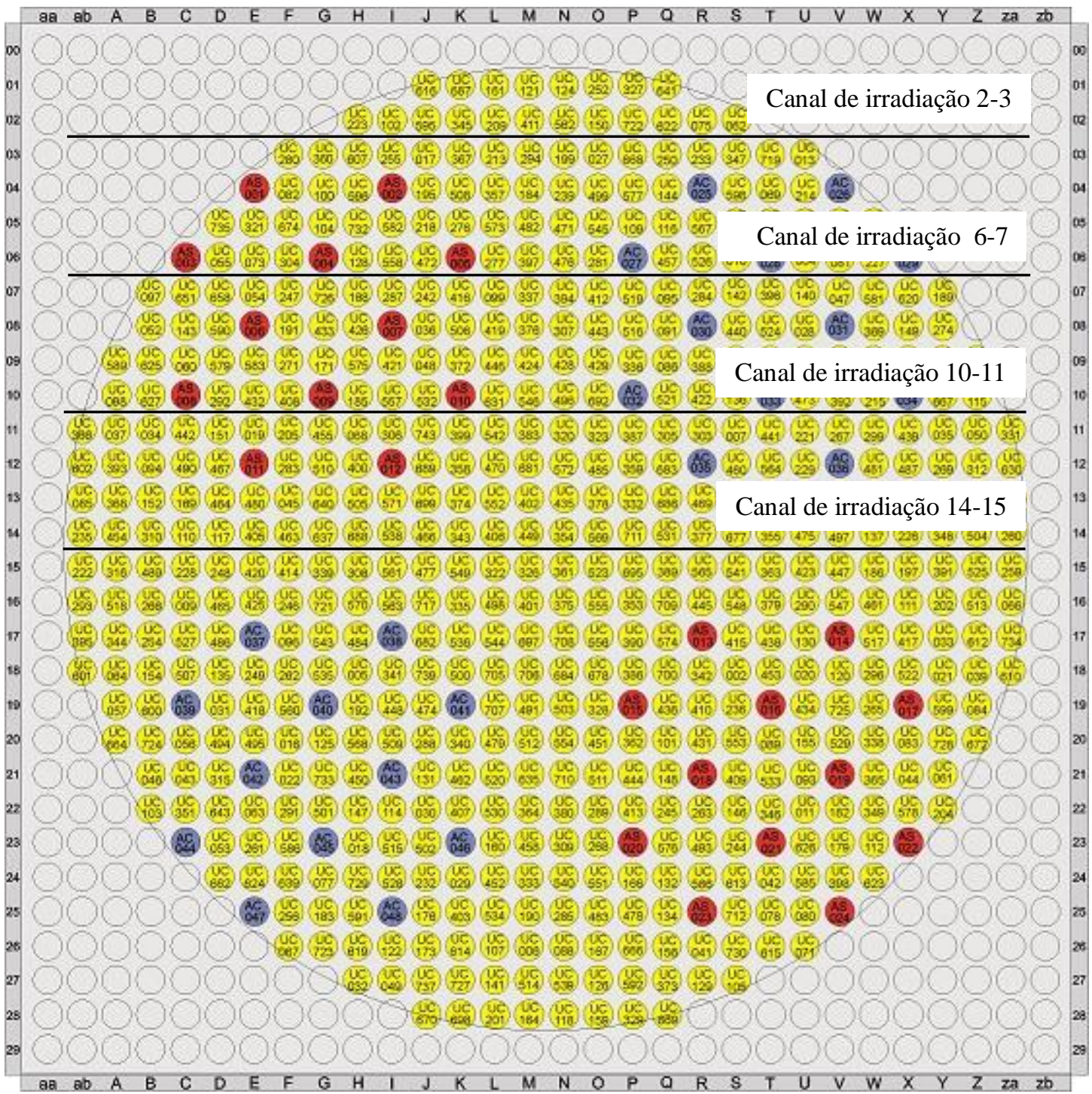
Legenda:
Varetas Combustíveis
$\bigcirc$
Varetas Absorvedoras
de Controle
Operadores:
Varetas Absorvedoras de Segurança
- Rogério
- César

Figura 6.6 - Núcleo do reator IPEN/MB-01 na configuração cilíndrica. 
Foi realizado o mapeamento de um hemisfério do núcleo do reator e, considerou-se que a magnitude dos fluxos térmicos e epitérmicos obtidos, seja a mesma do hemisfério não mapeado dada sua simetria construtiva.

Para a calibração do reator nuclear pelo canal de pulsos (canal nuclear de pulso 10), foi realizada a operação do reator IPEN/MB-01 nas potências de 1 watt, 10 watts, 50 watts e 100 watts (informadas pelo canal nuclear 6), nas configurações cilíndrica e retangular. Estas potências foram as mesmas utilizadas na calibração realizada por Lucas [1]. Com a leitura das contagens, obteve-se a reta de calibração na configuração cilíndrica de núcleo e comparou-se com a reta na configuração padrão retangular.

Os canais nucleares de potência 5 e 6 estão muito próximos do núcleo, e assim, a leitura do fluxo de nêutrons pode sofrer distorções pelas barras de controle. O canal 10, dada sua posição mais afastada do núcleo $(80 \mathrm{~cm})$, obtém teoricamente a leitura das contagens de maneira mais homogênea, ou seja, sem distorções, informando a potência de operação independente da configuração de núcleo.

\subsection{Condições para a Irradiação}

Todas as irradiações foram realizadas aproximadamente a 100 watts (indicação dp canal 6 para a configuração cilíndrica) por um período de $1 \mathrm{~h}$ (3600 s). A temperatura da água leve (moderador) se manteve em média a $24,32 \pm 0,32{ }^{\circ} \mathrm{C}$, medida por um total de 12 termopares inseridos dentro do núcleo do reator.

As operações de calibração pelo canal de pulso de ${ }^{10} \mathrm{~B}$ (canal 10) foram realizadas nas potências de 1 watts, 10 watts, 50 watts e 100 watts, obtidas do canal calibrado para a configuração padrão retangular $28 \times 26$ de $n^{\circ} 6$, sendo que em cada nível de potência o período de leitura foi de $15 \mathrm{~min}$. As aquisições foram realizadas on-line em um computador com processador Intel de 2,40 GHz, 4MB RAM de 64 bits, na sala de controle do Reator IPEN/MB-01, numa plataforma LABVIEW versão 8.5, idealizado por Jerez [28]. 


\subsection{Fatores Experimentais de Correção}

Os valores de contagens obtidos nos experimentos precisam ser corrigidos devido à algumas condições de irradiação, tais como, flutuação de potência entre as operações, rampa de elevação de reatividade (aumento da população neutrônica) até a criticalização do reator e a autoabsorção gama durante a contagem (espectrometria gama) das folhas de ativação de ouro.

\subsubsection{Fator de normalização}

Nas diversas operações para se obter o valor de fluxo de nêutrons médio no núcleo do reator, podem ocorrer pequenas oscilações involuntárias de potência, de forma que as contagens induzidas nas folhas de ouro irradiadas no sistema detector de germânio também apresentem tais oscilações. Desta forma faz-se necessário normalizar as condições de irradiação destas oscilações para se obter valores de contagens livres de tais oscilações. Para tanto o canal de pulsos 10 foi monitorado para fornecer valores que servirão de parâmetro de normalização. Este canal apresenta a vantagem de estar mais distante do núcleo, e portanto, menos susceptível às oscilações involuntárias das barras de controle e por consequência da potência de operação do reator.

Considerando-se as contagens do canal 10, o fator de normalização é obtido pela razão entre a média das contagens que se quer normalizar, pela média das contagens de todas as irradiações realizadas. É necessário que todas as contagens envolvidas tenham sido realizadas no mesmo nível de potência. Deve-se lembrar que as diferenças entre os níveis de potência das diversas irradiações são involuntárias e inerentes ao sistema.

O fator de normalização é dado por

$$
F_{n}=\frac{\overline{C_{i}}}{\overline{C_{T}}}
$$


sendo $\overline{C_{i}}$ a média das contagens que se quer normalizar e, $\overline{C_{T}}$ a média total de todas as contagens de todas as irradiações envolvidas no processo de obtenção do fluxo de nêutrons.

\subsection{Fator de Rampa}

O reator opera em níveis muito baixos de potência na condição inicial de partida, porém, as folhas já estão sendo ativadas por menor que seja esta irradiação, ou seja, já estão absorvendo nêutrons antes do reator ter se tornado crítico. Como se quer descobrir o fluxo de nêutrons numa condição estacionária, ou de criticalidade, faz-se necessário corrigir esse acréscimo de ativação devido à rampa inicial de irradiação. Sob este aspecto, corrigir significa retirar tal ativação inicial.

O fator de rampa de subida de potência é dado por [30],

$$
F_{r}=\frac{\lambda\left(1-e^{-\lambda t}\right)\left(e^{\frac{T r}{T}}\right)+W}{\lambda\left(1-e^{-\lambda t}\right)\left(e^{\frac{T r}{T}}\right)} .
$$

O termo $W$ é definido como

$$
W=\frac{T}{\lambda(1+\lambda T)\left(e^{\frac{T_{r}}{T}}\right)\left(e^{-\lambda t}\right)-\left(e^{\lambda T_{r}}\right)} .
$$

Sendo $\lambda$ a constante de decaimento do radionuclídeo formado, $T$ o tempo de subida de potência, $t$ o tempo de irradiação no núcleo do reator, $T_{r}$ é o tempo de rampa. O tempo de rampa se refere ao tempo cronometrado digitalmente, desde a leitura da potência de 100 mW até a potência de irradiação considerada (100 watts). 
De forma a chegarmos numa equação mais simples, deduzida das equações (6.2) e (6.3), temos a equação (6.4),

$$
F_{r}=\frac{1}{1+\frac{T}{t}}
$$

sendo $T$ dado por

$$
T=\frac{T_{r}}{\ln \left(\frac{P}{P_{0}}\right)} .
$$

Sendo $T_{r}$ o tempo de rampa desde a potência inicial $P$ até potência final $P_{0}$.

Na FIG 6.7 apresenta-se o arquivo de dados de irradiação do canal nuclear 14-15, para servir de exemplo ao tempo de rampa $T_{r}$, desde a potência 0,1 watts até 100 watts.

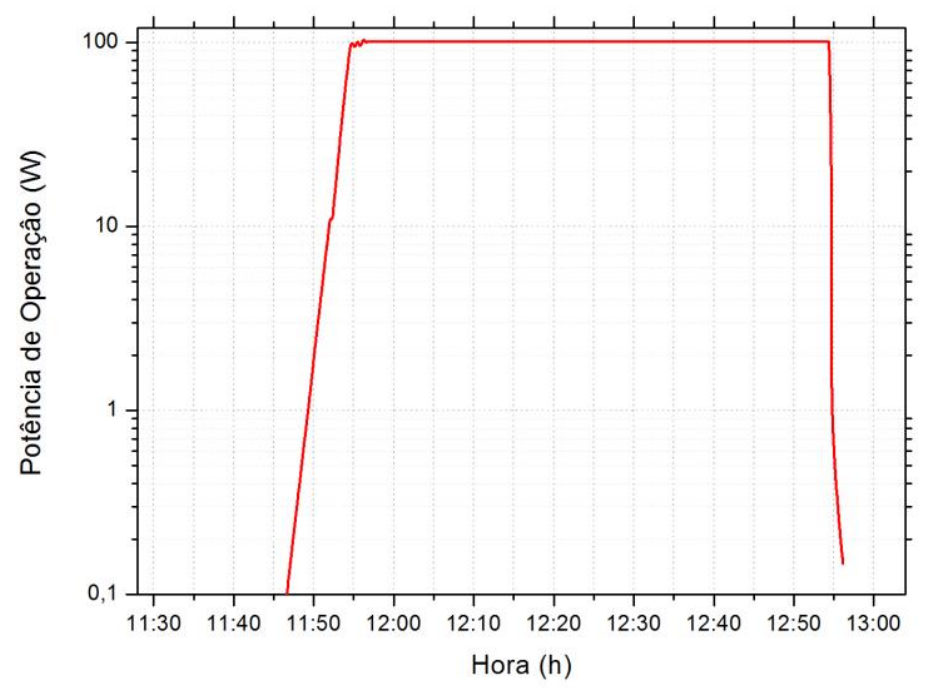

Figura 6.7 - Arquivo de irradiação do canal nuclear 14-15

Na FIG 6.8 tem-se a reta ampliada, respectiva ao tempo de subida da rampa na irradiação do canal de irradiação 14-15. A reta vermelha representa a potência de 
irradiação. As retas pontilhadas representam os limites horizontais inicial (0,1 watts) e final (100 watts) de potência. A seta vertical menor indica o início da contagem do tempo de rampa. A seta vertical maior indica o final da contagem do tempo de rampa e o início da contagem do tempo de irradiação na condição de criticalidade.

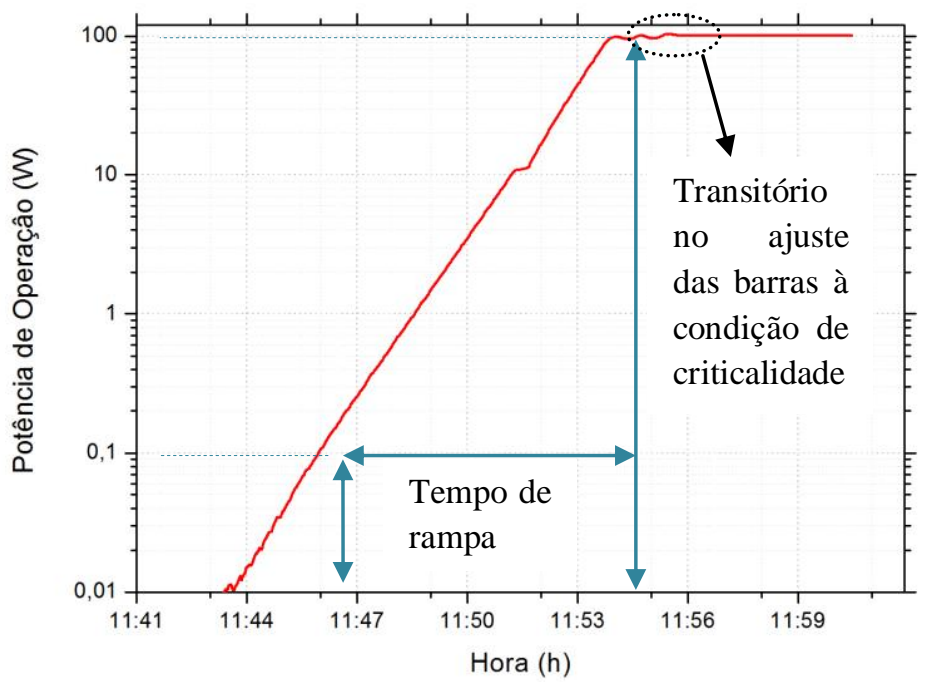

Figura 6.8 - Análise gráfica do tempo de rampa.

\subsection{Fator de Autoabsorção}

Pelo fato de ocorrer autoabsorção gama nas folhas de ativação durante a emissão dos fótons gama (para o Au-198 na energia de 411,80 KeV), deve-se corrigir a atividade pelo fator de autoabsorção gama, o qual é dado pela equação [29],

$$
F_{a b s}=\frac{1}{T}
$$

Sendo $T$ o fator de transmissão gama que é dado por,

$$
T=\frac{S\left[1-e^{-\frac{\mu}{\rho} \frac{m}{S}}\right]}{\frac{\mu}{\rho} m},
$$


$S$ a área da superfície da folha, $\mu$ o coeficiente de atenuação linear, $\rho$ a densidade do material da folha, $m$ a massa da folha. O parâmetro $\mu / \rho$ é o coeficiente de atenuação de massa. Os valores calculados do fator de autoabsorção estão no APÊNDICE G. 


\section{ANÁLISE DOS DADOS}

Após o término da cada irradiação, as folhas de Au-198 foram levadas para contagem no sistema de espectrometria gama. Neste sistema computacional está instalado o programa computacional MAESTRO [31]. Este programa computacional gerencia o processo de leitura dos dados e realiza sua análise.

O aparato experimental do sistema de espectrometria gama compõe-se de acordo com o diagrama de blocos da FIG 7.1:

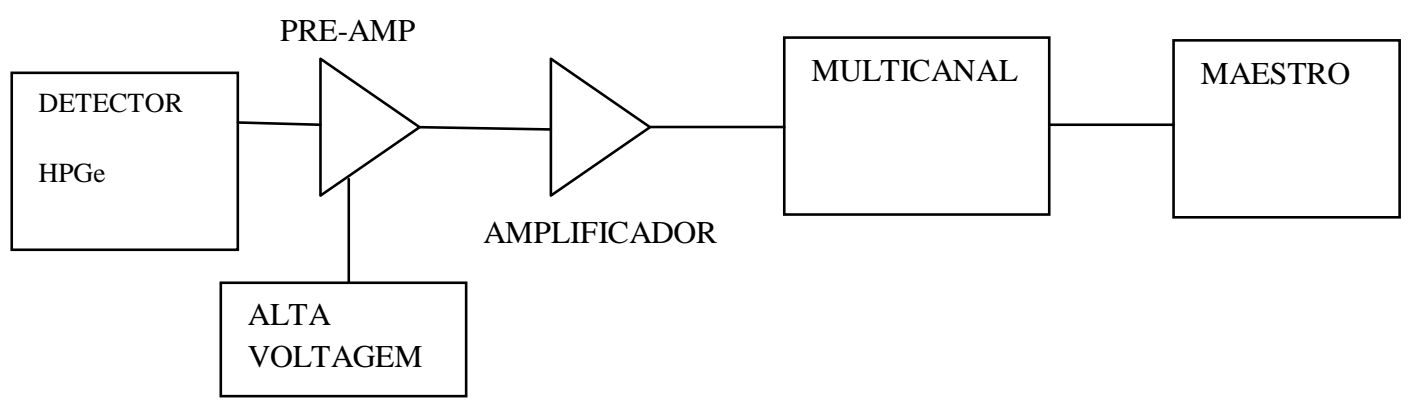

Figura 7.1 - Diagrama de blocos do sistema de detecção de germânio hiperpuro.

Sendo que o aparato é representado fisicamente como:

a) Detector transdutor de estado sólido de germânio de alta pureza (HPGe) e préamplificador (acoplado ao detector). O pré-amplificador realiza a amplificação do pequeno sinal proveniente da ionização do cristal de germânio para melhorar o casamento de impedância do amplificador FIG 7.2

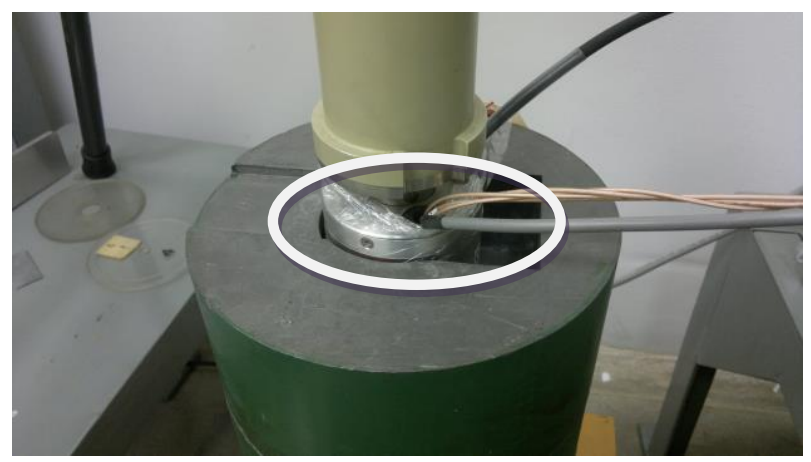

Figura 7.2 - Detector transdutor de germânio. 
b) É utilizado um reservatório de nitrogênio líquido para resfriar o cristal de germânio do detector afim de diminuir a corrente de fuga e o ruído eletrônico que ocorrem devido ao fato de que à temperatura ambiente a banda de valência e a banda de condução se encontram muito próximas uma da outra. Assim essa faixa sendo muito estreita facilita a fuga de corrente e ruído eletrônico e só é alargada com a diminuição da temperatura do cristal de Ge.

c) A blindagem de chumbo para colocar as folhas de ativação blindando a radiação cósmica e terrena, do meio ambiente e do laboratório (conhecido como background ou $\mathrm{BG})$.

Os itens 'b' e 'c' descritos anteriormente são apresentados na FIG 7.3 e FIG 7.4.

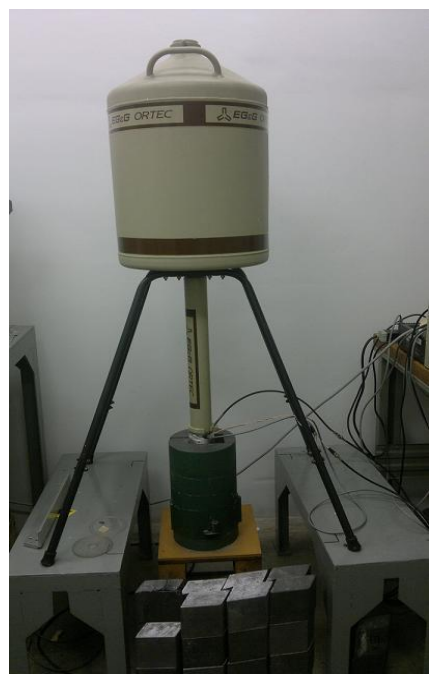

Figura 7.3 - Reservatório com nitrogênio, detector de germânio e blindagem de chumbo.

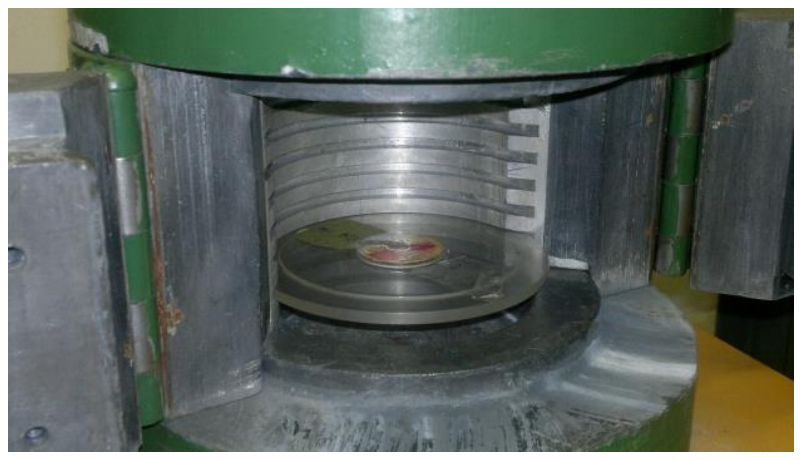

Figura 7.4 - Blindagem de chumbo com as gavetas e base em acrílico para posicionamento da folha de ativação. 
d) Amplificador - amplifica o sinal do pré-amplificador e filtra o ruído existente.

e) Placa multicanal - discrimina as diferentes energias e amplitudes dos pulsos do amplificador nos 8200 canais existentes, com $0,25 \mathrm{keV}$ de precisão com $2 \%$ de resolução;

f) Fonte de tensão de $-3600 \mathrm{~V}$ - fornece a alimentação para o sistema detector;

Os itens 'd', 'e' e 'f', apresenta-se na FIG 7.5.

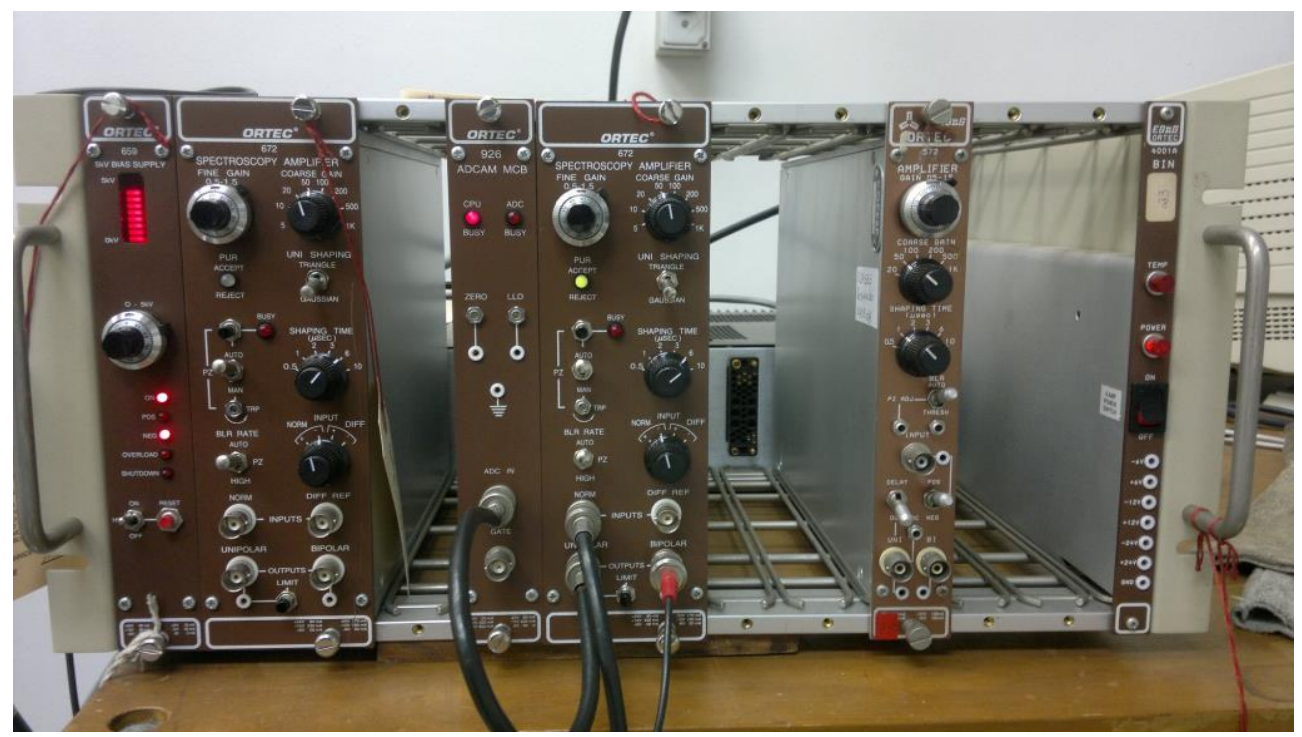

Figura 7.5 - Amplificador, placa multicanal e fonte de alta tensão.

g) Programa computacional Maestro [30] - o sinal de cada canal é enviado ao programa computacional por meio da placa de aquisição de dados. O programa computacional analisa estes dados e os reproduz na tela do monitor. 


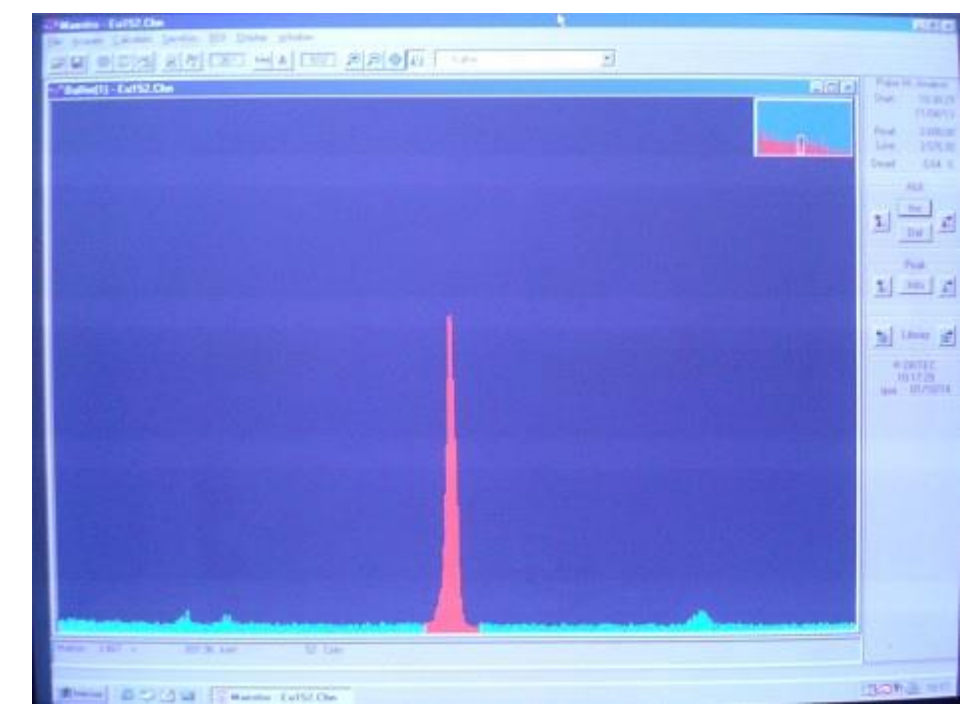

Figura 7.6 - Tela do MAESTRO com apresentação de pico do Eu-152 (utilizado para calibração do sistema) e demais informações de análise das partículas contadas.

\subsection{Eficiência Global do Sistema de Detecção HPGe.}

Grande parte dos sistemas de detecção de radiação nuclear não consegue ler todo o tipo de radiação emitida por um radioisótopo. Desta forma deve-se conhecer a eficiência do sistema para a radiação em questão que se deseja medir, e para tal, utilizam-se fontes padrões com atividades e energias muito bem conhecidas para obterem-se valores absolutos das taxas de reação nuclear (atividade de saturação) induzidas em materiais irradiados. Os fótons gama emitidos pelo Au-198 ionizam a região ativa do detector de forma a se tornarem perceptíveis pelo sistema. A eficiência está diretamente relacionada à taxa de contagem líquida integrada no fotopico gama, o qual é proporcional à atividade do radionuclídeo.

A eficiência de um sistema detector é diretamente afetada pela geometria do sistema, redução do número de cargas, pela perda de informação na coleção de dados e os efeitos da fonte [12]. 
Para a calibração de um sistema de detecção gama, utilizam-se fontes padrões conhecidas como, ${ }^{133} \mathrm{Ba},{ }^{60} \mathrm{Co},{ }^{152} \mathrm{Eu}$ ou ${ }^{137} \mathrm{Cs}$, de forma a obter-se a curva de eficiência global da contagem para as gavetas do sistema.

Foi utilizada a fonte padrão de ${ }^{152} \mathrm{Eu}$ em geometria circular de $8 \mathrm{~mm}$, que emite fótons de energia bem definida, para obter-se as curvas de eficiência das gavetas. Esta fonte em 01/03/1991 tinha uma atividade de 13,3 KBq, assim, foi calculada a atividade no momento da obtenção dos dados para a curva de eficiência. Determinou-se a eficiência $\varepsilon$ pela equação,

$$
\varepsilon=\frac{\lambda C e^{\lambda t_{e}}}{A I\left(1-e^{-\lambda t_{c}}\right)} .
$$

Sendo $\lambda$ a constante de decaimento do radionuclídeo, $C$ a contagem líquida integrada no fotopico gama, $t_{e} \mathrm{o}$ tempo de espera para a contagem, $A$ a atividade da fonte, $I$ a abundância do fotopico gama e $t_{c}$ o tempo de contagem no detector.

Como o tempo de contagem é muito menor que o inverso da constante de decaimento, pode-se considerar que a atividade de fonte é aproximadamente constante durante o tempo de contagem, Assim pode-se expandir o termo $e^{-\lambda t_{c}}$ em uma série de Taylor até a primeira ordem, e temos

$$
e^{-\lambda t_{c}}=1-\lambda t_{c}
$$

Substituindo-se na equação (7.1) temos

$$
\varepsilon=\frac{\lambda C e^{\lambda t_{e}}}{A I t_{c}}
$$

Se considerar que o tempo morto do sistema é muito pequeno, então $t_{c}=L T$, sendo LT o Live Time , tempo de contagem do sistema detector. Assim temos 


$$
\varepsilon=\frac{C e^{\lambda t_{e}}}{A I L T}
$$

A incerteza associada é dada pela lei de propagação de erros [12] de acordo com o Anexo B. A incerteza é dada por

$$
\sigma_{\varepsilon}=\varepsilon \sqrt{\left(\frac{\sigma_{c}}{C}\right)^{2}+\left(\frac{\sigma_{A}}{A}\right)^{2}+\left(\frac{\sigma_{I}}{I}\right)^{2}+\left(t_{e} \sigma_{\lambda}\right)^{2}}
$$

Sendo $\sigma_{c}$ a o desvio padrão da contagem, $\sigma_{A}$ o desvio padrão da atividade da fonte, $\sigma_{I} \mathrm{o}$ desvio padrão da abundância gama e $\sigma_{\lambda}$ o desvio padrão da constante de decaimento.

Na TAB 7.1 apresenta-se os dados nucleares da fonte de ${ }^{152} \mathrm{Eu}$ fabricada e calibrada em 1991, no Laboratório de Metrologia Nuclear do IPEN - CNEN/SP por Koskina [32].

Tabela 7.1 - Dados nucleares da fonte de ${ }^{152} \mathrm{Eu}$

\begin{tabular}{|c|c|c|c|}
\hline$A$ & $13,30 \mathrm{KBq}$ & $\sigma_{A}$ & 290 \\
\hline$\lambda$ & $1,6466 \times 10^{-9} \mathrm{~s}^{-1}$ & $\sigma_{\lambda}$ & $4,9411 \times 10^{-12} \mathrm{~s}^{-1}$ \\
\hline$T_{1 / 2}$ & $4,2095 \times 10^{8} \mathrm{~s}$ & $\sigma_{T_{1 / 2}}$ & $1,2632 \times 10^{6} \mathrm{~s}$ \\
\hline
\end{tabular}

Na TAB 7.2 apresentam-se as energias características, suas respectivas abundâncias e incertezas do fotopico gama do ${ }^{152} \mathrm{Eu}$.

Tabela 7.2 - Característica energética, abundância e incerteza do ${ }^{152} \mathrm{Eu}$ [17].

\begin{tabular}{|c|c|c|}
\hline Energia $(\mathbf{K e V})$ & $\mathbf{I}$ & $\sigma$ I \\
\hline 244,2 & 0,0751 & 0,0005 \\
\hline 344,6 & 0,2658 & 0,0018 \\
\hline 411,4 & 0,0223 & 0,0001 \\
\hline 444,2 & 0,0312 & 0,0002 \\
\hline 779,0 & 0,1296 & 0,0007 \\
\hline 964,1 & 0,1462 & 0,0006 \\
\hline 1113,0 & 0,1356 & 0,0006 \\
\hline 1213,5 & 0,0140 & 0,0001 \\
\hline 1408,7 & 0,2085 & 0,0008 \\
\hline
\end{tabular}


As gavetas utilizadas para a espectrometria gama da fonte no castelo de chumbo foram as $5^{\circ}, 6^{\circ}$ e $7^{\circ}$.

Para se determinar a eficiência do sistema de detecção foi utilizado, para todo o espectro de energia, o método de interpolação linear. Desta forma obtém-se uma equação analítica em que a variável dependente é a eficiência e a independente é a energia, da seguinte forma,

$$
\operatorname{Ln}(\text { Eficiência })=A+B \operatorname{Ln}(\text { Energia })
$$

$\mathrm{Na}$ TAB 7.3 apresentam-se os dados obtidos para as contagens da $5^{\circ}$ gaveta.

Tabela 7.3 - Dados das contagens da $5^{\circ}$ gaveta.

\begin{tabular}{|c|c|c|c|c|}
\hline Energia (Kev) & $C$ & $\varepsilon$ & $\sigma_{c}$ & $\sigma_{\varepsilon}$ \\
\hline 244,17 & 12845 & 0,022999 & 136 & 0,000584 \\
\hline 344,62 & 37017 & 0,018726 & 210 & 0,000446 \\
\hline 411,36 & 2466 & 0,014843 & 78 & 0,000579 \\
\hline 444,18 & 3064 & 0,013205 & 81 & 0,000461 \\
\hline 778,97 & 8557 & 0,008878 & 118 & 0,000236 \\
\hline 964,05 & 7296 & 0,00671 & 114 & 0,000184 \\
\hline 1112 & 5748 & 0,0057 & 113 & 0,00017 \\
\hline 1407,8 & 8491 & 0,005476 & 105 & 0,00014 \\
\hline
\end{tabular}

Por meio do programa computacional ORIGIN-PRO 8 [33], foi possível plotar a reta Eficiência (\%) versus Energia (keV), para a $5^{\circ}$ gaveta vista na FIG 7.7. 


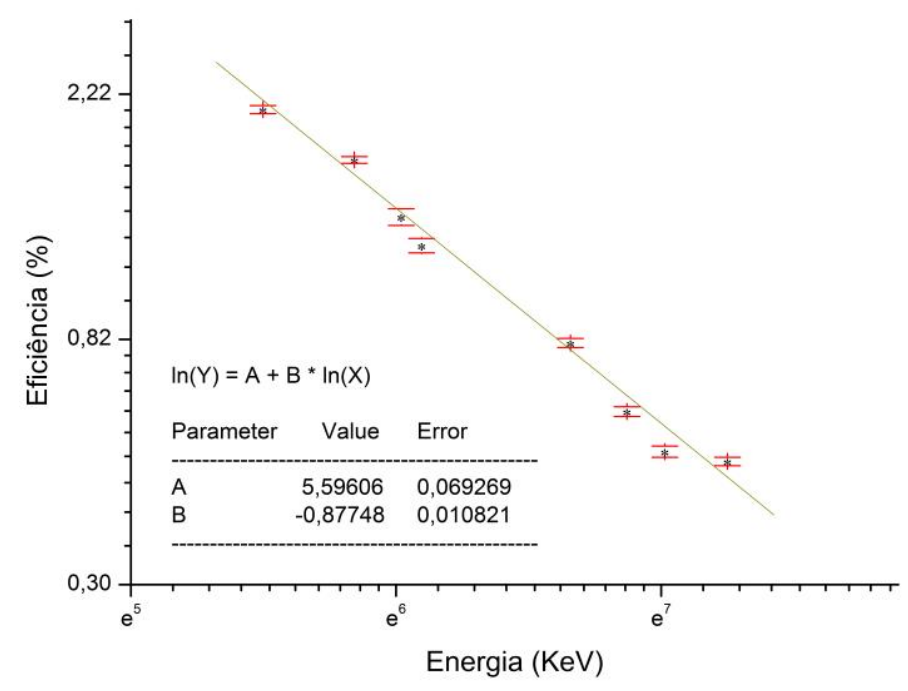

Figura 7.7 - Reta de eficiência da $5^{\circ}$ gaveta.

O valor da eficiência para o fotopico gama de energia $411,80 \mathrm{keV}$, foi de $0,014843 \pm 0,000579$

$\mathrm{Na}$ TAB 7.4 apresentam-se os dados obtidos para as contagens da $6^{\circ}$ gaveta.

Tabela 7.4 - Dados das contagens da $6^{\circ}$ gaveta.

\begin{tabular}{|c|c|c|c|c|}
\hline Energia (Kev) & $C$ & $\varepsilon$ & $\sigma_{c}$ & $\sigma_{\varepsilon}$ \\
\hline 244,17 & 10053 & 0,018 & 122 & 0,000469 \\
\hline 344,62 & 29092 & 0,014717 & 182 & 0,000352 \\
\hline 411,36 & 1928 & 0,011605 & 70 & 0,000498 \\
\hline 444,18 & 2651 & 0,011425 & 71 & 0,000402 \\
\hline 778,97 & 6930 & 0,00719 & 103 & 0,000195 \\
\hline 964,05 & 6167 & 0,005672 & 99 & 0,000157 \\
\hline 1112 & 5062 & 0,00502 & 94 & 0,000147 \\
\hline 1407,8 & 6691 & 0,004315 & 95 & 0,000115 \\
\hline
\end{tabular}

Com os dados da TAB 7.4 obteve-se a reta Eficiência (\%) versus Energia (keV), para a $6^{\circ}$ gaveta vista na FIG 7.8. 


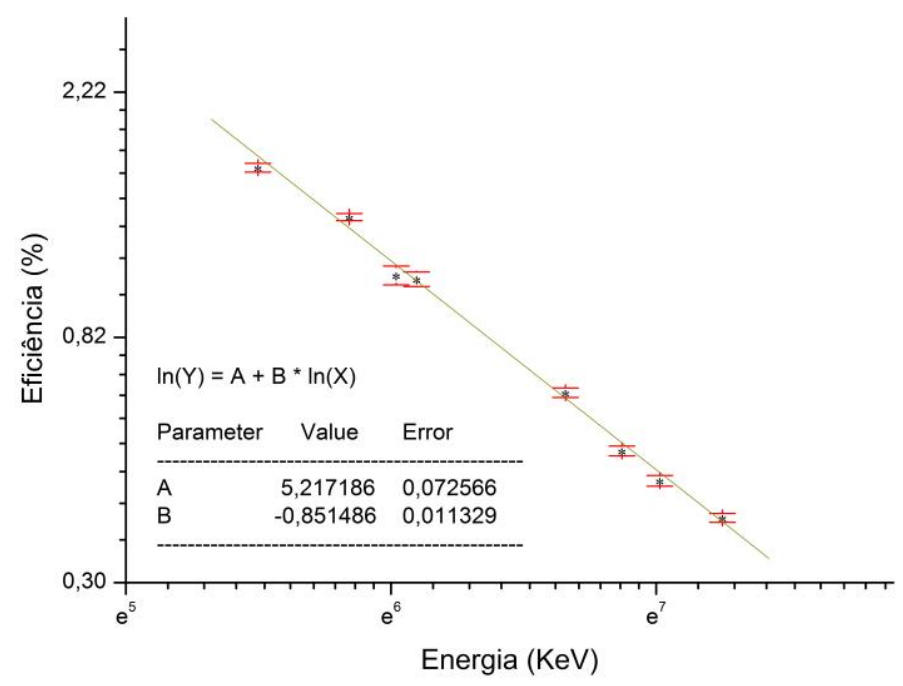

Figura 7.8 - Reta de eficiência da $6^{\circ}$ gaveta.

O valor da eficiência para o fotopico gama de energia $411,80 \mathrm{keV}$, foi de $0,011605 \pm 0,000498$.

$\mathrm{Na}$ TAB 7.5 apresentam-se os dados obtidos para as contagens da $7^{\circ}$ gaveta.

Tabela 7.5 - Dados das contagens da $7^{\circ}$ gaveta.

\begin{tabular}{|c|c|c|c|c|}
\hline Energia $($ Kev) & $C$ & $\varepsilon$ & $\sigma_{c}$ & $\sigma_{\varepsilon}$ \\
\hline 244,17 & 8184 & 0,014653 & 111 & 0,000392 \\
\hline 344,62 & 23288 & 0,011781 & 168 & 0,000285 \\
\hline 411,36 & 1501 & 0,009035 & 63 & 0,000432 \\
\hline 444,18 & 2050 & 0,008835 & 66 & 0,000349 \\
\hline 778,97 & 5596 & 0,005806 & 94 & 0,000164 \\
\hline 964,05 & 5147 & 0,004734 & 88 & 0,000134 \\
\hline 1112 & 4197 & 0,004162 & 85 & 0,000126 \\
\hline 1407,8 & 5287 & 0,00341 & 88 & $9,52 \mathrm{E}-05$ \\
\hline
\end{tabular}

Com os dados da TAB 7.5 obteve-se a reta Eficiência (\%) versus Energia (keV), para a $7^{\circ}$ gaveta vista na FIG 7.9. 


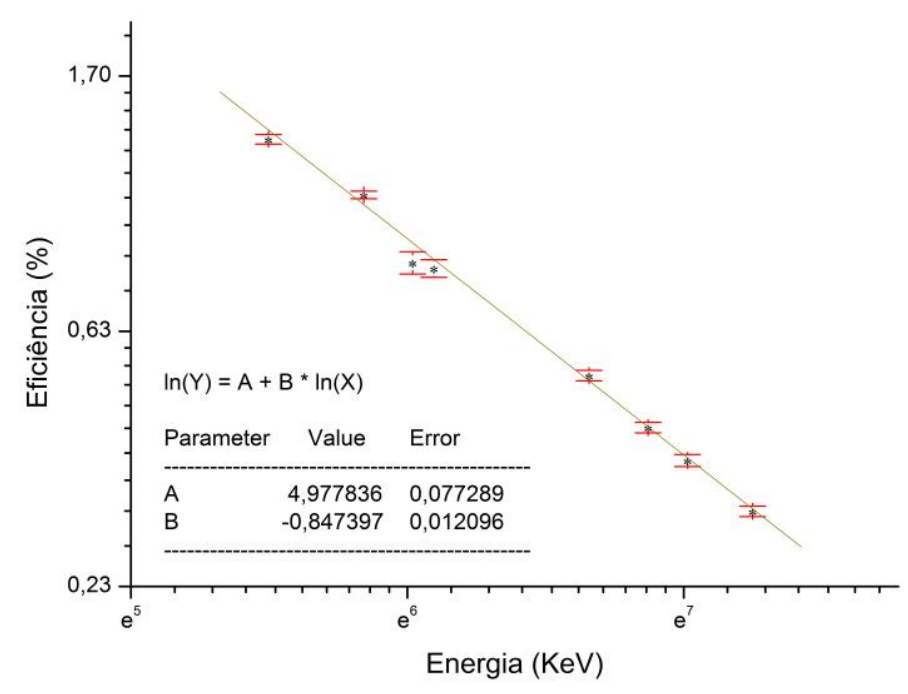

Figura 7.9 - Reta de eficiência da $7^{\circ}$ gaveta.

O valor da eficiência para o fotopico gama de energia 411,80 keV, foi de $0,009035 \pm 0,000432$.

\subsection{Análise Equacional}

Após conhecidos os fatores de correção simulados e experimentais, é necessária a análise equacional para incluir tais correções de forma a tornar os resultados mais exatos.

Ao analisar-se a equação da atividade de saturação (2.21) e inserirmos os fatores de normalização $\left(F_{n}\right)$, de rampa $\left(F_{r}\right)$ e de absorção $\left(F_{a b s}\right)$ gama que ocorre durante a espectrometria das folhas de ativação, temos,

$$
A^{\infty}=\frac{\lambda e^{\lambda t_{e}}(C-B G)}{\varepsilon I\left(1-e^{-\lambda t_{i}}\right)\left(1-e^{-\lambda t_{c}}\right)} \frac{F_{r}}{F_{n}} F_{a b s} .
$$

Sendo $N e t=(C-B G)$ a contagem líquida do detector de radiação gama, excetuando a contagem pela radiação ambiente ou de fundo (BackGround). 
Aplicando o método da propagação de erros para variáveis independentes [34] temse que o desvio padrão da atividade de saturação é dado por

$$
\sigma_{A^{\infty}}=A^{\infty} \sqrt{\left(\frac{\sigma_{e^{\lambda t_{e}}}}{e^{\lambda t_{e}}}\right)^{2}+\left(\frac{\sigma_{N e t}}{N e t}\right)^{2}+\left(\frac{\sigma_{\varepsilon}}{\varepsilon}\right)^{2}+\left(\frac{\sigma_{I}}{I}\right)^{2}+\left(\frac{\sigma_{\left(1-e^{-\lambda t_{i}}\right)}}{\left(1-e^{-\lambda t_{i}}\right)}\right)^{2}+\left(\frac{\sigma_{\left(1-e^{-\lambda t c}\right)}}{\left(1-e^{-\lambda t_{c}}\right)}\right)^{2}+\left(\frac{\sigma_{\lambda}}{\lambda}\right)^{2}}
$$

Para simplificar o cálculo da incerteza da equação (7.8), volta-se a equação (7.7) expande-se o termo $\left(1-e^{-\lambda t_{i}}\right)$ numa série de Taylor, e assim tem-se

$$
A^{\infty}=\frac{e^{\lambda t_{e}}(C-B G)}{\varepsilon I t_{c}\left(1-e^{-\lambda t_{i}}\right)} \frac{F_{r}}{F_{n}} F_{a b s}
$$

Então a incerteza da equação (7.8) pode ser reescrita da seguinte forma,

$$
\sigma_{A^{\infty}}=A^{\infty} \sqrt{\left(\frac{\sigma_{e^{\lambda t_{e}}}}{e^{\lambda t_{e}}}\right)^{2}+\left(\frac{\sigma_{N e t}}{N e t}\right)^{2}+\left(\frac{\sigma_{\varepsilon}}{\varepsilon}\right)^{2}+\left(\frac{\sigma_{I}}{I}\right)^{2}+\left(\frac{\sigma_{t_{c}}}{t_{c}}\right)^{2}+\left(\frac{\sigma_{\left(1-e^{-\lambda t_{i}}\right.}}{\left(1-e^{-\lambda t_{i}}\right)}\right)^{2}}
$$

Os erros percentuais segundo aos tempos são estimados como sendo metade da menor divisão dos cronômetros, então.

$$
\left(\frac{\sigma_{e^{\lambda t_{e}}}}{e^{\lambda t_{e}}}\right)^{2},\left(\frac{\sigma_{\left(1-e^{-\lambda t_{i}}\right)}}{\left(1-e^{-\lambda t_{i}}\right)}\right)^{2} \text { e }\left(\frac{\sigma_{t_{c}}}{t_{c}}\right)^{2} \ll 0,1 \%
$$

Considerando-se estes termos desprezíveis, temos o desvio padrão da atividade de saturação para a folha nua e coberta com cádmio, dado por

$$
\sigma_{A^{\infty}}=A^{\infty} \sqrt{\left(\frac{\sigma_{N e t}}{N e t}\right)^{2}+\left(\frac{\sigma_{\varepsilon}}{\varepsilon}\right)^{2}+\left(\frac{\sigma_{I}}{I}\right)^{2}}
$$


A contagem líquida foi fornecida pelo sistema de detecção gama, a eficiência do sistema foi obtida experimentalmente e a probabilidade de emissão gama (I) foi dada na biblioteca de dados nucleares [17].

O desvio padrão para a equação (3.2), que define a razão de cádmio, é dado pela teoria de propagação de erros para variáveis correlacionadas, então

$$
\sigma_{R_{c d}}=R_{c d} \sqrt{\left(\frac{\sigma_{A_{n u a}^{\infty}}}{A_{n u a}^{\infty}}\right)^{2}+\left(\frac{\sigma_{A_{c d}^{\infty}}^{\infty}}{A_{c d}^{\infty}}\right)^{2}-\frac{2 \operatorname{cov}\left(A_{n u a}^{\infty}, A_{c d}^{\infty}\right)}{\left(A_{n u a}^{\infty} A_{c d}^{\infty}\right)}}
$$

sendo que $\operatorname{cov}\left(A_{n u a}^{\infty}, A_{c d}^{\infty}\right)$ é a covariância entre as atividades de saturação nua e com cádmio. Esta covariância é dada por

$$
\operatorname{cov}\left(A_{n u a}^{\infty}, A_{c d}^{\infty}\right)=\rho \sigma_{A_{n u a}^{\infty}} \sigma_{A_{c d}^{\infty}}
$$

para variáveis totalmente relacionadas $\rho=1$ [28].

O desvio padrão para a equação (3.7), que define a atividade de saturação térmica, é dado por

$$
\sigma_{A_{\text {ter }}^{\infty}}=\sqrt{\left(\sigma_{A_{\text {nua }}^{\infty}}\right)^{2}+\left(A_{\text {nua }}^{\infty} \frac{F_{c d}}{R_{c d}}\right)^{2}\left[\left(\frac{\sigma_{A_{n u a}^{\infty}}}{A_{n u a}^{\infty}}\right)^{2}+\left(\frac{\sigma_{F_{c d}}}{F_{c d}}\right)^{2}+\left(\frac{\sigma_{R_{c d}}}{R_{c d}}\right)^{2}\right]}
$$

O desvio padrão para a equação (3.8), que define a atividade de saturação epitérmica, é dado por [34], 


$$
\sigma_{A_{e p i t}^{\infty}}=\sqrt{\sigma_{A_{\text {nua }}^{\infty}}^{2}+\sigma_{A_{\text {ter }}^{\infty}}^{2}-2 \operatorname{cov}\left(A_{\text {nua }}^{\infty}, A_{t e r}^{\infty}\right)}
$$

O desvio padrão para a equação (3.9), que define o fluxo de nêutrons térmicos, é dado por

$$
\sigma_{\phi_{t e r}}=\phi_{t e r} \frac{\sigma_{A_{t e r}^{\infty}}}{A_{t e r}^{\infty}}
$$

E para o fluxo epitérmico, definido pela equação (3.20), o desvio padrão é dado por

$$
\sigma_{\phi_{\text {epit }}}=\phi_{\text {epit }} \sqrt{\left(\frac{\sigma_{A_{n u a}^{\infty}}}{A_{n u a}^{\infty}}\right)^{2}+\left(\frac{\sigma_{R_{c d}}}{R_{c d}}\right)^{2}}
$$

Para a potência, definida pela equação (4.3), o desvio padrão é dado por

$$
\sigma_{P}=P \sqrt{\left(\frac{\sigma_{\phi_{t e r}}}{\overline{\phi_{t e r}}}\right)^{2}+\left(\frac{\sigma_{F}}{F}\right)^{2}+\left(\frac{\sigma_{R}}{R}\right)^{2}} .
$$

7.3 Procedimentos de Irradiação

A metodologia para as irradiações realizadas neste experimento é apresentada na TAB 7.6. 
Tabela 7.6 - Metodologia das irradiações nos canais nucleares.

\begin{tabular}{|c|c|c|c|c|}
\hline $\begin{array}{c}\text { Canal } \\
\text { Nuclear }\end{array}$ & $\begin{array}{c}\text { Número de Operações } \\
\text { no Reator }\end{array}$ & $\begin{array}{c}\text { Número de Folhas } \\
\text { Utilizadas }\end{array}$ & $\begin{array}{c}\text { Tipo das Folhas } \\
\text { Utilizadas }\end{array}$ & $\begin{array}{c}\text { Tipo de } \\
\text { Irradiação }\end{array}$ \\
\hline \multirow{4}{*}{$14-15$} & \multirow{4}{*}{4} & \multirow{4}{*}{140} & \multirow{2}{*}{70 Hiper-puras } & 35 Com cádmio \\
\hline & & & & 35 Sem cádmio \\
\hline & & & \multirow{2}{*}{$\begin{array}{c}70 \text { Infinitamente } \\
\text { diluídas }\end{array}$} & 35 Com cádmio \\
\hline & & & & 35 Sem cádmio \\
\hline \multirow{2}{*}{$10-11$} & \multirow[b]{2}{*}{2} & \multirow{2}{*}{70} & \multirow{2}{*}{ Infinitamente diluídas } & 35 Com cádmio \\
\hline & & & & 35 Sem cádmio \\
\hline \multirow{2}{*}{ 6-7 } & \multirow{2}{*}{2} & \multirow{2}{*}{42} & \multirow{2}{*}{ Infinitamente diluídas } & 21 Com cádmio \\
\hline & & & & 21 Sem cádmio \\
\hline \multirow{2}{*}{$2-3$} & \multirow{2}{*}{2} & \multirow{2}{*}{14} & \multirow{2}{*}{ Infinitamente diluídas } & 7 Com cádmio \\
\hline & & & & 7 Sem cádmio \\
\hline
\end{tabular}

Todos os cálculos para a obtenção do fluxo de nêutrons térmico e epitérmico foram realizados no programa computacional MICROSOFT EXCEL v.14.0.7116.5000.

Foram realizadas três (03) espectrometrias gama para cada folha de ativação. Dos três valores de contagem obtidos pelo HPGe, chegou-se ao valor inicial (de saturação) ajustando-se a curva de decaimento radioativo no programa computacional ORIGIN-PRO 8 [31] a partir do conhecimento prévio da constante de decaimento radioativo do Au-198. Após a plotagem, fez-se um ajuste linear e identificou-se o valor de saturação. Este valor foi então utilizado para o cálculo da atividade de saturação. Desta forma foram realizadas 588 espectrometrias.

O peso de cada folha foi obtido por meio da balança de precisão digital METLER TOLEDO, Modelo AL204 ( precisão $10^{-4} \mathrm{~g}$ ), marca do laboratório de medidas do reator IPEN/MB-01. O valor médio do peso em gramas foi obtido pela média aritmética de três (03) pesagens. 
O valor do fluxo médio de nêutrons térmicos e epitérmicos foi obtido por meio da média ponderada dos fluxos pontuais de cada folha. Como somente foram irradiadas folhas em um hemisfério do reator, considerou-se que o hemisfério não monitorado continha a mesma distribuição de folhas. Desta forma, exceto para o canal nuclear 14-15 (central), todas as demais posições monitoradas pelas folhas foram rebatidas simetricamente ao hemisfério não considerado, assim consideraram-se 161 folhas irradiadas para fins de média ponderada de fluxo e desvio padrão.

Os valores de atividade de saturação, razão de cádmio, fluxo de nêutrons térmicos e epitérmicos, fator de perturbação e fator de autoabsorção, são apresentados nos APÊNDICES B, C, D, E, F, G. 


\section{ANÁLISE E DISCUSSÃO DOS RESULTADOS}

8.1 Metodologias para Obtenção do Valor Médio de Fluxo de Nêutrons e Variância

Uma vez obtidos os valores pontuais de fluxo de nêutrons térmicos e epitérmicos obtidos das folhas de ativação de ouro em cada ponto interno do núcleo do reator, foi calculada a média ponderada de fluxo de nêutrons térmicos e epitérmicos e a variância média ponderada. Estes cálculos foram realizados por intermédio das equações (8.1), (8.2), (8.3) e (8.4) [35].

Os valores médios de fluxo de nêutrons térmicos e epitérmicos foram obtidos pela equação,

$$
\bar{\phi}=\frac{\sum_{i=1}^{n} \phi_{i} w_{i}}{\sum_{i=1}^{n} w_{i}} .
$$

Sendo $\bar{\phi}$ o fluxo médio ponderado de nêutrons térmicos ou epitérmicos, $\phi_{i}$ o fluxo térmico ou epitérmico em cada folha de ativação e $w_{i}$ o peso associado a cada folha cujo valor é dado por

$$
w_{i}=\frac{1}{S^{2}\left(\phi_{i}\right)} \text {. }
$$

Sendo $S^{2}\left(\phi_{i}\right)$ a variância obtida do fluxo $\phi_{i}$. 
Para o valor ponderado da variância tem-se ,

$$
S^{2}(\phi)=\frac{\sum_{i=1}^{n} w_{i}\left(\phi_{i}-\bar{\phi}\right)^{2} /(n-1)}{\sum_{i=1}^{n} w_{i} / n} .
$$

A variável $n$ recebe o valor inteiro de pontos mapeados, ou seja, de todas as folhas de ouro utilizadas (com e sem cobertura de Cd) ou seja 161 (folhas).

Por fim obtém-se a variância média ponderada pela equação dada por

$$
S^{2}(\bar{\phi})=\frac{S^{2}(\phi)}{n}
$$

Utilizando-se as equações apresentadas, o valor do fluxo médio ponderado de nêutrons térmicos e sua incerteza é de

$$
\bar{\phi}_{\text {ter }}=4,0529 \times 10^{8} \pm 3,27 \% \mathrm{n} / \mathrm{cm}^{2} \mathrm{~s} .
$$

O valor do fluxo médio ponderado de nêutrons epitérmicos e sua incerteza é de

$$
\bar{\phi}_{e p i}=5,1991 \times 10^{8} \pm 3,86 \% \mathrm{n} / \mathrm{cm}^{2} \mathrm{~s} .
$$

Obviamente que esses valores se referem ao nível de potência de operação na configuração cilíndrica $28 \times 28$ que se deseja determinar neste trabalho. O fluxo médio de nêutrons térmicos obtido experimentalmente, validou o resultado do fluxo médio de nêutrons térmicos obtido pelo código computacional CITATION por Bitelli e Lima [36], apresentado no ANEXO C. 
8.2 Medidas do Canal Nuclear de Pulsos $n^{\circ} 10\left({ }^{10} \mathrm{~B}\right)$

As medidas do canal nuclear de pulsos realizada na configuração padrão retangular e cilíndrica estão apresentadas na FIG 8.1.

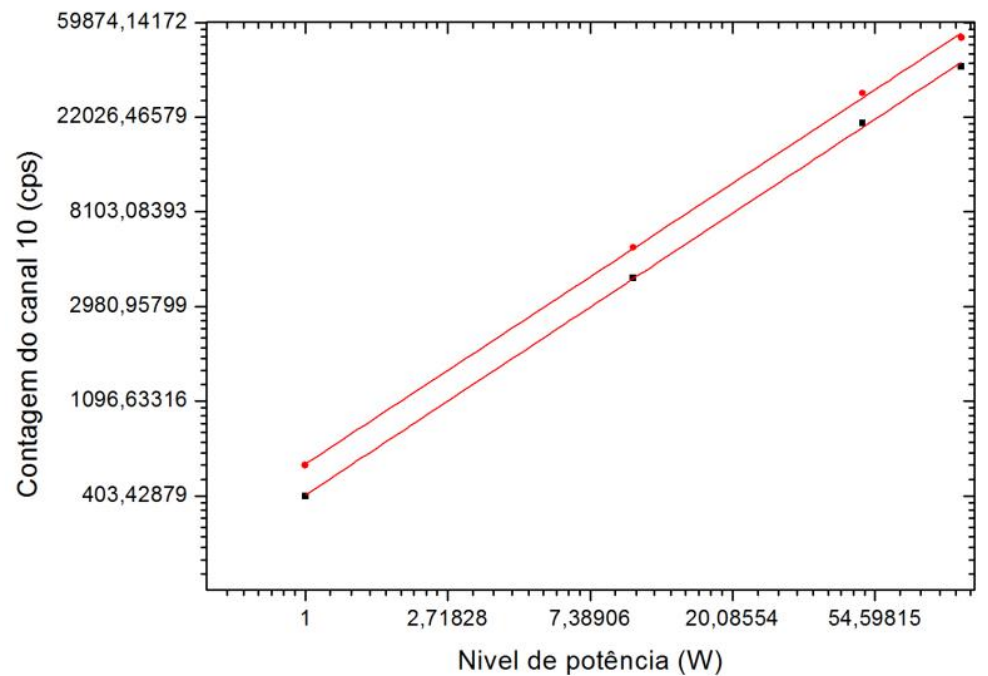

Figura 8.1 - Contagens do canal nuclear de pulsos 10 na configuração padrão retangular (linha superior) 28x26 e cilíndrica 28x28 (Linha inferior).

\subsection{Potência no Núcleo Cilíndrico}

Uma vez obtido o valor do fluxo médio de nêutrons térmicos no núcleo de configuração cilíndrica, utiliza-se este valor de fluxo na equação da potência (4.5),

$$
P=G \cdot \overline{\sum_{f}} \cdot \overline{\phi_{t e r}} \cdot V \cdot F \cdot R \text {. }
$$

Sendo,

$G$ - o valor da energia recuperável por fissão que é igual a $3.2 \times 10^{-11}$ joules.

$\overline{\sum_{f}}$ - a seção de choque macroscópica de fissão que é igual a $0,3494 \mathrm{~cm}^{-1}$.

V - o volume de combustível no núcleo que é igual a $18100 \mathrm{~cm}^{3}$.

$F$ - igual a $0,78735[7]$. 
$R$ - igual a 1,1556 [7].

Tem-se assim a potência de $P=74,65 \pm 2,45$ watts.

\subsection{Calibração dos Canais Nucleares}

Para a calibração da operação na configuração geométrica cilíndrica de núcleo, foram monitoradas as correntes dos canais nucleares 5 e 6 e as contagens do canal nuclear de pulsos 10. Foram realizadas operações com as potências aproximadas de 1 watts, 10 watts, 50 watts e 100 watts, as quais tomaram como referencia as leituras no canal nuclear de potência 6. Cada nível de potência foi mantido por 15 minutos para permitir a leitura das contagens no canal de pulsos 10. Os dados obtidos foram gravados em arquivos digitais e posteriormente analisados para gerar os gráficos e suas curvas ajustadas. As operações foram realizadas nas configurações retangular e cilíndrica de núcleo, de forma a obter uma comparação entre estas e a calibração necessária.

Na FIG 8.2 está apresentada a curva de contagens versus potência na configuração retangular. A contagem foi obtida pelo canal 10 e a corrente no canal 6 .

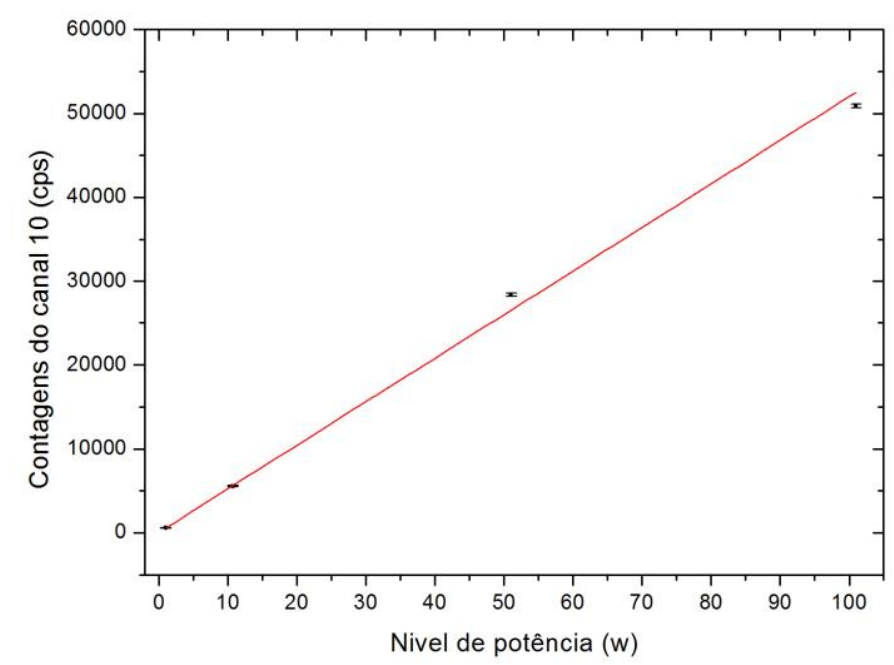

Figura 8.2 - Reta de calibração do canal nuclear 10 na configuração retangular. 
A equação (8.5) descreve a relação de contagens de pulso do canal 10 e potência do canal 6 com o ajuste linear obtido no ORIGIN [30].

$$
P(w)=\frac{C P S+(15,65,70 \pm 23,95)}{(566,61 \pm 3,26)}
$$

De posse da razão das potências na configuração cilíndrica e retangular de núcleo $(74,65 / 100=74,65 \%)$, obtiveram-se os demais valores de potência na configuração cilíndrica de núcleo. Feito isso se obteve a reta de ajuste da FIG 8.3.

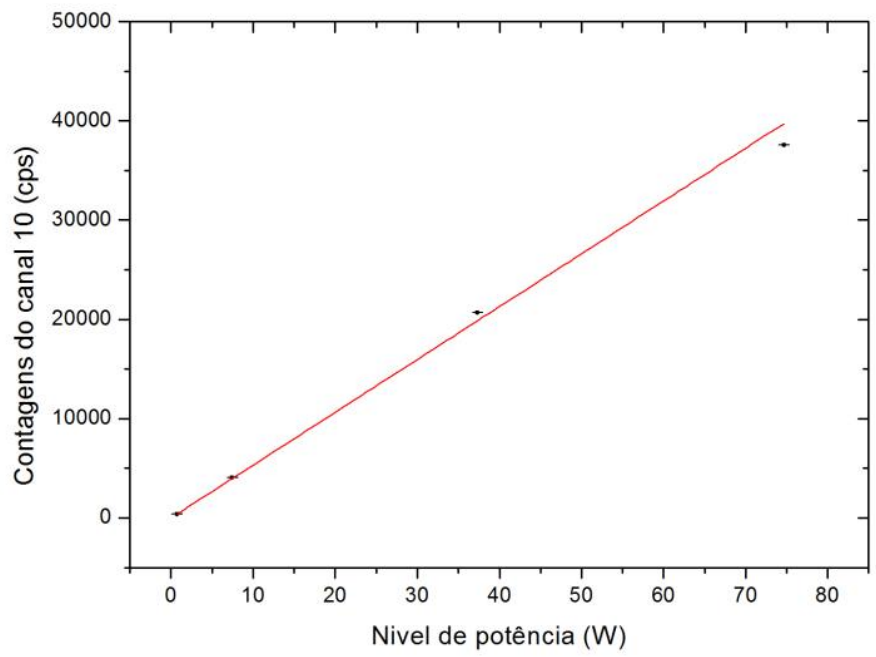

Figura 8.3 - Reta de calibração do canal nuclear 10 na configuração cilíndrica.

A equação (8.6) descreve a relação de contagens de pulso do canal 10 e potência na configuração cilíndrica, cujo ajuste linear obtido no ORIGIN [30] foi,

$$
P(w)=\frac{C P S+16,44}{553,04} \pm 2,3
$$

Uma vez obtidos os valores de potência para as contagens na configuração cilíndrica de núcleo, plotou-se a relação da potência com a corrente nos canais nucleares 5 e 6. 
Na FIG 8.4 apresenta-se a reta de calibração obtida pela potência cilíndrica com a equação (8.6) e a corrente correspondente do canal 5.

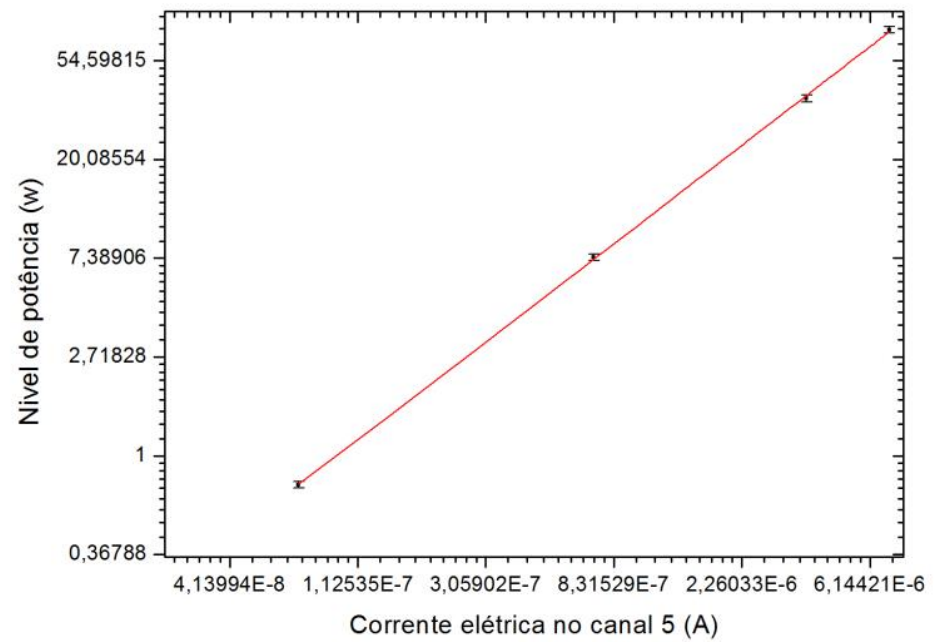

Figura 8.4 - Reta de calibração para o canal nuclear 5 na configuração cilíndrica.

A equação (8.7) descreve a relação da potência e corrente elétrica do canal nuclear 5, dado o ajuste linear realizado na FIG 8.4.

$$
P(w)=(1,0271 \pm 0,0232) \times 10^{7} I_{5}
$$

Na FIG 8.5 apresenta-se a reta de calibração obtida para a potência na configuração cilíndrica de núcleo e a corrente correspondente do canal 6. 


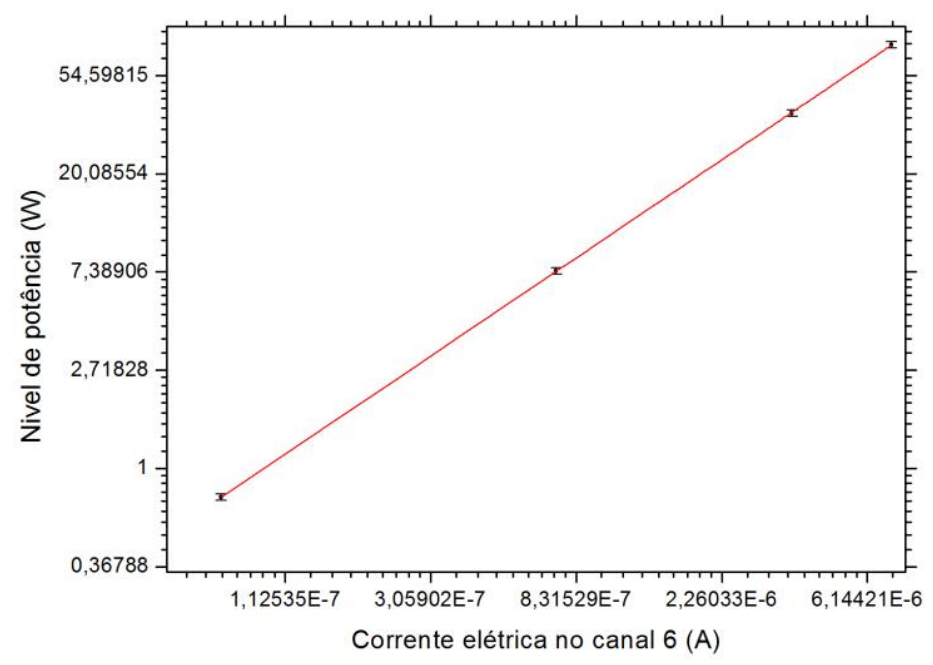

Figura 8.5 - Reta de calibração para o canal nuclear 6 na configuração cilíndrica.

A equação (8.8) descreve a relação da potência e corrente elétrica do canal nuclear 6, dado o ajuste linear realizado na FIG 8.5.

$$
P(w)=(1,0264 \pm 0,0203) \times 10^{7} I_{6}
$$

8.5 Considerações Sobre as Medidas das Contagens do Canal 10

Nas operações do reator IPEN/MB-01 que foram realizadas nas configurações geométricas de núcleo retangular e cilíndrico as quais resultaram nas FIG 8.2 e 8.3, constatou-se que aos 100 watts ( canal 6 calibrado para a configuração padrão retangular ), as contagens informadas pelo canal 10 apresentam uma redução no seu valor absoluto, o que mostra uma perda de linearidade entre a contagem e a potência informada pelo canal 6. Esta redução de contagem ocorre pela existência do tempo morto do canal 10 que aumenta com o aumento das contagens. Assim sendo, introduzimos então o fator de correção (FC) para obter a potência real considerando as contagens informadas pelo canal $10 \mathrm{e} \mathrm{o} \mathrm{seu}$ tempo morto. Trataremos do FC no item 8.6. 


\subsection{Fator de Correção do Canal de Pulsos 10}

A equação de calibração para a contagem (8.6) considerou o ajuste obtido pela extrapolação da reta gerada no programa computacional ORIGIN (para a configuração cilíndrica) a partir das potências de 1 watts, 5 watts, 50 watts e 100 watts, controladas pelo canal 6, não sendo até então considerado o tempo morto do detector para as contagens mais elevadas informadas pelo canal 10.

Pela observação na redução da contagem aos 100 watts no núcleo do reator, surgiu então a necessidade de se descobrir a partir de qual potência o tempo morto do canal 10 começa a interferir na resposta do detector. Realizaram-se então mais três operações no reator IPEN/MB-01 para obter-se o fator de correção (FC) para a potência em qualquer configuração de núcleo.

As operações foram realizadas em três diferentes configurações geométricas de núcleo e ainda utilizando-se de um flux trap (caixa fechada de acrílico posicionada no centro do núcleo do reator IPEN/MB-01 para inserção de água pesada - $\mathrm{D}_{2} \mathrm{O}$ ou água leve $\mathrm{H}_{2} \mathrm{O}$ ). As operações ocorreram nas potências nominais de 1 watts, 5 watts, 10 watts, 20 watts, 30 watts, 40 watts, 50 watts, 60 watts, 70 watts, 80 watts, 90 watts e 100 watts, as quais foram controladas no canal nuclear 6. Cada nível de potência foi mantido constante por 15 minutos para permitir a leitura estabilizada das contagens no canal nuclear de pulsos 10.

Objetivou-se medir a contagem em um número maior de pontos (12 diferentes potências) para observar o comportamento do FC, o que não pode ser feito com as potências inicialmente medidas (1, 5, 50 e 100 watts) que resultaram na equação (8.6). Os novos dados obtidos foram novamente gravados em arquivos digitais e analisados. 
8.6.1 Fator de correção para a configuração cilíndrica de 28 x 28 varetas

Este trabalho realizou a irradiação de folhas de ouro na configuração geométrica cilíndrica de núcleo de 28 x 28 varetas combustíveis, sendo assim trataremos nesta seção somente desta configuração, as duas demais configurações cilíndricas com flux trap contendo água pesada $\left(\mathrm{D}_{2} \mathrm{O}\right)$, água leve $\left(\mathrm{H}_{2} \mathrm{O}\right)$ e os valores de $\mathrm{FC}$ serão apresentadas no APÊNDICE I.

O núcleo do reator IPEN/MB-01 foi configurado na forma geométrica cilíndrica de núcleo e foi então operado nas potências de 1 watts, 5 watts, 10 watts, 20 watts, 30 watts, 40 watts, 50 watts, 60 watts, 70 watts, 80 watts, 90 watts e 100 watts por 15 minutos em cada potência. Foram colhidos e analisados os dados do canal 10. Na TAB 8.1 apresentamse os valores coletados das contagens do canal 10 sem correção e com correção e, o FC calculado.

Tabela 8.1 - Contagens do canal 10 corrigidas e não corrigidas e o fator de correção (FC) calculado para a configuração cilíndrica 28 x 28.

\begin{tabular}{|c|c|c|c|c|c|c|}
\hline $\begin{array}{c}\text { POTENCIA } \\
\text { NOMINAL } \\
\text { DO CANAL } \\
\text { 6 (w) } *\end{array}$ & $\begin{array}{c}\text { CONTAGEM } \\
\text { NÃO } \\
\text { CORRIGIDA } \\
* *\end{array}$ & $\begin{array}{c}\boldsymbol{\sigma} \\
\text { (CONTAGEM } \\
\text { NÃo } \\
\text { CORRIGIDA) }\end{array}$ & $\begin{array}{c}\text { CONTAGEM } \\
\text { CORRIGIDA } \\
* *\end{array}$ & $\begin{array}{c}\boldsymbol{\sigma} \\
\text { (CONTAGEM } \\
\text { CORRIGIDA) }\end{array}$ & $\begin{array}{c}\text { FATOR DE } \\
\text { CORREÇÃO } \\
* * *\end{array}$ & $\begin{array}{c}\text { POTENCIA } \\
\text { REAL (w) }\end{array}$ \\
\hline 1 & 405,67 & 20,14 & 405,67 & 20,14 & $\approx 1$ & 0,76 \\
\hline 5 & 2055,67 & 45,33 & 2028,37 & 45,03 & $\approx 1$ & 3,70 \\
\hline 10 & 4056,35 & 63,68 & 4111,35 & 64,11 & $\approx 1$ & 7,46 \\
\hline 20 & 9215,11 & 95,99 & 8112,71 & 90,07 & $\approx 1$ & 14,70 \\
\hline 30 & 13410,13 & 115,80 & 12169,07 & 110,31 & $\approx 1$ & 22,03 \\
\hline 40 & 17109,58 & 130,80 & 16225,43 & 127,37 & $\approx 1$ & 29,37 \\
\hline 50 & 20745,44 & 144,03 & 20281,79 & 142,41 & $\approx 1$ & 36,70 \\
\hline 60 & 24288,99 & 155,84 & 24338,14 & 156 & 1,002 & 44,04 \\
\hline 70 & 27764,19 & 166,62 & 28394,50 & 168,57 & 1,023 & 51,37 \\
\hline 80 & 31114,35 & 176,39 & 32450,86 & 180,12 & 1,043 & 58,71 \\
\hline 90 & 34501,99 & 185,74 & 36507,22 & 191,06 & 1,058 & 66,04 \\
\hline 100 & 37881,26 & 194,63 & 40563,58 & 201,40 & 1,071 & 73,38 \\
\hline
\end{tabular}

*A incerteza da potência nominal do canal 6 é de $2,03 \%$.

** Os valores de contagens não corrigidas foram obtidos das médias simples das diversas aquisições para cada potência do canal 10 .

*** A incerteza do FC é de $1,8 \%$. 
O fator de correção (FC) foi obtido pela razão da contagem corrigida e da contagem não corrigida para cada potência do canal 10. A contagem corrigida é obtida do valor esperado pelo comportamento linear do detector tendo como referencia as contagens iniciais.

Na TAB 8.1 observa-se que o fator de correção é aproximadamente 1 até valores próximos de 60 watts. A partir de 60 watts o valor de FC começa a subir, assim a equação (8.6) ajustada para potências acima de 60 watts fica

$$
P(w)=\left(\frac{C P S+16,44}{553,04}\right) x \cdot F C \pm 2,3 .
$$

Sendo que FC assume os valores da TAB 8.1 para potências acima de 60 watts.

Na FIG 8.5 apresenta-se o comportamento do fator de correção (FC) e a curva ajustada (em vermelho) da tendência de FC para valores de potência acima de 60 watts.

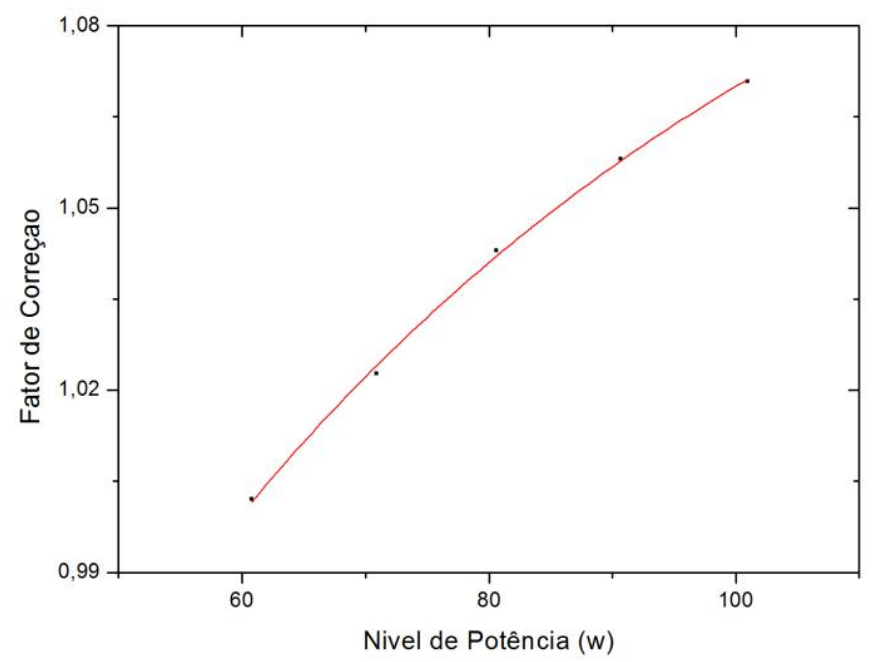

Figura 8.6 - Fator de Correção para a configuração cilíndrica de 28 x 28 varetas combustíveis. 
O ajuste realizado no programa computacional ORIGIN apresentou a equação (8.10) para o fator de correção tal como

$$
F C=1,14-0,4 \cdot e^{-0,017 . P} \pm 0,018 .
$$

Foram criadas diversas tabelas relacionando o nível de potência real e as contagens do canal 10 utilizando a equação (8.9), para auxiliar no controle do reator IPEN/MB-01 em diferentes configurações de núcleo do reator, as quais podem ser vistas no APÊNDICE H. 


\section{CONCLUSÃO}

No experimento mostrou-se uma diferença de potência, indicada no canal nuclear de potência $n^{\circ} 6$ usado na calibração de potência, entre as configurações cilíndrica e retangular em torno de $24,9 \%$. A corrente informada no canal 6 foi de $0,719 \times 10^{-5} \mathrm{~A}$ a 100 watts para a configuração retangular de $28 \times 26$ varetas combustíveis, enquanto que para a configuração cilíndrica de $28 \times 28$ varetas combustíveis, a mesma corrente indica uma potência de 74,65 \pm 4,9\% watts ao nível de confiança estatística de 95\% (obtida experimentalmente).

Da mesma forma a técnica de análise por ruído [37] indicou a potência de 82,53 \pm $18 \%$ watts ao nível de confiança estatística de 95\% [38] de acordo com o canal digital de potência 6 . A diferença entre a técnica de ativação por folhas de ouro e a técnica de ruído é de $9 \%$, dentro das margens de incerteza.

É importante salientar que na configuração cilíndrica (28 varetas ao longo do diâmetro nas direções N-S e L-O) tem-se 568 varetas combustíveis, o que representa uma quantidade de 112 a menos em relação à configuração retangular (28x26 varetas) com 680 varetas no núcleo do reator IPEN/MB-01. Esta diferença representa 16,47\% varetas a menos para a configuração cilíndrica, entretanto a densidade de potência não reduziu na mesma proporção e sim aumentou.

O método de cálculo do fluxo médio de nêutrons térmicos no núcleo do reator pela média ponderada dos fluxos medidos em cada folha, obteve o valor de 4,0529 $\times 10^{8} \pm 6.5 \%$ n/cm2.s ao nível de confiança estatística de 95\% (74,65 \pm 3,65 watts). Na configuração retangular, o fluxo médio calculado pelo valor médio das funções senoidais ajustadas sobre os valores dos fluxos de nêutrons térmicos medidos por Gonçalves [7] resultou num valor de $4,9560 \times 10^{8} \pm 5,50 \% \mathrm{n} / \mathrm{cm}^{2} . \mathrm{s}$ ao nível de confiança estatística de 95\% $(106,00 \pm$ 5,26 watts).

Para o mesmo nível de potência normalizada para a potência de 74,65 watts, o valor obtido por Gonçalves é 16,35\% menor que o valor obtido neste experimento. Isto 
demonstra que a densidade de potência aumentou para a configuração cilíndrica de 28x28 em relação à configuração padrão retangular 28x26.

O valor de fluxo médio de nêutrons térmicos calculado por Lima pelo Código CITATION [36] foi de $4,0304 \times 10^{8} \mathrm{n} / \mathrm{cm}^{2}$.s (normalizando a potência para o valor de 74,65 watts), o que representa uma diferença de $0,5 \%$ em relação ao valor obtido experimentalmente neste trabalho.

Pelo programa computacional ORIGIN, o ajuste fornecido possibilitou obter para a configuração retangular e à cilíndrica uma reta de calibração do canal nuclear $\mathrm{n}^{\circ} 10 . \mathrm{Na}$ retangular, cada nível de potência, 1 watts, 10 watts, 50 watts e 100 watts, representou para a configuração cilíndrica, uma redução média de $26 \%$ cujas potências relacionadas foram de 0,70 watts, 7,60 watts, 39,29 watts, 73,56 watts.

A análise mais apurada do comportamento do canal 10 quando se trabalha com potências acima de 60 watts, resultou na necessidade de se inserir o fator de calibração (FC) cujos valores para diferentes geometrias de núcleo são muito próximos (desvio de $1,8 \%$ para a maior variação encontrada), o que garante que diferente das geometrias de núcleo do reator que foram apresentadas neste trabalho, pode-se utilizar quaisquer destes fatores de correção em suas respectivas potências para a correção da potência gerada.

$\mathrm{Na}$ configuração cilíndrica o valor das contagens obtidas pelo canal nuclear de pulsos (canal 10), indicou uma redução média em relação às contagens da configuração padrão retangular de $26,12 \%$. Se normalizarmos as contagens na configuração retangular para a potência respectiva de 74,65 watts, teremos um desvio no valor nominal de $1 \%$ em relação à configuração cilíndrica de mesma potência. Assim mostra-se que o canal de pulsos 10 apresenta as contagens independentemente da configuração geométrica em que o núcleo do reator se encontre, tornando-se um importante canal para o controle da potência do reator nuclear IPEN/MB-01 em qualquer configuração de núcleo. Desta forma, quando se opera o reator em diferentes configurações de núcleo, os canais de potência 5 e 6 , não são os canais mais indicados (pela redução de exatidão) para se controlar a potência, uma vez que estes estão próximos das barras de controle e sofrem distorções. Assim, a 
importante conclusão deste trabalho é que o canal 10, para diferentes configurações geométricas de núcleo é o canal a ser utilizado para se controlar a potência de operação do reator IPEN/MB-01, dado o fato de que por estar mais afastado $(80 \mathrm{~cm}$ do centro da placa matriz) do núcleo ele se mostrou insensível as variações de barras decorrentes da compensação do excesso de reatividade de cada configuração de núcleo. 
APÊNDICE A - Modelagem do reator IPEN/MB-01 pelo código MCNP-5

Apresentamos neste anexo os códigos usados na modelagem do reator IPEM/MB01 realizada no programa computacional MCNP-5. Os códigos estão divididos em quatro grupos os quais tornaram possíveis obter grandezas nucleares simuladas para uso nos equacionamentos do cálculo do fluxo de nêutrons.

Para uma melhor compreensão, apresentamos as descrições e estrutura do código no MCNP.

\section{A.1 Estrutura do código}

Todo o código deve conter três seções ou blocos, onde cada um representa as células, as superfícies e os dados de materiais.

O bloco de células deve conter os volumes da geometria do problema que se quer simular. Este bloco tem como referência as superfícies do bloco de superfícies, as quais irão compor os volumes das geometrias. O bloco de dados de materiais contém os materiais que compõem toda a geometria envolvida na simulação do problema.

De forma geral, a estrutura do código deve seguir obrigatoriamente a seguinte organização:

- Título

- Linha em branco

- Bloco de células

- Linha em branco

- Bloco de superfícies

- Linha em branco

- Bloco de materiais e demais informações e comandos necessários para a obtenção dos resultados requeridos para o problema em estudo 
A.2 Formato usado no código

Em cada linha são aceitos um máximo de 80 caracteres sendo que os cinco primeiros devem ser os mnemônicos. O MCNP não há distinção entre caixa alta ou baixa no texto. Para organizar e facilitar a compreensão do código, pode-se introduzir linhas de comentário após a letra 'c' no início de cada linha seguido de um carácter em branco ou, após \$ em cada linha. Caso uma linha não acomode todos os caracteres, pode-se continuar na linha subsequente utilizando o caractere $\&$, iniciando após um carácter em branco.

No bloco de especificação de células (volumes), utiliza-se a seguinte formatação:

\# (número identificador da célula) m (especificador do material) d (densidade) <combinação de superfícies> imp (importância)

Como exemplo tem-se

$$
105 \quad 1.11860 \mathrm{e}-01 \quad-1-8 \quad \mathrm{u}=1
$$

No bloco de especificação de superfícies, utiliza-se a seguinte formatação:

\# (numero identificador da superfície) $\mathbf{M}$ (mnemônico especificador de superfície) $\mathbf{P}$ (parâmetros da superfície)

Como exemplo tem-se

14 px -23.25

No bloco de especificação de dados e materiais, utiliza-se a seguinte formatação para materiais:

M (material) ZAId1 Fração1 ZAId2 Fração2 .......... Parâmetros opcionais 
Sendo ZAId a representação de ZZZAAA.nnx, onde ZZZ é o número atômico, AAA é o número de massa, nn o identificador da base de dados e x, a classe de dados. A Fração de densidade pode ser positiva se representar fração atômica ou negativa se representar fração por massa.

Como exemplo tem-se

m3 26054.70c 3.57366e-03 26056.70c 5.40491e-02

Utilizou-se a fonte de nêutrons com o comando KCODE, que representa uma fonte iterativa usada para meios multiplicativos, cuja formatação é a seguinte:

KCODE 60000001.025070 ,

sendo 6000000 o número de histórias simuladas, 1.02 o K efetivo inicial, 50 o número de ciclos iniciais descartados e, 70 o número total de ciclos.

Este bloco ainda contém o comando tallies, que realiza determinada tarefa de interesse ao estudo. Na TAB A.1 apresentam-se alguns tallies em uso pelo MCNP e suas representações.

Tabela A.1 - Alguns tallies utilizados pelo MCNP

\begin{tabular}{|c|c|c|}
\hline Tally & Descrição & Unidade \\
\hline F1:N ou F1:E ou F1:P & Corrente integrada em uma superfície & $\mathrm{MeV}$ \\
\hline F2:N ou F2:E ou F2:P & Fluxo médio em uma superfície & $\mathrm{MeV} / \mathrm{cm}^{2}$ \\
\hline F4:N ou F4:E ou F4:P & Fluxo médio em uma célula & $\mathrm{MeV} / \mathrm{cm}^{2}$ \\
\hline F5:N ou F5:P & Fluxo em um detector & $\mathrm{MeV} / \mathrm{cm}^{2}$ \\
\hline F6:N ou F6:N,P ou F6:P & Energia média depositada na célula & $\mathrm{MeV} / \mathrm{g}$ \\
\hline
\end{tabular}


A.3 - Definição das superfícies

As superfícies utilizadas no bloco de superfícies no código da modelagem, estão apresentadas na TAB A.2.

Tabela A.2 - Superfícies utilizadas.

\begin{tabular}{|c|c|c|c|}
\hline Mnemônico & Tipo & Equação & $\begin{array}{c}\text { Dados de } \\
\text { Entrada }\end{array}$ \\
\hline PX & Plane & $\mathrm{x}-\mathrm{D}=0$ & \\
PY & Normal ao & $\mathrm{y}-\mathrm{D}=0$ & $\mathrm{D}$ \\
PZ & eixo & $\mathrm{z}-\mathrm{D}=0$ & \\
\hline C/X & Cilindro & $(\mathrm{y}-\mathrm{b})^{2}+(\mathrm{z}-\mathrm{c})^{2}-\mathrm{R}^{2}=0$ & $\mathrm{~b} \mathrm{c} \mathrm{R}$ \\
C/Y & paralelo ao & $(\mathrm{x}-\mathrm{a})^{2}+(\mathrm{z}-\mathrm{c})^{2}-\mathrm{R}^{2}=0$ & $\mathrm{a} \mathrm{c} \mathrm{R}$ \\
C/Z & eixo & $(\mathrm{x}-\mathrm{a})^{2}+(\mathrm{y}-\mathrm{b})^{2}-\mathrm{R}^{2}=0$ & $\mathrm{a} \mathrm{b} \mathrm{R}$ \\
\hline CX & & $\mathrm{y}^{2}+\mathrm{z}^{2}-\mathrm{R}^{2}=0$ & \\
CY & Cilindro & $\mathrm{x}^{2}+\mathrm{z}^{2}-\mathrm{R}^{2}=0$ & $\mathrm{R}$ \\
CZ & & $\mathrm{x}^{2}+\mathrm{y}^{2}-\mathrm{R}^{2}=0$ & \\
\hline
\end{tabular}

Abaixo têm-se um exemplo utilizado para criar um plano normal ao eixo $\mathrm{x}$.

14 px -23.25

Sendo 14 o número da superfície, px (plano normal ao eixo x) o mnemônico e, -23.25 a distância do plano até $\mathrm{x}=00.00 \mathrm{~cm}$. $\mathrm{O}$ sinal negativo $(-23.25)$ se refere ao sentido para o eixo negativo de $\mathrm{x}$.

A.4 Código da modelagem do reator IPEN/MB-01

Foram criados quatro códigos de entrada para:

- Folhas de ouro hiperpuras sem cádmio

- Folhas de ouro hiperpuras com cádmio

- Folhas de ouro infinitamente diluídas sem cádmio

- Folhas de ouro infinitamente diluídas com cádmio

Estes códigos estão apresentados respectivamente a seguir. 
Folha de ouro hiper-pura nua

c Reator IPEN/MB-01 - Enriquecimento $4.3 \%$ U-235

c arranjo cilindrico 28 varetas de diametro

$\mathrm{c}$

c vareta combustivel padrao

c parte inferior - alumina ----> -9.00 a $0.00 \mathrm{~cm}$

\begin{tabular}{|c|c|c|}
\hline 10 & $5 \quad 1.11860 \mathrm{e}-01-1-8$ & $\$$ alumina \\
\hline 20 & $2-0.0001$ & \$ gap \\
\hline & $38.65716 \mathrm{e}-02 \quad 2-3-8$ & $\$$ clad $(\mathrm{SS})$ \\
\hline \multicolumn{3}{|c|}{ c parte ativa - UO2 --------> 0.0 a $54.84 \mathrm{~cm}$} \\
\hline & $16.81901 \mathrm{e}-02-18-9$ & $\$ 1$ \\
\hline & $2-0.0001$ & \$ gap \\
\hline & 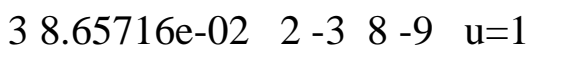 & \$ clad $(\mathrm{SS})$ \\
\hline \multicolumn{3}{|c|}{ c parte superior - alumina ----> 54.84 a $60.24 \mathrm{~cm}$} \\
\hline 70 & 5 1.11860e-01 $-1 \quad 9-23 \quad u=1$ & $\$$ alumina \\
\hline & $1-2 \quad 9-23 \quad u=1$ & \$ gap \\
\hline 90 & $38.65716 \mathrm{e}-02 \quad 2-3 \quad 9-23 \mathrm{u}=1$ & $\$$ clad $(\mathrm{SS})$ \\
\hline \multicolumn{3}{|c|}{ c parte superior - tubo espacador ---> 60.24 a $98.84 \mathrm{~cm}$} \\
\hline & $0-2823-24 u=1$ & vazio (interno) \\
\hline & $78.79133 \mathrm{e}-0228-123-24 \mathrm{u}=1$ & \$ tubo $(\mathrm{SS})$ \\
\hline & 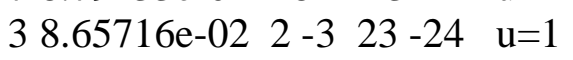 & $\$$ clad $(\mathrm{SS})$ \\
\hline & $1-223-24$ & \$ gap \\
\hline
\end{tabular}

c moderator

$140 \quad 4$ 1.00104e-01 $3 \quad \mathrm{u}=1 \quad$ \$ agua

c tubo guia

$150 \quad 41.00104 \mathrm{e}-01-18-24 \quad \mathrm{u}=2 \quad$ \$ agua (interna)

$16098.43026 \mathrm{e}-02 \quad 18-17-24 \quad \mathrm{u}=2 \quad$ \$ tubo (SS)

$170 \quad 41.00104 \mathrm{e}-01 \quad 17 \quad \mathrm{u}=2 \quad$ \$ agua (externa)

c barra de controle \#1 -----> superficie 31 define insercao

\begin{tabular}{|c|c|c|}
\hline 180 & $65.82335 e-02-2931-24 \quad u=5$ & $\$$ absorvedor (AgInCd) \\
\hline 190 & $29-2 \quad 31-24 \quad u=5$ & \$ gap \\
\hline 200 & $138.65451 \mathrm{e}-022-3 \quad 31-24 \quad u=5$ & $\$$ clad \\
\hline 210 & $41.00104 \mathrm{e}-013-18-24$ & $\$$ agua (interna) \\
\hline 220 & $98.43026 \mathrm{e}-02 \quad 18-17-24$ & $\$$ tubo $(\mathrm{SS})$ \\
\hline 230 & $41.00104 \mathrm{e}-0117$ & $\$$ agua (externa) \\
\hline \multicolumn{3}{|c|}{ c ponteira da barra de controle \#1 } \\
\hline 240 & $138.65451 e-02-3 \quad 30-31 \quad u=5$ & \$ ponteira $(\mathrm{SS})$ \\
\hline 250 & $41.00104 \mathrm{e}-01-3-30$ & \$ agua \\
\hline \multicolumn{3}{|c|}{ c barra de controle \#2 -----> superficie 41 define insercao } \\
\hline 260 & $65.82335 \mathrm{e}-02-29 \quad 41-24 \quad u=6$ & $\$$ absorvedor (AgInCd) \\
\hline 270 & $2-0.0001 \quad 29-2 \quad 41-24 \quad u=6$ & \$ gap \\
\hline 280 & $138.65451 \mathrm{e}-02 \quad 2 \quad-3 \quad 41-24 \quad u=6$ & $\$$ clad \\
\hline 290 & 4 1.00104e-01 $3-18-24$ & \$ agua (interna) \\
\hline 300 & $98.43026 \mathrm{e}-02 \quad 18-17-24$ & $\$$ tubo $(\mathrm{SS})$ \\
\hline 310 & $41.00104 \mathrm{e}-01 \quad 17$ & $\$$ agua (externa) \\
\hline \multicolumn{3}{|c|}{ c ponteira da barra de controle \#2 } \\
\hline 320 & $138.65451 e-02 \quad-3 \quad 40-41 \quad u=6$ & \$ ponteira (SS) \\
\hline 330 & $41.00104 \mathrm{e}-01 \quad-3-40$ & $\$$ agua \\
\hline
\end{tabular}


$\mathrm{c}$

c celula de agua

$340 \quad 41.00104 \mathrm{e}-01-24 \quad \mathrm{u}=8 \quad$ \$ agua

c

c Volume de uma Folha de Ouro

$360 \quad 155.96415 \mathrm{e}-02 \quad-60-6162 \quad \$$ vol $=0.00883125$

c Placa de Acrilico

$600 \quad 141.06657$ e-01 $25-5152$-53 54 -55 \#360

c Universo $\mathrm{u}=1$ vareta combustivel especial

c Universo $\mathrm{u}=1$ vareta combustivel padrao

c Universo $\mathrm{u}=2$ tubo guia

c Universo $\mathrm{u}=5$ barra de controle \#1 (BC\#1)

c Universo $\mathrm{u}=6$ barra de controle \#2 (BC\#2)

c Universo $\mathrm{u}=8$ moderador (agua)

c

$650 \quad 0-457-6 \mathrm{u}=15$ lat=1 fill=-15:14 -14:15 0:0

888888888888888888888888888888 888888888881111111188888888888 888888888111111111111888888888 888888811111111111111118888888 888888211121111111151115888888 8888811111111111111111111188888 888821112111211115111511158888 888111111111111111111111111888 888111211121111111151115111888 881111111111111111111111111188 881121112111211115111511151188 81111111111111111111111111111118 811111211121111111151115111118 811111111111111111111111111111118 811111111111111111111111111111118 8111111111111111111111111111118 8111111111111111111111111111118 811111611161111111121112111118 811111111111111111111111111118 881161116111611112111211121188 8811111111111111111111111111188 888111611161111111121112111888 8881111111111111111111111111888 888861116111611112111211128888 888881111111111111111111188888 888888611161111111121112888888 888888811111111111111118888888 888888888111111111111888888888 888888888881111111188888888888 888888888888888888888888888888 c

c limite do arranjo 


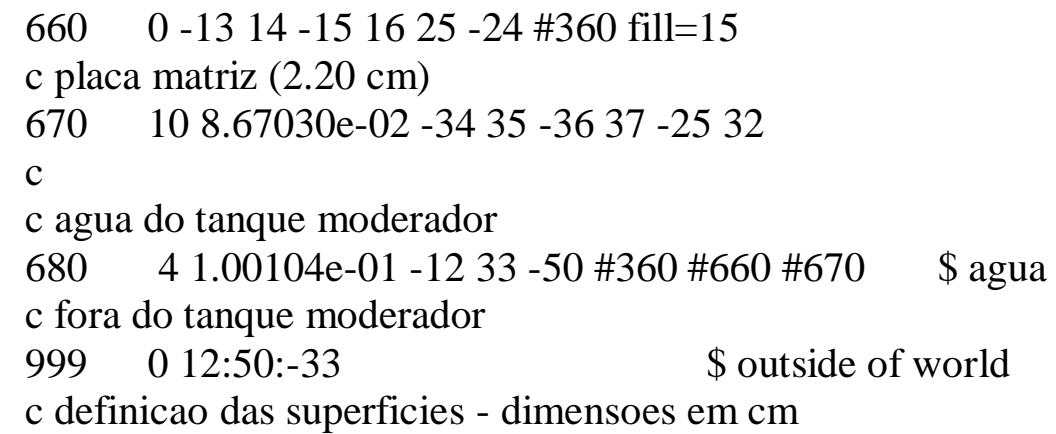

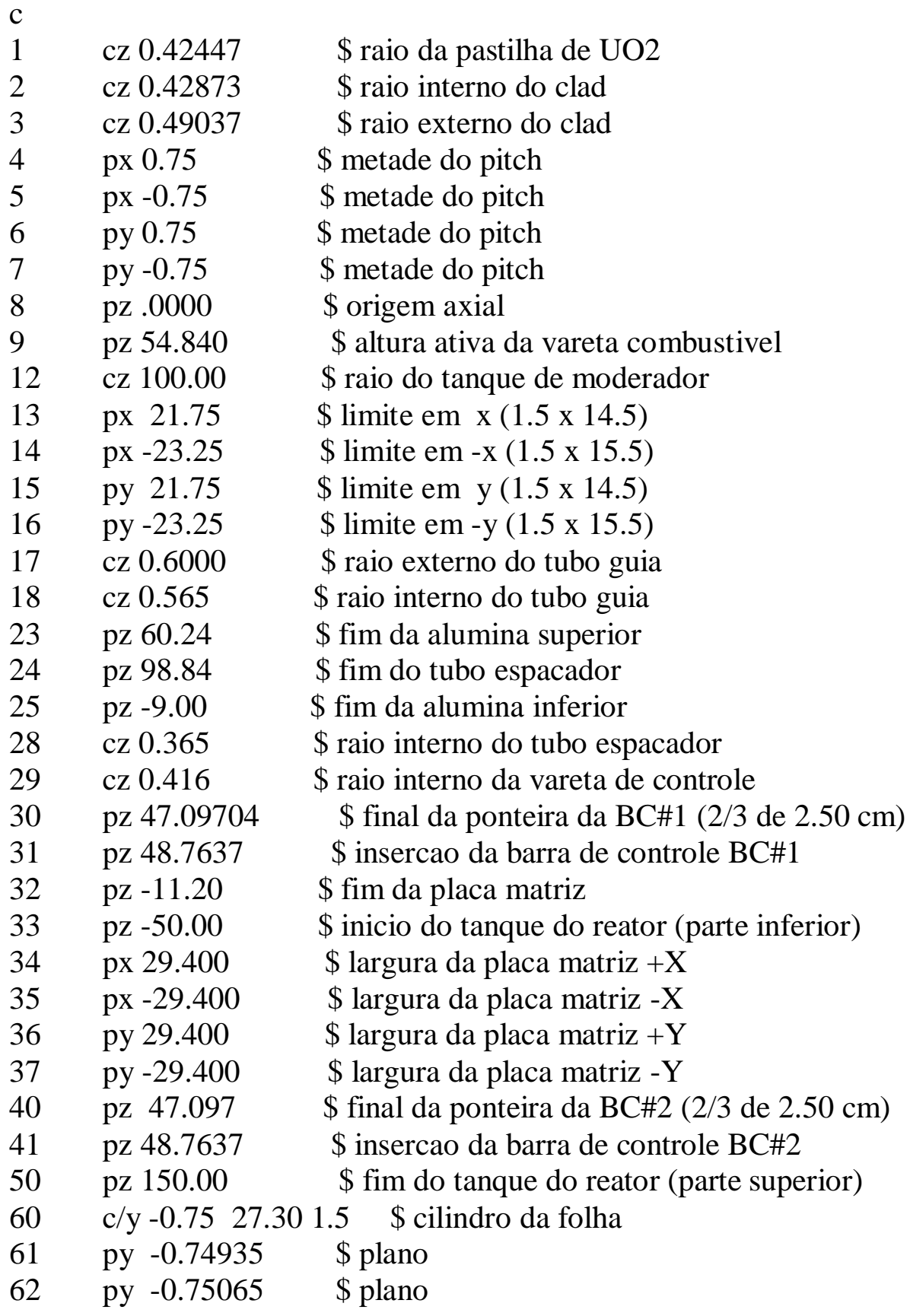

c Importancia das celulas 
c

imp:n 11111111111111111111

11111111111111111110

$\mathrm{c}$

kcode 60000001.025070

c

c Definicao dos Materiais

c ----> densidade (atom/cm3)

c pastilha - uo2

m1 92235.70c 9.99240e-04 92238.70c 2.1694e-02 8016.70c $4.54890 \mathrm{e}-02$ 92234.70c 7.84620e-06

c vazio (gap)

$\mathrm{m} 2 \quad 8016.70 \mathrm{c} \quad 0.0001$

c encamisamento da vareta combustivel - SS304 - (clad)

m3 26054.70c 3.57366e-03 26056.70c 5.40491e-02 26057.70c $1.22693 \mathrm{e}-03$ $26058.70 \mathrm{c} 1.59256 \mathrm{e}-04$

24050.70c 7.61902e-04 24052.70c $1.41123 \mathrm{e}-02$ 24053.70c $1.56980 \mathrm{e}-03$ $24054.70 \mathrm{c} 3.82755 \mathrm{e}-04$

28058.70c 5.62942e-03 28060.70c 2.09590e-03 28061.70c 8.96301e-05 $28062.70 \mathrm{c} 2.80805 \mathrm{e}-0428064.70 \mathrm{c} 6.96915 \mathrm{e}-05$

14028.70c 6.28990e-04 14029.70c 3.07498e-05 14030.70c $1.97329 \mathrm{e}-05$ $16032.70 \mathrm{c} 1.48849 \mathrm{e}-05$ 16033.70c $1.13926 \mathrm{e}-07$ 16034.70c $6.20747 \mathrm{e}-07$ $16036.70 \mathrm{c} 2.78500 \mathrm{e}-09$

42092.70c $1.30932 \mathrm{e}-05$ 42094.70c $7.98754 \mathrm{e}-06$ 42095.70c $1.36022 \mathrm{e}-05$ 42096.70c $1.41032 \mathrm{e}-05$ 42097.70c $7.99122 \mathrm{e}-06$ 42098.70c $1.99853 \mathrm{e}-05$ 42100.70c 7.81608e-06

25055.70c 1.46450e-03 15031.70c 4.00400e-05 6000.70c 1.12390e-04

$27059.70 \mathrm{c} 1.74020 \mathrm{e}-04$

c agua

m4 1001.70c 6.67160e-02 8016.70c 3.33580e-02

mt4 lwtr.01t

c alumina - al2o3

m5 $\quad 8016.70$ c $6.71160 \mathrm{e}-02$ 13027.70c $4.47440 \mathrm{e}-02$

c barra de controle - AG-IN-CD

m6 47107.70c 2.31847e-02 47109.70c 2.11443e-02

49113.70c 3.42556e-03 49115.70c 7.50941e-03

48106.70c 3.43547e-05 48108.70c $2.40077 \mathrm{e}-05$ 48110.70c $3.30790 \mathrm{e}-04$

48111.70c 3.35939e-04 48112.70c $6.27647 \mathrm{e}-04$ 48113.70c $3.15035 \mathrm{e}-04$

48114.70c 7.34172e-04 48116.70c $1.88096 \mathrm{e}-04$

16032.70 c $1.79100 \mathrm{e}-0416033.70$ c $1.37080 \mathrm{e}-06$ 16034.70c $7.46906 \mathrm{e}-06$

$16036.70 \mathrm{c} 3.35102 \mathrm{e}-08$

6000.70 c $1.50520 \mathrm{e}-038016.70$ c $1.77030 \mathrm{e}-03$

c tubo espacador - SS

m7 26054.70c $3.74872 \mathrm{e}-03$ 26056.70c $5.66967 \mathrm{e}-02$ 26057.70c $1.28703 \mathrm{e}-03$ $26058.70 \mathrm{c} 1.67057 \mathrm{e}-04$

24050.70c $7.59839 \mathrm{e}-0424052.70 \mathrm{c} \quad 1.40741 \mathrm{e}-02$ 24053.70c $1.56555 \mathrm{e}-03$ $24054.70 \mathrm{c} 3.81719 \mathrm{e}-04$

28058.70c $4.53128 \mathrm{e}-0328060.70 \mathrm{c} \quad 1.68705 \mathrm{e}-0328061.70 \mathrm{c} \quad 7.21458 \mathrm{e}-05$ 
28062.70c 2.26028e-04 28064.70c 5.60967e-05

$25055.70 \mathrm{c} 1.15810 \mathrm{e}-03$

14028.70 c $1.03286 \mathrm{e}-03$ 14029.70c $5.04940 \mathrm{e}-05$ 14030.70c $3.24033 \mathrm{e}-05$

15031.70 c 3.11240e-05 6000.70c 2.40780e-04 27059.70c $1.14500 \mathrm{e}-04$

c tubo guia - SS

m9 26054.70c 3.44894e-03 26056.70c 5.21628e-02 26057.70c $1.18411 \mathrm{e}-03$

26058.70c $1.53698 \mathrm{e}-04$

24050.70c 7.38069e-04 24052.70c $1.36708 \mathrm{e}-02$ 24053.70c $1.52070 \mathrm{e}-03$

24054.70c 3.70782e-04

28058.70c $6.27853 \mathrm{e}-03$ 28060.70c $2.33757 \mathrm{e}-03$ 28061.70c $9.99650 \mathrm{e}-05$

28062.70c 3.13183e-04 28064.70c 7.77273e-05

$25055.70 \mathrm{c} 1.15010 \mathrm{e}-03$

14028.70c $6.12655 \mathrm{e}-0414029.70 \mathrm{c} 2.99512 \mathrm{e}-05$ 14030.70c $1.92205 \mathrm{e}-05$

$15031.70 \mathrm{c} 4.50000 \mathrm{e}-056000.70 \mathrm{c} 8.89680 \mathrm{e}-05$

c placa matriz - SS

m10 26054.70c 3.63630e-03 26056.70c 5.49964e-02 26057.70c $1.24843 \mathrm{e}-03$ $26058.70 \mathrm{c} 1.62047 \mathrm{e}-04$

24050.70c $7.56501 \mathrm{e}-0424052.70$ c $1.40122 \mathrm{e}-0224053.70 \mathrm{c} \quad 1.55868 \mathrm{e}-03$ 24054.70c 3.80042e-04

28058.70c 5.28566e-03 28060.70c $1.96791 \mathrm{e}-03$ 28061.70c $8.41568 \mathrm{e}-05$ 28062.70c 2.63658e-04 28064.70c 6.54358e-05

14028.70 c $8.01962 \mathrm{e}-0414029.70 \mathrm{c} 3.92060 \mathrm{e}-05$ 14030.70c $2.51595 \mathrm{e}-05$ $16032.70 \mathrm{c} 4.25282 \mathrm{e}-0616033.70 \mathrm{c} 3.25504 \mathrm{e}-08$ 16034.70c $1.77356 \mathrm{e}-07$ $16036.70 \mathrm{c} 7.95715 \mathrm{e}-10$

42092.70c 4.62114e-06 42094.70c 2.81913e-06 42095.70c $4.80079 \mathrm{e}-06$ 42096.70c $4.97759 \mathrm{e}-0642097.70 \mathrm{c} \quad 2.82043 \mathrm{e}-06$ 42098.70c $7.05364 \mathrm{e}-06$ 42100.70c 2.75861e-06

25055.70c 1.25030e-03 15031.70c 5.54400e-05 6000.70c 7.94260e-05

c encamisamento das barras de controle e de seguranca - SS304

m13 26054.70c 3.50278e-03 26056.70c 5.29770e-02 26057.70c $1.20259 \mathrm{e}-03$ $26058.70 \mathrm{c} 1.56097 \mathrm{e}-04$

24050.70c $7.62733 \mathrm{e}-0424052.70 \mathrm{c} \quad 1.41277 \mathrm{e}-02$ 24053.70c $1.57152 \mathrm{e}-03$ 24054.70c 3.83172e-04

28058.70c 6.54682e-03 28060.70c 2.43746e-03 28061.70c $1.04236 \mathrm{e}-04$ 28062.70c 3.26566e-04 28064.70c 8.10488e-05

14028.70 c $7.07614 \mathrm{e}-04$ 14029.70c $3.45935 \mathrm{e}-05$ 14030.70c $2.21996 \mathrm{e}-05$ $16032.70 \mathrm{c} 4.25282 \mathrm{e}-0616033.70 \mathrm{c} 3.25504 \mathrm{e}-08$ 16034.70c $1.77356 \mathrm{e}-07$ $16036.70 \mathrm{c} 7.95715 \mathrm{e}-10$

42092.70c 2.31057e-06 42094.70c $1.40957 \mathrm{e}-06$ 42095.70c $2.40040 \mathrm{e}-06$ 42096.70c 2.48879e-06 42097.70c $1.41022 \mathrm{e}-06$ 42098.70c $3.52682 \mathrm{e}-06$ 42100.70c $1.37931 \mathrm{e}-06$

29063.70c 9.43728e-05 29065.70c 4.07687e-05

50112.70c 3.30769e-08 50114.70c 2.17761e-08 50115.70c $1.12914 \mathrm{e}-08$ 50116.70c $4.78714 \mathrm{e}-0750117.70 \mathrm{c} 2.50690 \mathrm{e}-07$ 50118.70c $7.83891 \mathrm{e}-07$ 50119.70c $2.75677 \mathrm{e}-07$ 50120.70c $1.03719 \mathrm{e}-06$ 50122.70c $1.44933 \mathrm{e}-07$ 50124.70c $1.78316 \mathrm{e}-07$

15031.70 c $4.15796 \mathrm{e}-056000.70$ c $8.33972 \mathrm{e}-05$ 27059.70c $1.37594 \mathrm{e}-04$ 25055.70c $1.18080 \mathrm{e}-03$ 
c placa de acrilico

m14 1001.70c 5.5063e-02 8016.70c $1.4369 \mathrm{e}-02$ 6000.70c $3.4916 \mathrm{e}-02$ 7014.70c 3.0208E-05

mt14 poly.60t

$\mathrm{c}$

c ouro $100 \%$

m15 79197.70c 5.96415e-02

c definicao de tally

f4:n 360

fm4:n (1 15 102)

e4 $\quad 0.55 \mathrm{e}-0620$

prdmp $10001000-1 \mathrm{j}$

print

Folha de ouro hiper-pura com Luva de Cadmio (0.508 mm)

c Reator IPEN/MB-01 - Enriquecimento $4.3 \%$ U-235

c arranjo cilindrico 28 varetas de diametro

$\mathrm{c}$

c vareta combustivel padrao (material densidade e geometria)

c parte inferior - alumina ----> -9.00 a $0.00 \mathrm{~cm}$

\begin{tabular}{|c|c|c|c|}
\hline b & 5 1.11860e-01 -1 -8 & $\mathrm{u}=1$ & $\$$ alumina \\
\hline & $2-0.0001$ & $\mathrm{u}=1$ & \$ gap \\
\hline & $38.65716 \mathrm{e}-02 \quad 2-3-8$ & $\mathrm{u}=1$ & $\$$ clad $(\mathrm{SS})$ \\
\hline & ativa - UO2 -----------> & $.0 \mathrm{a} 5$ & \\
\hline & $16.81901 \mathrm{e}-02-1 \quad 8-9$ & $\mathrm{u}=1$ & $\$$ uo2 (pastill \\
\hline & $2-0.0001$ & $\mathrm{u}=1$ & \$ gap \\
\hline & 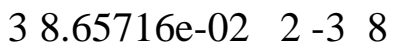 & $\mathrm{u}=1$ & $\$$ clad $(\mathrm{SS})$ \\
\hline
\end{tabular}

c parte superior - alumina ----> 54.84 a $60.24 \mathrm{~cm}$

$70 \quad 5$ 1.11860e-01 $-1 \quad 9-23 \quad \mathrm{u}=1 \quad$ \$ alumina

$80 \quad 2-0.0001 \quad 1-2 \quad 9-23 \quad u=1 \quad$ \$ gap

$90 \quad 38.65716 \mathrm{e}-02 \quad 2-3 \quad 9-23 \quad \mathrm{u}=1 \quad$ \$ clad (SS)

c parte superior - tubo espacador ---> 60.24 a $98.84 \mathrm{~cm}$
$100 \quad 0-2823-24 \mathrm{u}=1$
$\$$ vazio (interno)
$110 \quad 78.79133 \mathrm{e}-02 \quad 28-123-24 \quad \mathrm{u}=1$
$\$$ tubo (SS)
$120 \quad 38.65716 \mathrm{e}-02 \quad 2-3 \quad 23-24 \quad \mathrm{u}=1$
$\$$ clad (SS)
$1302-0.0001 \quad 1-2 \quad 23-24 \quad \mathrm{u}=1 \quad$ gap

c moderator

$140 \quad 4$ 1.00104e-01 $3 \quad \mathrm{u}=1 \quad$ \$ agua

c tubo guia (material densidade e geometria)
$150 \quad 41.00104 \mathrm{e}-01-18-24 \quad \mathrm{u}=2$
$16098.43026 \mathrm{e}-02 \quad 18-17-24 \quad \mathrm{u}=2$
\$ agua (interna)
$\$$ tubo (SS)
$170 \quad 41.00104 \mathrm{e}-01 \quad 17 \quad \mathrm{u}=2$
$\$$ agua (externa)

c barra de controle \#1 -----> superficie 31 define insercao

\begin{tabular}{|c|c|c|}
\hline 180 & $65.82335 e-02-2931-24$ & \$ absorvedor (AgInCd) \\
\hline 190 & $29-2 \quad 31-24 \quad u=5$ & \$ gap \\
\hline 200 & $138.65451 \mathrm{e}-02 \quad 2 \quad-3 \quad 31-24 \quad u=5$ & $\$$ clad \\
\hline 10 & $41.00104 \mathrm{e}-013-18-24$ & \$ agua (interna) \\
\hline
\end{tabular}




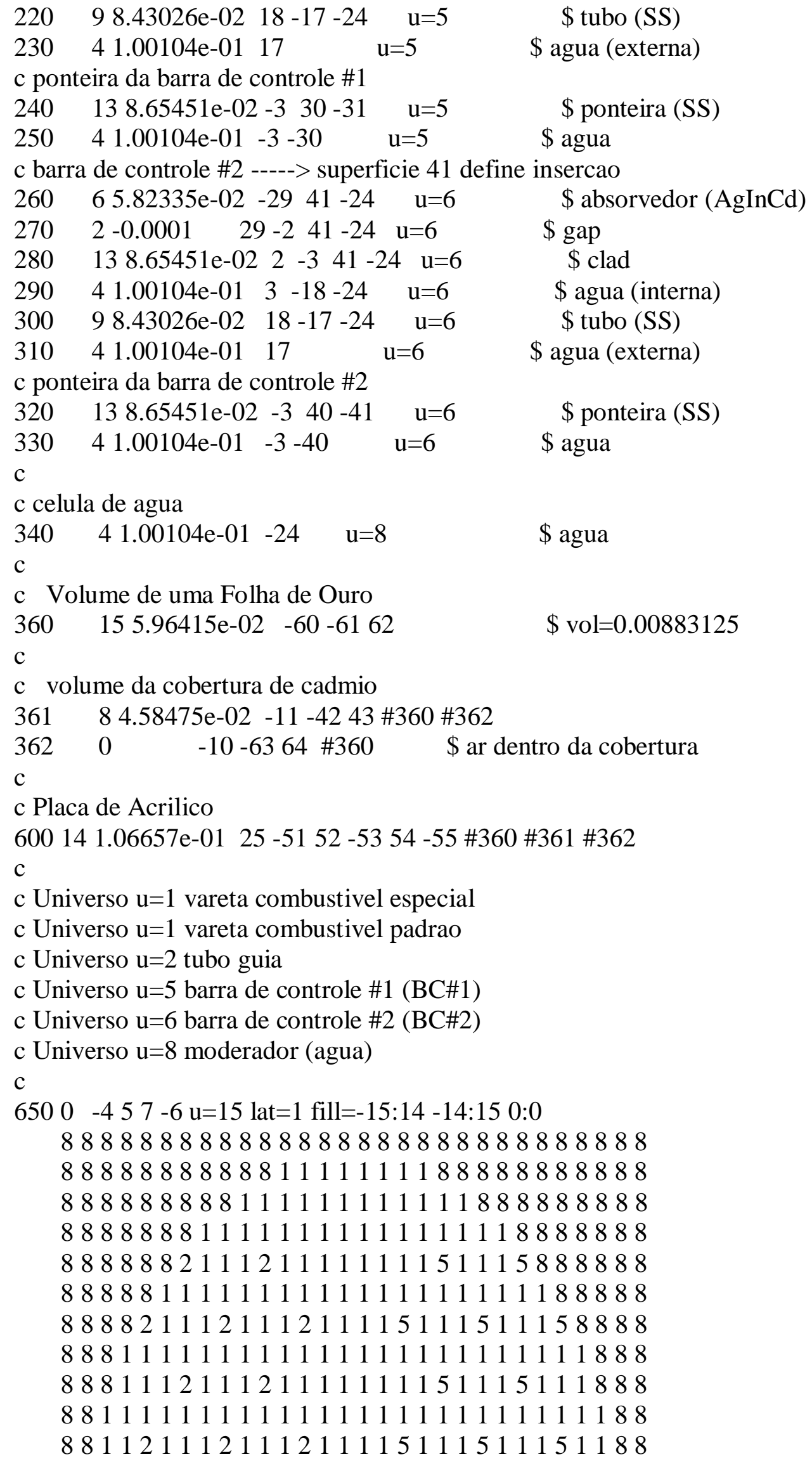




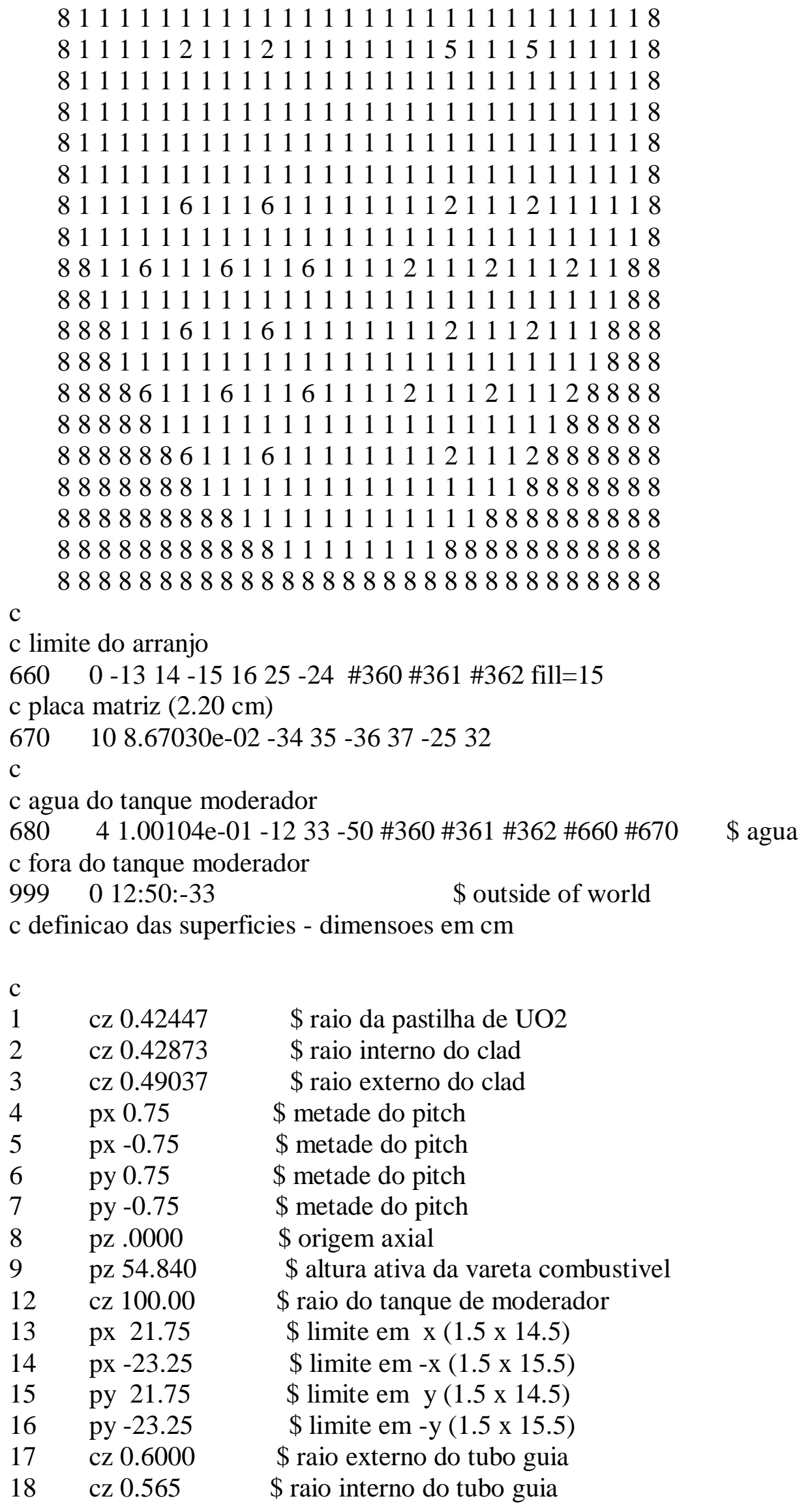




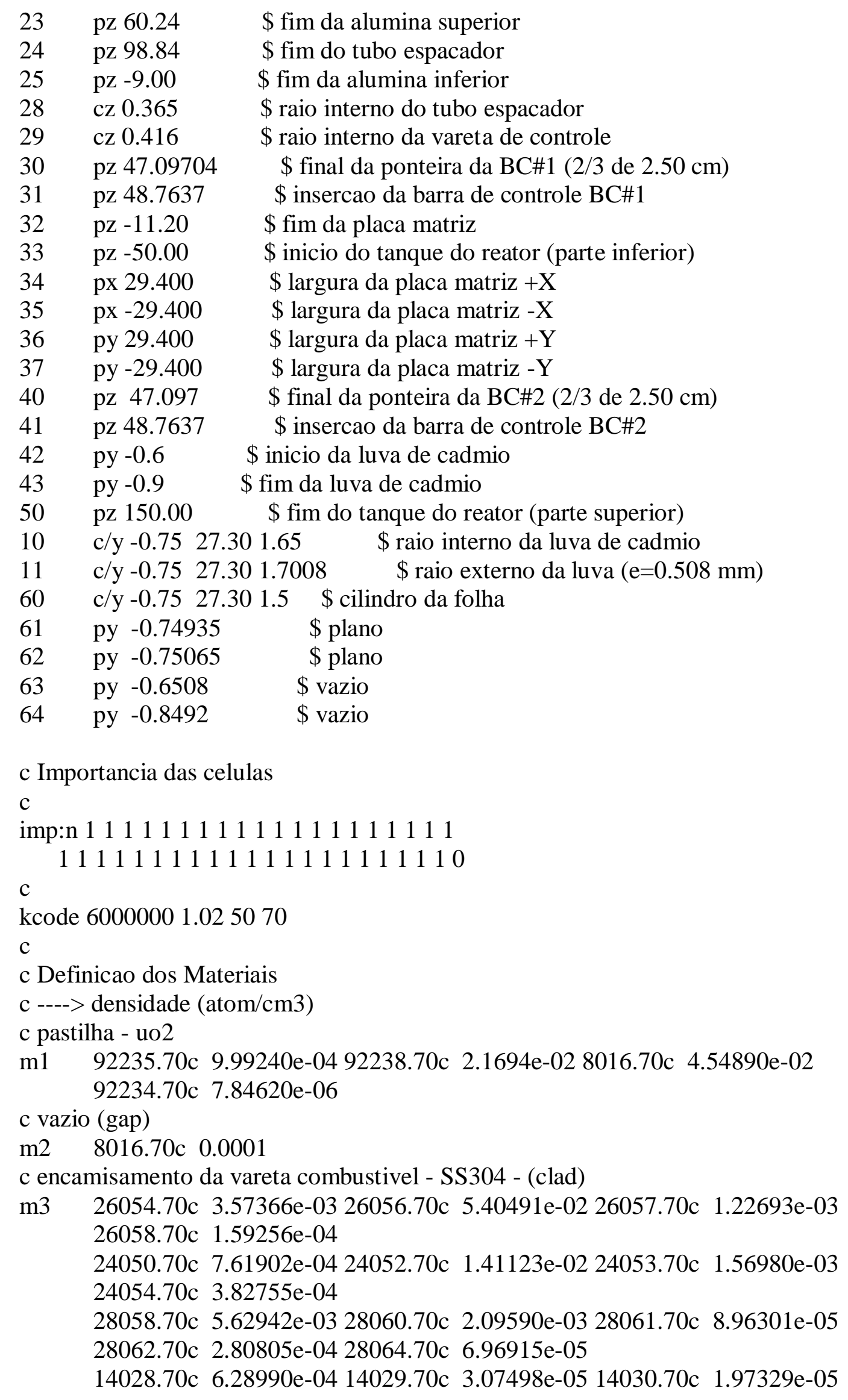


$16032.70 \mathrm{c} \quad 1.48849 \mathrm{e}-05$ 16033.70c $1.13926 \mathrm{e}-07$ 16034.70c $6.20747 \mathrm{e}-07$ $16036.70 \mathrm{c} 2.78500 \mathrm{e}-09$

42092.70c $1.30932 \mathrm{e}-05$ 42094.70c $7.98754 \mathrm{e}-06$ 42095.70c $1.36022 \mathrm{e}-05$ 42096.70c $1.41032 \mathrm{e}-05$ 42097.70c $7.99122 \mathrm{e}-06$ 42098.70c $1.99853 \mathrm{e}-05$ 42100.70c 7.81608e-06

25055.70c $1.46450 \mathrm{e}-03$ 15031.70c $4.00400 \mathrm{e}-05$ 6000.70c $1.12390 \mathrm{e}-04$

27059.70c $1.74020 \mathrm{e}-04$

c agua

m4 1001.70c 6.67160e-02 8016.70c 3.33580e-02

$\mathrm{mt} 4$ lwtr.01t

c alumina - al2o3

m5 8016.70c 6.71160e-02 13027.70c 4.47440e-02

c barra de controle - AG-IN-CD

m6 47107.70c 2.31847e-02 47109.70c 2.11443e-02

49113.70c 3.42556e-03 49115.70c 7.50941e-03

48106.70c 3.43547e-05 48108.70c $2.40077 \mathrm{e}-05$ 48110.70c 3.30790e-04

48111.70c 3.35939e-04 48112.70c $6.27647 \mathrm{e}-04$ 48113.70c $3.15035 \mathrm{e}-04$

48114.70c 7.34172e-04 48116.70c $1.88096 \mathrm{e}-04$

16032.70 c $1.79100 \mathrm{e}-0416033.70 \mathrm{c} 1.37080 \mathrm{e}-06$ 16034.70c $7.46906 \mathrm{e}-06$ $16036.70 \mathrm{c} 3.35102 \mathrm{e}-08$

6000.70c $1.50520 \mathrm{e}-03$ 8016.70c $1.77030 \mathrm{e}-03$

c tubo espacador - SS

m7 26054.70c 3.74872e-03 26056.70c $5.66967 \mathrm{e}-02$ 26057.70c $1.28703 \mathrm{e}-03$

26058.70 c $1.67057 \mathrm{e}-04$

24050.70c 7.59839e-04 24052.70c $1.40741 \mathrm{e}-02$ 24053.70c $1.56555 \mathrm{e}-03$

$24054.70 \mathrm{c} 3.81719 \mathrm{e}-04$

28058.70 c $4.53128 \mathrm{e}-0328060.70 \mathrm{c} 1.68705 \mathrm{e}-03$ 28061.70c $7.21458 \mathrm{e}-05$

$28062.70 \mathrm{c} 2.26028 \mathrm{e}-0428064.70 \mathrm{c} 5.60967 \mathrm{e}-05$

25055.70c $1.15810 \mathrm{e}-03$

14028.70c 1.03286e-03 14029.70c 5.04940e-05 14030.70c 3.24033e-05

15031.70c 3.11240e-05 6000.70c 2.40780e-04 27059.70c $1.14500 \mathrm{e}-04$

c luva de cadmio

$\mathrm{m} 8 \quad 48106.70 \mathrm{c} \quad 6.08286 \mathrm{e}-04$ 48108.70c $4.25082 \mathrm{e}-04$ 48110.70c $5.85698 \mathrm{e}-03$

48111.70 c $5.94816 \mathrm{e}-03$ 48112.70c $1.11131 \mathrm{e}-02$ 48113.70c $5.57803 \mathrm{e}-03$

48114.70c $1.29993 \mathrm{e}-02$ 48116.70c $3.33044 \mathrm{e}-03$

c tubo guia - SS

m9 26054.70c 3.44894e-03 26056.70c 5.21628e-02 26057.70c $1.18411 \mathrm{e}-03$

$26058.70 \mathrm{c} 1.53698 \mathrm{e}-04$

24050.70c 7.38069e-04 24052.70c $1.36708 \mathrm{e}-02$ 24053.70c $1.52070 \mathrm{e}-03$

24054.70c 3.70782e-04

28058.70c $6.27853 \mathrm{e}-03$ 28060.70c $2.33757 \mathrm{e}-03$ 28061.70c 9.99650e-05

28062.70c 3.13183e-04 28064.70c 7.77273e-05

25055.70c $1.15010 \mathrm{e}-03$

14028.70c $6.12655 \mathrm{e}-04$ 14029.70c $2.99512 \mathrm{e}-05$ 14030.70c $1.92205 \mathrm{e}-05$

15031.70 c $4.50000 \mathrm{e}-056000.70 \mathrm{c} 8.89680 \mathrm{e}-05$

c placa matriz - SS

m10 26054.70c 3.63630e-03 26056.70c 5.49964e-02 26057.70c $1.24843 \mathrm{e}-03$ 26058.70c $1.62047 \mathrm{e}-04$ 
24050.70c $7.56501 \mathrm{e}-0424052.70 \mathrm{c} \quad 1.40122 \mathrm{e}-0224053.70 \mathrm{c} \quad 1.55868 \mathrm{e}-03$ 24054.70c 3.80042e-04

28058.70c 5.28566e-03 28060.70c $1.96791 \mathrm{e}-03$ 28061.70c $8.41568 \mathrm{e}-05$ $28062.70 \mathrm{c} 2.63658 \mathrm{e}-0428064.70 \mathrm{c} 6.54358 \mathrm{e}-05$

14028.70 c $8.01962 \mathrm{e}-0414029.70$ c $3.92060 \mathrm{e}-05$ 14030.70c $2.51595 \mathrm{e}-05$ $16032.70 \mathrm{c} \quad 4.25282 \mathrm{e}-06$ 16033.70c $3.25504 \mathrm{e}-08$ 16034.70c $1.77356 \mathrm{e}-07$ $16036.70 \mathrm{c} 7.95715 \mathrm{e}-10$

42092.70c $4.62114 \mathrm{e}-06$ 42094.70c $2.81913 \mathrm{e}-06$ 42095.70c $4.80079 \mathrm{e}-06$ 42096.70c $4.97759 \mathrm{e}-06$ 42097.70c $2.82043 \mathrm{e}-06$ 42098.70c $7.05364 \mathrm{e}-06$ $42100.70 \mathrm{c} 2.75861 \mathrm{e}-06$

25055.70c 1.25030e-03 15031.70c 5.54400e-05 6000.70c 7.94260e-05

c encamisamento das barras de controle e de seguranca - SS304

m13 26054.70c 3.50278e-03 26056.70c 5.29770e-02 26057.70c $1.20259 \mathrm{e}-03$ 26058.70c $1.56097 \mathrm{e}-04$

$24050.70 \mathrm{c} \quad 7.62733 \mathrm{e}-0424052.70 \mathrm{c} \quad 1.41277 \mathrm{e}-0224053.70 \mathrm{c} \quad 1.57152 \mathrm{e}-03$

$24054.70 \mathrm{c} 3.83172 \mathrm{e}-04$

28058.70c $6.54682 \mathrm{e}-03$ 28060.70c $2.43746 \mathrm{e}-03$ 28061.70c $1.04236 \mathrm{e}-04$

$28062.70 \mathrm{c} 3.26566 \mathrm{e}-0428064.70 \mathrm{c} 8.10488 \mathrm{e}-05$

14028.70 c $7.07614 \mathrm{e}-0414029.70 \mathrm{c} 3.45935 \mathrm{e}-05$ 14030.70c $2.21996 \mathrm{e}-05$

$16032.70 \mathrm{c} 4.25282 \mathrm{e}-06$ 16033.70c $3.25504 \mathrm{e}-08$ 16034.70c $1.77356 \mathrm{e}-07$

$16036.70 \mathrm{c} 7.95715 \mathrm{e}-10$

42092.70c $2.31057 \mathrm{e}-06$ 42094.70c $1.40957 \mathrm{e}-06$ 42095.70c $2.40040 \mathrm{e}-06$ 42096.70c $2.48879 \mathrm{e}-0642097.70 \mathrm{c} \quad 1.41022 \mathrm{e}-06$ 42098.70c $3.52682 \mathrm{e}-06$ $42100.70 \mathrm{c} 1.37931 \mathrm{e}-06$

29063.70c 9.43728e-05 29065.70c $4.07687 \mathrm{e}-05$

50112.70c $3.30769 \mathrm{e}-08$ 50114.70c $2.17761 \mathrm{e}-08$ 50115.70c $1.12914 \mathrm{e}-08$

50116.70c 4.78714e-07 50117.70c 2.50690e-07 50118.70c 7.83891e-07

50119.70c $2.75677 \mathrm{e}-07$ 50120.70c $1.03719 \mathrm{e}-06$ 50122.70c $1.44933 \mathrm{e}-07$ 50124.70c $1.78316 \mathrm{e}-07$

15031.70c $4.15796 \mathrm{e}-05$ 6000.70c $8.33972 \mathrm{e}-05$ 27059.70c $1.37594 \mathrm{e}-04$

25055.70c $1.18080 \mathrm{e}-03$

c placa de acrilico

m14 1001.70c 5.5063e-02 8016.70c $1.4369 \mathrm{e}-02$ 6000.70c $3.4916 \mathrm{e}-02$

7014.70c 3.0208E-05

mt14 poly.60t

c ouro e aluminio

m15 79197.70c 5.96415e-02

c definicao de tally

f4:n $\quad 360$

fm4:n (1 15 102)

e4 $0.55 \mathrm{e}-0620$

c

prdmp $10001000-1 \mathrm{j}$

print 
Folha de ouro infinitamente diluida nua

c Reator IPEN/MB-01 - Enriquecimento $4.3 \%$ U-235

c arranjo cilindrico 28 varetas de diametro

$\mathrm{c}$

c vareta combustivel padrao (material densidade e geometria)

c parte inferior - alumina ----> -9.00 a $0.00 \mathrm{~cm}$

\begin{tabular}{|c|c|c|c|}
\hline & 5 1.11860e-01-1-8 & $\mathrm{u}=1$ & $\$$ alumina \\
\hline & $2-0.0001$ & $\mathrm{u}=1$ & \$ gap \\
\hline & $38.65716 \mathrm{e}-02 \quad 2-3-8$ & $\mathrm{u}=1$ & $\$$ clad $(\mathrm{SS})$ \\
\hline \multicolumn{4}{|c|}{ c parte ativa - UO2 ----------> 0.0 a $54.84 \mathrm{~cm}$} \\
\hline & $16.81901 \mathrm{e}-02-1 \quad 8-9$ & $\mathrm{u}=1$ & \$ uo2 (p \\
\hline & $2-0.0001$ & $\mathrm{u}=1$ & \$ gap \\
\hline & $38.65716 \mathrm{e}-02 \quad 2-38$ & $\mathrm{u}=1$ & $\$$ clad $(\mathrm{SS})$ \\
\hline
\end{tabular}

c parte superior - alumina ----> 54.84 a $60.24 \mathrm{~cm}$

$70 \quad 5$ 1.11860e-01 $-1 \quad 9-23 \quad \mathrm{u}=1 \quad$ S alumina

$80 \quad 2-0.0001 \quad 1-2 \quad 9-23 \quad u=1 \quad$ \$ gap

$9038.65716 \mathrm{e}-02 \quad 2-3 \quad 9-23 \quad \mathrm{u}=1 \quad$ \$ clad (SS)

c parte superior - tubo espacador ---> 60.24 a $98.84 \mathrm{~cm}$

$\begin{array}{llllllll}100 & 0 & -28 & 23 & -24 \mathrm{u}=1 & & \text { \$ vazio (interno) } \\ 110 & 7 & 8.79133 \mathrm{e}-02 & 28 & -1 & 23 & -24 \quad \mathrm{u}=1 & \text { \$ tubo (SS) } \\ 120 & 3 & 8.65716 \mathrm{e}-02 & 2 & -3 & 23 & -24 \quad \mathrm{u}=1 & \text { \$ clad (SS) } \\ 130 & 2 & -0.0001 & 1 & -2 & 23 & -24 \quad \mathrm{u}=1 & \text { \$ gap }\end{array}$

c moderator

$140 \quad 41.00104 \mathrm{e}-013 \quad \mathrm{u}=1 \quad$ \$ agua

c tubo guia (material densidade e geometria)

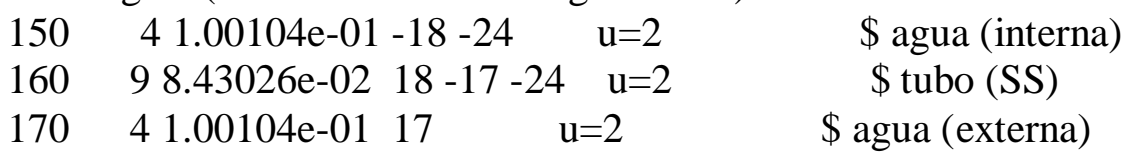

c barra de controle \#1 -----> superficie 31 define insercao

\begin{tabular}{|c|c|c|}
\hline 180 & $65.82335 e-02-2931-24$ & \$ absorvedor (AgInCd) \\
\hline 190 & $29-2 \quad 31-24 \quad u=5$ & \$ gap \\
\hline 0 & $138.65451 \mathrm{e}-022 \quad-3 \quad 31-24 \quad u=5$ & $\$$ clad \\
\hline 10 & $4 \begin{array}{llll}1.00104 e-01 & 3 & -18-24 \quad u=5\end{array}$ & \$ agua (interna) \\
\hline 20 & $98.43026 \mathrm{e}-02 \quad 18-17-24$ & $\$$ tubo $(\mathrm{SS})$ \\
\hline 30 & $41.00104 \mathrm{e}-0117$ & $\$$ agua (externa) \\
\hline \multicolumn{3}{|c|}{ c ponteira da barra de controle \#1 } \\
\hline 40 & $138.65451 \mathrm{e}-02-3 \quad 30-31$ & \$ ponteira (SS) \\
\hline & $41.00104 \mathrm{e}-01-3-30$ & $\$$ agua \\
\hline \multicolumn{3}{|c|}{ c barra de controle \#2 -----> superficie 41 define insercao } \\
\hline 260 & $65.82335 \mathrm{e}-02-29 \quad 41-24$ & \$ absorvedor (AgInCd) \\
\hline 70 & $29-2 \quad 41-24 \quad u=6$ & \$ gap \\
\hline 30 & $138.65451 \mathrm{e}-02 \quad 2 \quad-3 \quad 41-24 \quad \mathrm{u}=6$ & $\$$ clad \\
\hline 0 & $41.00104 \mathrm{e}-01 \quad 3-18-24$ & \$ agua (interna) \\
\hline 300 & $98.43026 \mathrm{e}-02 \quad 18-17-24$ & $\$$ tubo (SS) \\
\hline 310 & $41.00104 \mathrm{e}-01 \quad 17$ & $\$$ agua (externa) \\
\hline \multicolumn{3}{|c|}{ c ponteira da barra de controle \#2 } \\
\hline & $138.65451 e-02 \quad-3 \quad 40-41$ & \$ ponteira (SS) \\
\hline & $41.00104 \mathrm{e}-01 \quad-3-40$ & $\$$ agua \\
\hline
\end{tabular}


c

c celula de agua

$340 \quad 41.00104 \mathrm{e}-01-24 \quad \mathrm{u}=8 \quad$ \$ agua

c

c Volume de uma Folha de Ouro(agua)

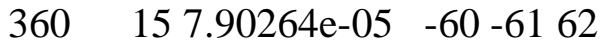

c

c Placa de Acrilico

$600 \quad 141.06657 \mathrm{e}-0125-5152-5354-55$ \#360

$\mathrm{c}$

c Universo $\mathrm{u}=1$ vareta combustivel especial

c Universo $\mathrm{u}=1$ vareta combustivel padrao

c Universo $\mathrm{u}=2$ tubo guia

c Universo $\mathrm{u}=5$ barra de controle \#1 (BC\#1)

c Universo $\mathrm{u}=6$ barra de controle \#2 (BC\#2)

c Universo $\mathrm{u}=8$ moderador (agua)

c

$6500-457-6 u=15$ lat=1 fill=-15:14 -14:15 0:0

888888888888888888888888888888 888888888881111111188888888888 888888888111111111111888888888 888888811111111111111118888888 888888211121111111151115888888 888881111111111111111111188888 888821112111211115111511158888 888111111111111111111111111888 888111211121111111151115111888 8811111111111111111111111111188 881121112111211115111511151188 811111111111111111111111111111118 811111211121111111151115111118 8111111111111111111111111111118 811111111111111111111111111118 811111111111111111111111111118 811111111111111111111111111111118 811111611161111111121112111118 81111111111111111111111111111118 881161116111611112111211121188 8811111111111111111111111111188 888111611161111111121112111888 8881111111111111111111111111888 888861116111611112111211128888 8888811111111111111111111188888 888888611161111111121112888888 888888811111111111111118888888 888888888111111111111888888888 888888888881111111188888888888 888888888888888888888888888888 
c

c limite do arranjo

$660 \quad 0-13 \quad 14-151625-24 \quad \# 360$ fill=15

c placa matriz $(2.20 \mathrm{~cm})$

$670 \quad 108.67030 \mathrm{e}-02-3435-3637-2532$

c

c agua do tanque moderador

$68041.00104 \mathrm{e}-01-1233-50 \# 360$ \#660 \#670 \$ agua

c fora do tanque moderador

$999 \quad 0$ 12:50:-33 \$ outside of world

\begin{tabular}{|c|c|c|}
\hline 1 & cz 0.42447 & \$ raio da pastilha de UO2 \\
\hline 2 & cz 0.42873 & $\$$ raio interno do clad \\
\hline 3 & cz 0.49037 & $\$$ raio externo do clad \\
\hline 4 & px 0.75 & $\$$ metade do pitch \\
\hline 5 & $\mathrm{px}-0.75$ & $\$$ metade do pitch \\
\hline 6 & py 0.75 & $\$$ metade do pitch \\
\hline 7 & py -0.75 & $\$$ metade do pitch \\
\hline 8 & pz .0000 & $\$$ origem axial \\
\hline 9 & pz 54.840 & $\$$ altura ativa da vareta combustivel \\
\hline 12 & cz 100.00 & $\$$ raio do tanque de moderador \\
\hline 13 & px 21.75 & $\$$ limite em $x(1.5 \times 14.5)$ \\
\hline 14 & $\mathrm{px}-23.25$ & $\$$ limite em -x (1.5 x 15.5) \\
\hline 15 & py 21.75 & $\$$ limite em y $(1.5 \times 14.5)$ \\
\hline 16 & py -23.25 & $\$$ limite em -y (1.5 x 15.5) \\
\hline 17 & cz 0.6000 & $\$$ raio externo do tubo guia \\
\hline 18 & $\mathrm{cz} 0.565$ & $\$$ raio interno do tubo guia \\
\hline 23 & pz 60.24 & $\$$ fim da alumina superior \\
\hline 24 & pz 98.84 & $\$$ fim do tubo espacador \\
\hline 25 & pz -9.00 & $\$$ fim da alumina inferior \\
\hline 28 & $\mathrm{cz} 0.365$ & $\$$ raio interno do tubo espacador \\
\hline 29 & $\mathrm{cz} 0.416$ & $\$$ raio interno da vareta de controle \\
\hline 30 & pz 47.09704 & $\$$ final da ponteira da $\mathrm{BC} \# 1(2 / 3$ de $2.50 \mathrm{~cm})$ \\
\hline 31 & pz 48.7637 & \$ insercao da barra de controle BC\#1 \\
\hline 32 & $\mathrm{pz}-11.20$ & $\$$ fim da placa matriz \\
\hline 33 & $\mathrm{pz}-50.00$ & $\$$ inicio do tanque do reator (parte inferior) \\
\hline 34 & px 29.400 & $\$$ largura da placa matriz $+X$ \\
\hline 35 & px -29.400 & $\$$ largura da placa matriz $-X$ \\
\hline 36 & py 29.400 & $\$$ largura da placa matriz $+Y$ \\
\hline 37 & py -29.400 & $\$$ largura da placa matriz $-\mathrm{Y}$ \\
\hline 40 & pz 47.097 & $\$$ final da ponteira da $\mathrm{BC} \# 2(2 / 3$ de $2.50 \mathrm{~cm})$ \\
\hline 41 & pz 48.7637 & \$ insercao da barra de controle BC\#2 \\
\hline 50 & pz 150.00 & $\$$ fim do tanque do reator (parte superior) \\
\hline 60 & c/y -0.7527 & $1.5 \$$ cilindro da folha \\
\hline 61 & py -0.74 & $\$$ plano \\
\hline 62 & py -0.76 & $\$$ plano \\
\hline
\end{tabular}

c Importancia das celulas 
c

imp:n 11111111111111111111

11111111111111111110

$\mathrm{c}$

kcode 60000001.025070

c

c Definicao dos Materiais

c ----> densidade (atom/barn.cm)

c pastilha - uo2

m1 92235.70c 9.99240e-04 92238.70c 2.1694e-02 8016.70c $4.54890 \mathrm{e}-02$ 92234.70c 7.84620e-06

c vazio (gap)

$\mathrm{m} 2 \quad 8016.70 \mathrm{c} \quad 0.0001$

c encamisamento da vareta combustivel - SS304 - (clad)

m3 26054.70c 3.57366e-03 26056.70c 5.40491e-02 26057.70c $1.22693 \mathrm{e}-03$ 26058.70 c $1.59256 \mathrm{e}-04$

24050.70c 7.61902e-04 24052.70c $1.41123 \mathrm{e}-02$ 24053.70c $1.56980 \mathrm{e}-03$ 24054.70 c $3.82755 \mathrm{e}-04$

28058.70c 5.62942e-03 28060.70c 2.09590e-03 28061.70c 8.96301e-05 $28062.70 \mathrm{c} 2.80805 \mathrm{e}-0428064.70 \mathrm{c} 6.96915 \mathrm{e}-05$

14028.70 c $6.28990 \mathrm{e}-0414029.70 \mathrm{c} \quad 3.07498 \mathrm{e}-05$ 14030.70c $1.97329 \mathrm{e}-05$ $16032.70 \mathrm{c} 1.48849 \mathrm{e}-05$ 16033.70c $1.13926 \mathrm{e}-07$ 16034.70c $6.20747 \mathrm{e}-07$ $16036.70 \mathrm{c} 2.78500 \mathrm{e}-09$

42092.70c 1.30932e-05 42094.70c 7.98754e-06 42095.70c $1.36022 \mathrm{e}-05$

42096.70c $1.41032 \mathrm{e}-05$ 42097.70c $7.99122 \mathrm{e}-06$ 42098.70c $1.99853 \mathrm{e}-05$ $42100.70 \mathrm{c} 7.81608 \mathrm{e}-06$

25055.70c 1.46450e-03 15031.70c 4.00400e-05 6000.70c 1.12390e-04

27059.70c $1.74020 \mathrm{e}-04$

c agua

$\mathrm{m} 4 \quad 1001.70 \mathrm{c} \quad 6.67160 \mathrm{e}-02$ 8016.70c $3.33580 \mathrm{e}-02$

mt4 lwtr.01t

c alumina - al2o3

m5 8016.70c 6.71160e-02 13027.70c 4.47440e-02

c barra de controle - AG-IN-CD

m6 47107.70c $2.31847 \mathrm{e}-02$ 47109.70c $2.11443 \mathrm{e}-02$

49113.70c 3.42556e-03 49115.70c 7.50941e-03

48106.70c $3.43547 \mathrm{e}-05$ 48108.70c $2.40077 \mathrm{e}-05$ 48110.70c $3.30790 \mathrm{e}-04$

48111.70c 3.35939e-04 48112.70c $6.27647 \mathrm{e}-04$ 48113.70c $3.15035 \mathrm{e}-04$

48114.70c 7.34172e-04 48116.70c 1.88096e-04

16032.70 c $1.79100 \mathrm{e}-0416033.70$ c $1.37080 \mathrm{e}-06$ 16034.70c $7.46906 \mathrm{e}-06$

$16036.70 \mathrm{c} 3.35102 \mathrm{e}-08$

6000.70c 1.50520e-03 8016.70c 1.77030e-03

c tubo espacador - SS

m7 26054.70c $3.74872 \mathrm{e}-03$ 26056.70c $5.66967 \mathrm{e}-02$ 26057.70c $1.28703 \mathrm{e}-03$ $26058.70 \mathrm{c} 1.67057 \mathrm{e}-04$

24050.70 c $7.59839 \mathrm{e}-0424052.70 \mathrm{c} \quad 1.40741 \mathrm{e}-02$ 24053.70c $1.56555 \mathrm{e}-03$ $24054.70 \mathrm{c} 3.81719 \mathrm{e}-04$

28058.70c $4.53128 \mathrm{e}-0328060.70 \mathrm{c} \quad 1.68705 \mathrm{e}-0328061.70 \mathrm{c} \quad 7.21458 \mathrm{e}-05$ 
28062.70c 2.26028e-04 28064.70c 5.60967e-05

25055.70c $1.15810 \mathrm{e}-03$

14028.70 c $1.03286 \mathrm{e}-03$ 14029.70c $5.04940 \mathrm{e}-05$ 14030.70c $3.24033 \mathrm{e}-05$

15031.70 c 3.11240e-05 6000.70c 2.40780e-04 27059.70c $1.14500 \mathrm{e}-04$

c tubo guia - SS

m9 26054.70c 3.44894e-03 26056.70c 5.21628e-02 26057.70c $1.18411 \mathrm{e}-03$

26058.70c $1.53698 \mathrm{e}-04$

24050.70c 7.38069e-04 24052.70c $1.36708 \mathrm{e}-02$ 24053.70c $1.52070 \mathrm{e}-03$

24054.70c 3.70782e-04

28058.70c $6.27853 \mathrm{e}-03$ 28060.70c $2.33757 \mathrm{e}-03$ 28061.70c $9.99650 \mathrm{e}-05$

28062.70 c 3.13183e-04 28064.70c 7.77273e-05

25055.70c $1.15010 \mathrm{e}-03$

$14028.70 \mathrm{c} \quad 6.12655 \mathrm{e}-0414029.70 \mathrm{c} 2.99512 \mathrm{e}-05$ 14030.70c $1.92205 \mathrm{e}-05$

$15031.70 \mathrm{c} 4.50000 \mathrm{e}-056000.70 \mathrm{c} 8.89680 \mathrm{e}-05$

c placa matriz - SS

m10 26054.70c 3.63630e-03 26056.70c 5.49964e-02 26057.70c $1.24843 \mathrm{e}-03$

$26058.70 \mathrm{c} 1.62047 \mathrm{e}-04$

24050.70c 7.56501e-04 24052.70c $1.40122 \mathrm{e}-02$ 24053.70c $1.55868 \mathrm{e}-03$

$24054.70 \mathrm{c} 3.80042 \mathrm{e}-04$

28058.70c 5.28566e-03 28060.70c 1.96791e-03 28061.70c 8.41568e-05

28062.70c 2.63658e-04 28064.70c 6.54358e-05

14028.70 c 8.01962e-04 14029.70c 3.92060e-05 14030.70c $2.51595 \mathrm{e}-05$

$16032.70 \mathrm{c} 4.25282 \mathrm{e}-0616033.70 \mathrm{c} 3.25504 \mathrm{e}-08$ 16034.70c $1.77356 \mathrm{e}-07$

$16036.70 \mathrm{c} 7.95715 \mathrm{e}-10$

42092.70c 4.62114e-06 42094.70c 2.81913e-06 42095.70c $4.80079 \mathrm{e}-06$

42096.70c $4.97759 \mathrm{e}-0642097.70$ c $2.82043 \mathrm{e}-06$ 42098.70c $7.05364 \mathrm{e}-06$

42100.70c 2.75861e-06

25055.70c 1.25030e-03 15031.70c 5.54400e-05 6000.70c 7.94260e-05

c encamisamento das barras de controle e de seguranca - SS304

m13 26054.70c 3.50278e-03 26056.70c 5.29770e-02 26057.70c $1.20259 \mathrm{e}-03$

$26058.70 \mathrm{c} 1.56097 \mathrm{e}-04$

24050.70c $7.62733 \mathrm{e}-0424052.70 \mathrm{c} \quad 1.41277 \mathrm{e}-02$ 24053.70c $1.57152 \mathrm{e}-03$

24054.70c 3.83172e-04

28058.70c 6.54682e-03 28060.70c 2.43746e-03 28061.70c $1.04236 \mathrm{e}-04$

28062.70c 3.26566e-04 28064.70c 8.10488e-05

14028.70c 7.07614e-04 14029.70c 3.45935e-05 14030.70c $2.21996 \mathrm{e}-05$

$16032.70 \mathrm{c} 4.25282 \mathrm{e}-0616033.70 \mathrm{c} 3.25504 \mathrm{e}-08$ 16034.70c $1.77356 \mathrm{e}-07$ 16036.70 c $7.95715 \mathrm{e}-10$

42092.70c 2.31057e-06 42094.70c $1.40957 \mathrm{e}-06$ 42095.70c $2.40040 \mathrm{e}-06$ 42096.70c 2.48879e-06 42097.70c $1.41022 \mathrm{e}-06$ 42098.70c 3.52682e-06 42100.70c $1.37931 \mathrm{e}-06$

29063.70c 9.43728e-05 29065.70c 4.07687e-05

50112.70c 3.30769e-08 50114.70c $2.17761 \mathrm{e}-08$ 50115.70c $1.12914 \mathrm{e}-08$ 50116.70c $4.78714 \mathrm{e}-0750117.70 \mathrm{c} \quad 2.50690 \mathrm{e}-07$ 50118.70c $7.83891 \mathrm{e}-07$ 50119.70c $2.75677 \mathrm{e}-07$ 50120.70c $1.03719 \mathrm{e}-06$ 50122.70c $1.44933 \mathrm{e}-07$ $50124.70 \mathrm{c} 1.78316 \mathrm{e}-07$

15031.70 c $4.15796 \mathrm{e}-056000.70$ c $8.33972 \mathrm{e}-05$ 27059.70c $1.37594 \mathrm{e}-04$ 25055.70c $1.18080 \mathrm{e}-03$ 
c placa de acrilico

m14 1001.70c 5.5063e-02 8016.70c $1.4369 \mathrm{e}-02$ 6000.70c $3.4916 \mathrm{e}-02$

$7014.70 \mathrm{c} 3.0208 \mathrm{E}-05$

$\mathrm{mt} 14$ poly. $60 \mathrm{t}$

c ouro e aluminio

c

m15 79197.70c 7.90264e-05 13027.70c 5.95625e-02

$\mathrm{c}$

c definicao de tally

f4:n 360

fm4:n (1 15 102)

e4 $\quad 0.55 \mathrm{e}-0620$

prdmp $10001000-1 \mathrm{j}$

print

Folha de ouro infinitamente diluida com Luva de Cadmio $(0.508 \mathrm{~mm})$

c Reator IPEN/MB-01 - Enriquecimento $4.3 \%$ U-235

c arranjo cilindrico 28 varetas de diametro

$\mathrm{c}$

c vareta combustivel padrao (material densidade e geometria)

c parte inferior - alumina ----> -9.00 a $0.00 \mathrm{~cm}$

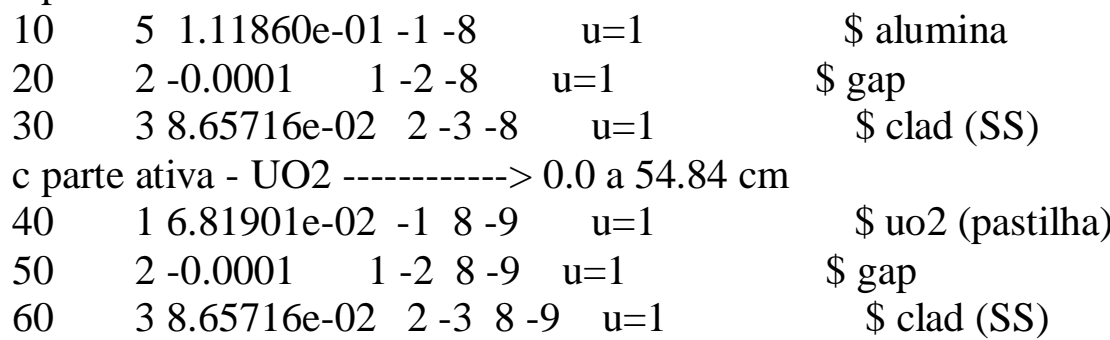

c parte superior - alumina ----> 54.84 a $60.24 \mathrm{~cm}$

\begin{tabular}{|c|c|c|}
\hline 0 & 5 1.11860e-01 -1 $9-23$ & $\$$ alumina \\
\hline 30 & $1-2 \quad 9-23 \quad u=1$ & \$ gap \\
\hline & 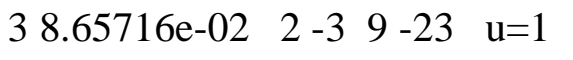 & $\$$ clad $(\mathrm{SS})$ \\
\hline \multicolumn{3}{|c|}{ c parte superior - tubo espacador ---> 60.24 a $98.84 \mathrm{~cm}$} \\
\hline & $0-2823-24 u=1$ & $\$$ vazio (interno) \\
\hline & $78.79133 \mathrm{e}-0228-1$ & $\$$ tubo $(\mathrm{SS})$ \\
\hline & $38.65716 \mathrm{e}-022-$ & $\$$ clad $(\mathrm{SS})$ \\
\hline & $1-2 \quad 23-24 \quad u=1$ & \$ gap \\
\hline
\end{tabular}

c moderator

$140 \quad 41.00104 \mathrm{e}-013 \quad \mathrm{u}=1 \quad$ \$ agua

c tubo guia (material densidade e geometria)
$150 \quad 41.00104 \mathrm{e}-01-18-24 \quad \mathrm{u}=2$
$16098.43026 \mathrm{e}-02 \quad 18-17-24 \quad \mathrm{u}=2$
\$ agua (interna)
$\$$ tubo $(\mathrm{SS})$
$170 \quad 41.00104 \mathrm{e}-01 \quad 17 \quad \mathrm{u}=2$
$\$$ agua (externa)

c barra de controle \#1 -----> superficie 31 define insercao

\begin{tabular}{|c|c|c|}
\hline 80 & $65.82335 e-02-2931-24$ & \$ absorvedor (AgInCd) \\
\hline 9 & $29-2 \quad 31-24 \quad u=5$ & \$ gap \\
\hline & $138.65451 \mathrm{e}-022-3 \quad 31-24 \quad u=5$ & $\$$ clad \\
\hline
\end{tabular}




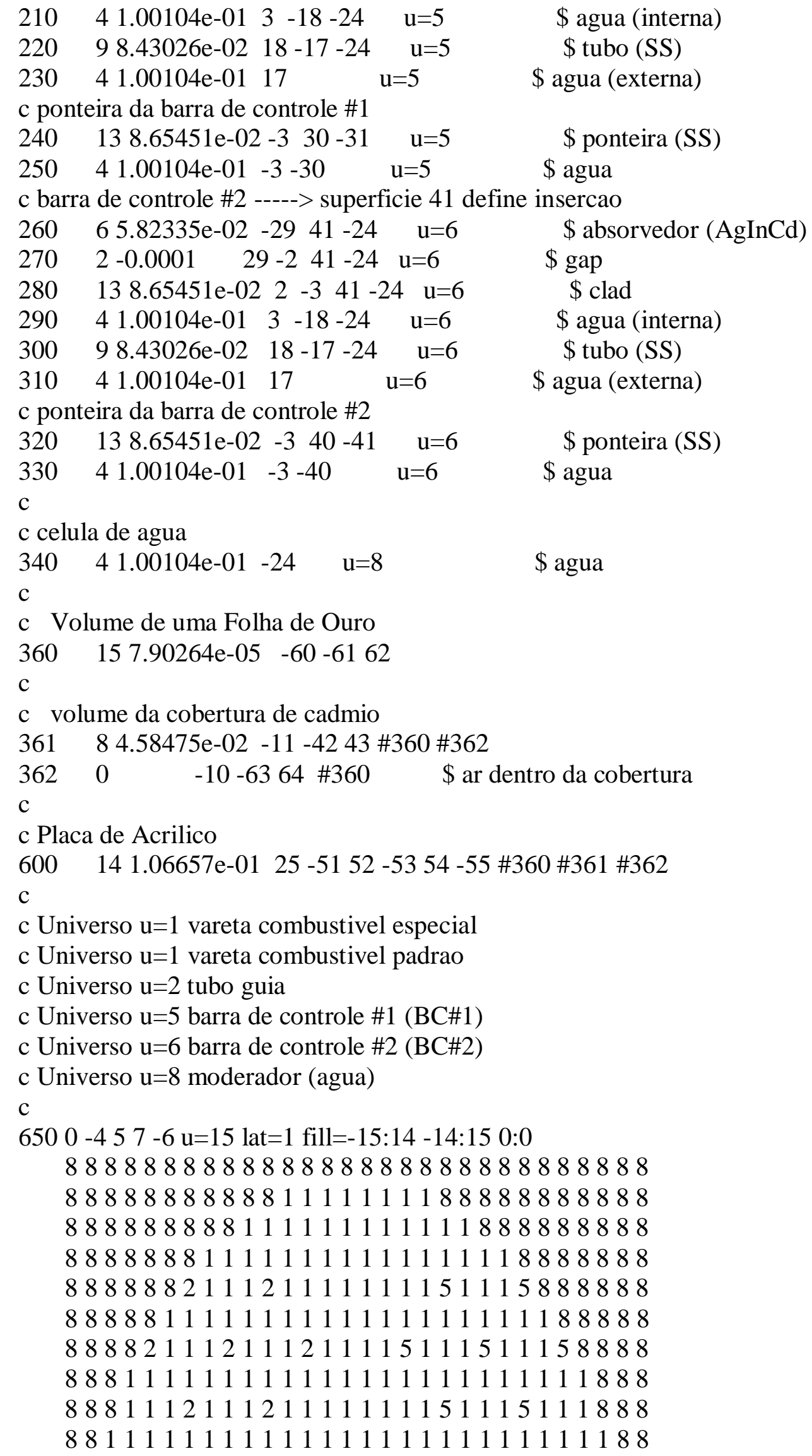


881121112111211115111511151188 811111111111111111111111111118 811111211121111111151115111118 811111111111111111111111111118 811111111111111111111111111118 811111111111111111111111111118 811111111111111111111111111118 811111611161111111121112111118 811111111111111111111111111118 881161116111611112111211121188 881111111111111111111111111188 888111611161111111121112111888 888111111111111111111111111888 888861116111611112111211128888 888881111111111111111111188888 888888611161111111121112888888 888888811111111111111118888888 888888888111111111111888888888 888888888881111111188888888888 888888888888888888888888888888 $\mathrm{c}$

c limite do arranjo

$660 \quad 0-1314-151625-24 \# 360$ \#361 \#362 fill=15

c placa matriz $(2.20 \mathrm{~cm})$

$670 \quad 108.67030 \mathrm{e}-02-3435-3637-2532$

$\mathrm{c}$

c agua do tanque moderador

6804 1.00104e-01 -12 33 -50 \#360 \#361 \#362 \#660 \#670 \$ agua c fora do tanque moderador 999 0 12:50:-33 \$ outside of world c definicao das superficies - dimensoes em $\mathrm{cm}$

$\begin{array}{lll}\text { c } & & \\ 1 & \text { cz } 0.42447 & \text { \$ raio da pastilha de UO2 } \\ 2 & \text { cz } 0.42873 & \text { \$ raio interno do clad } \\ 3 & \text { cz } 0.49037 & \text { \$ raio externo do clad } \\ 4 & \text { px } 0.75 & \text { \$ metade do pitch } \\ 5 & \text { px }-0.75 & \text { \$ metade do pitch } \\ 6 & \text { py } 0.75 & \text { \$ metade do pitch } \\ 7 & \text { py }-0.75 & \text { \$ metade do pitch } \\ 8 & \text { pz } .0000 & \text { \$ origem axial } \\ 9 & \text { pz } 54.840 & \text { \$ altura ativa da vareta combustivel } \\ 12 & \text { cz } 100.00 & \text { \$ raio do tanque de moderador } \\ 13 & \text { px } 21.75 & \text { \$ limite em x }(1.5 \times 14.5) \\ 14 & \text { px }-23.25 & \text { \$ limite em -x }(1.5 \times 15.5) \\ 15 & \text { py } 21.75 & \text { \$ limite em y }(1.5 \times 14.5) \\ 16 & \text { py }-23.25 & \text { \$ limite em -y }(1.5 \times 15.5) \\ 17 & \text { cz } 0.6000 & \text { \$ raio externo do tubo guia }\end{array}$




\begin{tabular}{|c|c|c|}
\hline 18 & cz 0.565 & interno do tubo guia \\
\hline 23 & pz 60.24 & da alumina superior \\
\hline 24 & pz 98.84 & do tubo espacador \\
\hline 25 & pz -9.00 & da alumina inferior \\
\hline 28 & cz 0.365 & interno do tubo espacador \\
\hline 29 & cz 0.416 & o interno da vareta de controle \\
\hline 30 & pz 47.09704 & inal da ponteira da BC\#1 $(2 / 3$ de $2.50 \mathrm{~cm})$ \\
\hline 31 & pz 48.7637 & sercao da barra de controle BC\#1 \\
\hline 32 & $\mathrm{pz}-11.20$ & a da placa matriz \\
\hline 33 & $\mathrm{pz}-50.00$ & cio do tanque do reator (parte inferior) \\
\hline 34 & px 29.400 & rgura da placa matriz $+X$ \\
\hline 35 & px -29.400 & rgura da placa matriz $-X$ \\
\hline 36 & py 29.400 & rgura da placa matriz $+Y$ \\
\hline 37 & py -29.400 & rgura da placa matriz $-Y$ \\
\hline 40 & pz 47.097 & hal da ponteira da $\mathrm{BC} \# 2(2 / 3$ de $2.50 \mathrm{~cm})$ \\
\hline 41 & pz 48.7637 & sercao da barra de controle $\mathrm{BC} \# 2$ \\
\hline 42 & $\$$ inicio & o da luva de cadmio \\
\hline 43 & $\$$ fim da & la luva de cadmio \\
\hline 50 & pz 150.00 & $\mathrm{n}$ do tanque do reator (parte superior) \\
\hline 10 & c/y -0.7527 .301 .65 & $\$$ raio interno da luva de cadmio \\
\hline 11 & c/y -0.7527 .301 .7008 & $\$$ raio externo da luva $(e=0.508 \mathrm{~mm})$ \\
\hline 60 & c/y -0.7527 .301 .5 & $\$$ cilindro da folha \\
\hline 61 & py -0.74 & ano \\
\hline 62 & py -0.76 & ano \\
\hline 63 & py -0.6508 & vazio \\
\hline 64 & py -0.8492 & vazio \\
\hline
\end{tabular}

c Importancia das celulas

c

imp:n 11111111111111111111

1111111111111111111110

$\mathrm{c}$

kcode 60000001.025070

$\mathrm{c}$

c Definicao dos Materiais

c ----> densidade (atom/barn.cm)

c pastilha - uo2

m1 92235.70c 9.99240e-04 92238.70c $2.1694 \mathrm{e}-02$ 8016.70c $4.54890 \mathrm{e}-02$ 92234.70c 7.84620e-06

c vazio (gap)

$\mathrm{m} 2 \quad 8016.70 \mathrm{c} \quad 0.0001$

c encamisamento da vareta combustivel - SS304 - (clad)

m3 26054.70c 3.57366e-03 26056.70c 5.40491e-02 26057.70c 1.22693e-03 26058.70c $1.59256 \mathrm{e}-04$

24050.70c 7.61902e-04 24052.70c $1.41123 \mathrm{e}-02$ 24053.70c $1.56980 \mathrm{e}-03$

$24054.70 \mathrm{c} 3.82755 \mathrm{e}-04$

28058.70c 5.62942e-03 28060.70c 2.09590e-03 28061.70c 8.96301e-05

28062.70 c 2.80805e-04 28064.70c 6.96915e-05 
14028.70c 6.28990e-04 14029.70c 3.07498e-05 14030.70c $1.97329 \mathrm{e}-05$ $16032.70 \mathrm{c} \quad 1.48849 \mathrm{e}-05$ 16033.70c $1.13926 \mathrm{e}-07$ 16034.70c $6.20747 \mathrm{e}-07$ $16036.70 \mathrm{c} 2.78500 \mathrm{e}-09$

42092.70c $1.30932 \mathrm{e}-05$ 42094.70c $7.98754 \mathrm{e}-06$ 42095.70c $1.36022 \mathrm{e}-05$ 42096.70c $1.41032 \mathrm{e}-0542097.70$ c $7.99122 \mathrm{e}-06$ 42098.70c $1.99853 \mathrm{e}-05$ 42100.70c 7.81608e-06

25055.70c $1.46450 \mathrm{e}-03$ 15031.70c $4.00400 \mathrm{e}-05$ 6000.70c $1.12390 \mathrm{e}-04$

27059.70c $1.74020 \mathrm{e}-04$

c agua

m4 1001.70c $6.67160 \mathrm{e}-02$ 8016.70c $3.33580 \mathrm{e}-02$

mt4 lwtr.01t

c alumina - al2o3

m5 8016.70c 6.71160e-02 13027.70c 4.47440e-02

c barra de controle - AG-IN-CD

m6 47107.70c 2.31847e-02 47109.70c 2.11443e-02

49113.70c 3.42556e-03 49115.70c 7.50941e-03

48106.70c 3.43547e-05 48108.70c 2.40077e-05 48110.70c $3.30790 \mathrm{e}-04$

48111.70c $3.35939 \mathrm{e}-04$ 48112.70c $6.27647 \mathrm{e}-04$ 48113.70c $3.15035 \mathrm{e}-04$

48114.70c 7.34172e-04 48116.70c $1.88096 \mathrm{e}-04$

$16032.70 \mathrm{c} 1.79100 \mathrm{e}-0416033.70 \mathrm{c} 1.37080 \mathrm{e}-06$ 16034.70c $7.46906 \mathrm{e}-06$

16036.70 c $3.35102 \mathrm{e}-08$

6000.70c $1.50520 \mathrm{e}-03$ 8016.70c $1.77030 \mathrm{e}-03$

c tubo espacador - SS

m7 26054.70c $3.74872 \mathrm{e}-03$ 26056.70c $5.66967 \mathrm{e}-02$ 26057.70c $1.28703 \mathrm{e}-03$

$26058.70 \mathrm{c} 1.67057 \mathrm{e}-04$

24050.70 c $7.59839 \mathrm{e}-0424052.70 \mathrm{c} \quad 1.40741 \mathrm{e}-02$ 24053.70c $1.56555 \mathrm{e}-03$

$24054.70 \mathrm{c} 3.81719 \mathrm{e}-04$

28058.70c $4.53128 \mathrm{e}-03$ 28060.70c $1.68705 \mathrm{e}-03$ 28061.70c $7.21458 \mathrm{e}-05$

28062.70c $2.26028 \mathrm{e}-0428064.70 \mathrm{c} 5.60967 \mathrm{e}-05$

$25055.70 \mathrm{c} 1.15810 \mathrm{e}-03$

14028.70 c $1.03286 \mathrm{e}-03$ 14029.70c $5.04940 \mathrm{e}-05$ 14030.70c $3.24033 \mathrm{e}-05$

15031.70c 3.11240e-05 6000.70c 2.40780e-04 27059.70c $1.14500 \mathrm{e}-04$

c luva de cadmio

$\mathrm{m} 8 \quad 48106.70 \mathrm{c} \quad 6.08286 \mathrm{e}-04$ 48108.70c $4.25082 \mathrm{e}-04$ 48110.70c $5.85698 \mathrm{e}-03$

48111.70c 5.94816e-03 48112.70c $1.11131 \mathrm{e}-02$ 48113.70c $5.57803 \mathrm{e}-03$

48114.70c $1.29993 \mathrm{e}-02$ 48116.70c 3.33044e-03

c tubo guia - SS

m9 26054.70c 3.44894e-03 26056.70c 5.21628e-02 26057.70c $1.18411 \mathrm{e}-03$

$26058.70 \mathrm{c} 1.53698 \mathrm{e}-04$

24050.70c 7.38069e-04 24052.70c $1.36708 \mathrm{e}-02$ 24053.70c $1.52070 \mathrm{e}-03$

24054.70 c $3.70782 \mathrm{e}-04$

28058.70c $6.27853 \mathrm{e}-03$ 28060.70c $2.33757 \mathrm{e}-03$ 28061.70c $9.99650 \mathrm{e}-05$

28062.70c 3.13183e-04 28064.70c 7.77273e-05

$25055.70 \mathrm{c} 1.15010 \mathrm{e}-03$

14028.70c $6.12655 \mathrm{e}-04$ 14029.70c $2.99512 \mathrm{e}-05$ 14030.70c $1.92205 \mathrm{e}-05$

15031.70 c $4.50000 \mathrm{e}-056000.70 \mathrm{c} 8.89680 \mathrm{e}-05$

c placa matriz - SS

m10 26054.70c 3.63630e-03 26056.70c 5.49964e-02 26057.70c $1.24843 \mathrm{e}-03$ 
26058.70c $1.62047 \mathrm{e}-04$

24050.70c $7.56501 \mathrm{e}-0424052.70 \mathrm{c} \quad 1.40122 \mathrm{e}-0224053.70 \mathrm{c} \quad 1.55868 \mathrm{e}-03$ $24054.70 \mathrm{c} 3.80042 \mathrm{e}-04$

28058.70c 5.28566e-03 28060.70c $1.96791 \mathrm{e}-03$ 28061.70c $8.41568 \mathrm{e}-05$

28062.70c 2.63658e-04 28064.70c 6.54358e-05

14028.70 c $8.01962 \mathrm{e}-0414029.70$ c $3.92060 \mathrm{e}-05$ 14030.70c $2.51595 \mathrm{e}-05$ $16032.70 \mathrm{c} 4.25282 \mathrm{e}-0616033.70 \mathrm{c} 3.25504 \mathrm{e}-08$ 16034.70c $1.77356 \mathrm{e}-07$ $16036.70 \mathrm{c} 7.95715 \mathrm{e}-10$

42092.70c $4.62114 \mathrm{e}-0642094.70$ c $2.81913 \mathrm{e}-06$ 42095.70c $4.80079 \mathrm{e}-06$ $42096.70 \mathrm{c} 4.97759 \mathrm{e}-0642097.70 \mathrm{c} \quad 2.82043 \mathrm{e}-06$ 42098.70c $7.05364 \mathrm{e}-06$ $42100.70 \mathrm{c} 2.75861 \mathrm{e}-06$

25055.70c 1.25030e-03 15031.70c 5.54400e-05 6000.70c 7.94260e-05

c encamisamento das barras de controle e de seguranca - SS304

m13 26054.70c 3.50278e-03 26056.70c 5.29770e-02 26057.70c $1.20259 \mathrm{e}-03$ $26058.70 \mathrm{c} 1.56097 \mathrm{e}-04$

24050.70c $7.62733 \mathrm{e}-0424052.70 \mathrm{c} \quad 1.41277 \mathrm{e}-0224053.70 \mathrm{c} \quad 1.57152 \mathrm{e}-03$ $24054.70 \mathrm{c} 3.83172 \mathrm{e}-04$

28058.70c $6.54682 \mathrm{e}-03$ 28060.70c $2.43746 \mathrm{e}-03$ 28061.70c $1.04236 \mathrm{e}-04$ 28062.70c 3.26566e-04 28064.70c 8.10488e-05

14028.70 c $7.07614 \mathrm{e}-0414029.70 \mathrm{c} 3.45935 \mathrm{e}-05$ 14030.70c $2.21996 \mathrm{e}-05$ $16032.70 \mathrm{c} 4.25282 \mathrm{e}-06$ 16033.70c 3.25504e-08 16034.70c $1.77356 \mathrm{e}-07$ $16036.70 \mathrm{c} 7.95715 \mathrm{e}-10$

42092.70c $2.31057 \mathrm{e}-06$ 42094.70c $1.40957 \mathrm{e}-06$ 42095.70c $2.40040 \mathrm{e}-06$ 42096.70 c 2.48879e-06 42097.70c $1.41022 \mathrm{e}-06$ 42098.70c $3.52682 \mathrm{e}-06$ 42100.70c $1.37931 \mathrm{e}-06$

29063.70c $9.43728 \mathrm{e}-0529065.70 \mathrm{c} 4.07687 \mathrm{e}-05$

50112.70c 3.30769e-08 50114.70c $2.17761 \mathrm{e}-08$ 50115.70c $1.12914 \mathrm{e}-08$ 50116.70c $4.78714 \mathrm{e}-0750117.70 \mathrm{c} 2.50690 \mathrm{e}-07$ 50118.70c $7.83891 \mathrm{e}-07$ 50119.70c $2.75677 \mathrm{e}-0750120.70 \mathrm{c} \quad 1.03719 \mathrm{e}-06$ 50122.70c $1.44933 \mathrm{e}-07$ $50124.70 \mathrm{c} 1.78316 \mathrm{e}-07$

15031.70c 4.15796e-05 6000.70c 8.33972e-05 27059.70c $1.37594 \mathrm{e}-04$ 25055.70c $1.18080 \mathrm{e}-03$

c ouro e aluminio

m15 79197.70c 7.90264e-05 13027.70c 5.95625e-02

$\mathrm{c}$

c definicao de tally

f4:n $\quad 360$

fm4:n (1 15 102)

e4 $\quad 0.55 \mathrm{e}-0620$

c

prdmp $10001000-1 \mathrm{j}$

print 
APÊNDICE B - Atividades de saturação

$\mathrm{Na}$ TAB B.1 apresentam-se as atividades de saturação das folhas de ouro hiperpuras sem cádmio (nua) e cobertas com cádmio, e TAB B.2, B.3, B.4, B.5 as atividades de saturação para as folhas de ouro infinitamente diluídas sem cádmio (nua) e cobertas com cádmio. As atividades de saturação referem-se aos quatro planos de irradiação (14-15,10-11, 6-7, 2-3).

Tabela B.1 - Atividade de saturação das folhas de ouro hiperpuras no canal de irradiação 14-15.

\begin{tabular}{|c|c|c|c|c|}
\hline Posição & $A_{n u a}^{\infty}(\mathbf{B q})$ & $\sigma_{A_{n u a}^{\infty}}(\%)$ & $A_{c d}^{\infty}(\mathbf{B q})$ & $\sigma_{A_{c d}^{\infty}}(\%)$ \\
\hline 637-1 & $9,21 \mathrm{E}+05$ & 2,20 & $3,46 \mathrm{E}+05$ & 2,45 \\
\hline $637-2$ & $1,40 \mathrm{E}+06$ & 2,18 & $6,97 \mathrm{E}+05$ & 2,24 \\
\hline $637-3$ & $1,68 \mathrm{E}+06$ & 2,22 & $9,00 \mathrm{E}+05$ & 2,20 \\
\hline $637-4$ & $1,33 \mathrm{E}+06$ & 2,26 & $6,73 \mathrm{E}+05$ & 2,19 \\
\hline $637-5$ & $8,91 \mathrm{E}+05$ & 2,19 & $3,32 \mathrm{E}+05$ & 2,32 \\
\hline 546-1 & $1,45 \mathrm{E}+06$ & 2,20 & $7,45 \mathrm{E}+05$ & 2,19 \\
\hline $546-2$ & $2,67 \mathrm{E}+06$ & 2,20 & $1,58 \mathrm{E}+06$ & 2,33 \\
\hline $546-3$ & $3,31 \mathrm{E}+06$ & 2,21 & $1,89 \mathrm{E}+06$ & 2,18 \\
\hline $546-4$ & $2,67 \mathrm{E}+06$ & 2,21 & $1,56 \mathrm{E}+06$ & 2,20 \\
\hline $546-5$ & $1,44 \mathrm{E}+06$ & 2,27 & $7,25 \mathrm{E}+05$ & 2,28 \\
\hline $455-1$ & $2,19 \mathrm{E}+06$ & 2,30 & $1,09 \mathrm{E}+06$ & 2,19 \\
\hline $455-2$ & $3,71 \mathrm{E}+06$ & 2,19 & $2,16 \mathrm{E}+06$ & 2,20 \\
\hline $455-3$ & $4,69 \mathrm{E}+06$ & 2,20 & $2,72 \mathrm{E}+06$ & 2,21 \\
\hline $455-4$ & $3,64 \mathrm{E}+06$ & 2,18 & $2,18 \mathrm{E}+06$ & 2,24 \\
\hline $455-5$ & $2,18 \mathrm{E}+06$ & 2,19 & $1,06 \mathrm{E}+06$ & 2,28 \\
\hline 364-1 & $2,38 \mathrm{E}+06$ & 2,21 & $1,19 \mathrm{E}+06$ & 2,26 \\
\hline $364-2$ & $4,28 \mathrm{E}+06$ & 2,22 & $2,47 \mathrm{E}+06$ & 2,18 \\
\hline $364-3$ & $5,15 \mathrm{E}+06$ & 2,18 & $2,90 \mathrm{E}+06$ & 2,20 \\
\hline $364-4$ & $4,23 \mathrm{E}+06$ & 2,21 & $2,43 \mathrm{E}+06$ & 2,18 \\
\hline $364-5$ & $2,45 \mathrm{E}+06$ & 2,20 & $1,13 \mathrm{E}+06$ & 5,12 \\
\hline $273-1$ & $2,18 \mathrm{E}+06$ & 2,18 & $1,11 \mathrm{E}+06$ & 2,18 \\
\hline $273-2$ & $4,06 \mathrm{E}+06$ & 2,19 & $2,25 \mathrm{E}+06$ & 2,21 \\
\hline $273-3$ & $4,84 \mathrm{E}+06$ & 2,20 & $2,77 \mathrm{E}+06$ & 2,18 \\
\hline $273-4$ & $3,95 \mathrm{E}+06$ & 2,19 & $2,34 \mathrm{E}+06$ & 2,19 \\
\hline $273-5$ & $2,34 \mathrm{E}+06$ & 2,46 & $1,08 \mathrm{E}+06$ & 2,19 \\
\hline $182-1$ & $1,62 \mathrm{E}+06$ & 2,28 & $7,90 \mathrm{E}+05$ & 2,19 \\
\hline $182-2$ & $2,92 \mathrm{E}+06$ & 2,19 & $1,67 \mathrm{E}+06$ & 2,19 \\
\hline $182-3$ & $3,50 \mathrm{E}+06$ & 2,26 & $2,02 \mathrm{E}+06$ & 2,18 \\
\hline $182-4$ & $2,91 \mathrm{E}+06$ & 2,19 & $1,64 \mathrm{E}+06$ & 2,29 \\
\hline $182-5$ & $1,66 \mathrm{E}+06$ & 2,27 & $7,77 \mathrm{E}+05$ & 2,19 \\
\hline
\end{tabular}




\begin{tabular}{|c|c|c|c|c|}
\hline Posição & $\left.A_{\text {nua }}^{\infty} \mathbf{( B q}\right)$ & $\sigma_{A_{\text {nua }}^{\infty}}(\mathbf{\%})$ & $A_{c d}^{\infty}(\mathbf{B q})$ & $\sigma_{A_{c d}^{\infty}}(\boldsymbol{\%})$ \\
\hline $91-1$ & $1,07 \mathrm{E}+06$ & 2,18 & $3,75 \mathrm{E}+05$ & 2,20 \\
\hline $91-2$ & $1,90 \mathrm{E}+06$ & 2,18 & $7,72 \mathrm{E}+05$ & 2,18 \\
\hline $91-3$ & $2,04 \mathrm{E}+06$ & 2,23 & $9,59 \mathrm{E}+05$ & 2,26 \\
\hline $91-4$ & $1,84 \mathrm{E}+06$ & 2,19 & $7,71 \mathrm{E}+05$ & 2,18 \\
\hline $91-5$ & $1,10 \mathrm{E}+06$ & 2,18 & $3,71 \mathrm{E}+05$ & 2,21 \\
\hline
\end{tabular}

Tabela B.2 - Atividade de saturação das folhas de ouro infinitamente diluídas no canal de irradiação 14-15.

\begin{tabular}{|c|c|c|c|c|}
\hline Posição & $A_{\text {nиa }}^{\infty}(\mathbf{B q})$ & $\sigma_{A_{\text {nua }}^{\infty}}(\boldsymbol{\%})$ & $A_{c d}^{\infty}(\mathbf{B q})$ & $\sigma_{A_{c d}^{\infty}}(\boldsymbol{\%})$ \\
\hline $637-1$ & $3,29 \mathrm{E}+04$ & $1,20 \%$ & $1,97 \mathrm{E}+04$ & $1,23 \%$ \\
\hline $637-2$ & $5,54 \mathrm{E}+04$ & $1,22 \%$ & $3,38 \mathrm{E}+04$ & $3,11 \%$ \\
\hline $637-3$ & $5,82 \mathrm{E}+04$ & $1,41 \%$ & $2,98 \mathrm{E}+04$ & $1,13 \%$ \\
\hline $637-4$ & $5,49 \mathrm{E}+04$ & $1,18 \%$ & $2,69 \mathrm{E}+04$ & $1,28 \%$ \\
\hline $637-5$ & $3,27 \mathrm{E}+04$ & $2,88 \%$ & $8,23 \mathrm{E}+03$ & $5,53 \%$ \\
\hline $546-1$ & $6,05 \mathrm{E}+04$ & $2,32 \%$ & $4,74 \mathrm{E}+04$ & $1,10 \%$ \\
\hline $546-2$ & $1,20 \mathrm{E}+05$ & $1,10 \%$ & $7,79 \mathrm{E}+04$ & $1,15 \%$ \\
\hline $546-3$ & $1,16 \mathrm{E}+05$ & $1,82 \%$ & $6,86 \mathrm{E}+04$ & $1,10 \%$ \\
\hline $546-4$ & $1,18 \mathrm{E}+05$ & $1,42 \%$ & $6,08 \mathrm{E}+04$ & $1,23 \%$ \\
\hline $546-5$ & $6,09 \mathrm{E}+04$ & $1,96 \%$ & $2,10 \mathrm{E}+04$ & $1,65 \%$ \\
\hline $455-1$ & $8,94 \mathrm{E}+04$ & $1,42 \%$ & $7,01 \mathrm{E}+04$ & $1,28 \%$ \\
\hline $455-2$ & $1,72 \mathrm{E}+05$ & $1,56 \%$ & $1,18 \mathrm{E}+05$ & $1,19 \%$ \\
\hline $455-3$ & $1,51 \mathrm{E}+05$ & $1,17 \%$ & $9,20 \mathrm{E}+04$ & $1,10 \%$ \\
\hline $455-4$ & $1,69 \mathrm{E}+05$ & $1,38 \%$ & $8,96 \mathrm{E}+04$ & $1,09 \%$ \\
\hline $455-5$ & $8,97 \mathrm{E}+04$ & $1,15 \%$ & $3,28 \mathrm{E}+04$ & $3,40 \%$ \\
\hline $364-1$ & $1,02 \mathrm{E}+05$ & $1,39 \%$ & $8,01 \mathrm{E}+04$ & $1,45 \%$ \\
\hline $364-2$ & $1,94 \mathrm{E}+05$ & $1,57 \%$ & $1,35 \mathrm{E}+05$ & $1,68 \%$ \\
\hline $364-3$ & $1,85 \mathrm{E}+05$ & $1,10 \%$ & $1,15 \mathrm{E}+05$ & $1,10 \%$ \\
\hline $364-4$ & $1,94 \mathrm{E}+05$ & $1,58 \%$ & $1,05 \mathrm{E}+05$ & $1,85 \%$ \\
\hline $364-5$ & $9,88 \mathrm{E}+04$ & $1,45 \%$ & $3,81 \mathrm{E}+04$ & $1,55 \%$ \\
\hline $273-1$ & $8,98 \mathrm{E}+04$ & $1,19 \%$ & $7,05 \mathrm{E}+04$ & $1,46 \%$ \\
\hline $273-2$ & $1,80 \mathrm{E}+05$ & $1,26 \%$ & $1,24 \mathrm{E}+05$ & $1,10 \%$ \\
\hline $273-3$ & $1,70 \mathrm{E}+05$ & $1,42 \%$ & $1,06 \mathrm{E}+05$ & $1,11 \%$ \\
\hline $273-4$ & $1,74 \mathrm{E}+05$ & $1,27 \%$ & $9,73 \mathrm{E}+04$ & $1,78 \%$ \\
\hline $273-5$ & $8,62 \mathrm{E}+04$ & $1,69 \%$ & $3,78 \mathrm{E}+04$ & $2,08 \%$ \\
\hline $182-1$ & $6,85 \mathrm{E}+04$ & $1,52 \%$ & $5,23 \mathrm{E}+04$ & $1,20 \%$ \\
\hline $182-2$ & $1,32 \mathrm{E}+05$ & $1,40 \%$ & $9,30 \mathrm{E}+04$ & $1,19 \%$ \\
\hline $182-3$ & $1,27 \mathrm{E}+05$ & $1,18 \%$ & $8,00 \mathrm{E}+04$ & $1,90 \%$ \\
\hline $182-4$ & $1,22 \mathrm{E}+05$ & $1,11 \%$ & $7,08 \mathrm{E}+04$ & $1,09 \%$ \\
\hline $182-5$ & $6,77 \mathrm{E}+04$ & $1,22 \%$ & $3,03 \mathrm{E}+04$ & $1,38 \%$ \\
\hline $91-1$ & $3,98 \mathrm{E}+04$ & $1,23 \%$ & $2,55 \mathrm{E}+04$ & $3,06 \%$ \\
\hline $91-2$ & $7,27 \mathrm{E}+04$ & $1,20 \%$ & $4,68 \mathrm{E}+04$ & $2,19 \%$ \\
\hline $91-3$ & $6,81 \mathrm{E}+04$ & $1,55 \%$ & $3,98 \mathrm{E}+04$ & $1,10 \%$ \\
\hline $91-4$ & $7,27 \mathrm{E}+04$ & $1,20 \%$ & $3,67 \mathrm{E}+04$ & $1,62 \%$ \\
\hline $91-5$ & $4,06 \mathrm{E}+04$ & $1,14 \%$ & $1,49 \mathrm{E}+04$ & $4,76 \%$ \\
\hline & & & & \\
\hline
\end{tabular}


Tabela B.3 - Atividade de saturação das folhas de ouro infinitamente diluídas no canal de irradiação 10-11.

\begin{tabular}{|c|c|c|c|c|}
\hline Posição & $A_{\text {nиа }}^{\infty}(\mathbf{B q})$ & $\sigma_{A_{\text {nua }}^{\infty}}(\boldsymbol{\%})$ & $A_{c d}^{\infty}(\mathbf{B q})$ & $\sigma_{A_{c d}^{\infty}}(\%)$ \\
\hline $637-1$ & $3,06 \mathrm{E}+04$ & $2,18 \%$ & $1,553 \mathrm{E}+04$ & $2,49 \%$ \\
\hline $637-2$ & $5,71 \mathrm{E}+04$ & $2,18 \%$ & $3,420 \mathrm{E}+04$ & $2,36 \%$ \\
\hline $637-3$ & $6,13 \mathrm{E}+04$ & $2,18 \%$ & $4,014 \mathrm{E}+04$ & $2,22 \%$ \\
\hline $637-4$ & $3,83 \mathrm{E}+04$ & $2,18 \%$ & $2,765 \mathrm{E}+04$ & $2,86 \%$ \\
\hline $637-5$ & $2,75 \mathrm{E}+04$ & $2,18 \%$ & $1,416 \mathrm{E}+04$ & $3,07 \%$ \\
\hline $546-1$ & $5,71 \mathrm{E}+04$ & $2,18 \%$ & $3,420 \mathrm{E}+04$ & $2,45 \%$ \\
\hline $546-2$ & $1,14 \mathrm{E}+05$ & $2,18 \%$ & $7,664 \mathrm{E}+04$ & $2,30 \%$ \\
\hline $546-3$ & $1,22 \mathrm{E}+05$ & $2,18 \%$ & $9,096 \mathrm{E}+04$ & $2,19 \%$ \\
\hline $546-4$ & $1,09 \mathrm{E}+05$ & $2,18 \%$ & $7,311 \mathrm{E}+04$ & $3,61 \%$ \\
\hline $546-5$ & $5,58 \mathrm{E}+04$ & $2,18 \%$ & $3,305 \mathrm{E}+04$ & $2,24 \%$ \\
\hline $455-1$ & $8,39 \mathrm{E}+04$ & $2,18 \%$ & $4,823 \mathrm{E}+04$ & $2,37 \%$ \\
\hline $455-2$ & $1,54 \mathrm{E}+05$ & $2,18 \%$ & $1,049 \mathrm{E}+05$ & $2,38 \%$ \\
\hline $455-3$ & $1,81 \mathrm{E}+05$ & $2,18 \%$ & $1,241 \mathrm{E}+05$ & $2,28 \%$ \\
\hline $455-4$ & $1,55 \mathrm{E}+05$ & $2,18 \%$ & $1,065 \mathrm{E}+05$ & $2,57 \%$ \\
\hline $455-5$ & $8,35 \mathrm{E}+04$ & $2,18 \%$ & $4,737 \mathrm{E}+04$ & $2,57 \%$ \\
\hline $364-1$ & $9,16 \mathrm{E}+04$ & $2,18 \%$ & $5,173 \mathrm{E}+04$ & $2,90 \%$ \\
\hline $364-2$ & $1,79 \mathrm{E}+05$ & $2,18 \%$ & $1,235 \mathrm{E}+05$ & $2,78 \%$ \\
\hline $364-3$ & $2,04 \mathrm{E}+05$ & $2,18 \%$ & $1,434 \mathrm{E}+05$ & $2,32 \%$ \\
\hline $364-4$ & $1,85 \mathrm{E}+05$ & $2,18 \%$ & $1,203 \mathrm{E}+05$ & $2,34 \%$ \\
\hline $364-5$ & $9,51 \mathrm{E}+04$ & $2,18 \%$ & $5,268 \mathrm{E}+04$ & $2,18 \%$ \\
\hline $273-1$ & $8,78 \mathrm{E}+04$ & $2,18 \%$ & $4,943 \mathrm{E}+04$ & $2,18 \%$ \\
\hline $273-2$ & $1,69 \mathrm{E}+05$ & $2,18 \%$ & $1,099 \mathrm{E}+05$ & $2,20 \%$ \\
\hline $273-3$ & $1,87 \mathrm{E}+05$ & $2,18 \%$ & $1,288 \mathrm{E}+05$ & $2,22 \%$ \\
\hline $273-4$ & $1,60 \mathrm{E}+05$ & $2,18 \%$ & $1,026 \mathrm{E}+05$ & $2,18 \%$ \\
\hline $273-5$ & $8,32 \mathrm{E}+04$ & $2,18 \%$ & $4,580 \mathrm{E}+04$ & $2,42 \%$ \\
\hline $182-1$ & $6,64 \mathrm{E}+04$ & $2,18 \%$ & $3,653 \mathrm{E}+04$ & $2,25 \%$ \\
\hline $182-2$ & $1,21 \mathrm{E}+05$ & $2,18 \%$ & $8,046 \mathrm{E}+04$ & $2,64 \%$ \\
\hline $182-3$ & $1,35 \mathrm{E}+05$ & $2,18 \%$ & $9,583 \mathrm{E}+04$ & $2,38 \%$ \\
\hline $182-4$ & $1,25 \mathrm{E}+05$ & $2,18 \%$ & $8,024 \mathrm{E}+04$ & $2,27 \%$ \\
\hline $182-5$ & $6,08 \mathrm{E}+04$ & $2,18 \%$ & $3,412 \mathrm{E}+04$ & $2,40 \%$ \\
\hline $91-1$ & $3,73 \mathrm{E}+04$ & $2,18 \%$ & $1,679 \mathrm{E}+04$ & $2,37 \%$ \\
\hline $91-2$ & $6,73 \mathrm{E}+04$ & $2,18 \%$ & $3,717 \mathrm{E}+04$ & $2,25 \%$ \\
\hline $91-3$ & $7,76 \mathrm{E}+04$ & $2,18 \%$ & $4,182 \mathrm{E}+04$ & $3,00 \%$ \\
\hline $91-4$ & $6,72 \mathrm{E}+04$ & $2,18 \%$ & $3,519 \mathrm{E}+04$ & $2,22 \%$ \\
\hline $91-5$ & $3,50 \mathrm{E}+04$ & $2,18 \%$ & $1,587 \mathrm{E}+04$ & $4,25 \%$ \\
\hline
\end{tabular}


Tabela B.4 - Atividade de saturação das folhas de ouro infinitamente diluídas no canal de irradiação 6-7.

\begin{tabular}{|c|c|c|c|c|}
\hline Posição & $A_{\text {nиa }}^{\infty}(\mathbf{B q})$ & $\sigma_{A_{\text {nua }}^{\infty}}(\boldsymbol{\%})$ & $A_{c d}^{\infty}(\mathbf{B q})$ & $\sigma_{A_{c d}^{\infty}}(\boldsymbol{\%})$ \\
\hline $637-2$ & $3,67 \mathrm{E}+04$ & $2,32 \%$ & $2,150 \mathrm{E}+04$ & $2,18 \%$ \\
\hline $637-3$ & $3,73 \mathrm{E}+04$ & $2,33 \%$ & $1,939 \mathrm{E}+04$ & $2,18 \%$ \\
\hline $637-4$ & $2,34 \mathrm{E}+04$ & $2,46 \%$ & $1,123 \mathrm{E}+04$ & $2,20 \%$ \\
\hline $546-2$ & $6,97 \mathrm{E}+04$ & $2,25 \%$ & $4,968 \mathrm{E}+04$ & $2,18 \%$ \\
\hline $546-3$ & $8,32 \mathrm{E}+04$ & $2,26 \%$ & $5,468 \mathrm{E}+04$ & $2,18 \%$ \\
\hline $546-4$ & $6,08 \mathrm{E}+04$ & $2,20 \%$ & $2,791 \mathrm{E}+04$ & $2,18 \%$ \\
\hline $455-2$ & $9,39 \mathrm{E}+04$ & $2,63 \%$ & $7,046 \mathrm{E}+04$ & $2,18 \%$ \\
\hline $455-3$ & $1,14 \mathrm{E}+05$ & $2,22 \%$ & $8,337 \mathrm{E}+04$ & $2,18 \%$ \\
\hline $455-4$ & $9,39 \mathrm{E}+04$ & $2,63 \%$ & $7,046 \mathrm{E}+04$ & $2,18 \%$ \\
\hline $364-2$ & $1,08 \mathrm{E}+05$ & $2,51 \%$ & $8,243 \mathrm{E}+04$ & $2,27 \%$ \\
\hline $364-3$ & $1,29 \mathrm{E}+05$ & $2,21 \%$ & $9,384 \mathrm{E}+04$ & $2,18 \%$ \\
\hline $364-4$ & $1,13 \mathrm{E}+05$ & $2,27 \%$ & $5,676 \mathrm{E}+04$ & $2,19 \%$ \\
\hline $273-2$ & $1,02 \mathrm{E}+05$ & $2,22 \%$ & $7,653 \mathrm{E}+04$ & $2,22 \%$ \\
\hline $273-3$ & $1,19 \mathrm{E}+05$ & $2,18 \%$ & $8,544 \mathrm{E}+04$ & $2,31 \%$ \\
\hline $273-4$ & $1,05 \mathrm{E}+05$ & $2,19 \%$ & $5,558 \mathrm{E}+04$ & $3,58 \%$ \\
\hline $182-2$ & $7,90 \mathrm{E}+04$ & $2,29 \%$ & $6,267 \mathrm{E}+04$ & $2,21 \%$ \\
\hline $182-3$ & $8,95 \mathrm{E}+04$ & $2,54 \%$ & $6,627 \mathrm{E}+04$ & $2,59 \%$ \\
\hline $182-4$ & $8,95 \mathrm{E}+04$ & $2,54 \%$ & $4,540 \mathrm{E}+04$ & $2,41 \%$ \\
\hline $91-2$ & $4,23 \mathrm{E}+04$ & $2,76 \%$ & $2,960 \mathrm{E}+04$ & $3,92 \%$ \\
\hline $91-3$ & $4,68 \mathrm{E}+04$ & $2,41 \%$ & $3,075 \mathrm{E}+04$ & $2,25 \%$ \\
\hline $91-4$ & $4,54 \mathrm{E}+04$ & $2,32 \%$ & $2,277 \mathrm{E}+04$ & $2,20 \%$ \\
\hline
\end{tabular}

Tabela B.5 - Atividade de saturação das folhas de ouro infinitamente diluídas no canal de irradiação 2-3.

\begin{tabular}{|c|c|c|c|c|}
\hline Posição & $A_{\text {nua }}^{\infty}(\mathbf{B q})$ & $\sigma_{A_{n u a}^{\infty}}(\boldsymbol{\%})$ & $A_{c d}^{\infty}(\mathbf{B q})$ & $\sigma_{A_{c d}^{\infty}}(\%)$ \\
\hline $637-3$ & $2,73 \mathrm{E}+04$ & $2,53 \%$ & $1,54 \mathrm{E}+04$ & $2,92 \%$ \\
\hline $546-3$ & $5,06 \mathrm{E}+04$ & $2,46 \%$ & $3,69 \mathrm{E}+04$ & $2,18 \%$ \\
\hline $455-3$ & $7,51 \mathrm{E}+04$ & $2,18 \%$ & $5,25 \mathrm{E}+04$ & $2,43 \%$ \\
\hline $364-3$ & $8,33 \mathrm{E}+04$ & $2,18 \%$ & $5,91 \mathrm{E}+04$ & $2,44 \%$ \\
\hline $273-3$ & $7,81 \mathrm{E}+04$ & $2,18 \%$ & $5,53 \mathrm{E}+04$ & $3,19 \%$ \\
\hline $182-3$ & $5,66 \mathrm{E}+04$ & $2,19 \%$ & $4,11 \mathrm{E}+04$ & $2,39 \%$ \\
\hline $91-3$ & $3,27 \mathrm{E}+04$ & $2,63 \%$ & $1,97 \mathrm{E}+04$ & $2,24 \%$ \\
\hline
\end{tabular}


APÊNDICE C - Razão de cádmio

Na TAB C.1 constam as razões de cádmio para as folhas de ouro hiperpuras e nas TAB C.2, C.3, C.4 e C.5, as razões de cádmio para as folhas de ouro infinitamente diluídas, nos quatro canais de irradiação.

Tabela C.1 - Razão de cádmio das folhas de ouro hiperpuras no canal de irradiação 14-15.

\begin{tabular}{|c|c|c|}
\hline Posição & $R_{c d}$ & $\sigma_{R_{c d}}(\%)$ \\
\hline $637-1$ & 1,7448 & $3,39 \%$ \\
\hline $637-2$ & 1,7107 & $3,22 \%$ \\
\hline $637-3$ & 2,0373 & $3,22 \%$ \\
\hline 637-4 & 2,1299 & $3,24 \%$ \\
\hline $637-5$ & 4,1412 & $3,29 \%$ \\
\hline 546-1 & 1,3330 & $3,20 \%$ \\
\hline $546-2$ & 1,6100 & $3,31 \%$ \\
\hline $546-3$ & 1,7703 & $3,21 \%$ \\
\hline $546-4$ & 2,0259 & $3,22 \%$ \\
\hline $546-5$ & 3,0234 & $3,32 \%$ \\
\hline $455-1$ & 1,3322 & $3,27 \%$ \\
\hline $455-2$ & 1,5229 & $3,20 \%$ \\
\hline $455-3$ & 1,7158 & $3,22 \%$ \\
\hline $455-4$ & 1,9670 & $3,23 \%$ \\
\hline $455-5$ & 2,8524 & $3,26 \%$ \\
\hline $364-1$ & 1,3280 & $3,26 \%$ \\
\hline $364-2$ & 1,8238 & $3,21 \%$ \\
\hline $364-3$ & 1,6785 & $3,20 \%$ \\
\hline $364-4$ & 1,9242 & $3,20 \%$ \\
\hline $364-5$ & 2,7043 & $5,06 \%$ \\
\hline 273-1 & 1,3296 & $3,18 \%$ \\
\hline $273-2$ & 1,5165 & $3,20 \%$ \\
\hline $273-3$ & 1,6713 & $3,19 \%$ \\
\hline $273-4$ & 1,8699 & $3,20 \%$ \\
\hline $273-5$ & 2,3822 & $3,39 \%$ \\
\hline $182-1$ & 1,3671 & $3,26 \%$ \\
\hline $182-2$ & 1,4861 & $3,19 \%$ \\
\hline $182-3$ & 1,6560 & $3,24 \%$ \\
\hline $182-4$ & 1,8039 & $3,26 \%$ \\
\hline $182-5$ & 2,3337 & $3,25 \%$ \\
\hline $91-1$ & 1,6292 & $3,19 \%$ \\
\hline $91-2$ & 1,6197 & $3,18 \%$ \\
\hline $91-3$ & 1,7857 & $3,28 \%$ \\
\hline $91-4$ & 2,0652 & $3,19 \%$ \\
\hline $91-5$ & 2,8370 & $3,20 \%$ \\
\hline
\end{tabular}


Tabela C.2 - Razão de cádmio das folhas de ouro infinitamente diluídas no canal de irradiação 14-15.

\begin{tabular}{|c|c|c|}
\hline Posição & $R_{c d}$ & $\sigma_{R_{c d}}(\%)$ \\
\hline $637-1$ & 1,6718 & $1,72 \%$ \\
\hline $637-2$ & 1,6391 & $3,34 \%$ \\
\hline $637-3$ & 1,9521 & $1,80 \%$ \\
\hline $637-4$ & 2,0408 & $1,74 \%$ \\
\hline $637-5$ & 3,9681 & $6,24 \%$ \\
\hline $546-1$ & 1,2773 & $2,57 \%$ \\
\hline $546-2$ & 1,5426 & $1,59 \%$ \\
\hline $546-3$ & 1,6962 & $2,13 \%$ \\
\hline $546-4$ & 1,9412 & $1,88 \%$ \\
\hline $546-5$ & 2,8969 & $2,56 \%$ \\
\hline $455-1$ & 1,2765 & $1,91 \%$ \\
\hline $455-2$ & 1,4592 & $1,96 \%$ \\
\hline $455-3$ & 1,6441 & $1,61 \%$ \\
\hline $455-4$ & 1,8848 & $1,76 \%$ \\
\hline $455-5$ & 2,7332 & $3,59 \%$ \\
\hline $364-1$ & 1,2724 & $2,01 \%$ \\
\hline $364-2$ & 1,8437 & $2,43 \%$ \\
\hline $364-3$ & 1,6083 & $1,56 \%$ \\
\hline $364-4$ & 1,8437 & $2,43 \%$ \\
\hline $364-5$ & 2,5912 & $2,12 \%$ \\
\hline $273-1$ & 1,2740 & $1,88 \%$ \\
\hline $273-2$ & 1,4531 & $1,67 \%$ \\
\hline $273-3$ & 1,6014 & $1,80 \%$ \\
\hline $273-4$ & 1,7917 & $2,18 \%$ \\
\hline $273-5$ & 2,2826 & $2,68 \%$ \\
\hline $182-1$ & 1,3099 & $1,93 \%$ \\
\hline $182-2$ & 1,4239 & $1,84 \%$ \\
\hline $182-3$ & 1,5867 & $2,24 \%$ \\
\hline $182-4$ & 1,7285 & $1,56 \%$ \\
\hline $182-5$ & 2,2361 & $1,84 \%$ \\
\hline $91-1$ & 1,5610 & $3,30 \%$ \\
\hline $91-2$ & 1,5520 & $2,50 \%$ \\
\hline $91-3$ & 1,7110 & $1,90 \%$ \\
\hline $91-4$ & 1,9788 & $2,02 \%$ \\
\hline $91-5$ & 2,7183 & $4,89 \%$ \\
\hline
\end{tabular}


Tabela C.3 - Razão de cádmio das folhas de ouro infinitamente diluídas no canal de irradiação 10-11.

\begin{tabular}{|c|c|c|}
\hline Posição & $R_{c d}$ & $\sigma_{R_{c d}}(\%)$ \\
\hline $637-1$ & 1,9714 & $3,31 \%$ \\
\hline $637-2$ & 1,6696 & $3,21 \%$ \\
\hline $637-3$ & 1,5283 & $3,12 \%$ \\
\hline $637-4$ & 1,3839 & $3,60 \%$ \\
\hline $637-5$ & 1,9451 & $3,77 \%$ \\
\hline $546-1$ & 1,6708 & $3,28 \%$ \\
\hline $546-2$ & 1,4922 & $3,17 \%$ \\
\hline $546-3$ & 1,3417 & $3,09 \%$ \\
\hline $546-4$ & 1,4866 & $4,22 \%$ \\
\hline $546-5$ & 1,6874 & $3,13 \%$ \\
\hline $455-1$ & 1,7391 & $3,22 \%$ \\
\hline $455-2$ & 1,4652 & $3,23 \%$ \\
\hline $455-3$ & 1,4626 & $3,16 \%$ \\
\hline $455-4$ & 1,4550 & $3,37 \%$ \\
\hline $455-5$ & 1,7625 & $3,37 \%$ \\
\hline $364-1$ & 1,7713 & $3,63 \%$ \\
\hline $364-2$ & 1,4501 & $3,54 \%$ \\
\hline $364-3$ & 1,4195 & $3,19 \%$ \\
\hline $364-4$ & 1,5389 & $3,20 \%$ \\
\hline $364-5$ & 1,8052 & $3,09 \%$ \\
\hline $273-1$ & 1,7773 & $3,09 \%$ \\
\hline $273-2$ & 1,5342 & $3,10 \%$ \\
\hline $273-3$ & 1,4480 & $3,11 \%$ \\
\hline $273-4$ & 1,5626 & $3,09 \%$ \\
\hline $273-5$ & 1,8155 & $3,26 \%$ \\
\hline $182-1$ & 1,8182 & $3,13 \%$ \\
\hline $182-2$ & 1,4984 & $3,43 \%$ \\
\hline $182-3$ & 1,4047 & $3,23 \%$ \\
\hline $182-4$ & 1,5571 & $3,15 \%$ \\
\hline $182-5$ & 1,7819 & $3,25 \%$ \\
\hline $91-1$ & 2,2210 & $3,22 \%$ \\
\hline $91-2$ & 1,8111 & $3,14 \%$ \\
\hline $91-3$ & 1,8560 & $3,71 \%$ \\
\hline $91-4$ & 1,9092 & $3,11 \%$ \\
\hline $91-5$ & 2,2066 & $4,77 \%$ \\
\hline
\end{tabular}


Tabela C.4 - Atividade de saturação das folhas de ouro infinitamente diluídas no canal de irradiação 6-7.

\begin{tabular}{|c|c|c|}
\hline Posição & $R_{c d}$ & $\sigma_{R_{c d}}(\boldsymbol{\%})$ \\
\hline $637-2$ & 1,7067 & $3,18 \%$ \\
\hline $637-3$ & 1,9255 & $3,19 \%$ \\
\hline $637-4$ & 2,0802 & $3,30 \%$ \\
\hline $546-2$ & 1,4032 & $3,13 \%$ \\
\hline $546-3$ & 1,5224 & $3,14 \%$ \\
\hline $546-4$ & 2,1785 & $3,10 \%$ \\
\hline $455-2$ & 1,3326 & $3,42 \%$ \\
\hline $455-3$ & 1,3684 & $3,12 \%$ \\
\hline $455-4$ & 1,3326 & $3,42 \%$ \\
\hline $364-2$ & 1,3111 & $3,39 \%$ \\
\hline $364-3$ & 1,3790 & $3,10 \%$ \\
\hline $364-4$ & 1,9871 & $3,15 \%$ \\
\hline $273-2$ & 1,3376 & $3,14 \%$ \\
\hline $273-3$ & 1,3885 & $3,18 \%$ \\
\hline $273-4$ & 1,8963 & $4,20 \%$ \\
\hline $182-2$ & 1,2599 & $3,19 \%$ \\
\hline $182-3$ & 1,3507 & $3,63 \%$ \\
\hline $182-4$ & 1,9718 & $3,50 \%$ \\
\hline $91-2$ & 1,4299 & $4,80 \%$ \\
\hline $91-3$ & 1,5210 & $3,30 \%$ \\
\hline $91-4$ & 1,9957 & $3,20 \%$ \\
\hline
\end{tabular}

Tabela C.5 - Atividade de saturação das folhas de ouro infinitamente diluídas no canal de irradiação 2-3.

\begin{tabular}{|c|c|c|}
\hline Posição & $R_{c d}$ & $\sigma_{R_{c d}}(\boldsymbol{\%})$ \\
\hline $637-3$ & 1,7757 & $3,86 \%$ \\
\hline $546-3$ & 1,3705 & $3,29 \%$ \\
\hline $455-3$ & 1,4306 & $3,26 \%$ \\
\hline $364-3$ & 1,4104 & $3,27 \%$ \\
\hline $273-3$ & 1,4121 & $3,87 \%$ \\
\hline $182-3$ & 1,3769 & $3,24 \%$ \\
\hline $91-3$ & 1,6604 & $3,46 \%$ \\
\hline
\end{tabular}


APÊNDICE D - Fluxo de nêutrons térmicos

Nas TAB D.1, D.2, D.3, D.4 apresentam-se os fluxos de nêutrons térmicos nas posições medidas em todos os canais de irradiação (14-15,10-11, 6-7, 2-3).

Tabela D.1 - Fluxo de nêutrons térmicos no canal de irradiação 14-15.

\begin{tabular}{|c|c|c|}
\hline Posição & $\phi_{t e r}\left(\mathbf{n} / \mathrm{cm}^{2} \mathbf{s}\right)$ & $\sigma_{\phi_{t e r}}(\%)$ \\
\hline $637-1$ & $1,93 \mathrm{E}+08$ & $4,19 \%$ \\
\hline $637-2$ & $3,13 \mathrm{E}+08$ & $5,35 \%$ \\
\hline $637-3$ & $4,82 \mathrm{E}+08$ & $4,97 \%$ \\
\hline $637-4$ & $4,05 \mathrm{E}+08$ & $4,45 \%$ \\
\hline $637-5$ & $3,67 \mathrm{E}+08$ & $1,72 \%$ \\
\hline 546-1 & $1,63 \mathrm{E}+08$ & $7,10 \%$ \\
\hline $546-2$ & $5,80 \mathrm{E}+08$ & $7,56 \%$ \\
\hline 546-3 & $8,09 \mathrm{E}+08$ & $6,24 \%$ \\
\hline 546-4 & $8,21 \mathrm{E}+08$ & $5,72 \%$ \\
\hline $546-5$ & $5,91 \mathrm{E}+08$ & $3,18 \%$ \\
\hline $455-1$ & $2,36 \mathrm{E}+08$ & $6,98 \%$ \\
\hline $455-2$ & $7,38 \mathrm{E}+08$ & $7,50 \%$ \\
\hline $455-3$ & $1,06 \mathrm{E}+09$ & $6,66 \%$ \\
\hline $455-4$ & $1,16 \mathrm{E}+09$ & $6,15 \%$ \\
\hline $455-5$ & $8,35 \mathrm{E}+08$ & $3,15 \%$ \\
\hline $364-1$ & $2,68 \mathrm{E}+08$ & $6,97 \%$ \\
\hline $364-2$ & $8,50 \mathrm{E}+08$ & $6,22 \%$ \\
\hline $364-3$ & $1,15 \mathrm{E}+09$ & $6,42 \%$ \\
\hline $364-4$ & $1,25 \mathrm{E}+09$ & $5,81 \%$ \\
\hline $364-5$ & $8,92 \mathrm{E}+08$ & $4,38 \%$ \\
\hline $273-1$ & $2,44 \mathrm{E}+08$ & $6,98 \%$ \\
\hline 273-2 & $7,50 \mathrm{E}+08$ & $6,92 \%$ \\
\hline $273-3$ & $1,10 \mathrm{E}+09$ & $6,62 \%$ \\
\hline $273-4$ & $1,09 \mathrm{E}+09$ & $6,34 \%$ \\
\hline $273-5$ & $7,29 \mathrm{E}+08$ & $3,80 \%$ \\
\hline $182-1$ & $2,06 \mathrm{E}+08$ & $6,65 \%$ \\
\hline $182-2$ & $5,35 \mathrm{E}+08$ & $7,41 \%$ \\
\hline $182-3$ & $7,97 \mathrm{E}+08$ & $6,92 \%$ \\
\hline $182-4$ & $7,63 \mathrm{E}+08$ & $6,07 \%$ \\
\hline $182-5$ & $5,47 \mathrm{E}+08$ & $3,72 \%$ \\
\hline 91-1 & $1,96 \mathrm{E}+08$ & $4,09 \%$ \\
\hline $91-2$ & $3,59 \mathrm{E}+08$ & $4,57 \%$ \\
\hline 91-3 & $5,04 \mathrm{E}+08$ & $4,88 \%$ \\
\hline $91-4$ & $5,23 \mathrm{E}+08$ & $3,69 \%$ \\
\hline $91-5$ & $3,77 \mathrm{E}+08$ & $2,31 \%$ \\
\hline
\end{tabular}


Tabela D.2 - Fluxo de nêutrons térmicos no canal de irradiação 10-11.

\begin{tabular}{|c|c|c|}
\hline Posição & $\phi_{\text {ter }}\left(\mathbf{n} / \mathbf{c m}^{\mathbf{2}} \mathbf{s}\right)$ & $\sigma_{\phi_{\text {trr }}}(\boldsymbol{\%})$ \\
\hline $637-1$ & $2,1553 \mathrm{E}+08$ & $3,96 \%$ \\
\hline $637-2$ & $3,1429 \mathrm{E}+08$ & $3,88 \%$ \\
\hline $637-3$ & $2,8826 \mathrm{E}+08$ & $3,80 \%$ \\
\hline $637-4$ & $1,4225 \mathrm{E}+08$ & $4,21 \%$ \\
\hline $637-5$ & $1,8764 \mathrm{E}+08$ & $4,35 \%$ \\
\hline $546-1$ & $3,1921 \mathrm{E}+08$ & $3,94 \%$ \\
\hline $546-2$ & $5,0104 \mathrm{E}+08$ & $3,85 \%$ \\
\hline $546-3$ & $3,9022 \mathrm{E}+08$ & $3,78 \%$ \\
\hline $546-4$ & $4,6869 \mathrm{E}+08$ & $4,75 \%$ \\
\hline $546-5$ & $3,1908 \mathrm{E}+08$ & $3,82 \%$ \\
\hline $455-1$ & $5,0230 \mathrm{E}+08$ & $3,89 \%$ \\
\hline $455-2$ & $6,6995 \mathrm{E}+08$ & $3,89 \%$ \\
\hline $455-3$ & $7,6093 \mathrm{E}+08$ & $3,84 \%$ \\
\hline $455-4$ & $6,4290 \mathrm{E}+08$ & $4,02 \%$ \\
\hline $455-5$ & $5,1037 \mathrm{E}+08$ & $4,02 \%$ \\
\hline $364-1$ & $5,5853 \mathrm{E}+08$ & $4,24 \%$ \\
\hline $364-2$ & $7,2869 \mathrm{E}+08$ & $4,15 \%$ \\
\hline $364-3$ & $7,8779 \mathrm{E}+08$ & $3,86 \%$ \\
\hline $364-4$ & $8,6891 \mathrm{E}+08$ & $3,87 \%$ \\
\hline $364-5$ & $5,9386 \mathrm{E}+08$ & $3,78 \%$ \\
\hline $273-1$ & $5,4181 \mathrm{E}+08$ & $3,78 \%$ \\
\hline $273-2$ & $7,9085 \mathrm{E}+08$ & $3,79 \%$ \\
\hline $273-3$ & $7,6116 \mathrm{E}+08$ & $3,80 \%$ \\
\hline $273-4$ & $8,2169 \mathrm{E}+08$ & $3,78 \%$ \\
\hline $273-5$ & $5,4374 \mathrm{E}+08$ & $3,92 \%$ \\
\hline $182-1$ & $4,1757 \mathrm{E}+08$ & $3,82 \%$ \\
\hline $182-2$ & $5,3545 \mathrm{E}+08$ & $4,06 \%$ \\
\hline $182-3$ & $4,9974 \mathrm{E}+08$ & $3,90 \%$ \\
\hline $182-4$ & $6,0346 \mathrm{E}+08$ & $3,83 \%$ \\
\hline $182-5$ & $3,9115 \mathrm{E}+08$ & $3,91 \%$ \\
\hline $91-1$ & $3,0202 \mathrm{E}+08$ & $3,89 \%$ \\
\hline $91-2$ & $4,2086 \mathrm{E}+08$ & $3,82 \%$ \\
\hline $91-3$ & $5,0873 \mathrm{E}+08$ & $4,30 \%$ \\
\hline $91-4$ & $4,7123 \mathrm{E}+08$ & $3,80 \%$ \\
\hline $91-5$ & $2,7810 \mathrm{E}+08$ & $5,25 \%$ \\
\hline & & \\
\hline
\end{tabular}


Tabela D.3 - Fluxo de nêutrons térmicos no canal de irradiação 6-7.

\begin{tabular}{|c|c|c|}
\hline Posição & $\phi_{\text {ter }}\left(\mathbf{n} / \mathbf{c m}^{\mathbf{2}} \mathbf{s}\right)$ & $\sigma_{\phi_{\text {ter }}}(\boldsymbol{\%})$ \\
\hline $637-2$ & $2,6075 \mathrm{E}+08$ & $3,94 \%$ \\
\hline $637-3$ & $3,1353 \mathrm{E}+08$ & $3,95 \%$ \\
\hline $637-4$ & $2,2050 \mathrm{E}+08$ & $4,11 \%$ \\
\hline $546-2$ & $3,2252 \mathrm{E}+08$ & $3,85 \%$ \\
\hline $546-3$ & $4,6070 \mathrm{E}+08$ & $3,87 \%$ \\
\hline $546-4$ & $6,1671 \mathrm{E}+08$ & $3,80 \%$ \\
\hline $455-2$ & $3,8444 \mathrm{E}+08$ & $4,31 \%$ \\
\hline $455-3$ & $4,8843 \mathrm{E}+08$ & $3,83 \%$ \\
\hline $455-4$ & $3,8444 \mathrm{E}+08$ & $4,31 \%$ \\
\hline $364-2$ & $3,9831 \mathrm{E}+08$ & $4,22 \%$ \\
\hline $364-3$ & $5,6147 \mathrm{E}+08$ & $3,81 \%$ \\
\hline $364-4$ & $1,0039 \mathrm{E}+09$ & $3,88 \%$ \\
\hline $273-2$ & $4,0357 \mathrm{E}+08$ & $3,84 \%$ \\
\hline $273-3$ & $5,4012 \mathrm{E}+08$ & $3,85 \%$ \\
\hline $273-4$ & $8,8291 \mathrm{E}+08$ & $4,74 \%$ \\
\hline $182-2$ & $2,2194 \mathrm{E}+08$ & $3,93 \%$ \\
\hline $182-3$ & $3,5395 \mathrm{E}+08$ & $4,43 \%$ \\
\hline $182-4$ & $7,5732 \mathrm{E}+08$ & $4,32 \%$ \\
\hline $91-2$ & $2,0538 \mathrm{E}+08$ & $5,54 \%$ \\
\hline $91-3$ & $2,7877 \mathrm{E}+08$ & $4,09 \%$ \\
\hline $91-4$ & $3,8501 \mathrm{E}+08$ & $3,95 \%$ \\
\hline
\end{tabular}

Tabela D.4 - Fluxo de nêutrons térmicos no canal de irradiação 2-3

\begin{tabular}{|c|c|c|}
\hline Posição & $\phi_{\text {ter }}\left(\mathbf{n} / \mathbf{c m}^{2} \mathbf{s}\right)$ & $\sigma_{\phi_{\text {ter }}}(\boldsymbol{\%})$ \\
\hline $637-3$ & $1,96 \mathrm{E}+08$ & $2,92 \%$ \\
\hline $546-3$ & $4,70 \mathrm{E}+08$ & $2,19 \%$ \\
\hline $455-3$ & $6,71 \mathrm{E}+08$ & $2,43 \%$ \\
\hline $364-3$ & $7,52 \mathrm{E}+08$ & $2,44 \%$ \\
\hline $273-3$ & $6,90 \mathrm{E}+08$ & $3,19 \%$ \\
\hline $182-3$ & $5,25 \mathrm{E}+08$ & $2,39 \%$ \\
\hline $91-3$ & $2,50 \mathrm{E}+08$ & $2,24 \%$ \\
\hline
\end{tabular}


APÊNDICE E - Fluxo de nêutrons epitérmicos

Nas TAB E.1, E.2, E.3, E.4 apresentam-se os fluxos de nêutrons epitérmicos nas posições medidas em todos os canais de irradiação (14-15,10-11, 6-7, 2-3).

Tabela E.1 - Fluxo de nêutrons epitérmicos no canal de irradiação 14-15.

\begin{tabular}{|c|c|c|}
\hline Posição & $\phi_{t e r}\left(\mathbf{n} / \mathbf{c m}^{2} \mathbf{s}\right)$ & $\sigma_{\phi_{t e r}}(\%)$ \\
\hline $637-1$ & $9,23 \mathrm{E}+07$ & $2,45 \%$ \\
\hline $637-2$ & $3,50 \mathrm{E}+08$ & $2,24 \%$ \\
\hline $637-3$ & $3,51 \mathrm{E}+08$ & $2,20 \%$ \\
\hline $637-4$ & $2,68 \mathrm{E}+08$ & $2,19 \%$ \\
\hline $637-5$ & $8,22 \mathrm{E}+07$ & $2,32 \%$ \\
\hline $546-1$ & $4,77 \mathrm{E}+08$ & $2,19 \%$ \\
\hline $546-2$ & $7,75 \mathrm{E}+08$ & $2,33 \%$ \\
\hline $546-3$ & $8,23 \mathrm{E}+08$ & $2,18 \%$ \\
\hline 546-4 & $6,04 \mathrm{E}+08$ & $2,20 \%$ \\
\hline $546-5$ & $2,09 \mathrm{E}+08$ & $2,28 \%$ \\
\hline $455-1$ & $6,93 \mathrm{E}+08$ & $2,19 \%$ \\
\hline $455-2$ & $1,19 \mathrm{E}+09$ & $2,20 \%$ \\
\hline $455-3$ & $1,18 \mathrm{E}+09$ & $2,21 \%$ \\
\hline $455-4$ & $9,08 \mathrm{E}+08$ & $2,24 \%$ \\
\hline $455-5$ & $3,25 \mathrm{E}+08$ & $2,28 \%$ \\
\hline $364-1$ & $8,02 \mathrm{E}+08$ & $2,26 \%$ \\
\hline $364-2$ & $1,07 \mathrm{E}+09$ & $2,18 \%$ \\
\hline $364-3$ & $1,35 \mathrm{E}+09$ & $2,20 \%$ \\
\hline $364-4$ & $1,03 \mathrm{E}+09$ & $2,18 \%$ \\
\hline $364-5$ & $3,79 \mathrm{E}+08$ & $5,12 \%$ \\
\hline $273-1$ & $7,23 \mathrm{E}+08$ & $2,18 \%$ \\
\hline $273-2$ & $1,23 \mathrm{E}+09$ & $2,21 \%$ \\
\hline $273-3$ & $1,31 \mathrm{E}+09$ & $2,18 \%$ \\
\hline $273-4$ & $9,65 \mathrm{E}+08$ & $2,19 \%$ \\
\hline $273-5$ & $3,88 \mathrm{E}+08$ & $2,19 \%$ \\
\hline $182-1$ & $5,27 \mathrm{E}+08$ & $2,19 \%$ \\
\hline $182-2$ & $9,44 \mathrm{E}+08$ & $2,19 \%$ \\
\hline $182-3$ & $9,77 \mathrm{E}+08$ & $2,18 \%$ \\
\hline $182-4$ & $7,38 \mathrm{E}+08$ & $2,29 \%$ \\
\hline $182-5$ & $3,02 \mathrm{E}+08$ & $2,19 \%$ \\
\hline 91-1 & $2,52 \mathrm{E}+08$ & $2,20 \%$ \\
\hline $91-2$ & $4,70 \mathrm{E}+08$ & $2,18 \%$ \\
\hline $91-3$ & $5,00 \mathrm{E}+08$ & $2,26 \%$ \\
\hline $91-4$ & $3,69 \mathrm{E}+08$ & $2,18 \%$ \\
\hline $91-5$ & $1,48 \mathrm{E}+08$ & $2,21 \%$ \\
\hline
\end{tabular}


Tabela E.2 - Fluxo de nêutrons epitérmicos no canal de irradiação 10-11.

\begin{tabular}{|c|c|c|}
\hline Posição & $\phi_{\text {ter }}\left(\mathbf{n} / \mathbf{c m}^{\mathbf{2}} \mathbf{s}\right)$ & $\sigma_{\phi_{\text {ter }}}(\boldsymbol{\%})$ \\
\hline $637-1$ & $1,6109 \mathrm{E}+08$ & $2,49 \%$ \\
\hline $637-2$ & $3,5118 \mathrm{E}+08$ & $2,36 \%$ \\
\hline $637-3$ & $4,1926 \mathrm{E}+08$ & $2,23 \%$ \\
\hline $637-4$ & $2,9916 \mathrm{E}+08$ & $2,86 \%$ \\
\hline $637-5$ & $1,4441 \mathrm{E}+08$ & $3,07 \%$ \\
\hline $546-1$ & $3,5599 \mathrm{E}+08$ & $2,45 \%$ \\
\hline $546-2$ & $7,8971 \mathrm{E}+08$ & $2,30 \%$ \\
\hline $546-3$ & $9,4367 \mathrm{E}+08$ & $2,19 \%$ \\
\hline $546-4$ & $7,4829 \mathrm{E}+08$ & $3,61 \%$ \\
\hline $546-5$ & $3,4644 \mathrm{E}+08$ & $2,25 \%$ \\
\hline $455-1$ & $5,0385 \mathrm{E}+08$ & $2,37 \%$ \\
\hline $455-2$ & $1,1263 \mathrm{E}+09$ & $2,38 \%$ \\
\hline $455-3$ & $1,2874 \mathrm{E}+09$ & $2,28 \%$ \\
\hline $455-4$ & $1,1085 \mathrm{E}+09$ & $2,57 \%$ \\
\hline $455-5$ & $4,9486 \mathrm{E}+08$ & $2,57 \%$ \\
\hline $364-1$ & $5,3487 \mathrm{E}+08$ & $2,90 \%$ \\
\hline $364-2$ & $1,2725 \mathrm{E}+09$ & $2,78 \%$ \\
\hline $364-3$ & $1,4928 \mathrm{E}+09$ & $2,32 \%$ \\
\hline $364-4$ & $1,2359 \mathrm{E}+09$ & $2,34 \%$ \\
\hline $364-5$ & $5,4282 \mathrm{E}+08$ & $2,18 \%$ \\
\hline $273-1$ & $5,1453 \mathrm{E}+08$ & $2,18 \%$ \\
\hline $273-2$ & $1,1360 \mathrm{E}+09$ & $2,20 \%$ \\
\hline $273-3$ & $1,3364 \mathrm{E}+09$ & $2,22 \%$ \\
\hline $273-4$ & $1,1137 \mathrm{E}+09$ & $2,18 \%$ \\
\hline $273-5$ & $4,9023 \mathrm{E}+08$ & $2,42 \%$ \\
\hline $182-1$ & $3,7513 \mathrm{E}+08$ & $2,25 \%$ \\
\hline $182-2$ & $8,3195 \mathrm{E}+08$ & $2,64 \%$ \\
\hline $182-3$ & $9,8751 \mathrm{E}+08$ & $2,38 \%$ \\
\hline $182-4$ & $8,2685 \mathrm{E}+08$ & $2,27 \%$ \\
\hline $182-5$ & $3,6910 \mathrm{E}+08$ & $2,40 \%$ \\
\hline $91-1$ & $1,7720 \mathrm{E}+08$ & $2,37 \%$ \\
\hline $91-2$ & $3,8168 \mathrm{E}+08$ & $2,25 \%$ \\
\hline $91-3$ & $4,3534 \mathrm{E}+08$ & $3,00 \%$ \\
\hline $91-4$ & $3,7798 \mathrm{E}+08$ & $2,22 \%$ \\
\hline $91-5$ & $1,6521 \mathrm{E}+08$ & $4,25 \%$ \\
\hline
\end{tabular}


Tabela E.3 - Fluxo de nêutrons epitérmicos no canal de irradiação 6-7.

\begin{tabular}{|c|c|c|}
\hline Posição & $\phi_{t e r}\left(\mathbf{n} / \mathbf{c m}^{2} \mathbf{s}\right)$ & $\sigma_{\phi_{\text {ter }}}(\boldsymbol{\%})$ \\
\hline $637-2$ & $2,6075 \mathrm{E}+08$ & $3,94 \%$ \\
\hline $637-3$ & $3,1353 \mathrm{E}+08$ & $3,95 \%$ \\
\hline $637-4$ & $2,2050 \mathrm{E}+08$ & $4,11 \%$ \\
\hline $546-2$ & $3,2252 \mathrm{E}+08$ & $3,85 \%$ \\
\hline $546-3$ & $4,6070 \mathrm{E}+08$ & $3,87 \%$ \\
\hline $546-4$ & $6,1671 \mathrm{E}+08$ & $3,80 \%$ \\
\hline $455-2$ & $3,8444 \mathrm{E}+08$ & $4,31 \%$ \\
\hline $455-3$ & $4,8843 \mathrm{E}+08$ & $3,83 \%$ \\
\hline $455-4$ & $3,8444 \mathrm{E}+08$ & $4,31 \%$ \\
\hline $364-2$ & $3,9831 \mathrm{E}+08$ & $4,22 \%$ \\
\hline $364-3$ & $5,6147 \mathrm{E}+08$ & $3,81 \%$ \\
\hline $364-4$ & $1,0039 \mathrm{E}+09$ & $3,88 \%$ \\
\hline $273-2$ & $4,0357 \mathrm{E}+08$ & $3,84 \%$ \\
\hline $273-3$ & $5,4012 \mathrm{E}+08$ & $3,85 \%$ \\
\hline $273-4$ & $8,8291 \mathrm{E}+08$ & $4,74 \%$ \\
\hline $182-2$ & $2,2194 \mathrm{E}+08$ & $3,93 \%$ \\
\hline $182-3$ & $3,5395 \mathrm{E}+08$ & $4,43 \%$ \\
\hline $182-4$ & $7,5732 \mathrm{E}+08$ & $4,32 \%$ \\
\hline $91-2$ & $2,0538 \mathrm{E}+08$ & $5,54 \%$ \\
\hline $91-3$ & $2,7877 \mathrm{E}+08$ & $4,09 \%$ \\
\hline $91-4$ & $3,8501 \mathrm{E}+08$ & $3,95 \%$ \\
\hline
\end{tabular}

Tabela E.4 - Fluxo de nêutrons epitérmicos no canal de irradiação 2-3.

\begin{tabular}{|c|c|c|}
\hline Posição & $\phi_{\text {ter }}\left(\mathbf{n} / \mathbf{c m}^{2} \mathbf{s}\right)$ & $\sigma_{\phi_{\text {ter }}}(\boldsymbol{\%})$ \\
\hline $637-3$ & $1,96 \mathrm{E}+08$ & $2,92 \%$ \\
\hline $546-3$ & $4,70 \mathrm{E}+08$ & $2,19 \%$ \\
\hline $455-3$ & $6,71 \mathrm{E}+08$ & $2,43 \%$ \\
\hline $364-3$ & $7,52 \mathrm{E}+08$ & $2,44 \%$ \\
\hline $273-3$ & $6,90 \mathrm{E}+08$ & $3,19 \%$ \\
\hline $182-3$ & $5,25 \mathrm{E}+08$ & $2,39 \%$ \\
\hline $91-3$ & $2,50 \mathrm{E}+08$ & $2,24 \%$ \\
\hline
\end{tabular}


APÊNDICE F - Fatores de perturbação das folhas de ouro hiperpuras

Os fatores de perturbação nesta pesquisa foram obtidos experimentalmente e comparados com valores típicos das literaturas de física de reatores [7].

Foram utilizadas folhas de ouro hiperpuras no canal de irradiação 14-15, assim os valores encontrados experimentalmente, foram usados na obtenção do fluxo de nêutrons térmicos apenas nesta posição de irradiação. A faixa de energia térmica utilizada foi até $0,55 \mathrm{eV}$ (energia de corte do cádmio) [21,42].

Na TAB F.1 apresentam-se os valores dos fatores de perturbação térmico e epitérmico, para o canal de irradiação 14-15, obtidos através da razão entre os valores da $\frac{A^{\infty}}{N}$ para as folhas hiperpuras e infinitamente diluídas respectivamente.

Tabela F.1 - Valores dos fatores de perturbação térmico e epitérmico para o canal de irradiação 14-15.

\begin{tabular}{|c|c|c|c|c|}
\hline Posição & $F P_{\text {ter }}$ & $\begin{array}{c}\sigma_{F P_{\text {ter }}} \\
\mathbf{( \% )}\end{array}$ & $F P_{\text {epit }}$ & $\begin{array}{c}\sigma_{F P_{\text {epit }}} \\
\mathbf{( \% )}\end{array}$ \\
\hline $637-1$ & 1,1005 & $4,90 \%$ & 0,4535 & $2,23 \%$ \\
\hline $637-2$ & 0,7750 & $7,30 \%$ & 0,5226 & $6,80 \%$ \\
\hline $637-3$ & 0,5505 & $4,10 \%$ & 0,6733 & $5,92 \%$ \\
\hline $637-4$ & 0,5829 & $3,35 \%$ & 0,6879 & $5,43 \%$ \\
\hline $637-5$ & 0,5567 & $4,65 \%$ & 1,0682 & $7,43 \%$ \\
\hline $546-1$ & 1,5439 & $21,15 \%$ & 0,4243 & $8,21 \%$ \\
\hline $546-2$ & 0,6235 & $5,52 \%$ & 0,5455 & $8,12 \%$ \\
\hline $546-3$ & 0,6045 & $6,69 \%$ & 0,6171 & $7,20 \%$ \\
\hline $546-4$ & 0,4465 & $4,21 \%$ & 0,6757 & $6,58 \%$ \\
\hline $546-5$ & 0,4380 & $3,59 \%$ & 0,9581 & $5,08 \%$ \\
\hline $455-1$ & 1,5994 & $14,05 \%$ & 0,4038 & $7,74 \%$ \\
\hline $455-2$ & 0,7024 & $8,68 \%$ & 0,4807 & $8,21 \%$ \\
\hline $455-3$ & 0,6185 & $4,88 \%$ & 0,6109 & $7,30 \%$ \\
\hline $455-4$ & 0,4365 & $4,26 \%$ & 0,6634 & $6,92 \%$ \\
\hline $455-5$ & 0,4621 & $3,03 \%$ & 0,8483 & $5,40 \%$ \\
\hline $364-1$ & 1,5529 & $14,48 \%$ & 0,3911 & $7,72 \%$ \\
\hline $364-2$ & 0,5286 & $5,37 \%$ & 0,6056 & $7,12 \%$ \\
\hline $364-3$ & 0,6896 & $4,89 \%$ & 0,5889 & $7,06 \%$ \\
\hline $364-4$ & 0,4933 & $5,37 \%$ & 0,6320 & $6,87 \%$ \\
\hline
\end{tabular}




\begin{tabular}{|c|c|c|c|c|}
\hline Posição & $F P_{\text {ter }}$ & $\begin{array}{c}\sigma_{F P_{\text {ter }}} \\
\mathbf{( \% )}\end{array}$ & $F P_{\text {epit }}$ & $\begin{array}{c}\sigma_{F P_{\text {epit }}} \\
\mathbf{( \% )}\end{array}$ \\
\hline $364-5$ & 0,5191 & $3,03 \%$ & 0,7724 & $5,55 \%$ \\
\hline $273-1$ & 1,5133 & $12,88 \%$ & 0,4009 & $7,66 \%$ \\
\hline $273-2$ & 0,8108 & $7,26 \%$ & 0,4758 & $7,56 \%$ \\
\hline $273-3$ & 0,6482 & $6,12 \%$ & 0,5698 & $7,36 \%$ \\
\hline $273-4$ & 0,4789 & $4,79 \%$ & 0,6310 & $7,18 \%$ \\
\hline $273-5$ & 0,5972 & $4,17 \%$ & 0,7207 & $5,55 \%$ \\
\hline $182-1$ & 1,4534 & $12,88 \%$ & 0,4073 & $7,46 \%$ \\
\hline $182-2$ & 0,8131 & $8,59 \%$ & 0,4790 & $8,08 \%$ \\
\hline $182-3$ & 0,6406 & $6,18 \%$ & 0,5611 & $7,72 \%$ \\
\hline $182-4$ & 0,5674 & $4,17 \%$ & 0,5912 & $6,75 \%$ \\
\hline $182-5$ & 0,5843 & $3,05 \%$ & 0,6990 & $4,90 \%$ \\
\hline $91-1$ & 1,2857 & $8,30 \%$ & 0,3862 & $5,84 \%$ \\
\hline $91-2$ & 1,1567 & $7,02 \%$ & 0,4417 & $5,79 \%$ \\
\hline $91-3$ & 0,7498 & $5,67 \%$ & 0,5025 & $5,92 \%$ \\
\hline $91-4$ & 0,7289 & $3,75 \%$ & 0,5480 & $4,92 \%$ \\
\hline $91-5$ & 0,6832 & $3,69 \%$ & 0,6411 & $5,96 \%$ \\
\hline
\end{tabular}

Os valores obtidos por Gonçalves [1] em 2008 foram pelo uso do código MCNP-4C, ou seja, foram valores calculados. Neste trabalho, optou-se pela utilização dos valores experimentais obtidos graças a irradiação de folhas de ouro hiperpuras e infinitamente diluídas num mesmo canal de irradiação (14-15), apesar de notarmos uma grande variação nos seus valores, o que requer uma análise futura. O cálculo de Gonçalves foi realizado com uma concentração de $10^{-5}$ átomos de ouro na folha infinitamente diluída, enquanto que a medida real é feita com uma de $10^{-2}$ (1\% de Au para 99\% de Al). 
APÊNDICE G- Fatores de autoabsorção das folhas de ouro hiperpuras

Durante a espectrometria gama o próprio detector de ativação pode absorver partículas gama, fato que reduz a ionização no cristal de germânio e consequentemente reduz também a contagem na leitura realizada pelo HPGe.

O fator de autoabsorção é um valor bastante pequeno porém, quando se calcula valores absolutos de fluxo de nêutrons, este é um fator que deve também ser considerado como fator de correção de fluxo de nêutrons.

Tomando por base as folhas de ouro hiperpuro utilizadas em todas as posições do plano de lucite do canal de irradiação14-15, a área da superfície da folha é aproximadamente a mesma, assim como a densidade do material (Au-197) e a massa das folhas, considera-se então que o fator de autoabsorção é constante. O mesmo raciocínio é válido para as folhas de ouro infinitamente diluído em todos os planos de irradiação no núcleo do reator nuclear (14-15, 10-11, 6-7 e 2-3). Na TAB G.1 apresentam-se os valores dos fatores de autoabsorção das folhas de ouro hiperpuro e infinitamente diluído.

Tabela G.1 - Valores dos fatores de autoabsorção para as folhas hiperpuras e infinitamente diluídas.

\begin{tabular}{|c|c|c|c|c|}
\hline Folha de Ativação & Espessura (cm) & Massa(g) & Raio (cm) & Fator de autoabsorção \\
\hline Hiperpura & 0,0013 & 0,0112 & 0,4 & 1,00726 \\
\hline $\begin{array}{c}\text { Infinitamente } \\
\text { diluída }\end{array}$ & 0,02 & 0,0291 & 0,375 & 1,00333 \\
\hline
\end{tabular}

Os resultados dos cálculos dos fatores de autoabsorção mostram que o acréscimo nas contagens, dada pela autoabsorção gama das folhas hiperpuras, é de $0,72 \%$ e nas folhas infinitamente diluídas é de 0,33\%. 
APÊNDICE H - Relação de potência real versus contagens do canal 10 na configuração cilíndrica de núcleo do reator IPEN/MB-01

As relações de potência real (gerada no núcleo do reator nuclear) versus contagens de saída do canal de pulsos 10 estão nas TAB H.1, H.2, H.3, H.4, H.5 e H.6. As contagens da saída do canal 10 não foram corrigidas pelo fator de correção (FC) pois, trata-se das contagens registradas no sistema de aquisição de dados digital (SAD) da mesa de controle, que o operador irá utilizar para controlar o reator nuclear.

Tabela H.1 - Nível de potência de 20 a 100 mwatts e contagens do canal 10 na configuração cilíndrica.

\begin{tabular}{|c|c|c|}
\hline Potência real (w) & CPS- Saída do canal 10 & Incerteza \\
\hline 0,02 & 0,01 & 0,10 \\
\hline 0,03 & 0,15 & 0,38 \\
\hline 0,04 & 5,68 & 2,38 \\
\hline 0,05 & 11,21 & 3,34 \\
\hline 0,06 & 16,74 & 4,09 \\
\hline 0,07 & 22,27 & 4,71 \\
\hline 0,08 & 27,80 & 5,27 \\
\hline 0,09 & 33,33 & 5,77 \\
\hline 0,1 & 38,86 & 6,23 \\
\hline
\end{tabular}

Tabela H.2 - Nível de potência de 200 a 1000 mwatts e contagens do canal 10 na configuração cilíndrica.

\begin{tabular}{|c|c|c|}
\hline Potência real $(w)$ & CPS- Saída do canal 10 & Incerteza \\
\hline 0,2 & 94,17 & 9,70 \\
\hline 0,3 & 149,47 & 12,23 \\
\hline 0,4 & 204,78 & 14,31 \\
\hline 0,5 & 260,08 & 16,13 \\
\hline 0,6 & 315,38 & 17,76 \\
\hline 0,7 & 370,69 & 19,25 \\
\hline 0,8 & 425,99 & 20,64 \\
\hline 0,9 & 481,30 & 21,94 \\
\hline 1 & 536,60 & 23,16 \\
\hline
\end{tabular}


Tabela H.3 - Nível de potência de 2 a 10 watts e contagens do canal 10 na configuração cilíndrica.

\begin{tabular}{|c|c|c|}
\hline Potência real (w) & CPS- Saída do canal 10 & Incerteza \\
\hline 2 & 1090 & 33,01 \\
\hline 3 & 1643 & 40,53 \\
\hline 4 & 2196 & 46,86 \\
\hline 5 & 2749 & 52,43 \\
\hline 6 & 3302 & 57,46 \\
\hline 7 & 3855 & 62,09 \\
\hline 8 & 4408 & 66,39 \\
\hline 9 & 4961 & 70,43 \\
\hline 10 & 5514 & 74,26 \\
\hline
\end{tabular}

Tabela H.4 - Nível de potência de 12 a 44 watts e contagens do canal 10 na configuração cilíndrica.

\begin{tabular}{|c|c|c|}
\hline Potência real $(w)$ & CPS- Saída do canal 10 & Incerteza \\
\hline 12 & 6620 & 81,36 \\
\hline 14 & 7726 & 87,90 \\
\hline 16 & 8832 & 93,98 \\
\hline 18 & 9938 & 99,69 \\
\hline 20 & 11044 & 105,09 \\
\hline 22 & 12150 & 110,23 \\
\hline 24 & 13257 & 115,14 \\
\hline 26 & 14363 & 119,84 \\
\hline 28 & 15469 & 124,37 \\
\hline 30 & 16575 & 128,74 \\
\hline 32 & 17681 & 132,97 \\
\hline 34 & 18787 & 137,07 \\
\hline 36 & 19893 & 141,04 \\
\hline 38 & 20999 & 144,91 \\
\hline 40 & 22105 & 148,68 \\
\hline 42 & 23211 & 152,35 \\
\hline 44 & 24317 & 155,94 \\
\hline
\end{tabular}


Tabela H.5 - Nível de potência de 46 a 78 watts e contagens do canal 10 na configuração cilíndrica.

\begin{tabular}{|c|c|c|}
\hline Potência real $(w)$ & CPS- Saída do canal 10 & Incerteza \\
\hline 46 & 25423 & 159,45 \\
\hline 48 & 26529 & 162,88 \\
\hline 50 & 27636 & 166,24 \\
\hline 52 & 28742 & 169,53 \\
\hline 54 & 29848 & 172,76 \\
\hline 56 & 30954 & 175,94 \\
\hline 58 & 32060 & 179,05 \\
\hline 60 & 33166 & 182,12 \\
\hline 62 & 34272 & 185,13 \\
\hline 64 & 35378 & 188,09 \\
\hline 66 & 36484 & 191,01 \\
\hline 68 & 37590 & 193,88 \\
\hline 70 & 38696 & 196,71 \\
\hline 72 & 39802 & 199,51 \\
\hline 74 & 40909 & 202,26 \\
\hline 76 & 42015 & 204,97 \\
\hline 78 & 43121 & 207,66 \\
\hline
\end{tabular}

Tabela H.6 - Nível de potência de 80 a 120 watts e contagens do canal 10 na configuração cilíndrica.

\begin{tabular}{|c|c|c|}
\hline Potência real $(w)$ & CPS- Saída do canal 10 & Incerteza \\
\hline 80 & 44227 & 210,30 \\
\hline 82 & 45333 & 212,92 \\
\hline 84 & 46439 & 215,50 \\
\hline 86 & 47545 & 218,05 \\
\hline 88 & 48651 & 220,57 \\
\hline 90 & 49757 & 223,06 \\
\hline 92 & 50863 & 225,53 \\
\hline 94 & 51969 & 227,97 \\
\hline 96 & 53075 & 230,38 \\
\hline 98 & 54181 & 232,77 \\
\hline 100 & 55288 & 235,13 \\
\hline 102 & 56394 & 237,47 \\
\hline 104 & 57500 & 239,79 \\
\hline 106 & 58606 & 242,09 \\
\hline 108 & 59712 & 244,36 \\
\hline 110 & 60818 & 246,61 \\
\hline 120 & 66348 & 257,58 \\
\hline
\end{tabular}


APÊNDICE I - Núcleos cilindrizados

No trabalho em desenvolvimento de Bitelli e Santos [41] utilizam-se as configurações geométricas de núcleo cilindrizado 30 x 30 varetas combustíveis com um flux trap de água pesada $\left(\mathrm{D}_{2} \mathrm{O}\right)$ no interior do núcleo, assim como uma geometria cilindrizada de também 30 x 30 varetas, porém com água leve (H2O) em seu interior. Foram realizadas operações nestas configurações para medir o espectro e o fluxo de nêutrons no núcleo, que são parâmetros da física de reatores que dependem do conhecimento preciso da potência de operação do reator.

A configuração geométrica de núcleo cilindrizado de 30 x 30 varetas combustíveis com flux trap utilizado para água pesada e água leve é apresentada na FIG I.1.

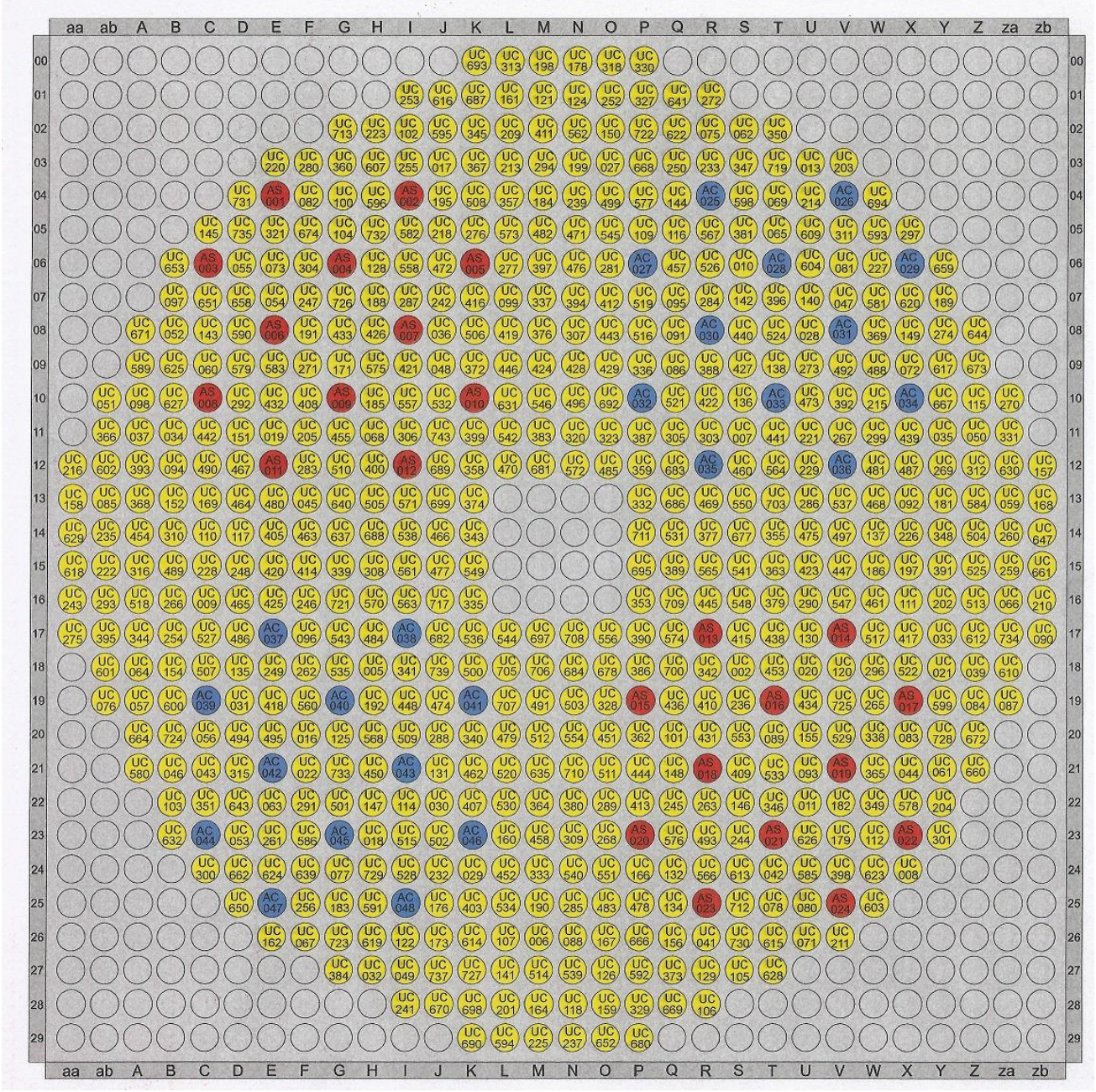

Figura I.1 - Configuração cilindrizada 30 x 30 com flux trap no centro do núcleo. 
Os fatores de correção para a configuração cilindrizada com flux trap de água pesada e água leve, são apresentados nas TAB I.1 e I.2.

Tabela I.1 - Valores de FC para a configuração cilindrizada 30 x 30 com flux trap de água pesada $\left(\mathrm{D}_{2} \mathrm{O}\right)$.

\begin{tabular}{|c|c|c|c|c|c|c|}
\hline $\begin{array}{c}\text { POTÊNCIA } \\
\text { NOMINAL } \\
\text { DO CANAL 6 } \\
(\mathbf{w})^{*}\end{array}$ & $\begin{array}{c}\text { CONTAGEM } \\
\text { NÃO } \\
\text { CORRIGIDA } \\
* *\end{array}$ & $\begin{array}{c}\boldsymbol{\sigma} \\
\text { (CONTAGEM } \\
\text { Não } \\
\text { CORIGIDA) }\end{array}$ & $\begin{array}{c}\text { CONTAGEM } \\
\text { CORRIGIDA } \\
* *\end{array}$ & $\begin{array}{c}\boldsymbol{\sigma} \\
\text { (CONTAGEM } \\
\text { CORRIGIDA })\end{array}$ & $\begin{array}{c}\text { FATOR DE } \\
\text { CORREÇÃO } \\
* * *\end{array}$ & $\begin{array}{c}\text { POTÊNCIA } \\
\text { REAL (w) }\end{array}$ \\
\hline 1 & 401,11 & 20,02 & 401,11 & 20,02 & $\approx 1$ & 0,76 \\
\hline 5 & 2027,64 & 45,02 & 2005,51 & 44,78 & $\approx 1$ & 3,66 \\
\hline 10 & 4016,61 & 63,37 & 4011,10 & 63,33 & $\approx 1$ & 7,28 \\
\hline 20 & 9472,35 & 97,32 & 8022,20 & 89,56 & $\approx 1$ & 14,53 \\
\hline 30 & 13222,49 & 114,98 & 12033,30 & 109,69 & $\approx 1$ & 21,79 \\
\hline 40 & 16883,13 & 129,93 & 16044,40 & 126,66 & $\approx 1$ & 29,04 \\
\hline 50 & 20476,65 & 143,09 & 20055,51 & 141,61 & $\approx 1$ & 36,29 \\
\hline 60 & 23976,96 & 154,84 & 24066,61 & 155,13 & 1,004 & 43,55 \\
\hline 70 & 27410,86 & 165,56 & 28077,71 & 167,56 & 1,024 & 50,80 \\
\hline 80 & 30777,69 & 175,43 & 32088,81 & 179,13 & 1,043 & 58,05 \\
\hline 90 & 34131,09 & 184,74 & 36099,91 & 189,99 & 1,058 & 65,31 \\
\hline 100 & 37391,81 & 193,36 & 40111,02 & 200,27 & 1,073 & 72,56 \\
\hline
\end{tabular}

*A incerteza da potência nominal do canal 6 é de $2,03 \%$.

** Os valores de contagens não corrigidas foram obtidos das médias simples das diversas aquisições para cada potência do canal 10.

*** A incerteza do FC é de $1,8 \%$. 
Tabela I.2 - Valores de FC para a configuração cilindrizada 30 x 30 com flux trap de água leve $\left(\mathrm{H}_{2} \mathrm{O}\right)$.

\begin{tabular}{|c|c|c|c|c|c|c|}
\hline $\begin{array}{c}\text { POTÊNCIA } \\
\text { NOMINAL } \\
\text { DO CANAL } 6 \\
(w)^{*}\end{array}$ & $\begin{array}{c}\text { CONTAGEM } \\
\text { NÃO } \\
\text { CORRIGIDA } \\
* * \\
\end{array}$ & $\begin{array}{c}\boldsymbol{\sigma} \\
\text { (CONTAGEM } \\
\text { NÃo } \\
\text { CORRIGIDA) } \\
\end{array}$ & $\begin{array}{c}\text { CONTAGE } \\
\text { M } \\
\text { CORRIGID } \\
\text { A } * * \\
\end{array}$ & $\begin{array}{c}\boldsymbol{\sigma} \\
\text { (CONTAGEM } \\
\text { CORRIGIDA) }\end{array}$ & $\begin{array}{c}\text { FATOR DE } \\
\text { COREEÇÃO } \\
\text { CO** }\end{array}$ & $\begin{array}{l}\text { POTÊNCIA } \\
\text { REAL (w) }\end{array}$ \\
\hline 1 & 388,63 & 19,71 & 388,64 & 19,71 & $\approx 1$ & 0,73 \\
\hline 5 & 1960,04 & 44,27 & 1943,19 & 44,08 & $\approx 1$ & 3,54 \\
\hline 10 & 3878,69 & 62,27 & 3920,08 & 62,61 & $\approx 1$ & 7,11 \\
\hline 20 & 9200,51 & 95,91 & 7757,38 & 88,07 & $\approx 1$ & 14,05 \\
\hline 30 & 12802,60 & 113,14 & 11636,08 & 107,87 & $\approx 1$ & 21,06 \\
\hline 40 & 16393,29 & 128,03 & 15514,77 & 124,55 & $\approx 1$ & 28,08 \\
\hline 50 & 19907,34 & 141,09 & 19600,44 & 140,00 & $\approx 1$ & 35,47 \\
\hline 60 & 23350,21 & 152,80 & 23272,16 & 152,55 & $\approx 1$ & 42,11 \\
\hline 70 & 26724,36 & 163,47 & 27150,86 & 164,77 & 1,016 & 49,12 \\
\hline 80 & 30014,46 & 173,24 & 31029,55 & 176,15 & 1,034 & 56,13 \\
\hline 90 & 33478,70 & 182,97 & 34908,24 & 186,83 & 1,043 & 63,15 \\
\hline 100 & 36816,77 & 191,87 & 38786,94 & 196,94 & 1,054 & 70,16 \\
\hline
\end{tabular}

*A incerteza da potência nominal do canal 6 é de 2,03\%.

** Os valores de contagens não corrigidas foram obtidos das médias simples das diversas aquisições para cada potência do canal 10.

*** A incerteza do FC é de $1,8 \%$. 
ANEXO A - Reator nuclear IPEN/MB-01

A.1 Introdução

O IPEN/MB-01 é um reator nuclear brasileiro, projetado por pesquisadores e Engenheiros do Instituto de Pesquisas Energéticas e Nucleares (IPEN-CNEN/SP) e da antiga COPESP (Coordenadoria para Projetos Especiais), atual CTMSP (Centro Tecnológico da Marinha em São Paulo), financiado e construído pela Marinha do Brasil, atingiu sua primeira criticalidade às 15 horas e 35 minutos do dia 9 de Novembro de 1988, sendo oficialmente entregue para operação ao IPENCNEN/SP em 28 de Novembro deste mesmo ano.

O Reator IPEN/MB-01 é uma instalação nuclear que possibilita a simulação de todas as características nucleares de um reator de grande porte em escala reduzida, sem que haja a necessidade de construir-se um complexo sistema secundário de remoção de calor. Esse tipo de reator é conhecido mundialmente como Reator de Potência Zero, sendo o nosso reator especificamente, homologado para operar a potência máxima de 100 watts. Esses reatores representam uma ferramenta básica, que permitem aos pesquisadores estudarem não apenas por cálculos teóricos, mas também com medidas experimentais, o desempenho e as características do núcleo de um reator de potência ou de propulsão naval, antes da sua efetiva instalação, simulando as condições de projeto na própria instalação.

A filosofia que norteou o projeto do reator IPEN/MB-01, foi no sentido de se projetar e testar um núcleo típico para uso em propulsão naval, ou seja, que o controle de reatividade se desse a partir da inserção ou retirada de barras de controle, contrariando o modelo de muitos reatores nucleares em que o controle se dá pelo nível d'água no tanque moderador. Esse controle de reatividade por barras de controle é típico de reatores navais, em que se necessitam de rápidas variações de potência, a fim de se empreenderem manobras de fuga ou de perseguição. 
A.2 Descrição do reator IPEN/MB-01

O primeiro núcleo do Reator IPEN/MB-01 possuía a forma de paralelepípedo com dimensões ativas de 39 × 42 × 54,6 cm, chamada de retangular, sendo constituído de um arranjo de 28 x 26 varetas (680 varetas) combustíveis e 48 tubos guias, destinados à inserção das barras de controle e segurança, responsáveis pelo controle da reação em cadeia e desligamento do reator.

Uma excelente característica do Reator Nuclear IPEN/MB-01 é que seu núcleo possibilita a montagem de diferentes arranjos críticos, isto é, diferentes configurações de núcleos, uma vez que foi projetado para que apresentasse a versatilidade e a flexibilidade necessárias para tais finalidades. Para tal, a placa matriz que sustenta o núcleo do reator possui 900 furos espaçados entre si por 1,5 cm, em um arranjo de 30x30 furos. Nesta placa matriz foram montados os arranjos críticos, retangular (visto na FIG A.1), quadrado, cilindrizado e cilíndrico (visto na FIG A.2). Este último foi utilizado como objeto de estudo deste trabalho.

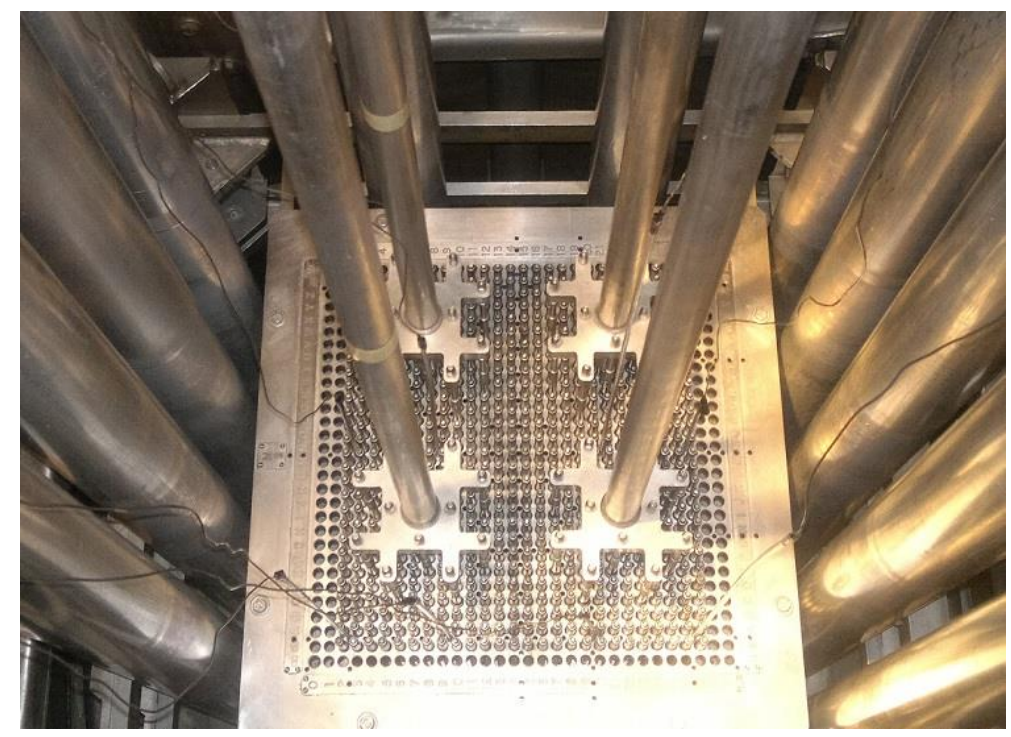

Figura A.1 - Vista do núcleo: Arranjo retangular de 30x30 varetas combustíveis 


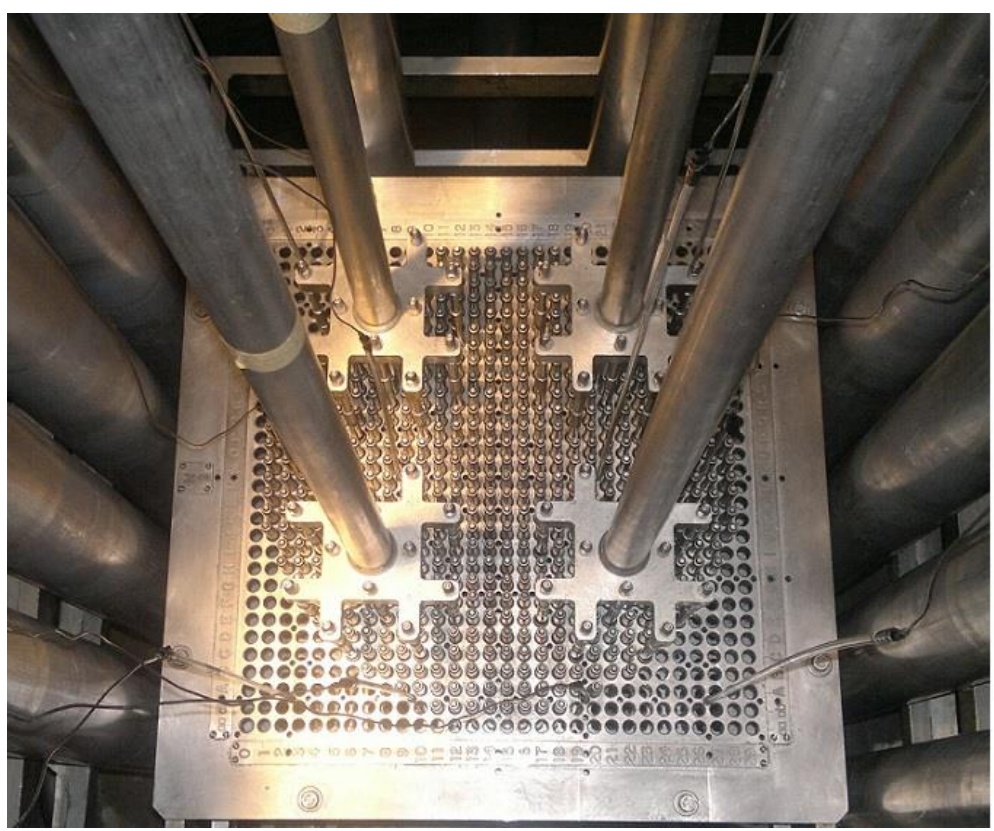

Figura A.2 - Vista do núcleo: Arranjo cilíndrico de 28x28 varetas combustíveis

As varetas combustíveis do reator são constituídas de tubos de aço inox AISI-304, contendo em seu interior um total de 52 pastilhas combustíveis de $\mathrm{UO}_{2}$ enriquecidas a 4,3 $\%$. A altura ativa da coluna de pastilhas é de $54,6 \mathrm{~cm}$, sendo que cada pastilha possui uma altura de $1,05 \mathrm{~cm}$ e diâmetro de $0,849 \mathrm{~cm}$. As extremidades não ativas das varetas são preenchidas com pastilhas de $\mathrm{Al}_{2} \mathrm{O}_{3}$. Os 48 tubos guias para as varetas absorvedoras de nêutrons (barras de controle e segurança) estão dispostos em 4 grupos, contendo cada um deles 12 varetas absorvedoras, sendo dois grupos de barras de segurança e 2 grupos de controle, dispostos cada um deles em um quadrante do núcleo do reator. Cada conjunto de 12 varetas absorvedoras é unido através de um corpo central, denominado aranha, o qual é ligado a uma haste de acionamento, que por sua vez é conectada a mecanismos acionados por magnetos energizados.

Apresentam-se nas Tabelas A.1, A.2, A.3 e A.4 a seguir, as composições detalhadas e as geometrias das varetas combustíveis e de controle do Reator IPEN/MB-01. O diagrama esquemático da vareta combustível e de controle, podem ser vistos na Figura A.3 a seguir. 

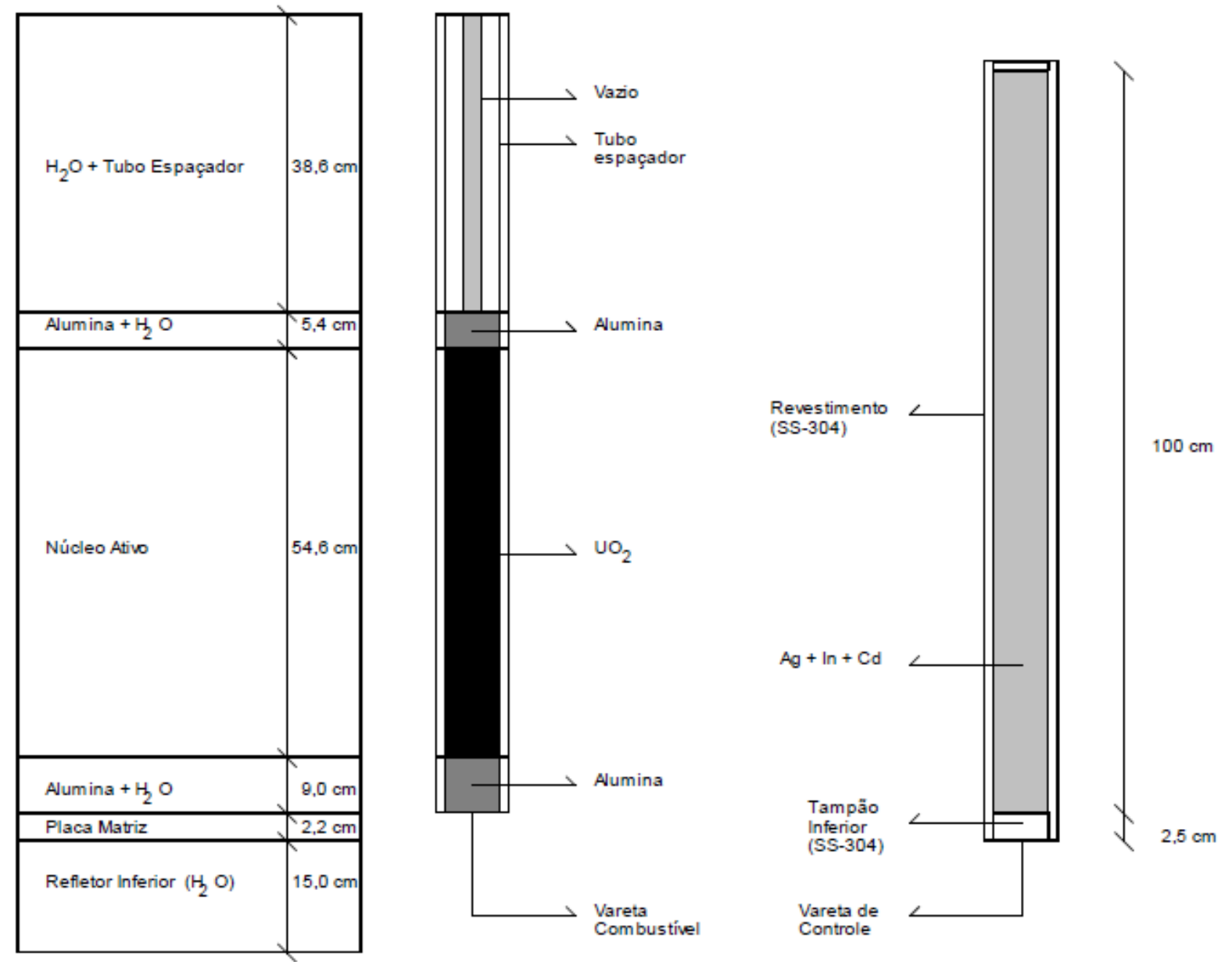

Figura A.3 - Diagrama esquemático das varetas de combustível e de controle

A reatividade integral de cada barra de controle ou de segurança é suficiente para desligar o reator, ou seja, é de aproximadamente 3200 pcm. As barras de segurança apresentam as mesmas características geométricas das barras de controle, diferenciando das mesmas pelo material absorvedor de nêutrons utilizado, no caso $\mathrm{B}_{4} \mathrm{C}$ e pelo fato de que durante a operação normal do reator, serem mantidas totalmente retiradas do núcleo ativo do mesmo, com o objetivo de desligá-lo com grande margem de segurança. As barras de controle são as responsáveis por controlarem a população de nêutrons, e assim controlarem igualmente os vários níveis de potência.

Quando inseridas no núcleo do reator nuclear, as barras de controle mantêm o nível de população neutrônica, através da absorção dos mesmos em seu material estrutural composto de uma liga de $\mathrm{Ag}-\mathrm{In}-\mathrm{Cd}$, encapsulada num revestimento de aço inox austenítico. 
Tabela A.1 - Dados geométricos da vareta de controle do reator IPEN/MB-01.

\begin{tabular}{|l|c|}
\hline Material Absorvedor & Ag-In-Cd \\
\hline Diâmetro do Absorvedor & $0,832 \mathrm{~cm}$ \\
\hline Diâmetro Externo do Revestimento & $0,980 \mathrm{~cm}$ \\
\hline Espessura do Revestimento & $0,060 \mathrm{~cm}$ \\
\hline Diâmetro Externo do Tubo Guia & $1,200 \mathrm{~cm}$ \\
\hline Espessura do Tubo Guia & $0,035 \mathrm{~cm}$ \\
\hline
\end{tabular}

Tabela A.2 - Dados geométricos da vareta de combustível do reator IPEN/MB-01.

\begin{tabular}{|c|c|}
\hline \multicolumn{2}{|l|}{ Região Ativa } \\
\hline Combustível & $\mathrm{UO}_{2}$ \\
\hline Diâmetro da Pastilha & $0,849 \mathrm{~cm}$ \\
\hline Diâmetro Externo do Revestimento & $0,980 \mathrm{~cm}$ \\
\hline Espessura do Revestimento & $0,060 \mathrm{~cm}$ \\
\hline Passo da Rede & $1,500 \mathrm{~cm}$ \\
\hline \multicolumn{2}{|l|}{ Região de Alumina } \\
\hline Diâmetro da Pastilha & $0,949 \mathrm{~cm}$ \\
\hline Diâmetro Externo do Revestimento & $0,980 \mathrm{~cm}$ \\
\hline Espessura do Revestimento & $0,060 \mathrm{~cm}$ \\
\hline \multicolumn{2}{|l|}{ Região do Tubo Espaçador } \\
\hline Diâmetro Interno & $0,730 \mathrm{~cm}$ \\
\hline Diâmetro Externo & $0,849 \mathrm{~cm}$ \\
\hline
\end{tabular}


Tabela A.3 - Composição isotópica da vareta de combustível do reator IPEN/MB-01.

\begin{tabular}{|c|c|}
\hline Pastilha Combustivel & Concentração (atomos/barn-cm) \\
\hline${ }^{235} \mathrm{U}$ & $1,0034 \mathrm{E}-03$ \\
\hline${ }^{238} \mathrm{U}$ & $2,17938 \mathrm{E}-02$ \\
\hline${ }^{16 \circ}$ & $4,55138 \mathrm{E}-02$ \\
\hline Revestimento, Tubo Guia & Concentração (atomos/barn-cm) \\
\hline $\mathrm{Fe}$ & $5,67582 \mathrm{E}-02$ \\
\hline $\mathrm{Ni}$ & $8,64435 \mathrm{E}-03$ \\
\hline $\mathrm{Cr}$ & $1,72649 \mathrm{E}-02$ \\
\hline${ }^{55} \mathrm{Mn}$ & $1,59898 \mathrm{E}-03$ \\
\hline $\mathrm{Si}$ & $3,34513 \mathrm{E}-04$ \\
\hline Pastilha de Alumina & Concentração (atomos/barn-cm) \\
\hline $\mathrm{Al}$ & $4,30049 \mathrm{E}-02$ \\
\hline $16 。$ & $6,45074 \mathrm{E}-02$ \\
\hline
\end{tabular}

Tabela A.4 - Composição isotópica da vareta de controle do reator IPEN/MB-01.

\begin{tabular}{|c|c|}
\hline Absorvedor & Concentração (atomos/barn-cm) \\
\hline${ }^{107} \mathrm{Ag}$ & $2,35462 \mathrm{E}-02$ \\
\hline${ }^{109} \mathrm{Ag}$ & $2,18835 \mathrm{E}-02$ \\
\hline${ }^{113} \mathrm{In}$ & $3,42506 \mathrm{E}-04$ \\
\hline${ }^{115} \mathrm{In}$ & $7,6599 \mathrm{E}-03$ \\
\hline $\mathrm{Cd}$ & $2,72492 \mathrm{E}-03$ \\
\hline Revestimento, Tubo guia, Tampão & Concentração (atomos/barn-cm) \\
\hline Inferior & $5,67582 \mathrm{E}-02$ \\
\hline $\mathrm{Fe}$ & $8,64435 \mathrm{E}-03$ \\
\hline $\mathrm{Ni}$ & $1,72649 \mathrm{E}-02$ \\
\hline $\mathrm{Cr}$ & $1,59898 \mathrm{E}-03$ \\
\hline${ }^{55} \mathrm{Mn}$ & $3,34513 \mathrm{E}-04$ \\
\hline $\mathrm{Si}$ & \\
\hline
\end{tabular}

Todo o núcleo do reator, bem como os mecanismos de acionamento de barras, as guias para as aranhas e o amortecedor de queda de barras, é apoiado por uma estrutura suporte, fixada na parte superior por uma plataforma metálica, e na parte inferior mantida suspensa no interior do tanque moderador, o qual contém água tratada e desmineralizada, utilizada como elemento moderador da energia dos nêutrons de fissão. 
Além das barras de controle e segurança, o sistema de controle de reatividade inclui um sistema de esvaziamento rápido do tanque moderador que provoca o desligamento do reator por perda do fluído moderador. No desligamento por barras, dito de primeiro nível, as 4 barras caem por gravidade no núcleo, a partir do sinal de corte de energia dos magnetos enquanto no desligamento de segundo nível, além de todas as 4 barras caírem , são abertas duas válvulas tipo borboletas de abertura rápida de 50,8 cm de diâmetro, situadas na parte inferior do tanque moderador, causando a retirada de toda água em aproximadamente 4 segundos. A água como sabemos, é um elemento fundamental para a moderação da energia dos nêutrons rápidos de fissão, termalizando-os e com isso tornando a probabilidade de fissão dos núcleos de Urânio-235, muito maiores para os nêutrons de baixa energia, os chamados nêutrons térmicos. A água drenada caindo por gravidade é estocada no primeiro subsolo do reator, mais propriamente no Tanque de estocagem, onde ficará armazenada até ser novamente bombeada para o tanque moderador numa futura operação do reator, ou mesmo para tratamento da mesma, através de filtragem e controle de seu nível de condutividade em um vaso trocador de leito de resina mista ou mesmo para o controle de sua temperatura em trocadores de calor aquecedores ou resfriadores.

\section{A.3 Instrumentação do reator IPEN/MB-01}

A instrumentação nuclear tem por finalidade permitir a operação e o controle do Conjunto Crítico dentro de limites seguros, incorporando assim, tanto funções de acompanhamento de operação quanto às de segurança. Como o Reator IPEN/MB-01 visa o estudo de núcleos de reatores, além dessas funções, uma parte do equipamento deve possibilitar a realização de medidas de desempenho do núcleo.

O Subsistema de Instrumentação Nuclear está dividido em 10 partes ou canais, os quais foram nomeados de acordo com a faixa de operação da Unidade Crítica em que eles prioritariamente atuam (partida/potência), ou de acordo com a sua função (segurança), ou mesmo, tipo de escala (linear).

Estes canais são identificados de acordo com a TAB A.5. 
Tabela A.5 - Sinais e escalas de medidas dos detectores.

\begin{tabular}{|c|c|c|c|}
\hline Canal & Nome & Sinal do Detector & Escala de Medida \\
\hline 1 e 2 & Partida & Pulsos & Log \\
\hline 3 e 4 & Potência & Corrente & $\log$ \\
\hline 5 e 6 & Linear & Corrente & Linear (variável) \\
\hline 7 e 8 & Segurança 1 & Corrente & Linear (fixa) \\
\hline 9 & Segurança 2 (Partida) & Pulsos & $\log$ \\
\hline 10 & Segurança 2 (Potência) & Pulsos & $\log$ \\
\hline
\end{tabular}

O Canal de Partida é um canal de pulsos, utilizando um detector do tipo proporcional $\left(\mathrm{BF}_{3}\right)$ para monitoração da faixa inicial de operação do Reator IPEN/MB-01, quando o fluxo neutrônico é relativamente baixo (nas quatro primeiras décadas). São utilizados dois canais deste tipo (redundantes).

O Canal de Potência é um canal de corrente, cobrindo a parte superior da faixa de partida (duas décadas) até cerca de duas décadas acima de $100 \%$ da potência. O fluxo é monitorado por uma câmara de ionização compensada. Após o processamento pelo canal é gerada uma tensão analógica de saída, a qual é proporcional ao logaritmo da corrente de entrada. São utilizados dois canais desse tipo (redundantes).

Os dois Canais de Segurança tipo 1 (canais 7 e 8) cobrem uma década da faixa de potência do reator. Um dos canais de segurança tipo 2 (canal 10) cobre as mesmas décadas que os canais de potência ( 3 e 4). O outro canal de segurança tipo 2 (canal 9), foi colocado em paralelo com os canais de partida, abrangendo o mesmo número de décadas que aqueles.

O Canal de Segurança 1 opera com uma câmara de ionização não compensada, cuja corrente de saída é proporcional ao fluxo neutrônico.

O Canal de Segurança tipo 2 é um canal de pulsos, operando com um detector do tipo $\mathrm{BF}_{3}$ para o canal 9 e outro de ${ }^{10} \mathrm{~B}$ para o canal 10 . Foi utilizado o detector de ${ }^{10} \mathrm{~B}$ para o canal 10 porque este detector é mais adequado para suportar os níveis de radiação da faixa de potência que o detector de $\mathrm{BF}_{3}$. $\mathrm{O}$ canal 9 foi colocado em paralelo com os canais 
de partida ( 1 e 2) e o canal 10 em paralelo com os canais de potência (canais 3 e 4). Os pulsos provenientes do detector $\left(\mathrm{BF}_{3}\right.$ ou $\left.{ }^{10} \mathrm{~B}\right)$ são processados adequadamente, obtendo-se na saída do canal (9 ou 10) uma tensão proporcional ao fluxo neutrônico.

O Canal Linear é utilizado para medida precisa do fluxo neutrônico, podendo cobrir até cerca de 8 décadas de fluxo. É utilizado pelo controle automático dentro das 3 últimas décadas de operação do Reator IPEN/MB-01. Utiliza uma câmara de ionização compensada, fornecendo a indicação do fluxo por meio de um medidor linear e um indicador de escala (11 escalas).

Os Comparadores efetuam a comparação das variáveis medidas pelos canais, exceto o Canal Linear, com 3 níveis pré-determinados para cada variável medida.

A FIG A.4 mostra as faixas de operação de cada um dois 10 canais nucleares.

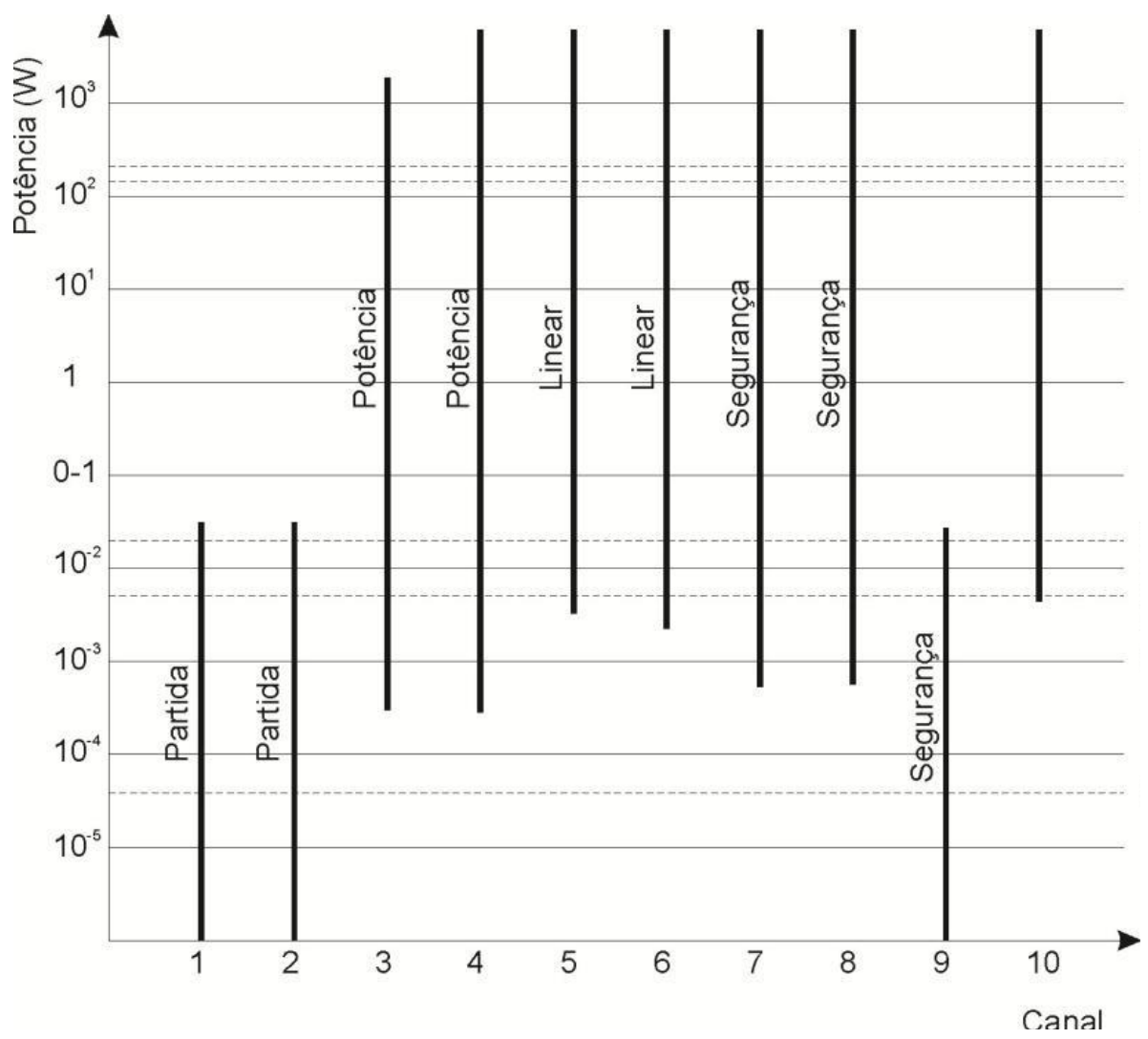

Figura A.4 - Faixa de operação dos canais nucleares. 
A instrumentação nuclear é responsável pelo processamento dos sinais gerados nos detectores nucleares. Após o processamento, estes sinais são enviados para os indicadores de potência e de período na mesa de controle do reator e para os comparadores de sinais que fazem a lógica de proteção do reator. Existem vários valores de limiar operacionais ("set points") que constituem a rede de intertravamento dos canais nucleares. Assim, só para citar alguns exemplos, temos:

- Contagem mínima de 2 cps nos canais de partida e seu respectivo canal de segurança, para habilitar a malha de partida;

- Desligamento de sobrepotência $(110 \mathrm{~mW})$ de primeiro nível dos canais de partida;

- Desligamento por sobrepotência $(120 \mathrm{~mW})$ de segundo nível dos canais de partida;

- Desligamento por sobrepotência de primeiro nível (110 W) para os canais de potência;

- Desligamento por sobrepotência de segundo nível $(120 \mathrm{~W})$ para os canais de potência.

Para se atingir a contagem mínima nos canais lineares e liberar a partida do reator é necessária a utilização de uma fonte de nêutrons de Am-Be de atividade de $1 \mathrm{Ci}$ e intensidade de 2,5 x $10^{6}$ nêutrons/s. Esta fonte fica armazenada no segundo subsolo do prédio do reator e durante a partida do mesmo é levada através de um pequeno carrinho preso a um cabo de aço a se posicionar na base inferior do tanque moderador, onde pode então sensibilizar os canais nucleares citados, evitando-se assim que a partida do reator se dê às cegas, ou seja numa faixa operacional em que os detectores dos canais de partida e de segurança não estejam aptos a monitorar a taxa de crescimento da população de nêutrons, quando do início de sua operação (partida do reator).

Outros intertravamentos se fazem presentes nos canais nucleares. Talvez o mais importante seja aquele referente ao período de crescimento da população neutrônica quando da supercriticalidade do reator, quando a população de nêutrons cresce exponencialmente. Assim, para períodos menores ou iguais a 17 segundos ocorrem o desligamento involuntário ("Scram") de primeiro nível, com a correspondente queda das 4 barras . Para períodos menores ou iguais a 14 segundos ocorre o "Scram" de segundo nível, ou seja a abertura das válvulas para escoamento da água do tanque moderador. 
Existem vários outros intertravamentos que impedem que o reator seja ligado numa condição insegura (intertravamentos de segurança), a até intertravamentos que provocam o desligamento do reator (Operacionais). Podemos citar vários que vão desde a abertura da porta de acesso da Célula Crítica (saguão onde está o núcleo do reator), até condições inadequadas da água moderadora, que vai desde a baixa temperatura da mesma (menor de 17 graus) até um nível inadequado de condutividade.

Todos os sistemas citados (núcleo, tanque moderador, detectores dos canais nucleares, controle das barras, etc.) estão situados dentro de um prédio estanque, mantido à pressão negativa, situada na faixa de -50 a $-200 \mathrm{~Pa}$ (caso haja uma perda de estanqueidade o ar de fora é que entra), denominado de célula crítica, construído com paredes de concreto, com funções de confinamento e blindagem. Um dos intertravamentos de segurança é impedir a partida do reator caso a pressão negativa no interior da célula crítica não atinja a valores operacionais pré-estabelecidos em projeto, ou mesmo provocar o seu desligamento automático, caso a pressão negativa diminua em sua magnitude. Pode-se perceber, então, que o Reator IPEN/MB-01 tem segurança em excesso, o que permite a realização dos experimentos com máxima segurança. 
ANEXO B - Estimativa das incertezas associadas

Para obterem-se muitos parâmetros nucleares da área da física de reatores nucleares, deve-se realizar vários cálculos matemáticos envolvendo as grandezas físicas obtidas experimentalmente e suas incertezas associadas. Desta forma a lei geral da propagação de erros [34] é uma importante ferramenta para se determinar a estimativa da incerteza final. Esta lei é utilizada para o tratamento de variáveis dependentes e correlacionadas assim como, independentes e não correlacionadas entre si.

B.1 Variáveis independentes não correlacionadas

A lei geral de propagação de erro para variáveis independentes e não correlacionadas é dada por

$$
\sigma_{u}^{2}=\sum_{i=1}^{n}\left(\frac{\partial u}{\partial x_{i}}\right)^{2} \sigma_{i}^{2}
$$

Portanto torna-se de grande importância analisar alguns casos aplicados neste trabalho. $\mathrm{O}$ primeiro caso é a adição ou subtração de grandezas, ou seja $u=x_{1} \pm x_{2}$, cujo resultado é

$$
\sigma_{u}=\sqrt{\sigma_{1}^{2}+\sigma_{2}^{2}}
$$

sendo $\sigma_{1}$ o desvio padrão da grandeza $x_{1}$ e $\sigma_{2}$ o de $x_{2}$.

O segundo caso é a multiplicação de uma variável $x$ por uma constante $A$, $u=A x$, e o seu desvio padrão é dado por

$$
\sigma_{u}=A \sigma_{x}
$$

sendo $\sigma_{x}$ o desvio padrão da grandeza $x$. 
A multiplicação ou divisão entre variáveis, ou seja, $u=x_{1} x_{2}$ ou $u=x_{1} / x_{2}$ tem-se como desvio padrão,

$$
\frac{\sigma_{u}}{u}=\sqrt{\left(\frac{\sigma_{1}}{x_{1}}\right)^{2}+\left(\frac{\sigma_{2}}{x_{2}}\right)^{2}}
$$

B.2 Variáveis correlacionadas

Para variáveis correlacionadas, a lei de propagação é dada por

$$
\sigma_{u}^{2}=\sum_{i, j}^{n}\left(\frac{\partial u}{\partial x_{i}}\right)\left(\frac{\partial u}{\partial x_{j}}\right) \operatorname{cov}\left(x_{i}, x_{j}\right)
$$

sendo $\operatorname{cov}\left(x_{i}, x_{j}\right)$ a covariância entre as variáveis $x_{i}$ e $x_{j}$.

A covariância entre mesma grandeza é a variância desta grandeza em questão, por exemplo, $\operatorname{cov}\left(x_{i}, x_{j}\right)$ é $\sigma_{x_{i}}^{2}$.

Procedendo da mesma maneira que no caso das variáveis independentes, alguns casos serão analisados. Inicia-se pela adição entre variáveis correlacionadas, $u=x_{1}+x_{2}$, e aplicando a expressão (B.5) tem-se o desvio padrão dado por

$$
\sigma_{u}=\sqrt{\sigma_{1}^{2}+\sigma_{2}^{2}+2 \operatorname{cov}\left(x_{1}, x_{2}\right)}
$$

e o desvio padrão para a subtração de variáveis é

$$
\sigma_{u}=\sqrt{\sigma_{1}^{2}+\sigma_{2}^{2}-2 \operatorname{cov}\left(x_{1}, x_{2}\right)} .
$$


No caso da multiplicação de variáveis correlacionadas, $u=x_{1} x_{2}$, o resultado obtido para o desvio padrão é

$$
\frac{\sigma_{u}}{u}=\sqrt{\left(\frac{\sigma_{1}}{x_{1}}\right)^{2}+\left(\frac{\sigma_{2}}{x_{2}}\right)^{2}+2 \frac{\operatorname{cov}\left(x_{1}, x_{2}\right)}{x_{1} x_{2}}}
$$

e para a divisão entre variáveis, $u=x_{1} / x_{2}$, o desvio padrão é dado por

$$
\frac{\sigma_{u}}{u}=\sqrt{\left(\frac{\sigma_{1}}{x_{1}}\right)^{2}+\left(\frac{\sigma_{2}}{x_{2}}\right)^{2}-2 \frac{\operatorname{cov}\left(x_{1}, x_{2}\right)}{x_{1} x_{2}}}
$$

B.3 Propagação do desvio padrão para a eficiência.

Como exemplo do cálculo da propagação de erros é demonstrado passo a passo o cálculo para obtenção do desvio padrão da eficiência. Inicialmente são calculadas as derivadas da expressão (7.4) para eficiência com relação às grandezas em sua expressão que possuem desvio padrão. Essas grandezas são $C, \lambda, A$ e $I$.

Portanto as derivadas são:

$$
\begin{aligned}
& \frac{\partial \varepsilon}{\partial C}=\frac{\varepsilon}{C}, \\
& \frac{\partial \varepsilon}{\partial \lambda}=\varepsilon t_{e}, \\
& \frac{\partial \varepsilon}{\partial A}=-\frac{\varepsilon}{A}
\end{aligned}
$$




$$
\frac{\partial \varepsilon}{\partial I}=-\frac{\varepsilon}{I}
$$

Aplicando a equação (B.1) tem-se a expressão

$$
\sigma_{\varepsilon}^{2}=\left(\frac{\varepsilon}{C}\right)^{2} \sigma_{C}^{2}+\left(\varepsilon t_{e}\right)^{2} \sigma_{\lambda}^{2}+\left(-\frac{\varepsilon}{A}\right)^{2} \sigma_{A}^{2}+\left(-\frac{\varepsilon}{I}\right)^{2} \sigma_{I}^{2}
$$

Trabalhando a expressão anterior, tem-se

$$
\sigma_{\varepsilon}^{2}=\varepsilon^{2}\left\{\left(\frac{\sigma_{C}}{C}\right)^{2}+\left(\frac{\sigma_{A}}{A}\right)^{2}+\left(\frac{\sigma_{I}}{I}\right)^{2}+\left(t_{e} \sigma_{\lambda}\right)^{2}\right\} .
$$

A expressão final para o desvio padrão da eficiência é dada pela equação

$$
\sigma_{\varepsilon}=\varepsilon \sqrt{\left(\frac{\sigma_{C}}{C}\right)^{2}+\left(\frac{\sigma_{A}}{A}\right)^{2}+\left(\frac{\sigma_{I}}{I}\right)^{2}+\left(t_{e} \sigma_{\lambda}\right)^{2}} .
$$


ANEXO C - Simulação pelo código CITATION da distribuição do fluxo de nêutrons no núcleo do reator IPEN/MB-01 operando à 100 watts na configuração cilíndrica de 28x28 varetas combustíveis

\section{C.1. Objetivo}

Apresentar o cálculo da distribuição do fluxo de nêutrons no núcleo do Reator IPEN/MB-01 operando à potência de 100 watts, por intermédio do código computacional CITATION [39].

Os resultados obtidos neste relatório permitiram a comparação com o valor do fluxo médio ponderado de nêutrons térmicos obtido neste trabalho, e assim validar a metodologia de cálculo utilizada.

C.2 Desenvolvimento do trabalho

Para esta simulação foi considerado que o núcleo do Reator IPEN/MB-01 apresenta uma configuração cilíndrica de núcleo, consistindo de um arranjo com $28 \times 28$ varetas com pitch (distância entre os centros das varetas) de $1,5 \mathrm{~cm}$. Considerou-se que o reator está operando a uma potência de 100 watts com temperatura do moderador de $20^{\circ} \mathrm{C}$.

Na FIG C.1 apresenta-se a configuração do núcleo do Reator IPEN/MB-01 considerada para a realização dos cálculos neutrônicos deste trabalho. 


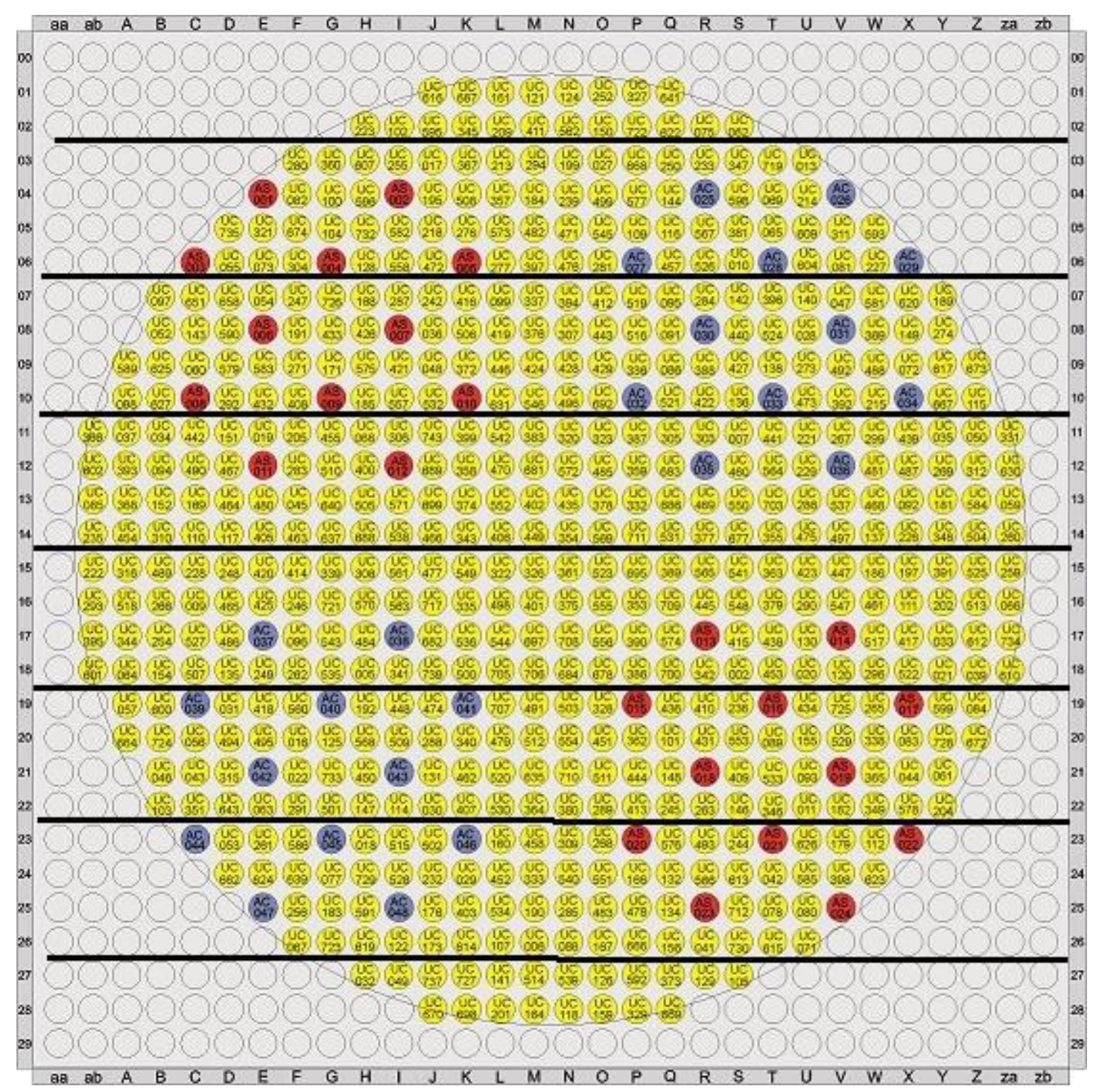

Figura C.1 - Configuração cilíndrica do núcleo do reator IPEN/MB-01.

Nesta configuração as varetas combustíveis estão representadas por círculos amarelos, as varetas absorvedoras de controle são representadas por círculos de cor azul e as varetas absorvedoras de segurança são representadas por círculos vermelhos.

A distribuição de fluxo de nêutrons foi determinada para sete canais de irradiação com relação à configuração cilíndrica do núcleo, sendo representados graficamente por uma linha cinza na FIG C.1. As coordenadas de cada canal de irradiação estão na TAB C.1. 
Tabela C.1 - Coordenadas dos sete canais de irradiação para determinação da distribuição de fluxo de nêutrons.

\begin{tabular}{|c|c|c|}
\hline \multicolumn{3}{|c|}{ Coordenadas } \\
\hline Posição & $\mathbf{X}(\mathbf{m m})$ & Y(mm) \\
\hline $\mathbf{1}$ & de F até U & entre 2 e 3 \\
\hline $\mathbf{2}$ & de B até Y & entre 6 E 7 \\
\hline $\mathbf{3}$ & de ab até za & entre 10 e 11 \\
\hline $\mathbf{4}$ & de ab até za & entre 14 e 15 \\
\hline $\mathbf{5}$ & de ab até za & entre 18 e 19 \\
\hline $\mathbf{6}$ & de B até Y & entre 22 e 23 \\
\hline $\mathbf{7}$ & de F até U & entre 26 e 27 \\
\hline
\end{tabular}

\section{C.3. Metodologia de Cálculo}

A metodologia de cálculo utilizada se baseou no programa HAMMER-TECHNION [40] para a geração de seções de choque. O código computacional CITATION que utiliza a teoria de difusão de nêutrons, foi utilizado para calcular a distribuição de fluxo de nêutrons em geometria tridimensional $(\mathrm{x}, \mathrm{y}, \mathrm{z})$ para quatro grupos de energia, sendo o grupo $1 \mathrm{de}$ 1,05 MeV até $10 \mathrm{MeV}$, o grupo 2 de 9,12 $\mathrm{keV}$ até 1,05 MeV, o grupo $3 \mathrm{de} 0,625 \mathrm{eV}$ até $9,12 \mathrm{keV}$ e o grupo 4 de 0 até $0,625 \mathrm{eV}$.

As posições que foram consideradas para o cálculo da distribuição de fluxo de nêutrons estão apresentadas na FIG C.2. Estas posições foram repetidas para as sete regiões especificadas da TAB C.1. 


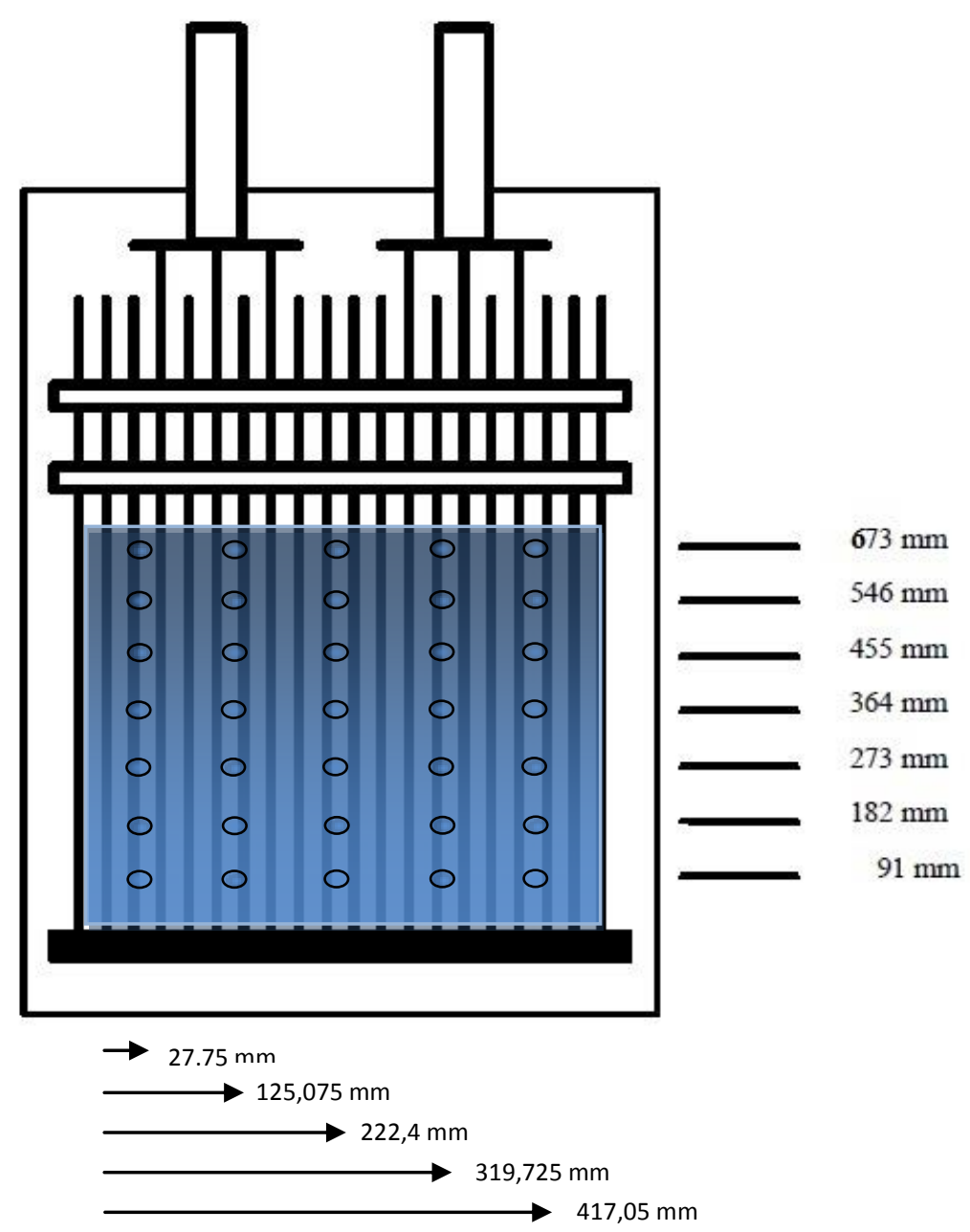

Figura C.2 - Corte axial do núcleo do Reator IPEN/MB-01 com as posições de medidas.

\section{C.4 Análise dos Resultados}

Nas TAB C.2, C.3, C.4, C.5, C.6, C.7 e C.8 apresentam-se as distribuições do fluxo de nêutrons nos quatro grupos de energia para cada um dos sete canais de irradiação.

Na TAB C.2 apresentam-se os resultados calculados para o canal de irradiação 1, entre as coordenadas 2 e 3 . 
Tabela C.2 - Fluxo de nêutrons para as posições do canal de irradiação 1.

\begin{tabular}{|c|c|c|c|c|}
\hline Posições & Grupo 1 & Grupo 2 & Grupo 3 & Grupo 4 \\
\hline $\mathbf{2}$ & $9,57588 \mathrm{E}+07$ & $1,08649 \mathrm{E}+08$ & $1,06792 \mathrm{E}+08$ & $2,53300 \mathrm{E}+08$ \\
\hline $\mathbf{3}$ & $1,15246 \mathrm{E}+08$ & $1,34256 \mathrm{E}+08$ & $1,21934 \mathrm{E}+08$ & $1,88538 \mathrm{E}+08$ \\
\hline $\mathbf{4}$ & $7,15607 \mathrm{E}+07$ & $8,41608 \mathrm{E}+12$ & $8,10549 \mathrm{E}+07$ & $1,79633 \mathrm{E}+08$ \\
\hline $\mathbf{7}$ & $2,36054 \mathrm{E}+08$ & $2,62300 \mathrm{E}+08$ & $2,43994 \mathrm{E}+08$ & $4,35580 \mathrm{E}+08$ \\
\hline $\mathbf{8}$ & $2,87327 \mathrm{E}+08$ & $3,27611 \mathrm{E}+08$ & $2,80286 \mathrm{E}+08$ & $2,92671 \mathrm{E}+08$ \\
\hline $\mathbf{9}$ & $1,79392 \mathrm{E}+08$ & $2,05882 \mathrm{E}+08$ & $1,87646 \mathrm{E}+08$ & $3,24777 \mathrm{E}+08$ \\
\hline $\mathbf{1 2}$ & $3,535520 \mathrm{E}+08$ & $3,94465 \mathrm{E}+08$ & $3,71195 \mathrm{E}+08$ & $6,93126 \mathrm{E}+08$ \\
\hline $\mathbf{1 3}$ & $4,460290 \mathrm{E}+08$ & $5,08847 \mathrm{E}+08$ & $4,39337 \mathrm{E}+08$ & $4,84145 \mathrm{E}+08$ \\
\hline $\mathbf{1 4}$ & $2,892740 \mathrm{E}+08$ & $3,31622 \mathrm{E}+08$ & $3,05797 \mathrm{E}+08$ & $5,55646 \mathrm{E}+08$ \\
\hline $\mathbf{1 7}$ & $4,387360 \mathrm{E}+08$ & $4,88492 \mathrm{E}+08$ & $4,56308 \mathrm{E}+08$ & $8,23302 \mathrm{E}+08$ \\
\hline $\mathbf{1 8}$ & $5,786440 \mathrm{E}+08$ & $6,56668 \mathrm{E}+08$ & $5,64590 \mathrm{E}+08$ & $6,01285 \mathrm{E}+08$ \\
\hline $\mathbf{1 9}$ & $4,07589 \mathrm{E}+08$ & $4,56729 \mathrm{E}+08$ & $4,25290 \mathrm{E}+08$ & $7,63771 \mathrm{E}+08$ \\
\hline $\mathbf{2 2}$ & $4,30930 \mathrm{E}+08$ & $4,81719 \mathrm{E}+08$ & $4,56537 \mathrm{E}+08$ & $8,80093 \mathrm{E}+08$ \\
\hline $\mathbf{2 3}$ & $5,85825 \mathrm{E}+08$ & $6,64478 \mathrm{E}+08$ & $5,78299 \mathrm{E}+08$ & $6,62373 \mathrm{E}+08$ \\
\hline $\mathbf{2 4}$ & $4,22344 \mathrm{E}+08$ & $4,72389 \mathrm{E}+08$ & $4,47681 \mathrm{E}+08$ & $8,61697 \mathrm{E}+08$ \\
\hline $\mathbf{2 7}$ & $3,41668 \mathrm{E}+08$ & $3,79719 \mathrm{E}+08$ & $3,52919 \mathrm{E}+08$ & $6,24231 \mathrm{E}+08$ \\
\hline $\mathbf{2 8}$ & $4,63442 \mathrm{E}+08$ & $5,24442 \mathrm{E}+08$ & $4,49308 \mathrm{E}+08$ & $4,67974 \mathrm{E}+08$ \\
\hline $\mathbf{2 9}$ & $3,39486 \mathrm{E}+08$ & $3,77319 \mathrm{E}+08$ & $3,50689 \mathrm{E}+08$ & $6,19895 \mathrm{E}+08$ \\
\hline $\mathbf{3 2}$ & $1,51166 \mathrm{E}+08$ & $1,70921 \mathrm{E}+08$ & $1,66603 \mathrm{E}+08$ & $3,82142 \mathrm{E}+08$ \\
\hline $\mathbf{3 3}$ & $2,04938 \mathrm{E}+08$ & $2,35890 \mathrm{E}+08$ & $2,12907 \mathrm{E}+08$ & $3,20975 \mathrm{E}+08$ \\
\hline $\mathbf{3 4}$ & $1,50708 \mathrm{E}+08$ & $1,70406 \mathrm{E}+08$ & $1,66111 \mathrm{E}+08$ & $3,81009 \mathrm{E}+08$ \\
\hline
\end{tabular}

Na TAB C.3 apresentam-se os resultados calculados para o canal de irradiação 2, entre as coordenadas 6 e 7 . 
Tabela C.3 - Fluxo de nêutrons para as posições do canal de irradiação 2.

\begin{tabular}{|c|c|c|c|c|}
\hline Posições & Grupo 1 & Grupo 2 & Grupo 3 & Grupo 4 \\
\hline 1 & $7,36554 \mathrm{E}+07$ & 8,40987E+07 & $9,30563 \mathrm{E}+07$ & $3,30546 \mathrm{E}+08$ \\
\hline 2 & $1,74237 \mathrm{E}+08$ & $2,02762 \mathrm{E}+08$ & $1,96475 \mathrm{E}+08$ & $2,79813 \mathrm{E}+08$ \\
\hline 3 & $1,82632 \mathrm{E}+08$ & $2,19404 \mathrm{E}+08$ & $1,99474 \mathrm{E}+08$ & $2,49869 \mathrm{E}+08$ \\
\hline 4 & $1,24292 \mathrm{E}+08$ & $1,54508 \mathrm{E}+08$ & $1,38337 \mathrm{E}+08$ & $1,43027 \mathrm{E}+08$ \\
\hline 5 & $4,97280 \mathrm{E}+07$ & $6,01540 \mathrm{E}+07$ & $6,17326 \mathrm{E}+07$ & $1,77113 \mathrm{E}+08$ \\
\hline 6 & $1,78912 \mathrm{E}+08$ & $2,00754 \mathrm{E}+08$ & $2,11566 \mathrm{E}+08$ & $6,31519 \mathrm{E}+08$ \\
\hline 7 & $4,31070 \mathrm{E}+08$ & $4,91708 \mathrm{E}+08$ & $4,49680 \mathrm{E}+08$ & $4,38912 \mathrm{E}+08$ \\
\hline 8 & $4,54716 \mathrm{E}+08$ & $5,34634 \mathrm{E}+08$ & $4,58278 \mathrm{E}+08$ & $3,95811 \mathrm{E}+08$ \\
\hline 9 & $3,11929 \mathrm{E}+08$ & $3,78090 \mathrm{E}+08$ & $3,19657 \mathrm{E}+08$ & $2,47488 \mathrm{E}+08$ \\
\hline 10 & $1,23048 \mathrm{E}+08$ & $1,45815 \mathrm{E}+08$ & $1,42700 \mathrm{E}+08$ & $3,60903 \mathrm{E}+08$ \\
\hline 11 & $2,69980 \mathrm{E}+08$ & $3,03080 \mathrm{E}+08$ & $3,19387 \mathrm{E}+08$ & $9,49793 \mathrm{E}+08$ \\
\hline 12 & $6,51218 \mathrm{E}+08$ & 7,44104E+08 & $6,86431 \mathrm{E}+08$ & 7,09732E+08 \\
\hline 13 & $7,11210 \mathrm{E}+08$ & $8,35248 \mathrm{E}+08$ & $7,22286 \mathrm{E}+08$ & $6,64220 \mathrm{E}+08$ \\
\hline 14 & $5,12556 \mathrm{E}+08$ & $6,16394 \mathrm{E}+08$ & $5,26743 \mathrm{E}+08$ & $4,40182 \mathrm{E}+08$ \\
\hline 15 & $2,05541 \mathrm{E}+08$ & $2,41746 \mathrm{E}+08$ & $2,36809 \mathrm{E}+08$ & $6,02221 \mathrm{E}+08$ \\
\hline 16 & $3,29687 \mathrm{E}+08$ & $3,70143 \mathrm{E}+08$ & $3,89977 \mathrm{E}+08$ & $1,15668 \mathrm{E}+09$ \\
\hline 17 & $8,08543 \mathrm{E}+08$ & $9,23062 \mathrm{E}+08$ & $8,46728 \mathrm{E}+08$ & $8,42949 \mathrm{E}+08$ \\
\hline 18 & $9,39669 \mathrm{E}+08$ & $1,08966 \mathrm{E}+09$ & $9,50560 \mathrm{E}+08$ & $8,73131 \mathrm{E}+08$ \\
\hline 19 & 7,48847E+08 & $8,63447 \mathrm{E}+08$ & $7,85611 \mathrm{E}+08$ & $7,73683 \mathrm{E}+08$ \\
\hline 20 & $2,98601 \mathrm{E}+08$ & $3,38410 \mathrm{E}+08$ & $3,54385 \mathrm{E}+08$ & $1,03812 \mathrm{E}+09$ \\
\hline 21 & $3,27800 \mathrm{E}+08$ & $3,68044 \mathrm{E}+08$ & $3,87710 \mathrm{E}+08$ & $1,14816 \mathrm{E}+09$ \\
\hline 22 & $8,01356 \mathrm{E}+08$ & $9,15812 \mathrm{E}+08$ & $8,49418 \mathrm{E}+08$ & $9,13362 \mathrm{E}+08$ \\
\hline 23 & $9,56432 \mathrm{E}+08$ & $1,10632 \mathrm{E}+09$ & $9,78092 \mathrm{E}+08$ & $9,74342 \mathrm{E}+08$ \\
\hline 24 & $7,86630 \mathrm{E}+08$ & $8,99606 \mathrm{E}+08$ & $8,34324 \mathrm{E}+08$ & $8,96778 \mathrm{E}+08$ \\
\hline 25 & $3,19031 \mathrm{E}+08$ & $3,58460 \mathrm{E}+08$ & $3,77573 \mathrm{E}+08$ & $1,11570 \mathrm{E}+09$ \\
\hline 26 & $2,53707 \mathrm{E}+08$ & $2,84763 \mathrm{E}+08$ & $2,99924 \mathrm{E}+08$ & $8,88812 \mathrm{E}+08$ \\
\hline 27 & $6,29962 \mathrm{E}+08$ & $7,18426 \mathrm{E}+08$ & $6,56493 \mathrm{E}+08$ & $6,38408 \mathrm{E}+08$ \\
\hline 28 & $4,97280 \mathrm{E}+07$ & $6,01540 \mathrm{E}+07$ & $6,17326 \mathrm{E}+07$ & $1,77113 \mathrm{E}+08$ \\
\hline 29 & $6,26474 \mathrm{E}+08$ & $7,14488 \mathrm{E}+08$ & $6,52900 \mathrm{E}+08$ & $6,34883 \mathrm{E}+08$ \\
\hline 30 & $2,51524 \mathrm{E}+08$ & $2,82339 \mathrm{E}+08$ & $2,97358 \mathrm{E}+08$ & $8,80444 \mathrm{E}+08$ \\
\hline 31 & $1,12655 \mathrm{E}+08$ & $1,28588 \mathrm{E}+08$ & $1,41805 \mathrm{E}+08$ & $4,96959 \mathrm{E}+08$ \\
\hline 32 & $2,77899 \mathrm{E}+08$ & $3,22472 \mathrm{E}+08$ & $3,10263 \mathrm{E}+08$ & $4,27749 \mathrm{E}+08$ \\
\hline 33 & $3,34568 \mathrm{E}+08$ & $3,92854 \mathrm{E}+08$ & $3,60640 \mathrm{E}+08$ & $4,67311 \mathrm{E}+08$ \\
\hline 34 & $2,77186 \mathrm{E}+08$ & $3,21648 \mathrm{E}+08$ & $3,09486 \mathrm{E}+08$ & $4,26783 \mathrm{E}+08$ \\
\hline 35 & $1,12201 \mathrm{E}+08$ & $1,28075 \mathrm{E}+08$ & $1,41243 \mathrm{E}+08$ & $4,94876 \mathrm{E}+08$ \\
\hline
\end{tabular}


Na TAB C.4 apresentam-se os resultados calculados para o canal de irradiação 3, entre as coordenadas 10 e 11 .

Tabela C.4 - Fluxo de nêutrons para as posições do canal de irradiação 3.

\begin{tabular}{|c|c|c|c|c|}
\hline Posições & Grupo 1 & Grupo 2 & Grupo 3 & Grupo 4 \\
\hline $\mathbf{1}$ & $1,28320 \mathrm{E}+08$ & $1,46914 \mathrm{E}+08$ & $1,41161 \mathrm{E}+08$ & $2,29055 \mathrm{E}+08$ \\
\hline $\mathbf{2}$ & $2,22495 \mathrm{E}+08$ & $2,61506 \mathrm{E}+08$ & $2,53899 \mathrm{E}+08$ & $3,51665 \mathrm{E}+08$ \\
\hline $\mathbf{3}$ & $2,36801 \mathrm{E}+08$ & $2,85318 \mathrm{E}+08$ & $2,59647 \mathrm{E}+08$ & $3,23787 \mathrm{E}+08$ \\
\hline $\mathbf{4}$ & $1,73349 \mathrm{E}+08$ & $2,16070 \mathrm{E}+08$ & $1,93413 \mathrm{E}+08$ & $1,97412 \mathrm{E}+08$ \\
\hline $\mathbf{5}$ & $9,78847 \mathrm{E}+07$ & $1,17492 \mathrm{E}+08$ & $1,05203 \mathrm{E}+08$ & $1,37984 \mathrm{E}+08$ \\
\hline $\mathbf{6}$ & $3,17899 \mathrm{E}+08$ & $3,56445 \mathrm{E}+08$ & $3,23412 \mathrm{E}+08$ & $3,60541 \mathrm{E}+08$ \\
\hline $\mathbf{7}$ & $5,51467 \mathrm{E}+08$ & $6,35156 \mathrm{E}+08$ & $5,82016 \mathrm{E}+08$ & $5,57985 \mathrm{E}+08$ \\
\hline $\mathbf{8}$ & $5,89364 \mathrm{E}+08$ & $6,94915 \mathrm{E}+08$ & $5,96178 \mathrm{E}+08$ & $5,13862 \mathrm{E}+08$ \\
\hline $\mathbf{9}$ & $4,33209 \mathrm{E}+08$ & $5,26932 \mathrm{E}+08$ & $4,45560 \mathrm{E}+08$ & $3,41136 \mathrm{E}+08$ \\
\hline $\mathbf{1 0}$ & $2,45883 \mathrm{E}+08$ & $2,87920 \mathrm{E}+08$ & $2,43421 \mathrm{E}+08$ & $2,30164 \mathrm{E}+08$ \\
\hline $\mathbf{1 1}$ & $4,80125 \mathrm{E}+08$ & $5,39439 \mathrm{E}+08$ & $4,94001 \mathrm{E}+08$ & $5,80593 \mathrm{E}+08$ \\
\hline $\mathbf{1 2}$ & $8,39509 \mathrm{E}+08$ & $9,68340 \mathrm{E}+08$ & $8,94838 \mathrm{E}+08$ & $9,09435 \mathrm{E}+08$ \\
\hline $\mathbf{1 3}$ & $9,19639 \mathrm{E}+08$ & $1,08321 \mathrm{E}+09$ & $9,37546 \mathrm{E}+08$ & $8,60562 \mathrm{E}+08$ \\
\hline $\mathbf{1 4}$ & $7,00546 \mathrm{E}+08$ & $8,46500 \mathrm{E}+08$ & $7,23651 \mathrm{E}+08$ & $5,97882 \mathrm{E}+08$ \\
\hline $\mathbf{1 5}$ & $3,97314 \mathrm{E}+08$ & $4,63385 \mathrm{E}+08$ & $3,95826 \mathrm{E}+08$ & $3,98636 \mathrm{E}+08$ \\
\hline $\mathbf{1 6}$ & $5,97089 \mathrm{E}+08$ & $6,70187 \mathrm{E}+08$ & $6,10133 \mathrm{E}+08$ & $6,91245 \mathrm{E}+08$ \\
\hline $\mathbf{1 7}$ & $1,05300 \mathrm{E}+09$ & $1,21284 \mathrm{E}+09$ & $1,11437 \mathrm{E}+09$ & $1,09048 \mathrm{E}+09$ \\
\hline $\mathbf{1 8}$ & $1,20915 \mathrm{E}+09$ & $1,40704 \mathrm{E}+09$ & $1,22841 \mathrm{E}+09$ & $1,12593 \mathrm{E}+09$ \\
\hline $\mathbf{1 9}$ & $9,97523 \mathrm{E}+08$ & $1,15907 \mathrm{E}+09$ & $1,05599 \mathrm{E}+09$ & $1,02305 \mathrm{E}+09$ \\
\hline $\mathbf{2 0}$ & $5,59233 \mathrm{E}+08$ & $6,32289 \mathrm{E}+08$ & $5,72129 \mathrm{E}+08$ & $6,43246 \mathrm{E}+08$ \\
\hline $\mathbf{2 1}$ & $5,91630 \mathrm{E}+08$ & $6,64974 \mathrm{E}+08$ & $6,12497 \mathrm{E}+08$ & $7,45892 \mathrm{E}+08$ \\
\hline $\mathbf{2 2}$ & $1,04943 \mathrm{E}+09$ & $1,20970 \mathrm{E}+09$ & $1,12368 \mathrm{E}+09$ & $1,18854 \mathrm{E}+09$ \\
\hline $\mathbf{2 3}$ & $1,22791 \mathrm{E}+09$ & $1,42561 \mathrm{E}+09$ & $1,26128 \mathrm{E}+09$ & $1,25374 \mathrm{E}+09$ \\
\hline $\mathbf{2 4}$ & $1,03695 \mathrm{E}+09$ & $1,19595 \mathrm{E}+09$ & $1,11076 \mathrm{E}+09$ & $1,17460 \mathrm{E}+09$ \\
\hline $\mathbf{2 5}$ & $5,81579 \mathrm{E}+08$ & $6,54072 \mathrm{E}+08$ & $6,02429 \mathrm{E}+08$ & $7,32976 \mathrm{E}+08$ \\
\hline $\mathbf{2 6}$ & $4,65806 \mathrm{E}+08$ & $5,22246 \mathrm{E}+08$ & $4,73529 \mathrm{E}+08$ & $5,24536 \mathrm{E}+08$ \\
\hline $\mathbf{2 7}$ & $8,26283 \mathrm{E}+08$ & $9,50417 \mathrm{E}+08$ & $8,69883 \mathrm{E}+08$ & $8,31392 \mathrm{E}+08$ \\
\hline $\mathbf{2 8}$ & $9,69785 \mathrm{E}+08$ & $1,12365 \mathrm{E}+09$ & $9,79613 \mathrm{E}+08$ & $8,79025 \mathrm{E}+08$ \\
\hline $\mathbf{2 9}$ & $8,23474 \mathrm{E}+08$ & $9,47208 \mathrm{E}+08$ & $8,66937 \mathrm{E}+08$ & $8,28596 \mathrm{E}+08$ \\
\hline
\end{tabular}




\begin{tabular}{|c|c|c|c|c|}
\hline Posições & Grupo 1 & Grupo 2 & Grupo 3 & Grupo 4 \\
\hline $\mathbf{3 0}$ & $4,63319 \mathrm{E}+08$ & $5,19507 \mathrm{E}+08$ & $4,71050 \mathrm{E}+08$ & $5,21610 \mathrm{E}+08$ \\
\hline $\mathbf{3 1}$ & $2,05313 \mathrm{E}+08$ & $2,34307 \mathrm{E}+08$ & $2,23458 \mathrm{E}+08$ & $3,49839 \mathrm{E}+08$ \\
\hline $\mathbf{3 2}$ & $3,65061 \mathrm{E}+08$ & $4,27324 \mathrm{E}+08$ & $4,11866 \mathrm{E}+08$ & $5,53758 \mathrm{E}+08$ \\
\hline $\mathbf{3 3}$ & $4,29377 \mathrm{E}+08$ & $5,06185 \mathrm{E}+08$ & $4,65147 \mathrm{E}+08$ & $5,99504 \mathrm{E}+08$ \\
\hline $\mathbf{3 4}$ & $3,64491 \mathrm{E}+08$ & $4,26653 \mathrm{E}+08$ & $4,11231 \mathrm{E}+08$ & $5,53017 \mathrm{E}+08$ \\
\hline $\mathbf{3 5}$ & $2,04804 \mathrm{E}+08$ & $2,33732 \mathrm{E}+08$ & $2,22918 \mathrm{E}+08$ & $3,49009 \mathrm{E}+08$ \\
\hline
\end{tabular}

Na TAB C.5 apresentam-se os resultados calculados para o canal de irradiação 4, entre as coordenadas 14 e 15.

Tabela C.5 - Fluxo de nêutrons para as posições do canal de irradiação 4.

\begin{tabular}{|c|c|c|c|c|}
\hline Posições & Grupo 1 & Grupo 2 & Grupo 3 & Grupo 4 \\
\hline $\mathbf{1}$ & $1,38667 \mathrm{E}+08$ & $1,62695 \mathrm{E}+08$ & $1,47434 \mathrm{E}+08$ & $2,05869 \mathrm{E}+08$ \\
\hline $\mathbf{2}$ & $2,32585 \mathrm{E}+08$ & $2,77876 \mathrm{E}+08$ & $2,55362 \mathrm{E}+08$ & $3,31211 \mathrm{E}+08$ \\
\hline $\mathbf{3}$ & $2,69877 \mathrm{E}+08$ & $3,23119 \mathrm{E}+08$ & $2,92998 \mathrm{E}+08$ & $3,79330 \mathrm{E}+08$ \\
\hline $\mathbf{4}$ & $2,25199 \mathrm{E}+08$ & $2,71189 \mathrm{E}+08$ & $2,46939 \mathrm{E}+08$ & $3,10340 \mathrm{E}+08$ \\
\hline $\mathbf{5}$ & $1,34320 \mathrm{E}+08$ & $1,58323 \mathrm{E}+08$ & $1,43084 \mathrm{E}+08$ & $1,97592 \mathrm{E}+08$ \\
\hline $\mathbf{6}$ & $3,44944 \mathrm{E}+08$ & $3,96419 \mathrm{E}+08$ & $3,38521 \mathrm{E}+08$ & $3,14929 \mathrm{E}+08$ \\
\hline $\mathbf{7}$ & $5,78496 \mathrm{E}+08$ & $6,76649 \mathrm{E}+08$ & $5,86026 \mathrm{E}+08$ & $5,19185 \mathrm{E}+08$ \\
\hline $\mathbf{8}$ & $6,71212 \mathrm{E}+08$ & $7,87037 \mathrm{E}+08$ & $6,72557 \mathrm{E}+08$ & $5,89369 \mathrm{E}+08$ \\
\hline $\mathbf{9}$ & $5,60685 \mathrm{E}+08$ & $6,60658 \mathrm{E}+08$ & $5,67016 \mathrm{E}+08$ & $4,91755 \mathrm{E}+08$ \\
\hline $\mathbf{1 0}$ & $3,34706 \mathrm{E}+08$ & $3,86252 \mathrm{E}+08$ & $3,28939 \mathrm{E}+08$ & $3,04302 \mathrm{E}+08$ \\
\hline $\mathbf{1 1}$ & $5,32801 \mathrm{E}+08$ & $6,12631 \mathrm{E}+08$ & $5,27743 \mathrm{E}+08$ & $5,20305 \mathrm{E}+08$ \\
\hline $\mathbf{1 2}$ & $8,97211 \mathrm{E}+08$ & $1,04925 \mathrm{E}+09$ & $9,16421 \mathrm{E}+08$ & $8,62708 \mathrm{E}+08$ \\
\hline $\mathbf{1 3}$ & $1,04006 \mathrm{E}+09$ & $1,21965 \mathrm{E}+09$ & $1,05107 \mathrm{E}+09$ & $9,78635 \mathrm{E}+08$ \\
\hline $\mathbf{1 4}$ & $8,76031 \mathrm{E}+08$ & $1,03102 \mathrm{E}+09$ & $8,92722 \mathrm{E}+08$ & $8,24296 \mathrm{E}+08$ \\
\hline $\mathbf{1 5}$ & $5,21030 \mathrm{E}+08$ & $6,01204 \mathrm{E}+08$ & $5,16536 \mathrm{E}+08$ & $5,06715 \mathrm{E}+08$ \\
\hline $\mathbf{1 6}$ & $6,84738 \mathrm{E}+08$ & $7,83990 \mathrm{E}+08$ & $6,72400 \mathrm{E}+08$ & $6,39917 \mathrm{E}+08$ \\
\hline $\mathbf{1 7}$ & $1,16296 \mathrm{E}+09$ & $1,35040 \mathrm{E}+09$ & $1,17719 \mathrm{E}+09$ & $1,07617 \mathrm{E}+09$ \\
\hline $\mathbf{1 8}$ & $1,34009 \mathrm{E}+09$ & $1,56404 \mathrm{E}+09$ & $1,34185 \mathrm{E}+09$ & $1,20575 \mathrm{E}+09$ \\
\hline $\mathbf{1 9}$ & $1,15502 \mathrm{E}+09$ & $1,34286 \mathrm{E}+09$ & $1,16903 \mathrm{E}+09$ & $1,06707 \mathrm{E}+09$ \\
\hline $\mathbf{2 0}$ & $6,79352 \mathrm{E}+08$ & $7,78500 \mathrm{E}+08$ & $6,67326 \mathrm{E}+08$ & $6,34673 \mathrm{E}+08$ \\
\hline $\mathbf{2 1}$ & $6,90792 \mathrm{E}+08$ & $7,90497 \mathrm{E}+08$ & $6,85891 \mathrm{E}+08$ & $7,04975 \mathrm{E}+08$ \\
\hline
\end{tabular}




\begin{tabular}{|c|c|c|c|c|}
\hline Posições & Grupo 1 & Grupo 2 & Grupo 3 & Grupo 4 \\
\hline $\mathbf{2 2}$ & $1,17600 \mathrm{E}+09$ & $1,36381 \mathrm{E}+09$ & $1,20305 \mathrm{E}+09$ & $1,19081 \mathrm{E}+09$ \\
\hline $\mathbf{2 3}$ & $1,35367 \mathrm{E}+09$ & $1,57865 \mathrm{E}+09$ & $1,36986 \mathrm{E}+09$ & $1,33277 \mathrm{E}+09$ \\
\hline $\mathbf{2 4}$ & $1,17433 \mathrm{E}+09$ & $1,36195 \mathrm{E}+09$ & $1,20135 \mathrm{E}+09$ & $1,18911 \mathrm{E}+09$ \\
\hline $\mathbf{2 5}$ & $6,89390 \mathrm{E}+08$ & $7,88957 \mathrm{E}+08$ & $6,84539 \mathrm{E}+08$ & $7,03536 \mathrm{E}+08$ \\
\hline $\mathbf{2 6}$ & $5,45135 \mathrm{E}+08$ & $6,22661 \mathrm{E}+08$ & $5,32159 \mathrm{E}+08$ & $4,94727 \mathrm{E}+08$ \\
\hline $\mathbf{2 7}$ & $9,27917 \mathrm{E}+08$ & $1,07405 \mathrm{E}+09$ & $9,33568 \mathrm{E}+08$ & $8,33970 \mathrm{E}+08$ \\
\hline $\mathbf{2 8}$ & $1,06786 \mathrm{E}+09$ & $1,24309 \mathrm{E}+09$ & $1,06284 \mathrm{E}+09$ & $9,32463 \mathrm{E}+08$ \\
\hline $\mathbf{2 9}$ & $9,27560 \mathrm{E}+08$ & $1,07361 \mathrm{E}+09$ & $9,33183 \mathrm{E}+08$ & $8,33664 \mathrm{E}+08$ \\
\hline $\mathbf{3 0}$ & $5,44796 \mathrm{E}+08$ & $6,22279 \mathrm{E}+08$ & $5,31828 \mathrm{E}+08$ & $4,94407 \mathrm{E}+08$ \\
\hline $\mathbf{3 1}$ & $2,41018 \mathrm{E}+08$ & $2,79979 \mathrm{E}+08$ & $2,52139 \mathrm{E}+08$ & $3,43323 \mathrm{E}+08$ \\
\hline $\mathbf{3 2}$ & $4,10705 \mathrm{E}+08$ & $4,83671 \mathrm{E}+08$ & $4,43208 \mathrm{E}+08$ & $5,70241 \mathrm{E}+08$ \\
\hline $\mathbf{3 3}$ & $4,73009 \mathrm{E}+08$ & $5,60202 \mathrm{E}+08$ & $5,04988 \mathrm{E}+08$ & $6,40729 \mathrm{E}+08$ \\
\hline $\mathbf{3 4}$ & $4,10620 \mathrm{E}+08$ & $4,83557 \mathrm{E}+08$ & $4,43104 \mathrm{E}+08$ & $5,70170 \mathrm{E}+08$ \\
\hline $\mathbf{3 5}$ & $2,40960 \mathrm{E}+08$ & $2,79874 \mathrm{E}+08$ & $2,52025 \mathrm{E}+08$ & $3,43371 \mathrm{E}+08$ \\
\hline
\end{tabular}

Na TAB C.6 apresentam-se os resultados calculados para o canal de irradiação 5, entre as coordenadas 18 e 19.

Tabela C.6 - Fluxo de nêutrons para as posições do canal de irradiação 5.

\begin{tabular}{|c|r|r|r|r|}
\hline Posições & Grupo 1 & Grupo 2 & Grupo 3 & Grupo 4 \\
\hline $\mathbf{1}$ & $1,09015 \mathrm{E}+08$ & $1,30278 \mathrm{E}+08$ & $1,17273 \mathrm{E}+08$ & $1,56083 \mathrm{E}+08$ \\
\hline $\mathbf{2}$ & $1,86846 \mathrm{E}+08$ & $2,31465 \mathrm{E}+08$ & $2,07726 \mathrm{E}+08$ & $2,23200 \mathrm{E}+08$ \\
\hline $\mathbf{3}$ & $2,54227 \mathrm{E}+08$ & $3,03925 \mathrm{E}+08$ & $2,78489 \mathrm{E}+08$ & $3,61337 \mathrm{E}+08$ \\
\hline $\mathbf{4}$ & $2,30159 \mathrm{E}+08$ & $2,70965 \mathrm{E}+08$ & $2,59558 \mathrm{E}+08$ & $3,54056 \mathrm{E}+08$ \\
\hline $\mathbf{5}$ & $1,35529 \mathrm{E}+08$ & $1,56345 \mathrm{E}+08$ & $1,45930 \mathrm{E}+08$ & $2,20222 \mathrm{E}+08$ \\
\hline $\mathbf{6}$ & $2,73340 \mathrm{E}+08$ & $3,19007 \mathrm{E}+08$ & $2,70789 \mathrm{E}+08$ & $2,51785 \mathrm{E}+08$ \\
\hline $\mathbf{7}$ & $4,66420 \mathrm{E}+08$ & $5,64119 \mathrm{E}+08$ & $4,78118 \mathrm{E}+08$ & $3,79620 \mathrm{E}+08$ \\
\hline $\mathbf{8}$ & $6,32259 \mathrm{E}+08$ & $7,40107 \mathrm{E}+08$ & $6,39159 \mathrm{E}+08$ & $5,65162 \mathrm{E}+08$ \\
\hline $\mathbf{9}$ & $5,70834 \mathrm{E}+08$ & $6,58463 \mathrm{E}+08$ & $5,95148 \mathrm{E}+08$ & $5,58064 \mathrm{E}+08$ \\
\hline $\mathbf{1 0}$ & $3,35982 \mathrm{E}+08$ & $3,79712 \mathrm{E}+08$ & $3,34263 \mathrm{E}+08$ & $3,38571 \mathrm{E}+08$ \\
\hline $\mathbf{1 1}$ & $4,37532 \mathrm{E}+08$ & $5,09108 \mathrm{E}+08$ & $4,36414 \mathrm{E}+08$ & $4,31756 \mathrm{E}+08$ \\
\hline $\mathbf{1 2}$ & $7,48266 \mathrm{E}+08$ & $9,00099 \mathrm{E}+08$ & $7,71122 \mathrm{E}+08$ & $6,58871 \mathrm{E}+08$ \\
\hline $\mathbf{1 3}$ & $9,79538 \mathrm{E}+08$ & $1,14663 \mathrm{E}+09$ & $9,98619 \mathrm{E}+08$ & $9,38186 \mathrm{E}+08$ \\
\hline
\end{tabular}




\begin{tabular}{|c|r|r|r|r|}
\hline Posições & Grupo 1 & Grupo 2 & Grupo 3 & Grupo 4 \\
\hline $\mathbf{1 4}$ & $8,71846 \mathrm{E}+08$ & $1,00698 \mathrm{E}+09$ & $9,17812 \mathrm{E}+08$ & $9,12243 \mathrm{E}+08$ \\
\hline $\mathbf{1 5}$ & $5,09808 \mathrm{E}+08$ & $5,77142 \mathrm{E}+08$ & $5,12609 \mathrm{E}+08$ & $5,48490 \mathrm{E}+08$ \\
\hline $\mathbf{1 6}$ & $6,04594 \mathrm{E}+08$ & $6,87749 \mathrm{E}+08$ & $6,04427 \mathrm{E}+08$ & $6,19334 \mathrm{E}+08$ \\
\hline $\mathbf{1 7}$ & $1,05096 \mathrm{E}+09$ & $1,22091 \mathrm{E}+09$ & $1,09811 \mathrm{E}+09$ & $1,04206 \mathrm{E}+09$ \\
\hline $\mathbf{1 8}$ & $1,26513 \mathrm{E}+09$ & $1,47196 \mathrm{E}+09$ & $1,27859 \mathrm{E}+09$ & $1,16466 \mathrm{E}+09$ \\
\hline $\mathbf{1 9}$ & $1,09874 \mathrm{E}+09$ & $1,26666 \mathrm{E}+09$ & $1,14797 \mathrm{E}+09$ & $1,09911 \mathrm{E}+09$ \\
\hline $\mathbf{2 0}$ & $6,37331 \mathrm{E}+08$ & $7,20690 \mathrm{E}+08$ & $6,36378 \mathrm{E}+08$ & $6,55996 \mathrm{E}+08$ \\
\hline $\mathbf{2 1}$ & $6,25422 \mathrm{E}+08$ & $7,08250 \mathrm{E}+08$ & $6,32452 \mathrm{E}+08$ & $7,01298 \mathrm{E}+08$ \\
\hline $\mathbf{2 2}$ & $1,08736 \mathrm{E}+09$ & $1,25487 \mathrm{E}+09$ & $1,14958 \mathrm{E}+09$ & $1,18845 \mathrm{E}+09$ \\
\hline $\mathbf{2 3}$ & $1,27797 \mathrm{E}+09$ & $1,48543 \mathrm{E}+09$ & $1,30545 \mathrm{E}+09$ & $1,28742 \mathrm{E}+09$ \\
\hline $\mathbf{2 4}$ & $1,09786 \mathrm{E}+09$ & $1,26637 \mathrm{E}+09$ & $1,16029 \mathrm{E}+09$ & $1,19990 \mathrm{E}+09$ \\
\hline $\mathbf{2 5}$ & $6,34047 \mathrm{E}+08$ & $7,17643 \mathrm{E}+08$ & $6,40910 \mathrm{E}+08$ & $7,11150 \mathrm{E}+08$ \\
\hline $\mathbf{2 6}$ & $4,96909 \mathrm{E}+08$ & $5,61301 \mathrm{E}+08$ & $4,93637 \mathrm{E}+08$ & $4,97029 \mathrm{E}+08$ \\
\hline $\mathbf{2 7}$ & $8,62335 \mathrm{E}+08$ & $9,92671 \mathrm{E}+08$ & $8,96188 \mathrm{E}+08$ & $8,37903 \mathrm{E}+08$ \\
\hline $\mathbf{2 8}$ & $1,00821 \mathrm{E}+09$ & $1,16966 \mathrm{E}+09$ & $1,01288 \mathrm{E}+09$ & $9,01333 \mathrm{E}+08$ \\
\hline $\mathbf{2 9}$ & $8,64684 \mathrm{E}+08$ & $9,95302 \mathrm{E}+08$ & $8,98582 \mathrm{E}+08$ & $8,40230 \mathrm{E}+08$ \\
\hline $\mathbf{3 0}$ & $4,99036 \mathrm{E}+08$ & $5,63648 \mathrm{E}+08$ & $4,95704 \mathrm{E}+08$ & $4,99235 \mathrm{E}+08$ \\
\hline $\mathbf{3 1}$ & $2,19764 \mathrm{E}+08$ & $2,52555 \mathrm{E}+08$ & $2,33849 \mathrm{E}+08$ & $3,40265 \mathrm{E}+08$ \\
\hline $\mathbf{3 2}$ & $3,81849 \mathrm{E}+08$ & $4,47269 \mathrm{E}+08$ & $4,25245 \mathrm{E}+08$ & $5,63064 \mathrm{E}+08$ \\
\hline $\mathbf{3 3}$ & $4,46370 \mathrm{E}+08$ & $5,26890 \mathrm{E}+08$ & $4,81000 \mathrm{E}+08$ & $6,16580 \mathrm{E}+08$ \\
\hline $\mathbf{3 4}$ & $3,82295 \mathrm{E}+08$ & $4,47770 \mathrm{E}+08$ & $4,25714 \mathrm{E}+08$ & $5,63704 \mathrm{E}+08$ \\
\hline $\mathbf{3 5}$ & $2,20185 \mathrm{E}+08$ & $2,52822 \mathrm{E}+08$ & $2,34149 \mathrm{E}+08$ & $3,42605 \mathrm{E}+08$ \\
\hline
\end{tabular}

Na TAB C.7 apresentam-se os resultados calculados para o canal de irradiação 6, entre as coordenadas 22 e 23.

Tabela C.7 - Fluxo de nêutrons para as posições do canal de irradiação 6.

\begin{tabular}{|c|l|l|r|c|}
\hline Posições & Grupo 1 & Grupo 2 & Grupo 3 & Grupo 4 \\
\hline $\mathbf{1}$ & $6,35881 \mathrm{E}+07$ & $7,57994 \mathrm{E}+07$ & $7,35225 \mathrm{E}+07$ & $1,57936 \mathrm{E}+08$ \\
\hline $\mathbf{2}$ & $1,36930 \mathrm{E}+08$ & $1,70599 \mathrm{E}+08$ & $1,53018 \mathrm{E}+08$ & $1,61702 \mathrm{E}+08$ \\
\hline $\mathbf{3}$ & $2,05312 \mathrm{E}+08$ & $2,44908 \mathrm{E}+08$ & $2,24885 \mathrm{E}+08$ & $2,92349 \mathrm{E}+08$ \\
\hline $\mathbf{4}$ & $1,90291 \mathrm{E}+08$ & $2,21899 \mathrm{E}+08$ & $2,13313 \mathrm{E}+08$ & $2,96887 \mathrm{E}+08$ \\
\hline $\mathbf{5}$ & $9,30827 \mathrm{E}+07$ & $1,05294 \mathrm{E} 08$ & $1,05881 \mathrm{E}+08$ & $2,66773 \mathrm{E}+08$ \\
\hline
\end{tabular}




\begin{tabular}{|c|c|c|c|c|}
\hline Posições & Grupo 1 & Grupo 2 & Grupo 3 & Grupo 4 \\
\hline 6 & $1,59292 \mathrm{E}+08$ & $1,85167 \mathrm{E}+08$ & $1,70215 \mathrm{E}+08$ & $2,94734 \mathrm{E}+08$ \\
\hline 7 & $3,43375 \mathrm{E}+08$ & $4,17112 \mathrm{E}+08$ & $3,53306 \mathrm{E}+08$ & $2,79393 \mathrm{E}+08$ \\
\hline 8 & $5,10626 \mathrm{E}+08$ & $5,96393 \mathrm{E}+08$ & $5,16109 \mathrm{E}+08$ & $4,57481 \mathrm{E}+08$ \\
\hline 9 & $4,70892 \mathrm{E}+08$ & $5,38222 \mathrm{E}+08$ & $4,88219 \mathrm{E}+08$ & $4,63867 \mathrm{E}+08$ \\
\hline 10 & $2,28779 \mathrm{E}+08$ & $2,53457 \mathrm{E}+08$ & $2,41349 \mathrm{E}+08$ & $4,66021 \mathrm{E}+08$ \\
\hline 11 & $2,61601 \mathrm{E}+08$ & $3,03073 \mathrm{E}+08$ & $2,81908 \mathrm{E}+08$ & $5,14769 \mathrm{E}+08$ \\
\hline 12 & $5,63309 \mathrm{E}+08$ & $6,78862 \mathrm{E}+08$ & $5,81337 \mathrm{E}+08$ & $4,95790 \mathrm{E}+08$ \\
\hline 13 & 7,92084E+08 & $9,24964 \mathrm{E}+08$ & $8,07209 \mathrm{E}+08$ & $7,60221 \mathrm{E}+08$ \\
\hline 14 & $7,12482 \mathrm{E}+08$ & $8,15670 \mathrm{E}+08$ & $7,46314 \mathrm{E}+08$ & $7,51293 \mathrm{E}+08$ \\
\hline 15 & $3,40781 \mathrm{E}+08$ & $3,79280 \mathrm{E}+08$ & $3,65554 \mathrm{E}+08$ & $7,37383 \mathrm{E}+08$ \\
\hline 16 & $3,83092 \mathrm{E}+08$ & $4,29125 \mathrm{E}+08$ & $4,08608 \mathrm{E}+08$ & $7,88948 \mathrm{E}+08$ \\
\hline 17 & $8,23196 \mathrm{E}+08$ & $9,50933 \mathrm{E}+08$ & $8,58352 \mathrm{E}+08$ & $8,23782 \mathrm{E}+08$ \\
\hline 18 & $1,02749 \mathrm{E}+09$ & $1,19133 \mathrm{E}+09$ & $1,03750 \mathrm{E}+09$ & $9,48587 \mathrm{E}+08$ \\
\hline 19 & $8,86040 \mathrm{E}+08$ & $1,01336 \mathrm{E}+09$ & $9,22063 \mathrm{E}+08$ & $8,93996 \mathrm{E}+08$ \\
\hline 20 & $4,20776 \mathrm{E}+08$ & $4,67248 \mathrm{E}+08$ & $4,46900 \mathrm{E}+08$ & $8,71769 \mathrm{E}+08$ \\
\hline 21 & $4,01003 \mathrm{E}+08$ & $4,47706 \mathrm{E}+08$ & $4,34712 \mathrm{E}+08$ & $9,02961 \mathrm{E}+08$ \\
\hline 22 & $8,64086 \mathrm{E}+08$ & $9,89866 \mathrm{E}+08$ & $9,10614 \mathrm{E}+08$ & $9,52784 \mathrm{E}+08$ \\
\hline 23 & $1,90291 \mathrm{E}+08$ & $2,21899 \mathrm{E}+08$ & $2,13313 \mathrm{E}+08$ & $2,96887 \mathrm{E}+08$ \\
\hline 24 & $8,79201 \mathrm{E}+08$ & $1,00649 \mathrm{E}+09$ & $9,25950 \mathrm{E}+08$ & $9,69215 \mathrm{E}+08$ \\
\hline 25 & $4,11240 \mathrm{E}+08$ & $4,58797 \mathrm{E}+08$ & $4,45504 \mathrm{E}+08$ & $9,27275 \mathrm{E}+08$ \\
\hline 26 & $3,23692 \mathrm{E}+08$ & $3,58777 \mathrm{E}+08$ & $3,41354 \mathrm{E}+08$ & $6,52579 \mathrm{E}+08$ \\
\hline 27 & $6,87567 \mathrm{E}+08$ & $7,85567 \mathrm{E}+08$ & $7,12118 \mathrm{E}+08$ & $6,74303 \mathrm{E}+08$ \\
\hline 28 & $8,20207 \mathrm{E}+08$ & $9,47946 \mathrm{E}+08$ & $8,23116 \mathrm{E}+08$ & $7,35393 \mathrm{E}+08$ \\
\hline 29 & $6,91100 \mathrm{E}+08$ & $7,89526 \mathrm{E}+08$ & $7,15699 \mathrm{E}+08$ & $6,77786 \mathrm{E}+08$ \\
\hline 30 & $3,26291 \mathrm{E}+08$ & $3,61613 \mathrm{E}+08$ & $3,44055 \mathrm{E}+08$ & $6,58302 \mathrm{E}+08$ \\
\hline 31 & $1,43980 \mathrm{E}+08$ & $1,62331 \mathrm{E}+08$ & $1,61868 \mathrm{E}+08$ & $3,94793 \mathrm{E}+08$ \\
\hline 32 & $3,04377 \mathrm{E}+08$ & $3,53803 \mathrm{E}+08$ & $3,37731 \mathrm{E}+08$ & $4,54897 \mathrm{E}+08$ \\
\hline 33 & $3,62944 \mathrm{E}+08$ & $4,26720 \mathrm{E}+08$ & $3,90588 \mathrm{E}+08$ & $5,03455 \mathrm{E}+08$ \\
\hline 34 & $3,05069 \mathrm{E}+08$ & $3,54588 \mathrm{E}+08$ & $3,38463 \mathrm{E}+08$ & $4,55866 \mathrm{E}+08$ \\
\hline 35 & $1,44520 \mathrm{E}+08$ & $1,62902 \mathrm{E}+08$ & $1,62410 \mathrm{E}+08$ & $3,96450 \mathrm{E}+08$ \\
\hline
\end{tabular}

Na TAB C.8 apresentam-se os resultados calculados para o canal de irradiação 7, entre as coordenadas 26 e 27. 
Tabela C.8 - Fluxo de nêutrons para as posições do canal de irradiação 7.

\begin{tabular}{|c|c|c|c|c|}
\hline Posições & Grupo 1 & Grupo 2 & Grupo 3 & Grupo 4 \\
\hline $\mathbf{2}$ & $8,77718 \mathrm{E}+07$ & $1,04786 \mathrm{E}+08$ & $9,56366 \mathrm{E}+07$ & $1,44715 \mathrm{E}+08$ \\
\hline $\mathbf{3}$ & $1,38655 \mathrm{E}+08$ & $1,62680 \mathrm{E}+08$ & $1,47422 \mathrm{E}+08$ & $2,05875 \mathrm{E}+08$ \\
\hline $\mathbf{4}$ & $1,20433 \mathrm{E}+08$ & $1,37022 \mathrm{E}+08$ & $1,30564 \mathrm{E}+08$ & $2,29019 \mathrm{E}+08$ \\
\hline $\mathbf{7}$ & $2,20900 \mathrm{E}+08$ & $2,57064 \mathrm{E}+08$ & $2,21402 \mathrm{E}+08$ & $2,44830 \mathrm{E}+08$ \\
\hline $\mathbf{8}$ & $3,44912 \mathrm{E}+08$ & $3,96377 \mathrm{E}+08$ & $3,38487 \mathrm{E}+08$ & $3,14916 \mathrm{E}+08$ \\
\hline $\mathbf{9}$ & $2,98055 \mathrm{E}+08$ & $3,32035 \mathrm{E}+08$ & $2,98545 \mathrm{E}+08$ & $3,62003 \mathrm{E}+08$ \\
\hline $\mathbf{1 2}$ & $3,59596 \mathrm{E}+08$ & $4,16671 \mathrm{E}+08$ & $3,62666 \mathrm{E}+08$ & $4,25058 \mathrm{E}+08$ \\
\hline $\mathbf{1 3}$ & $5,32735 \mathrm{E}+08$ & $6,12549 \mathrm{E}+08$ & $5,27673 \mathrm{E}+08$ & $5,20260 \mathrm{E}+08$ \\
\hline $\mathbf{1 4}$ & $4,48382 \mathrm{E}+08$ & $5,00681 \mathrm{E}+08$ & $4,54585 \mathrm{E}+08$ & $5,79210 \mathrm{E}+08$ \\
\hline $\mathbf{1 7}$ & $5,14249 \mathrm{E}+08$ & $5,78164 \mathrm{E}+08$ & $5,19157 \mathrm{E}+08$ & $6,33982 \mathrm{E}+08$ \\
\hline $\mathbf{1 8}$ & $6,84654 \mathrm{E}+08$ & $7,83882 \mathrm{E}+08$ & $6,72308 \mathrm{E}+08$ & $6,39869 \mathrm{E}+08$ \\
\hline $\mathbf{1 9}$ & $5,55277 \mathrm{E}+08$ & $6,19415 \mathrm{E}+08$ & $5,59019 \mathrm{E}+08$ & $6,87636 \mathrm{E}+08$ \\
\hline $\mathbf{2 2}$ & $5,37426 \mathrm{E}+08$ & $6,00980 \mathrm{E}+08$ & $5,49040 \mathrm{E}+08$ & $7,22075 \mathrm{E}+08$ \\
\hline $\mathbf{2 3}$ & $6,90717 \mathrm{E}+08$ & $7,90403 \mathrm{E}+08$ & $6,85812 \mathrm{E}+08$ & $7,04933 \mathrm{E}+08$ \\
\hline $\mathbf{2 4}$ & $5,48408 \mathrm{E}+08$ & $6,12844 \mathrm{E}+08$ & $5,59861 \mathrm{E}+08$ & $7,37229 \mathrm{E}+08$ \\
\hline $\mathbf{2 7}$ & $4,29071 \mathrm{E}+08$ & $4,78154 \mathrm{E}+08$ & $4,29767 \mathrm{E}+08$ & $5,17066 \mathrm{E}+08$ \\
\hline $\mathbf{2 8}$ & $5,45064 \mathrm{E}+08$ & $6,22573 \mathrm{E}+08$ & $5,32086 \mathrm{E}+08$ & $4,94690 \mathrm{E}+08$ \\
\hline $\mathbf{2 9}$ & $4,31806 \mathrm{E}+08$ & $4,81135 \mathrm{E}+08$ & $4,32435 \mathrm{E}+08$ & $5,20561 \mathrm{E}+08$ \\
\hline $\mathbf{3 2}$ & $1,89837 \mathrm{E}+08$ & $2,15298 \mathrm{E}+08$ & $2,03548 \mathrm{E}+08$ & $3,43625 \mathrm{E}+08$ \\
\hline $\mathbf{3 3}$ & $2,40977 \mathrm{E}+08$ & $2,79930 \mathrm{E}+08$ & $2,52097 \mathrm{E}+08$ & $3,43301 \mathrm{E}+08$ \\
\hline $\mathbf{3 4}$ & $1,90387 \mathrm{E}+08$ & $2,15905 \mathrm{E}+08$ & $2,04110 \mathrm{E}+08$ & $3,44608 \mathrm{E}+08$ \\
\hline
\end{tabular}

Por meio da análise do fluxo médio ponderado de nêutrons térmicos, referente ao grupo 4 de todos os canais de irradiação simulados, obteve-se o valor de $5,4937 \times 10^{8} \pm 5,50 \% \mathrm{n} / \mathrm{cm}^{2} \mathrm{~s}(1 \sigma)$ para a potência de operação de 100 watts.

O valor experimental do fluxo médio ponderado de nêutrons térmicos foi de $4,0529 \times 10^{8} \pm 3,27 \% \mathrm{n} / \mathrm{cm}^{2} \mathrm{~s}(1 \sigma)$ para a operação do reator nuclear em $74,65 \pm 2,45$ watts. 
Ao normalizarmos o valor da potência experimental de $74,65 \pm 2,45$ watts $(1 \sigma)$ para o CITATION, obtém-se o valor médio do fluxo de nêutrons térmicos de $4,1008 \times 10^{8} \mathrm{n} / \mathrm{cm}^{2} \mathrm{~s}$, o que representa um desvio de $1,16 \%$ do valor encontrado experimentalmente para o mesmo nível de potência. Na realidade este desvio está dentro da margem das incertezas, assim podemos considerar os resultados equivalentes.

De outra forma, se calcularmos a potência gerada no núcleo do reator IPEN/MB-01 pela a equação (4.3), utilizando o valor do fluxo médio de nêutrons térmicos dado pelo CITATION considerando a potência de operação de 100 watts da simulação, obtém-se o valor de 101,18 watts. Se normalizarmos o valor experimental para 100 watts na configuração cilíndrica, teremos um desvio de $1,16 \%$ do valor de potência de calculada pelo fluxo médio de nêutrons térmicos dado pelo CITATION. Novamente esta diferença está dentro das incertezas e os resultados são então considerados equivalentes.

A energia de corte para o cádmio usada experimentalmente foi de $0,55 \mathrm{eV}$, enquanto que para o código computacional CITATION foi de $0,625 \mathrm{eV}$. É esperado que o valor de fluxo e de potência obtidos por meio do CITATION seja um pouco maior dada a maior quantidade de nêutrons considerados térmicos. Este valor está em torno de $1 \%$ maior para o CITATION em relação aos valores experimentais obtidos.

Estas análises mostram que o valor do fluxo médio ponderado de nêutrons térmicos obtido neste trabalho, assim como sua metodologia experimental, valida o mesmo valor médio do fluxo de nêutrons térmicos quando este é obtido a partir dos valores calculados dos fluxos de nêutrons térmicos pelo código CITATION. 


\section{REFERÊNCIAS BIBLIOGRÁFICAS}

1. GONÇALVES, L.B. Calibração dos Canais Nucleares do Reator IPEN/MB-01 obtida a partir da Medida da Distribuição Espacial do Fluxo de Nêutrons Térmicos no Núcleo do Reator Através da Irradiação de Folhas de Ouro Infinitamente Diluídas. 2008. Dissertação (Mestrado) - Instituto de Pesquisas Energéticas e Nucleares. São Paulo.

2. GLASSTONE, S. Principles of nuclear reactor engineering. D. Van Nostrand Company, Inc. 1995.

3. ARKANI, M.; GHARIB M. Reactor Core Power measurement Using Cherenkov Radiation and Its Application in Tehran Research Reactor, Annals of Nuclear Energy, Vol. 36, issue 7, 2009.

4. KLIMOV, Y.U. V.; KOPEIKIN V.I.; MIKALYAN L. A.; OZEROV K. V.; SINEV, V. V. Neutrino Method Remote Measurement of Reactor Power and Power Output, Atomic Energy, Vol. 76, n 2, 1994.

5. PROFIO, A. E. Experimental Reactor Physics. New York, Wiley, 1976.

6. BAUM, E.M.; ERNESTI, M.C; KNOX, H.D; MILLER, T.R; WATSON, A.M. Nuclides and Isotopes, Chart of the Nuclides. Knoll Atomic Power Laboratory, Seventeenth Edition 2009.

7. BITELli, U. d'U. Medida e Cálculo da Distribuição Espacial e Energética de Nêutrons no Núcleo do Reator IEA-R1. Dissertação (Mestrado) - Instituto de Pesquisas Energéticas e Nucleares. São Paulo, 1988.

8. AREDES, V.O. Caracterização do Núcleo Cilíndrico de Menor Excesso de Reatividade do Reator IPEN/MB-01, pela Medida da Distribuição Espacial e Energética do Fluxo de Nêutrons. 2014. Dissertação (Mestrado) - Instituto de Pesquisas Energéticas e Nucleares. São Paulo.

9. PURGATO, R.T. Medida do Buckling e da Probabilidade de Fuga de Nêutrons do Núcleo do Reator IPEN/MB-01. 2014. Dissertação (Mestrado) - Instituto de Pesquisas Energéticas e Nucleares. São Paulo.

10. AMORIM, C.G.; SAMPAIO, D.O.C.; SOARES L.N. Carregamento $\boldsymbol{e}$ Descarregamento, Medida de Excesso de Reatividade da Mudança de Núcleo do Reator IPEM/MB-01 - Curso Introdutório de Operador de Reatores de Pesquisa. Instituto de Pesquisas Energéticas e Nucleares. CEN. São Paulo. 2011.

11. VEADO, M.A.R.V.; MIGUEL, R.A. Otimização da Técnica de Análise Por Ativação Neutrônica Instrumental e Adequação do Programa computacional "k0Labsue" Método Paramétrico k0. Fev. 2003

12. KNOLL, G.F.; Radiation Detection and Measurement. John Wiley \& Sons, 1989. 
13. LAMARSH, J.R. Introduction to Nuclear Engineering. Second Edition. Addisonwesley Publishing Company, Inc., USA, 1983

14. BITELLI, T. Física da Dosimetria das Radiações. $2^{\circ}$ edição, Ed.Atheneu, 2006.

15. SANTOS, W.N. Método Matemáticos e Numéricos da Física Nuclear. Universidade Federal de São Carlos, Centro de Ciências e Tecnologia. 1983.

16. MARQUES, A.L.F. Medida do Fluxo de Nêutrons Térmicos do Reator IPEN/MB-01 com Detectores de Ativação de Fios de ${ }^{197}$ Au. 1995. Dissertação (Mestrado) - Instituto de Pesquisas Energéticas Nucleares, São Paulo.

17. REUS, U., WESTMEIER, W. Catalog of Gamma Rays from Radioactive Decay Part II. Atomic Data and Nuclear Data Tabels, Academic Press, Vol.29, n², p.193-406, West Germany, 1983.

18. ZAMBONI, C.B., BITELli, U.d'U., et al. Fundamentos da Física de Nêutrons, ed. livraria da física, São Paulo, 2007.

19. LAMARSH, J. R. Introduction to Nuclear Theory. Reading, Mass., Addison-wesley, 1966.

20. ZSOLNAY, E. M.; NOLTHENIUS, H. On the Quality of the Uncertainty Information in the International Reactor Dosimetry - File IRDR-90. ECN-I-93-019, Pitten, Netherlands, June, 1993.

21. BENSCH, F.; FLECK, C.M. Neutronenphysikaliches Praktkum. Mannhein Bibliographisches Institut, 1968.

22. TODREAS, E.N.; KAZIMI, S.M. Nuclear Systems I, Thermal Hydraulic Fundamentals. Taylor \& Francis, second printing, USA, 1993.

23. DUDERSTADT, J. J.; HAMILTON, L.J. Nuclear Reactor Theory. John Wiley \& Sons, USA, 1976.

24. TARDELli, T. C.; STECHER, L. C.; COELHO, T. S.; DE CASTRO, V. A.; CAVALIERI, T. A.; MENZEL, F.; GIAROLA, R. S.; DOMINGOS, D. B.; YORIYAZ, H. Diferenças entre Bibliotecas de Seções de Choque para Dosimetria de Nêutrons. Aceito em 15 de julho de 2013. Centro de Engenharia Nuclear - Instituto de Pesquisas Energéticas e Nucleares, São Paulo.

\section{Goodfellow .}

Disponível em www.goodfellow.com. Acesso em 14/04/2014.

\section{Joint Research Centre at European.}

Disponível em www. http://ec.europa.eu/dgs/jrc/index.cfm. Acesso em 19/04/2014.

27. Disponível em: http://atom.kaeri.re.kr/. Acesso em 18/03/2014. 
28. JEREZ, R. Comunicação pessoal em maio, 2014.

29. BITELLI, U. d'U. Medida de Parâmetros Integrais no Reator IPEN/MB-01. Tese (Doutorado) - Instituto de Pesquisas Energéticas e Nucleares. São Paulo, 2001.

30. BLEULER, E.; GOLDSMITH, G. J. Experimetal Nucleonics. Physikalisches Institute der Universitad Freiburg im Breisgau.

31. ORTEC CORPORATION. MAESTRO for Windows Version 6.06.

32. KOSKINAS, M. F. Certificado de Calibração de Fontes Radioativas, Laboratório de Metrologia Nuclear, ${ }^{\circ}$ AI-004/91 - Instituto de Pesquisas Energéticas e Nucleares. São Paulo, 19/03/1991.

33. ORIGIN LAB. CORPORATION. Data Analyses and Technical Graphics. ORIGIN5.0.

34. VUOLO, J. H. Fundamentos da Teoria de Erros. Editora Edgard Blücher, 1996,

35. ZIJP, W.L. Treatment of Measurement Uncertainties. Netherlands Energy Research Foundation, january 1987. (ECN-A94).

36. BITELLI, U.d'U.; LIMA, A.C.S. Cálculo da Distribuição de Fluxo de Nêutrons no Núcleo Cilíndrico de 28x28 do Reator IPEN/MB-01. Relatório P\&D.CENF.CENR.069.00, abril, 2014.

37. MARTINS, F.R., Medida de Parâmetros Nucleares de Um Reator de Potência Zero Aplicando a Técnica de Análise de Ruídos. Dissertação (Mestrado) - Instituto de Pesquisas Energéticas e Nucleares, 1992.

38. Diniz, R. Comunicação pessoal , julho, 2013

39. FOWLER,T.B.; VONDY, D.R.; CUNNINGHAM, G.W. Nuclear Reactor Core Analysis Code: CITATION, Oak Ridge National Laboratory, ORNL-TM-2496, Revision 2, July, 1971

40. BARHEN, J.; RHOTENSTEIN, W.; TAVIV, E. The HAMMER Code System Technion. Israel Institute of Technology, Haifa, Israel, NP-565, 1.

41. Bitelli, Ulysses d'Utra ; Santos, Diogo F. Comunicação pessoal, Setembro de 2014.

42. BECKURTZ, K.H; WIRTZ, K. Neutron Physics, New York, Springer, 1964 